Asuman Lätzer

\title{
Studien zu einem späthellenistisch-frührömischen Fundkomplex aus dem Hanghaus 2 in Ephesos*
}

\begin{abstract}
Ausgangslage
Im Folgenden soll ausgewähltes Material aus einem Fundkomplex aus dem Hanghaus 2 vorgestellt werden. Es handelt sich um einen geschlossenen Fundkomplex der späthellenistischen Zeit, anhand dessen Stratigraphie eine relative Chronologie für die Feinkeramik ${ }^{1}$ erstellt werden konnte. Den terminus post quem liefern hellenistische Münzfunde, der terminus ante quem ist mit der Errichtung der Insula in augusteisch-tiberischer Zeit gegeben². Das Fundmaterial besteht zum größten Teil aus Keramik oder keramischen Produkten, wie z. B. Lampen, Terrakotten und Webgewichten, aber auch aus Metall, Glas, Bein und Stuck. Aufgrund der Fülle an Keramikfragmenten wurde das Material zunächst statistisch aufgenommen und im Hinblick auf Definition, Datierung/Laufzeit, Herkunft und gegebenenfalls Verbreitung ausgewertet; anschließend wurde eine Typenreihe erstellt.
\end{abstract}

\section{Befundbeschreibung}

Im Jahre 1999 wurde über dem Hanghaus 2 eine neuer Schutzbau errichtet ${ }^{3}$. Durch den Einbau tragender Pfeiler in die antike Bausubstanz war es notwendig, den Bau archäologisch zu begleiten und Sondagen anzulegen $^{4}$. Dabei konnten erstmalig die frühesten Straten des Areals auszugsweise ergraben werden. Eine der Sondagen, Sondage B6, wurde in Wohneinheit 7, Raum 32c, nach Abnahme eines Mosaikpaviments angelegt. Die Grabungsfläche war 4,72 m lang, 3,42 m breit und durchschnittlich etwa 2,50 m tief, somit wurden knapp über $40 \mathrm{~m}^{3}$ Erdmasse ausgehoben. Auf dem Boden des Raumes 32c lag ein schwarz-weißes Mosaik als Paviment ${ }^{5}$. Unter dem Mosaik und seinen Rollsplittunterlagen konnte die Ausgräberin Reste von zwei

Für die Erlaubnis, das Material im Rahmen einer Magisterarbeit zu bearbeiten, danke ich F. Krinzinger. Besonderer Dank gilt S. Ladstätter, die das Thema initiiert und mich stets sowohl wissenschaftlich als auch in allen anderen Belangen tatkräftig unterstützt hat. Zudem danke ich T. Fischer, der das Thema wohlwollend als Abschlussarbeit annahm und mir seinen Rat und seine Kritik zur Verfügung stellte. L. Rembart, J. Struber und M. Weissteiner bin ich sehr verbunden, da sie mich vor Ort unterstützt haben. Ohne die wissenschaftliche Arbeitslust des zuständigen Regierungsvertreters und Archäologen B. Aydın wäre die Materialaufnahme in dem zeitlichen Rahmen nicht möglich gewesen. Für wissenschaftlichen Rat und Austausch danke ich herzlich A. Waldner und U. Mandel. Zuletzt möchte ich mich in spezieller Weise bei B. Lasar bedanken, der mir nicht nur bei der digitalen Aufbereitung geholfen hat, sondern mir auch in anstrengenden Zeiten zur Seite stand. - Abkürzungen und abgekürzt zitierte Literatur folgen den Richtlinien des ÖAI <http://www.oeai.at/publik/autoren.html>; Kurzzitate finden sich am Ende des Beitrags aufgelöst.

${ }^{1}$ Zur Problematik der Chronologie hellenistischer Keramik: Rogl 2007, 182; Giuliani 2007, 172; Mitsopoulos-Leon 1991, 15. Datierte Fundkomplexe aus Ephesos: Ladstätter 2003a-c; Meriç 2002; Rogl 2003a. Pergamon: Schäfer 1968; Ziegenhaus - de Luca 1968.

2 Die Errichtung des Hanghauses 2 (Bauphase I) wird anhand der Auswertung mehrerer Fundkomplexe in diesen Zeitraum datiert. Ladstätter 2005a, passim.

3 s. dazu ausführlich: Krinzinger 2000, passim.

${ }^{4}$ Die Leitung des Projekts oblag S. Ladstätter. Die Sondage B6 wurde von E. Juen ausgegraben.

${ }^{5}$ Wozu der Raum ursprünglich diente, ist unklar. Nach einer Verkleinerung in einer späteren Umbauphase benutzte man ihn als Verteilergang in andere Räumlichkeiten. In einer weiteren oder derselben Bauphase, die nicht datiert werden kann, wurde in den Raum ein Präfurnium eingebaut, das zur Beheizung der übrigen Räume diente. 
weiteren Mosaikböden mit den zu ihnen gehörenden Untergrundkonstruktionen nachweisen. Unter diesen waren weitere Bebauungsspuren aus verschiedenen Perioden festzustellen. Sowohl im Norden als auch im Osten und Süden befanden sich Ziegelmauern, die teilweise aus ungebrannten Lehmziegeln bestanden und die in die Frühkaiserzeit, also in die Entstehungsphase der Insula, zu datieren sind ${ }^{6}$. Der bedeutendste Befund war jedoch eine im Südprofil gelegene Steinquadermauer. Sie gehört zu den umfangreichen Terrassierungsmaßnahmen, die in hellenistischer Zeit auf dem Areal stattfanden ${ }^{7}$, und erstreckt sich über die gesamte Länge der Sondage. Die Mauer ist bis zu 1,68 m hoch erhalten'; für ihre Errichtung war der Fels künstlich eingetieft worden'.

Die fundführenden Schichten $1-4^{10}$ sind stratigraphisch von den darüberliegenden Straten, die zu den Mosaiken gehören, klar zu trennen. In den vier Straten fand sich neben Grobkeramik feinchronologisch gut datierbare Feinkeramik. Man kann von einem ausgewogenen Mischverhältnis sprechen, wie es für einen häuslichen Siedlungsbefund nicht unüblich ist. Die vier relevanten Straten setzen sich aus insgesamt 21439 Keramikfragmenten zusammen. Dabei entfallen ca. $10 \%$ auf Rand- und Bodenfragmente sowie dekorierte Wandscherben ${ }^{11}$. Von diesen wiederum ist ungefähr die Hälfte, also 1115 Fragmente, der Feinkeramik zuzuordnen, welche im Folgenden vorgestellt wird. Es handelt sich dabei um 936 Gefäßindividuen, die anhand von 562 Randfragmenten, 255 Bodenfragmenten, 219 Wandfragmenten, 75 Lampenfragmenten und 4 zur Gänze erhaltenen Lampenformen ${ }^{12}$ erkannt wurden.

Gerade an der Feinkeramik zeigt sich, dass die Keramikfunde der Straten 1-3 sehr kleinteilig zerscherbt sind: Die durchschnittlichen Scherbengrößen liegen zwischen 0,8 $\times 1,2 \mathrm{~cm}$ und 5,4 $\times 7 \mathrm{~cm}$. Man kann davon ausgehen, dass es sich dabei um mehrfach umgelagertes Planiermaterial handelt ${ }^{13}$. Wie S. Ladstätter bereits für die Wohneinheit 4 festgestellt hat, war das Material benutzt worden, um das Areal anlässlich der frühkaiserzeitlichen Baumaßnahmen aufzufüllen, bevor als Abschluss jeweils ein Mosaikboden darüber gelegt wurde $^{14}$. Stratum 4 der Wohneinheit 7 ist davon auszunehmen: Es korreliert mit Lehmstraten aus den Wohneinheiten 4 und 5, die direkt über dem Fels angetroffen wurden und hellenistisch datiert werden ${ }^{15}$. Das erhaltene Keramikmaterial ist großscherbiger gebrochen, es lassen sich zahlreiche Anpassungen durchführen.

\section{Stratigraphie der Sondage B6 der Wohneinheit 7}

Mit ca. $62,5 \mathrm{~cm}$ ist das oberste auch das stärkste der vier Straten. Größtenteils besteht das Füllmaterial aus Bauschutt, also Ziegeln, Mörtel und Steinen, aber auch aus Keramik und einigen Kleinfunden ${ }^{16}$. Im oberen Bereich sind Reste einer aschehaltigen Kalkgrube und im unteren einer Ziegelsetzung, die zu einer später abgetragenen Ziegelmauer gehört, erhalten. Ein keilförmiger Einbruch ist in der Mitte des Ostprofils zu sehen (Abb. 1). Aus dieser Schicht wurden 248 signifikante Scherben aufgenommen.

\footnotetext{
${ }^{6}$ Unklar sind die Funktionen der Mauern und wie diese zeitlich zueinander stehen. Lediglich die Datierung in römische Zeit ist gesichert. Freundliche Mitteilung S. Ladstätter.

7 Ladstätter 2002, 117 Anm. 612.

${ }^{8}$ Aus der Mauer stehen drei Gesimse vor. Diese wurden normalerweise benutzt, um eine Unterlage, z. B. einen Dielenboden o. Ä., zu stützen. Leider ist der Ausschnitt der Sondage zu klein, um zu erkennen, ob es sich um die Fundamentierung einer Straße oder eines Hausbodens handelt. Freundliche Mitteilung S. Ladstätter, U. Mandel, W. Raeck und E. Laufer.

9 Auf dem Fels befinden sich drei Pfostenlöcher. Es ist nicht klar, zu welchem Bau diese gehören oder aus welcher Periode sie stammen.

${ }^{10}$ Dem vorliegenden Fundkomplex konnten nach Auswertung der Grabungsdokumentation vier Straten zugewiesen werden. Für die Informationen sei hier S. Ladstätter gedankt. Der Einfachheit halber werden hier diese vier Schichten beginnend mit 1 von oben durchnummeriert. In der eigentlichen Grabungsdokumentation sind die Schichten ursprünglich mit 8, 9, 10 und 12 bezeichnet.

${ }^{11}$ Das entspricht 2146 Fragmenten.

12 Der Großteil der Keramik befindet sich im Depot des österreichischen Grabungshauses in Selçuk, ausgewähltes Material und die übrigen Gattungen stammen aus dem Depot des Efes Müzesi in Selçuk. Für die Unterstützung bei der Bearbeitung möchte ich dem Museumsdirektor C. Topal danken.

${ }^{13}$ Ladstätter 2000, 98.

14 Ladstätter 2005a, $231 \mathrm{f}$.

${ }^{15}$ Ladstätter 2005a, 231 f.; Ladstätter 2005c, 260. 263.

16 Terrakottafragmente, Metallfunde, Glasspielsteine und Münzen.
} 


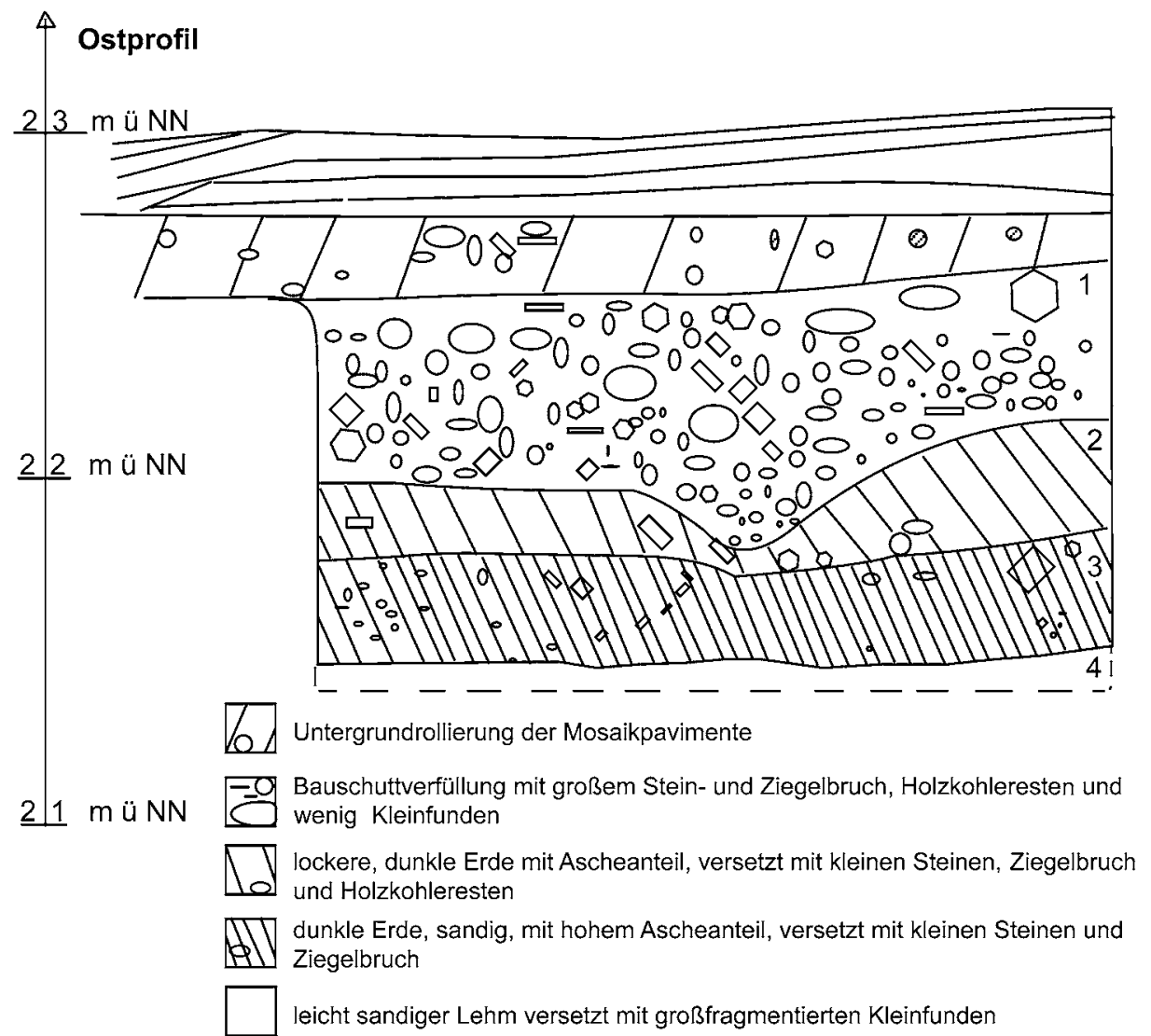

1 Ostprofil der Sondage B6

Die Qualität des Füllmaterials von Stratum 2 verändert sich zu lockerer Erde mit weniger Steinaufkommen, durchsetzt mit einigen Ziegelfragmenten und Keramik. Im oberen Bereich ist die 27,3 cm starke Schicht dunkler verfärbt, da sie einen größeren Anteil an Holzkohleresten enthält. Das Keramikspektrum umfasst Fragmente von 350 Gefäßindividuen.

Der Übergang vom zweiten in das dritte Stratum ist durch eine Lehmlinse abgesetzt. Die Erdqualität bleibt zwar dunkel und aschig, wird jedoch sandig. Die Schicht ähnelt in ihrer Beschaffenheit Stratum 2, jedoch wirkt das Füllmaterial viel kompakter. Aus dem 21,8 cm dicken Stratum 3 wurden 202 signifikante Scherben ausgewertet. Die Verteilung der Warengattungen deutet auf ein mit Stratum 2 vergleichbares Repertoire ${ }^{17}$.

Das vierte und mit 21,6 cm schmalste Stratum setzt sich deutlich von den vorhergehenden ab. Es ist in seiner Gesamtkonsistenz sehr homogen, besteht aus einem leicht sandigen Lehm, der nicht steril ist, sondern eine vergleichsmäßig hohe Konzentration an ausgewerteten Scherben (Fragmente von 135 Gefäßindividuen) aufweist. Es konnten einige wenige Gefäße fast komplett zusammengefügt und restauriert werden. Man kann davon ausgehen, dass dieses Stratum keine Auffüll- oder Planierschicht als Bauvorbereitung war, wie die anderen drei Straten, sondern einen Gehhorizont darstellt. Die Webgewichte deuten auf einen häuslichen Siedlungskontext.

\footnotetext{
${ }^{17}$ Es konnten mehrere schichtübergreifende Anpassungen vorgenommen werden. Die Straten müssen dabei nicht zwingend zusammengehören, Anpassungen können auch durch eine Bioturbation entstehen. Ein Anzeichen dafür liefert der Fund eines Mäusenestes, welches mit rezentem Material wie Plastik und Zigarettenfilter gefüllt war.
} 


\section{Fundgattungen}

\section{Münzen}

Insgesamt konnten 18 Bronzemünzen aus den vier Straten geborgen werden ${ }^{18}$. Sie werden durchweg hellenistisch bis frühaugusteisch datiert ${ }^{19}$, wobei zu beachten ist, dass hellenistische Prägungen eine lange Laufzeit haben. So treten im Hanghaus immer wieder sog. Altstücke in frühkaiserzeitlichen Komplexen auf ${ }^{20}$.

Tabelle 1: Münzfunde aus Stratum 1

\begin{tabular}{|c|c|c|c|c|c|c|}
\hline Nummer & $\begin{array}{l}\varnothing \text { in } \mathbf{m m} \\
\text { Gewicht }\end{array}$ & $\begin{array}{c}\text { Datierung } \\
\text { Münzstätte }\end{array}$ & $\begin{array}{c}\text { Metall } \\
\text { Nominal }\end{array}$ & Vorderseite & Rückseite & Literatur \\
\hline Mü 17 & $\begin{array}{r}19,5 \\
3,8 \mathrm{~g} \\
\end{array}$ & $\begin{array}{l}\text { hellenistisch } \\
\text { Ilion }\end{array}$ & $Æ$ & Gegenstempel & Palladion & \\
\hline Mü 18 & $\begin{array}{l}13,5 \\
2,2 \mathrm{~g}\end{array}$ & $\begin{array}{l}\text { Antiochos II., } \\
\text { 261-246 v. Chr. } \\
\text { Sardis } \\
\end{array}$ & $Æ$ & $\begin{array}{l}\text { Apollonkopf nach } \\
\text { rechts, Dutt am Hin- } \\
\text { terkopf }\end{array}$ & hoher Dreifuß & $\begin{array}{l}\text { Newell } 1977, \\
255 \text { Nr. } 1404 .\end{array}$ \\
\hline Mü 19 & $\begin{array}{c}14 \\
3,3 \mathrm{~g}\end{array}$ & $\begin{array}{l}\text { hellenistisch } \\
\text { Kleinasien }\end{array}$ & $Æ$ & $?$ & $?$ & \\
\hline Mü 20 & $\begin{array}{c}20 \\
4,3 \mathrm{~g} \\
\end{array}$ & $\begin{array}{l}\text { hellenistisch } \\
\text { Kleinasien }\end{array}$ & $Æ$ & $?$ & $?$ & \\
\hline Mü 21 & $\begin{array}{c}17 \\
3,1 \mathrm{~g} \\
\end{array}$ & $\begin{array}{l}\text { hellenistisch } \\
\text { Kleinasien }\end{array}$ & 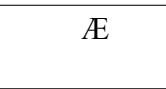 & Kopf nach rechts (?) & $?$ & \\
\hline Mü 22 & $\begin{array}{c}19 \\
4,9 \mathrm{~g}\end{array}$ & $\begin{array}{l}\text { 48-27 v. Chr. } \\
\text { Ephesos }\end{array}$ & $Æ$ & $\begin{array}{l}\text { Artemisbüste mit } \\
\text { Zopf im Perlenkranz, } \\
\text { Bogen und Köcher } \\
\text { über der Schulter }\end{array}$ & \begin{tabular}{|l|} 
zwei gegenüber- \\
stehende Hirsche, \\
unter ihnen die \\
Buchstaben E und $\Phi$, \\
dazwischen Fackel, \\
darunter Legende: \\
{$[\Sigma \Omega \Pi A ?] T P O[\Sigma]$} \\
\end{tabular} & $\begin{array}{l}\text { Head 1964, } 69 \\
\text { Taf. } 11,8 .\end{array}$ \\
\hline Mü 23 & $\begin{array}{c}10 \\
0,8 \mathrm{~g}\end{array}$ & $\begin{array}{l}\text { hellenistisch } \\
\text { Ephesos }\end{array}$ & $Æ$ & Biene & $?$ & \\
\hline Mü 24 & $\begin{array}{c}29 \\
10,2 \mathrm{~g}\end{array}$ & $\begin{array}{l}\text { Augustus, } 25 \mathrm{v} . \\
\text { Chr. } \\
\text { Antiochia am } \\
\text { Orontes }\end{array}$ & $\begin{array}{l}\text { Kopf nach } \\
\text { rechts, } \\
\text { CAESA[R] } \\
\text { links des } \\
\text { Kopfes }\end{array}$ & $\begin{array}{l}\text { AVG[VS]TVS } \\
\text { im Lorbeerkranz }\end{array}$ & & $\begin{array}{l}\text { Burnett 1992, } \\
\text { Nr. 2235; Arslan } \\
\text { 1992, } 23 \text { Nr. } 13 .\end{array}$ \\
\hline
\end{tabular}

Die meisten Münzfunde stammen aus Stratum 1. Die Münzen sind zeitlich sehr durchmischt. Das früheste Beispiel zeigt eine Bronzeprägung (Mü 18) mit einem Apollonkopf nach rechts auf dem Avers und einem Dreifuß (normalerweise mit einem Monogramm) auf dem Revers. Die Münzprägestätte Sardis emittierte diesen Typus zwischen 261 und 246 v. Chr. für den Seleukidenkönig Antiochos II. ${ }^{21}$. Sein Sohn und Nachfolger Antiochos III. ließ den gleichen Bildtypus für sich zwischen 223 und 208 v. Chr. in Apameia prägen $^{22}$. Aufgrund der fehlenden Legende kann die Münze nicht mit Sicherheit einem der beiden Herrscher zugeschrieben werden. In das 1. Jahrhundert v. Chr. gehört die Münze Mü 22 (Abb. 2 a), welche vorn die

\footnotetext{
18 Das Schema für die numismatischen Angaben wurde übernommen aus Voegtli 1993, 27.

19 Erste Angaben basieren auf einer Auflistung der Münzfunde der Grabung in Ephesos des Jahres 1999 von S. Karwiese für das Efes Müzesi in Selçuk (auf Türkisch). Fehlende Maße, Avers- und Reversbestimmungen, Legendenlesung und die photographische Aufnahme konnten nachträglich von der Verfasserin mit Unterstützung von S. Ateşoğulları (Museum für Anatolische Kulturen in Ankara) dokumentiert werden. Ihm sei herzlich gedankt.

${ }^{20}$ Ladstätter 2005c, 263.

${ }^{21}$ Vgl. Newell 1977, 255 Nr. 1404; <http://www.coinarchives.com/a/> (01. 08. 2007) mit der Referenz: Sammlung Spaer, 360; Houghton-Lorber 186, 523a.

${ }^{22}$ Vgl. Newell 1977, Nr. 1191.
} 

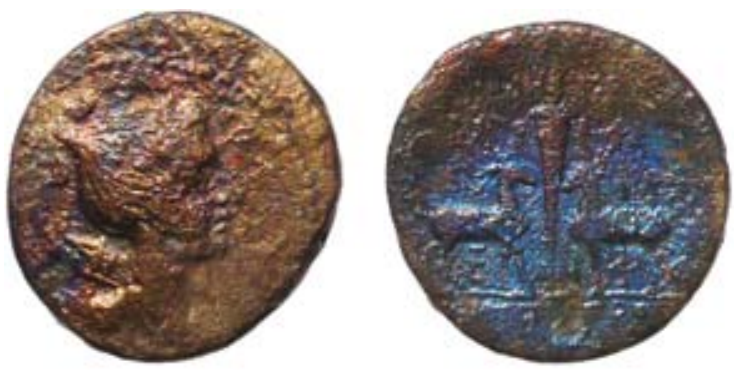

2 a Münze 22 aus Stratum 1
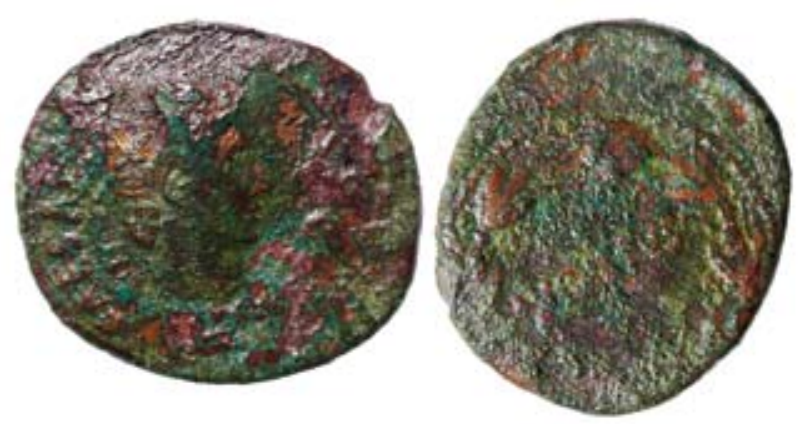

2 b Münze 24 aus Stratum 1

Büste der Göttin Artemis zeigt; hier mit einem hohen Zopf sowie Bogen und Köcher über der Schulter. Auf der Rückseite sind einige ihrer Attribute, zwei einander gegenüberstehende Hirsche mit einer Fackel zwischen ihnen, dargestellt. Die Buchstaben E und $\Phi$ kennzeichnen Ephesos als den Emissionsort, dort wurde die Münze von 48-27 v. Chr. geprägt ${ }^{23}$. Ein As (Mü 24; Abb. 2 b) zeigt auf der Vorderseite den Kopf des Kaisers Augustus im Profil nach rechts gewendet. Auf dem Revers steht der Titel AVGVSTVS in einem Lorbeerkranz. Die Münze gehört zu der \CA, Augustus, Class $2 \prec-S e r i e^{24}$, deren Münztyp im Jahre 25 v. Chr. in Antiochia am Orontes in Umlauf gebracht wurde - somit ist dies der späteste terminus post quem für das Stratum. Die restlichen fünf Münzen konnten nur grob dem hellenistischen Asien zugewiesen werden.

Tabelle 2: Münzfunde aus Stratum 2

\begin{tabular}{|l|c|l|c|c|c|c|}
\hline \multicolumn{1}{|c|}{ Nummer } & $\begin{array}{c}\text { Ø } \text { in mm } \\
\text { Gewicht }\end{array}$ & $\begin{array}{c}\text { Datierung } \\
\text { Münzstätte }\end{array}$ & $\begin{array}{c}\text { Metall } \\
\text { Nominal }\end{array}$ & Vorderseite & Rückseite & Literatur \\
\hline Mü 25 & 21,5 & hellenistisch & $Æ$ & $?$ & $?$ & $?$ \\
\hline Mü 27 & $\begin{array}{l}\text { Kleinasien } \\
2,1 \mathrm{~g}\end{array}$ & $\begin{array}{l}\text { hellenistisch } \\
\text { Kleinasien }\end{array}$ & $Æ$ & $?$ & $?$ & $?$ \\
\hline
\end{tabular}

Zwei Bronzemünzen (Mü 25 und Mü 27) wurden aus Stratum 2 geborgen. Ihre Oberflächen sind so stark abgerieben, dass sie nicht genauer als zum `hellenistischen Asien` gehörend bestimmt werden konnten.

Tabelle 3: Münzfund aus Stratum 3

\begin{tabular}{|c|c|c|c|c|c|c|}
\hline Nummer & $\begin{array}{l}\varnothing \text { in } \mathrm{mm} \\
\text { Gewicht }\end{array}$ & $\begin{array}{l}\text { Datierung } \\
\text { Münzstätte }\end{array}$ & $\begin{array}{c}\text { Metall } \\
\text { Nominal }\end{array}$ & Vorderseite & Rückseite & Literatur \\
\hline Mü 28 & $\begin{array}{l}18,5 \\
2,0 \mathrm{~g}\end{array}$ & $\begin{array}{l}202-133 \text { v. Chr. } \\
\text { Ephesos }\end{array}$ & $Æ$ & $\begin{array}{l}\text { Biene } \\
\text { E } \Phi\end{array}$ & $\begin{array}{l}\text { Hirsch vor einer } \\
\text { (Dattel?-)Palme }\end{array}$ & $\begin{array}{l}\text { Head 1964, } \\
\text { Taf. 11, 4-6. }\end{array}$ \\
\hline
\end{tabular}

In Stratum 3 wurde eine einzige Bronzemünze (Mü 28) gefunden. Auf ihrer Vorderseite ist die Biene, das Wappentier der Stadt Ephesos, zu sehen, flankiert von den Buchstaben E und $\Phi$, welche Ephesos als Emissionsort ausweisen. Auf dem Revers ist der Hirsch, ein Attribut der Artemis, vor einer (Dattel-)Palme dargestellt. Ohne die übliche Angabe des Magistratsnamen kann der Münztypus nicht näher als in die Zeitspanne zwischen 202 und 133 v. Chr., dem Produktionszeitraum, datiert werden ${ }^{25}$.

\footnotetext{
${ }^{23}$ Vgl. Head 1964, 69 Taf. 11, Abb. 8.

${ }^{24}$ Vgl. Burnett 1992, Nr. 2235 und Arslan 1992, 23 Nr. 13.

${ }^{25}$ Vgl. Head 1964, Taf. 11, Abb. 4-6.
} 
Tabelle 4: Münzfunde aus Stratum 4

\begin{tabular}{|c|c|c|c|c|c|c|}
\hline Nummer & $\begin{array}{l}\varnothing \text { in mm } \\
\text { Gewicht }\end{array}$ & $\begin{array}{l}\text { Datierung } \\
\text { Münzstätte }\end{array}$ & $\begin{array}{c}\text { Metall } \\
\text { Nominal }\end{array}$ & Vorderseite & Rückseite & Literatur \\
\hline Mü 29 & $\begin{array}{l}16,5 \\
2,5 \mathrm{~g}\end{array}$ & $\begin{array}{l}\text { hellenistisch } \\
\text { Ephesos }\end{array}$ & $Æ$ & Biene & äsender Hirsch & \\
\hline Mü 30 & $\begin{array}{c}16 \\
2,3 \mathrm{~g}\end{array}$ & $\begin{array}{l}\text { Antiochos II., } \\
\text { 295-280 v. Chr. } \\
\text { Ephesos (?) }\end{array}$ & $Æ$ & $?$ & $\begin{array}{l}\text { Dreifuß mit Gegen- } \\
\text { stempel } \\
\text { Antiochos II. }\end{array}$ & \\
\hline Mü 31 & 11 & $\begin{array}{l}\text { hellenistisch } \\
\text { Kleinasien }\end{array}$ & $Æ$ & $?$ & $?$ & \\
\hline Mü 32 & $\begin{array}{c}2,5 \\
1,2 \mathrm{~g}\end{array}$ & $\begin{array}{l}\text { Arsinoe II., } \\
\text { 288-280 v. Chr. } \\
\text { Ephesos }\end{array}$ & $Æ$ & $\begin{array}{l}\text { weiblicher Kopf nach } \\
\text { rechts mit Schleier }\end{array}$ & $\begin{array}{l}\text { stehender Hirsch } \\
\text { nach rechts }\end{array}$ & $\begin{array}{l}\text { ähnlich Head } \\
\text { 1964, Taf. 10, } 6 .\end{array}$ \\
\hline Mü 33 & $\begin{array}{l}30,5 \\
8,9 \mathrm{~g}\end{array}$ & $\begin{array}{l}\text { Imperium Roma- } \\
\text { num } \\
\text { Kleinasien } \\
\end{array}$ & Æ & $?$ & $?$ & \\
\hline Mü 34 & $\begin{array}{c}16 \\
3,5 \mathrm{~g}\end{array}$ & $280-258$ v. Chr. & $Æ$ & Biene im Kranz & äsender Hirsch & $\begin{array}{l}\text { Head 1964, } \\
\text { Taf. } 10,10 .\end{array}$ \\
\hline Mü 35 & $\begin{array}{c}18 \\
3,3 \mathrm{~g}\end{array}$ & $\begin{array}{l}\text { 280-258 v. Chr. } \\
\text { Ephesos }\end{array}$ & $Æ$ & Biene im Kranz & $\begin{array}{l}\text { äsender Hirsch } \\
\text { Legende: I } \Sigma \text { XoI (?) }\end{array}$ & $\begin{array}{l}\text { Head 1964, } \\
\text { Taf. } 10,10 .\end{array}$ \\
\hline
\end{tabular}

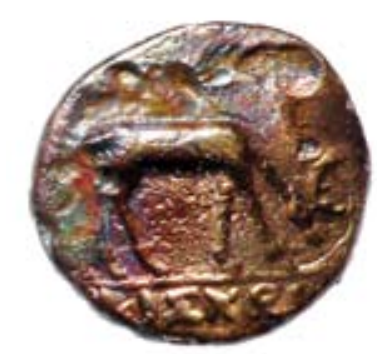

3 Münze 35 aus Stratum 4
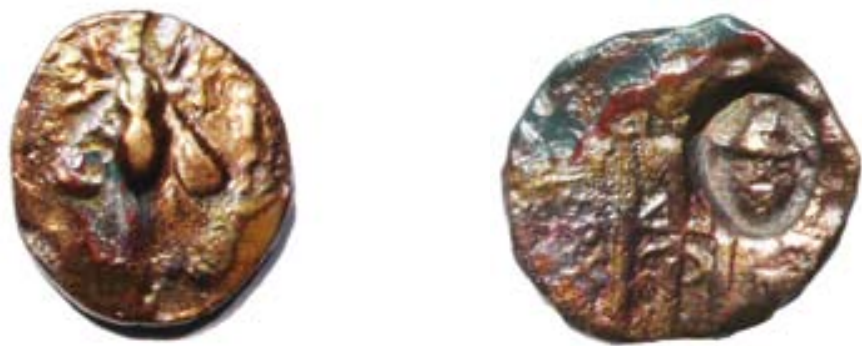

4 a. b Revers der Münze 30 und Münze 32 aus Stratum 4

Den terminus post quem für Stratum 4 liefern sieben hellenistische Münzen. Zwei Münzen (Mü 34-35) zeigen auf dem Avers jeweils eine umkränzte Biene und auf dem Revers einen äsenden Hirsch (Abb. 3$)^{26}$. Auf der Felsoberkante lag eine Münze der Arsinoe (Abb. 4 b). Auf der Vorderseite ist Arsinoe II. nach rechts mit einem Schleier über dem Kopf dargestellt. Die Rückseite zeigt einen Hirsch, der nach rechts gerichtet steht. Solche Asse wurden in den Jahren 288-280 v. Chr. in verschiedenen Typen emittiert ${ }^{27}$, zu einem davon gehört der hier beschriebene. Aus dem oberen Bereich ${ }^{28}$ stammt Mü 30, auf deren Revers ein Dreifuß dargestellt ist, welcher von Antiochos II. gegengestempelt wurde (Abb. 4 a). Die letzte identifizierbare Bronzemünze dieses Stratums, Mü 29, zeigt das hinreichend bekannte Bildprogramm mit Biene auf der Vorderseite und äsendem Hirsch auf der Rückseite. Datiert wird der in Ephesos emittierte Typus zwischen 280 und 258 v. $\mathrm{Chr}^{29}$.

\footnotetext{
${ }^{26}$ Vgl. Head 1964, Taf. 10, Abb. 10. Dort wird der Typus in die Jahre 280-258 v. Chr. datiert. Dies festigt den Datierungsansatz von S. Ladstätter, die eine Wohnbebauung auf dem Areal der Hanghäuser um das Ende des 2. Jhs. v. Chr. ansetzt. s. dazu: Ladstätter 2005a, 232.

${ }^{27}$ Vgl. Head 1964, Taf. 10, Abb. 6; <http://www.coinarchives.com/a/> (01. 08. 2007) mit der Referenz: Sammlung von Aulock, 1840; Klein, KM 52, 379.

${ }^{28}$ Der exakte Fundort konnte nicht ermittelt werden.

29 Vgl. Head 1964, Taf. 10, Abb. 10.
} 


\section{Keramik ${ }^{30}$}

\subsection{Eastern Sigillata A (ESA)}

Die Eastern Sigillata A (ESA) ist sowohl an ihrem individuellen Fabric als auch an dem Grad der Standardisierung ihrer Formen gut zu erkennen ${ }^{31}$. In Stratum 1 sind ausschließlich die Standardtellerformen Atlante 3 und 4 (Taf. 1, 1) vorzufinden. Auf der Innenseite des Bodens befinden sich leichte Roulettierungen. Zwei Exemplare weisen zusätzlich eine Stempelung in Form einer Palmette auf der Bodeninnenseite auf (Kat. 3 Taf. 9, 3). Stempel in Palmetten-, Isiskronen- oder Rosettenform sind bis zur frühen Kaiserzeit häufig zu beobachten ${ }^{32}$.

Im zweiten Stratum erscheinen wieder die Teller Atlante 3, 4 A und 4 B. Die Hälfte der ESA dieser Schicht bedient sich der Formen Atlante $22 \mathrm{~A}_{\text {und }} \mathrm{B}^{33}$, die eine halbkugelige Schale mit einem Ringfu $\beta$ beschreiben (Kat. 4 Taf. 1, 4). Das Formenspektrum der ESA entspricht in Stratum 3 dem in Stratum 2, zusätzlich weist sie hier aber den größten Mengenanteil (5\%) auf. In Stratum 4 fehlt die ESA gänzlich.

Die Formenvielfalt der ESA innerhalb des Fundkomplexes ist eingeschränkt. Die Tellerform Atlante 3/4 sticht immer wieder hervor und wird durch die Formen 13 und $22 \mathrm{zu}$ einem Service komplettiert. Das gleiche Ensemble tritt gehäuft in ephesischen Fundkontexten des Hellenismus und der Frühkaiserzeit auf ${ }^{34}$. ESA kommt in Ephesos das erste Mal in Fundkomplexen des späten 2. Jahrhunderts v. Chr. vor. Sie etabliert sich vor allem im Laufe der ersten Hälfte des 1. Jahrhunderts v. Chr., wird jedoch durch die lokal produzierten Eastern Sigillata B (ESB)-Formen schon in augusteischer Zeit langsam verdrängt ${ }^{35}$. Es verwundert zunächst, dass die ESA im vorliegenden Fundkomplex lediglich einen 3\%-igen Anteil am Gesamtvolumen einnimmt. In Kleinasien wie z. B. auch in Paphos, in Antiochia am Orontes, Tel Anafa, Tarsus, Anemurium oder in Samaria Sebaste ist die ESA die vorherrschende Keramikgattung mit einem der größeren oder sogar dem größten Anteil an der zeitgenössischen Feinkeramik ${ }^{36}$. Allerdings trifft dies nicht für Delos oder die Westküste Kleinasiens von Troja über Pergamon, Assos, Didyma, Knidos bis Ephesos zu. In Troja wird, ähnlich wie in Ephesos, das Tafelservice mit den Atlanteformen 3/4, 22, und hier mit der Ergänzung 23, ab dem 2. Jahrhundert v. Chr. benutzt. Ab augusteischer Zeit wird die ESA durch ESB, Eastern Sigillata C (ESC) und italische Sigillata ersetzt, die gemeinsam einen Marktanteil von bis zu $86 \%$ erreichen. Im Gegensatz dazu hält die ESA einen Anteil von nur $2 \%{ }^{37}$. Ab der zweiten Hälfte des 1 . Jahrhunderts n. Chr. verschwindet die ESA gänzlich aus dem Repertoire von Troja ${ }^{38}$. Das Inventar auf Delos der Jahre 88-69 v. Chr. ist mit nur wenig ESA durchsetzt, vorrangig werden pergamenische Importe und Weißgrundige Ware benutzt ${ }^{39}$. In Pergamon selbst bedient man sich der eigenen >Pergamenischen Sigillata<, nicht lokal produzierte Warengattungen sind

\footnotetext{
${ }^{30}$ Für diesen Fundkomplex schien es sinnvoll, die Nummerierung und Bezeichnung der Typen wie folgt abzukürzen: Ein oder zwei Großbuchstaben stehen für die Warengattung, d. h. G für Glanztonware, D für Dünnwandige Ware, GW für Graue Ware mit schwarzem Überzug usw. Anschließend folgt eine Zahl, wobei die Abfolge der Ziffern der Chronologie, der Gefäßgattung und der Auslegeordnung im Sommer 2006 entspricht. Die Angaben zur Struktur des Fabrics sind wie folgt eingeteilt: sehr feinporös, feinporös, mittel und grob. Vereinzelt wird die Bezeichnung »kompakt« substitutiv für feinporös verwendet. Die Magerung bzw. Körnung entspricht dem >geologischen System Auge und nur einige Male mit einem Mikroskop gemacht wurden, wurde, um Fehlschlüsse zu vermeiden, auf eine Zählung der Magerungspartikel verzichtet. Der Härtegrad wurde nach folgender Skala eingeteilt: sehr hart, hart, mittelhart, weich, sehr weich. Die Häufigkeit der Partikel wird bestimmt mit: sehr häufig, häufig, mittel, selten, vereinzelt. Abgebildet werden nur die grundlegenden Stellvertreter des jeweiligen Typs und dessen Varianten. Bei den Wandstücken mit Dekor und dem Großteil der Lampenfragmente wurde auf Zeichnungen verzichtet; sie wurden photographisch erfasst. Die Farbbestimmungen wurden nach dem Katalog Munsell, Soil colour charts (Newburgh, NY 1992) vorgenommen. Die Zeichnungen und Umzeichnungen stammen von der Verfasserin.

${ }^{31}$ Eine grundlegende Typologie dazu haben F. O. Waagé und J. W. Hayes aufgestellt, s. Warner Slane 1997, 271 mit Anm. 65.

${ }^{32}$ Ladstätter 2005b, 204.

33 Hayes 1985, 22 Abb. 9. 10.

${ }^{34}$ Ladstätter 2003a-c; Ladstätter 2005a; Meriç 2002; Mitsopoulos-Leon 1991; Rogl 2001a. Alle passim.

35 Ladstätter 2003a, 23.

${ }^{36}$ Hayes 1991a, 32; Warner Slane 1997, 272.

37 Tekkök 2003, 237.

38 Tekkök 2001, 372; Gessl 2007, 240.

39 Erste Katastrophe und Zerstörung durch Mithridates ( 88 v. Chr.) bis zur zweiten Zerstörung (69 v. Chr.). Lediglich drei Bodenfragmente in ESA: Peignard-Giros 2000, 134.
} 
äußerst spärlich vertreten. Auch in Assos beträgt der Anteil der ESA nur 2,8\% am Gesamtbestand ${ }^{40}$; der Großteil an Sigillata wird auch hier vom nahe gelegenen Pergamon bestritten. In Didyma stehen 22 ESA- 97 ESB-Fragmenten gegenüber ${ }^{41}$ - der Schwerpunkt liegt klar auf der ESB-Produktion. In Knidos sind zwar die Weißgrundige Ware und die ESA die häufigsten Importprodukte, doch ist deren Ausmaß verhältnismäßig gering. Das Tafelservice wird vornehmlich von regionalen Produkten wie `Knidischen Schalen`, halbkugeligen Bechern mit Kerbdekor, Tellern und Schalen dominiert. Auch in Ephesos wird der Großteil der Keramik mit den Gattungen der lokalen Waren, so der Glanztonware, der Grauen Ware mit schwarzem Überzug, den Reliefbechern oder der Dünnwandigen Ware, bestritten.

\subsection{Eastern Sigillata B (ESB)}

Die hier vorliegende Sigillata wird nach J. W. Hayes als Eastern Sigillata B I (ESB I) bezeichnet (Taf. 1, 5-13). In jüngerer Forschung wurde auf die lückenhafte Typologie der ESB und die große Menge erstmalig auftretender Typen hingewiesen ${ }^{42}$ : Es ist ein Forschungsdesiderat, den alten Bestand mit den neu hinzugekommenen Formen und ihren entsprechenden Datierungen zu komplettieren.

In Stratum 1 sind Schalen der Formen Atlante 24 (Taf. 1, 8) sowie Atlante 39 und ein nicht genau zuzuordnender Standringfuß gefunden worden. Letztgenannter ähnelt der für Schalen und Teller der Glanztonware häufig verwendeten Form G28 (s. u.; Taf. 4, 53). Es ist ein einfacher, schlauchartiger und recht hoher Standring mit kleinem Randdurchmesser von $6,4 \mathrm{~cm}$, wie er zu der Schale der Form Atlante 29 passen könnte ${ }^{43}$.

In Stratum 2 und 3 zeigt die ESB ihr breitestes Formenspektrum. Zunächst sind die Tellerformen Atlante 4 B, 13 (Taf. 1, 5), 14 (Taf. 1, 6) (44 $^{44}$ und 16/53 (Taf. 1, 7) zu nennen. An Schalen lassen sich die Atlanteformen 24, 29, 36 (Taf. 1, 10) und eine Form ähnlich Atlante 76 A (Taf. 1, 13) vorfinden. Das Fragment eines Kraters der Atlanteform 38 konnte erkannt werden. Im Allgemeinen stammen die bei J. W. Hayes angeführten Prototypen meist aus Korinth.

Zeitlich orientierte sich der Produktionsbeginn der ESB am Aufkommen der Arretinischen Sigillata im östlichen Mittelmeergebiet. Dies soll »frühestens in augusteischer Zeit bzw. um die Zeitwende oder knapp danach $\aleph^{45}$ passiert sein. Ausnahme war bis jetzt die sehr frühe Vergesellschaftung von ESB in einem Fundkomplex auf Delos, der vom letzten Drittel des 2. Jahrhunderts v. Chr. bis in das erste Drittel des 1. Jahrhunderts v. Chr. datiert wird. Der hier beschriebene Fundkomplex belegt ebenfalls, dass die ESB früher als bisher angenommen einsetzte, auch parallel mit der ESA produziert wurde und sich dabei stark der hellenistischen Formen bediente ${ }^{46}$. Der regelmäßige Verweis auf Prä- oder Proto-ESB in der Forschung ${ }^{47}$ bekräftigt die These, dass es einen fließenden Übergang von der hellenistischen roten Glanztonware zur ESB gab. Diesen Übergang in späthellenistischer Zeit anhand von Formentypologien genauer aufzuschlüsseln, stellt ebenfalls ein Desiderat dar.

\subsection{Mögliche Imitate von Sigillata und Frühe Eastern Sigillata B}

Sechs Gefäßindividuen vereinen die Charakteristika verschiedener Warengattungen: Es werden einerseits Gefäße hellenistischer Formen, jedoch in Sigillataton und -überzug produziert, andererseits gibt es Beispiele, deren Formen von Sigillatagefäßen entlehnt wurden, deren Fabric und Überzug dabei aber ganz der hellenistischen Glanztonware entsprechen (Taf. 1, 14-21).

\footnotetext{
40 Zelle 1997, 19.

${ }^{41}$ Gessl 2007, 108; Wintermeyer 2004, 145-146.

${ }^{42}$ So konstatiert S. Zabehlicky-Scheffenegger für einen Fundkomplex von der Tetragonos Agora inklusive der drei >neuen< Formen, publiziert bei Mitsopoulos-Leon 1991, mindestens 24 neu hinzukommende Formen. Zabehlicky-Scheffenegger $1995 \mathrm{~b}, 254 \mathrm{f}$. Überdies stammen aus der Marienkirche und auch aus dem Hanghaus 1 und 2 unbekannte Formen. s. dazu: Beyll 1993; Ladstätter 2003a-c und Ladstätter 2005a.

${ }^{43}$ Hayes 1985, 29.

${ }^{44}$ Die Atlanteform 14 ist nach V. Mitsopoulos-Leon eine flache Schale mit runder Wandung, s. Mitsopoulos-Leon 1991,99 mit Anm. 540.

${ }^{45}$ Mitsopoulos-Leon 1991, 94.

46 s. dazu den Fundkomplex der Wohneinheit 4 in Ladstätter 2005a, 236.

${ }^{47}$ Conspectus 1990, 4.
} 


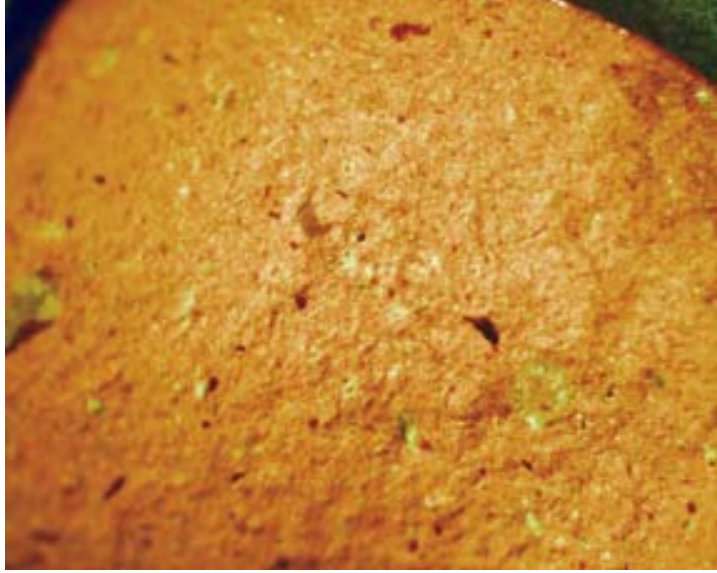

5 Mikroskopphoto von Kat. 14 (FE1)

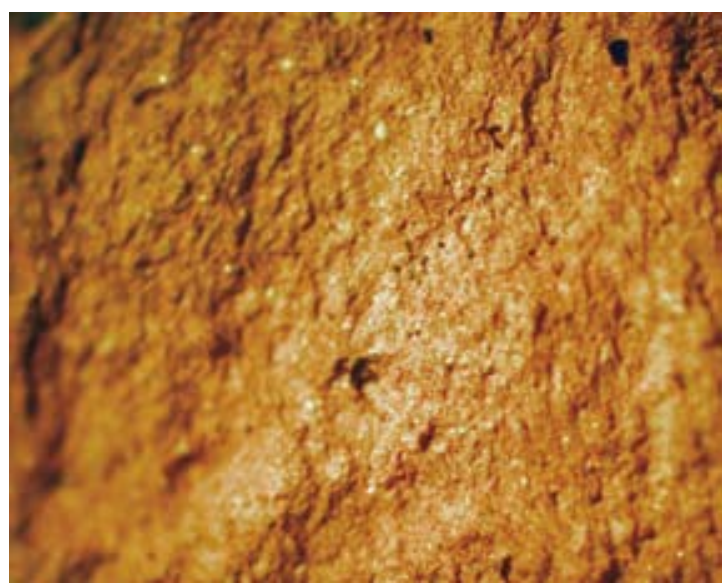

6 Mikroskopphoto von Kat. 15 (FE2)

In Stratum 1 finden sich zwei Becherformen (FE1 und FE3, Taf. 1, 14. 16). Die Wandung von FE1 (Kat. 14) ist eingeschnürt, wie es innerhalb der Dünnwandigen Ware gängig ist. Doch bleibt anzumerken, dass die Lippe bei diesem Stück im Gegensatz zu den dünnwandigen Bechern nach außen schwingt und die Form eher kantig ist. Man kann wohl vermuten, dass hier italische Formen als Vorläufer dienten, jedoch ließen sich keine geeigneten Parallelen als Vergleich heranziehen. Der Überzug entspricht der Sigillata, das Fabric wurde mithilfe des Mikroskops anhand seiner Beschaffenheit als lokal identifiziert (Abb. 5).

Das Randfragment von FE3 (Kat. 16) zeigt eine ausbiegende Lippe. Der Typ ähnelt der ESB-Form Atlante 13 B, 27, 49 oder auch rara a. Die Formen werden zwischen der zweiten Hälfte des 1. Jahrhunderts v. Chr. und dem 1. Jahrhundert n. Chr. (u. a. in Delos) datiert ${ }^{48}$.

Aus Stratum 2 sind zwei Schalen (FE2, Kat. 15, und FE7, Kat. 20), eine Becherform (FE5, Kat. 18 Taf. 9, 18) und ein Krater (FE8, Kat. 21) erhalten. Der Typ FE2 besitzt einen stark verdickten inneren Rand. Die Form ist typisch hellenistisch, allerdings ist der Überzug in ESB. Das Fabric ist zwar äußerst fein geschlämmt, konnte jedoch unter dem Mikroskop als zur Glanztonware gehörig erkannt werden (Abb. 6). Vergleichsbeispiele aus Pergamon werden von der Mitte des 1. Jahrhunderts v. Chr. bis in das 2. Jahrhundert n. Chr. datiert ${ }^{49}$.

Das Bodenfragment der Schale FE7 hat einen profilierten Fuß, der formtypologisch der ESB entspricht. Der Überzug und die Roulettierung als Dekor entsprechen ebenfalls der Eastern Sigillata, jedoch ist auch hier das Fabric lokal. Der Becher FE5 hat einen flachen Boden und einen nur außen aufgetragenen Überzug, was auf eine enge Mündung schließen lässt. Die Form tritt in Stratum 2 und 3 auf. In Stratum 2 ist ferner das Exemplar (Typ FE6, Taf. 1, 19) eines Tellers vertreten, bei dem die ESA-Tellerform Atlante 3/4 imitiert wurde, jedoch sind Überzug und Fabric in Glanztonware hergestellt. Das Randfragment eines Kraters mit einem Randdurchmesser von $18 \mathrm{~cm}$ (FE8, Taf. 1, 21) ähnelt der Atlanteform 38, welche in das 1. Jahrhundert v. Chr. datiert wird; wiederum ist das Fabric als lokal zu bestimmen.

Zuletzt ist aus Stratum 3 ein großes Fragment einer Schale mit Rand und Boden erhalten (FE4, Taf. 1, 17). Die halbkugelige Schale ist eher flach und breit, der Standring ebenfalls breit und niedrig. Die Wandung steigt senkrecht an und endet in einer schmalen, abgerundeten Lippe. Diese Form ist über das gesamte Mittelmeergebiet bis ins Rheinland verbreite ${ }^{50}$. Der Überzug entspricht der ESB, allerdings fällt eine Changierung im Farbton auf, was auf ein zweites Eintauchen hinweisen kann, wie es vor allem bei der Glanztonware (s. Echinusschale) beliebt ist.

Schon P. Kenrick erkannte die Problematik bei Übergangsformen, verwies auf fließende Grenzen zwischen der hellenistischen Glanztonware und der Eastern Sigillata und sprach auch die Schwierigkeiten in der Wahl der Terminologie $a^{51}$. Einige Objekte aus Samaria, Provinz Iudaea, entsprechen der oben beschrie-

\footnotetext{
${ }^{48}$ Hayes, Atlante 13B. 27. 49. rara a, Taf. 9, 3; Bruneau 1970, 246 Abb. 126, D 48.

${ }^{49}$ Meyer-Schlichtmann 1988, Sa 8 Kat. 203 Taf. 14.

${ }^{50}$ Conspectus 1990, Form 36.4.4.

${ }^{51}$ Kenrick 2000, 236.
} 
benen Gruppe. Der Überzug ist mit der \Çandarlı Ware〈 identisch ${ }^{52}$, die Formen sind hellenistisch einzuordnen. J. W. Crowfoot nennt diese Mischform »forerunner of Sigillata $\aleph^{53}$. Diese Hybride zeigen deutlich, dass sich die ephesischen Töpfer im 1. Jahrhundert v. Chr. in einem Stadium des Experimentierens befanden. Man kann annehmen, dass die Töpfer laufend Anregungen durch Importe oder italische Einwanderer ${ }^{54}$ erhielten $^{-}$ und diese, kombiniert mit ihren Materialien und verschiedenen Techniken, für den regionalen Absatzmarkt umzusetzen versuchten. Die Typen FE2, FE3, FE4 und FE6 bilden in der Überzug- und Fabricgestaltung eine homogene Gruppe, die man als Vorstufe zur Entwicklung der ESB ansehen kann. Daher scheint es plausibel, für diese Formen hier den Begriff $>$ Frühe Eastern Sigillata B anzuführen ${ }^{55}$. Diese Entwicklungsstufe ist anhand der Relativchronologie ab der Mitte des 1. Jahrhunderts v. Chr., durch die starke Schichtzusammengehörigkeit von Stratum 2 und 3 jedoch entsprechend der Datierung von S. Ladstätter ${ }^{56}$ im letzten Drittel des 1. Jahrhunderts v. Chr. anzusetzen.

\subsection{Glanztonware}

In späthellenistischer Zeit bediente man sich in Ephesos zumeist der Glanztonware. Der hier vorliegende Fundkomplex bestätigt dies mit seinem 47\%-igen Anteil der Glanztonware (Taf. 2, 22-4, 59). Der Ton enthält wenig Eisenoxyd, aber mindestens $15-20 \%$ Kalkspat und andere Magerungspartikel ${ }^{57}$. Das Fabric ist feinkörnig. Je nach Brenngrad und organischen oder anorganischen Zusätzen changiert die Fabricfarbe zwischen rötlichem Beige bis Braun oder Grau. Die feine Magerung enthält immer weiße Kalkpartikel und Glimmer. Oft sind feine bis mittelfeine Quarz- (Kalziumsilikat) oder bunte (rötliche, gelbliche, gräuliche, schwarze, grüne und orangefarbene) Partikel zu finden. Der Ton wurde lokal abgebaut. Trotz der hohen Frequenz von Einschlüssen ist das Fabric feinporös. Da Kalk und Quarz schon bei niedrigen Temperaturen (ver-)schmelzen, erhält der Scherben eine mittlere bis starke Härte.

Die Qualität dieser Massenware ist mittelmäßig, was besonders beim Überzug auffällt: Er wurde nicht aufgepinselt, sondern während des Drehens auf der Töpferscheibe dünn aufgetragen und vom Töpfer mit den Fingern oder einem Pinsel verstrichen. Oft sind sehr feine, durch die Fingerprofile oder Borsten erzeugte Rillen zu sehen. Der Überzug kann matt, matt glänzend, metallisch glänzend oder glänzend sein ${ }^{58}$, wobei der glänzende als der kompakteste gilt. Häufig ist ein fleckiger Brand zu beobachten. Die Farben variieren zwischen rot, braun, grau und schwarz. Bei der Engobe sind mehr Abreibungen als Abplatzungen zu beobachten, was wohl an der Dünnheit des Schlickers liegt. Die Oberfläche ist eher rau und nicht poliert.

Bei den Schalen, Bechern und Tellern, die in den folgenden Kapiteln beschrieben werden, ist der Dekor verhältnismäßig einfach. Oft sind nur die Ränder und Böden farblich hervorgehoben. Der Farbschlicker wurde wohl recht flüchtig aufgetragen, denn es kam häufig zu mehreren und langen Rinnspuren (〉Laufnasen $<$ ) auf den Gefäßen. Bei einigen Schalen sind die oberen Ränder andersfarbig als die Wandung. Bei den Tellern ist es die Bodenmitte, die zusätzlich durch eine nachträgliche Einritzung des Farbkreises betont wurde. Dies kann zum einen durch die Technik des Brandes verursacht worden sein, zumal man die Gefäße ineinander stapelte, wodurch es am selben Gefäß zu gleichzeitig reduzierendem und oxidierendem Brand kam. Zum anderen wurde die Technik des >double-dipping` angewandt, bei der zwei verschiedenfarbige Tonschlicker benutzt werden. In Anbetracht der Häufigkeit zweifarbiger Ware muss man davon ausgehen, dass diese Art der Herstellung intendiert war. Da die Bichromität erst ab der Mitte des 2. Jahrhunderts v. Chr. auftritt, kann sie für die chronologische Klassifizierung hilfreich $\operatorname{sein}^{59}$.

Allgemein ist auffallend, dass die früheren Stücke einen festeren Überzug und eine dickere Wandung aufweisen. Darüber hinaus wurden sie häufig mit einem Stempeldekor verziert. Bei der späteren Ware fallen diese Stempelungen weg und die Gefäßqualität verringert $\operatorname{sich}^{60}$.

\footnotetext{
${ }^{52}$ Entspricht der ESC bei Hayes 1985. Zur Definition dieser Gattung s. Loeschcke 1912, 344-386 Taf. 30.

${ }^{53}$ Crowfoot 1957, 226.

${ }^{54}$ Kirbihler 2007, passim.

${ }_{55}$ Freundlicher Vorschlag S. Ladstätter.

56 s. »ESB-Adaption«, Ladstätter 2005a, 233.

${ }^{57}$ Sauer 1995, 2.

${ }_{58}$ Beispiele mit mattem Überzug werden andernorts als »color-coated« bezeichnet.

${ }^{59}$ Mündliche Mitteilung S. Ladstätter.

${ }^{60}$ Dies muss sich im 2. Jh. v. Chr. vollzogen haben. s. dazu: Meriç 2002, 26.
} 


\subsubsection{Schalen}

Die universell sowohl für Flüssigkeiten als auch für feste Lebensmittel einsetzbare Schale war das gebräuchlichste Gefäß im Späthellenismus und der frühen Kaiserzeit ${ }^{61}$. Im ausgewerteten Gesamtkomplex waren 296 Fragmente enthalten, die zur Gattung der Schale zu zählen sind (Taf. 2, 22-28). Somit ist die Schale mit $72 \%$ die häufigste Gefäßform innerhalb der Glanztonware ${ }^{62}$. Neben der Echinusschale als Leitform gibt es im Fundspektrum drei weitere Arten: trichterförmige Schalen mit ausbiegendem Rand, Schalen mit geschwungener Wand und ausbiegender Lippe sowie konische Schalen.

Die trichterförmigen Schalen mit horizontal ausbiegendem Rand wie Typ G4 (Kat. 25 Taf. 2, 25) und G35 (Kat. 60 Taf. 4, 60) sind in ihrer Form schon seit klassischer Zeit bekannt. Im 2. Jahrhundert v. Chr. ändert sich die Morphologie: Die Schale wird kantiger, höher und dünnwandiger ${ }^{63}$. Diese Entwicklung lässt sich bei beiden Typen fassen. In Samaria und noch früher in Tarsus erfreute sich die trichterförmige Schale großer Beliebtheit, sie konnte dort in allen hellenistischen Straten nachgewiesen werden. Eine besondere Vermehrung war in Tarsus in den Schichten des 3. bis in die Mitte des 2. Jahrhunderts v. Chr. zu finden. In Antiochia am Orontes wird die trichterförmige Schale für die späteren Schichten des Frühhellenismus, also um 175 v. Chr., angeführt ${ }^{64}$.

In allen Straten, doch vor allem in Stratum 4 der Sondage B6 konnten insgesamt elf Fragmente des Typs G3 (Taf. 2, 24) geborgen werden, die dem Typus der >Schale/Schälchen mit Wandknick und ausgebogener Lippeく zuzuordnen sind ${ }^{65}$. Der Überzug ist meist rötlich und matt, in seltenen Fällen kann er schwarz sein. Spuren einer Tauchung durch Nichtexistenz von Engobe im unteren Gefäßteil, wie bei den Funden der Brunnenfüllung 2 im Hanghaus 1 in Ephesos, konnten nicht beobachtet werden. Eine Setfabrikation ist sehr wahrscheinlich, manifestieren sich doch beim Randdurchmesser zwei Durchschnittsgrößen von 10 bzw. $20 \mathrm{~cm}$. Auch dieser Formtypus ist ein Relikt aus der Klassik, eine durchgehende Produktion und weitgehende Distribution im Westen Kleinasiens zwischen dem 3. und dem 1. Jahrhundert v. Chr. kann als gesichert gelten $^{66}$.

Die Mündung des Typs G5 (Taf. 2, 26), der sog. feinen Schale ${ }^{67}$, ist weit nach außen gestellt, sodass die Gefäßform nach oben hin konisch wirkt. Die Randdurchmesser messen zwischen 12 und $20 \mathrm{~cm}$, meistens $16 \mathrm{~cm}$. Bei G5 ist die Lippe rund und dicker als die Wandung. Sie kann durch eine Profilrille abgesetzt sein wie bei G5 A (Taf. 2, 27), einer Variante, die nur in Stratum 1 und 4 vorkommt. Das früheste Beispiel aus Stratum 4 ist jedoch G5 B (Taf. 2, 28), auch als hemisphärische/ ${ }^{68}$ oder parabolische/r Schale/Mastos ${ }^{69}$ bezeichnet; die Form ist im Fundkomplex lediglich einmal enthalten. Viele Entsprechungen lassen sich in anderen Warengattungen finden, wie der Keramik im Westabhang-Nachfolgestil, wo ein Efeurankenfries im Gefäßinneren aufgemalt worden ist ${ }^{70}$, der ESA ${ }^{71}$, der Grauen Ware ${ }^{72}$ und der unbestimmten Sigillata ${ }^{73}$. Die Schale mit Innendekoration bei der Ware im Westabhang-Nachfolgestil wird in das späte 3.-2. Jahrhundert v. Chr. datiert und lässt sich sowohl in Ephesos als auch in Pergamon gut nachweisen ${ }^{74}$.

Einige Bodenfragmente konnten dank des Erhaltungszustandes den Schalen zugeordnet werden; sie wurden in drei Typen eingeteilt. Der erste Typ (G23, Taf. 3, 48) zeigt den häufig anzutreffenden Ringschlauch

\footnotetext{
${ }^{61}$ Ebenso in Pergamon, s. Schäfer 1968, 37.

${ }^{62}$ Um das Bild nicht zu verfälschen, muss eingeräumt werden, dass einige Skyphoifragmente vermutlich zu den Schalen gezählt wurden, da Anhaltspunkte zur Unterscheidung, wie Henkel oder besondere Formgebung, fehlten.

${ }^{63}$ Mitsopoulos-Leon 1991, 19, A 18.

${ }^{64}$ Crowfoot 1957, 223 Kat. 16 Taf. 37; Goldman 1959, Form T I, Nr. 41-49. Man sollte beachten, dass die stratigraphische Chronologie anhand historischer Eckdaten ermittelt wurde, weshalb die Datierung unbedingt mit Vorbehalt zu betrachten ist.

${ }^{65}$ Ladstätter 2005a, K 313; Ladstätter 2003a, 32 K 95-101; Gassner 1997, 42 Nr. 82-91.

${ }^{66}$ Ladstätter 2003a, 32; Gassner 1997, 42-43.

67 Mitsopoulos-Leon 1978, 114; Mitsopoulos-Leon 1991, 38.

${ }_{68}$ Rotroff 1997, 107-109 Taf. 20.

${ }^{69}$ Rotroff 1997, 109 Taf. 20; Rogl 2003, 176.

${ }^{70}$ Rogl 2003a, Abb. 198 Nr. 10 Taf. 58; Ladstätter 2003a, 30 K 72.

${ }^{71}$ V. Gassner sieht die Form Hayes Atlante 16: Gassner 1997, 49. S. Ladstätter erkennt die Formen Tel Anafa 15 und Atlante 40 , Ladstätter 2005a, K 65.

72 Ladstätter 2005a, K 134.

73 Ladstätter 2005a, K 367.

${ }^{74}$ Mitsopoulos-Leon 1978, $114 \mathrm{f}$.
} 
als Standfuß, der schlank und recht hoch ist. Die Wandung geht in eine bauchige/halbkugelige Form über, wie sie von den Echinusschalen bekannt ist. Häufig ist der Überzug nur innen belegt. Die Qualität ist mäßig. Die Randdurchmesser liegen zwischen 4,4 und 12,5 cm. In der untersten Schicht wurden keine Vertreter gefunden, anscheinend setzte die Form später ein. Der zweite Typ, G24 (Taf. 3, 49), ist der gebräuchlichste er kommt in allen Perioden vor. G24 hat ebenfalls einen Boden mit einem niedrigen Ringfuß, der im Profil rundlicher ausgeprägt ist. Die Wandung ist eher steil und lässt eine schmale, tiefe Schale vermuten. Die Randdurchmesser $(3,8-10 \mathrm{~cm})$ sind kleiner als bei Typ G23, in Beschaffenheit und Farbspektrum jedoch gleich. Der letzte Typ, G25 (Taf. 2, 50), ist zweimal und nur in Stratum 3 vertreten. Seine Standfläche liegt flach auf, die Wandung steigt konisch an.

\subsubsection{Echinusschalen}

Der ephesische Scherben der Echinusschalen folgt dem Kanon: hart gebrannt, weiße, feine Einschlüsse und feiner Glimmer. Es können Varia hinzukommen, wie Quarz oder graue Partikel. Die Formen und der Dekor der Echinusschalen sind, trotz der unterschiedlichen Produktionsorte, einander sehr ähnlich. Beim Dekor wurde meistens die Randzone betont, d. h. mit einer Engobe überzogen, während der Rest tonfarben belassen wurde ${ }^{75}$. War das Gefäß komplett mit einer Engobe überzogen, dann bekam der betonte Rand durch ein zweites Eintauchen eine andere Farbe; das Gefäß war also bichrom ${ }^{76}$.

Knapp ein Drittel (166 von 502 Fragmenten) der gesamten Glanztonware gehört zur Gattung der Echinusschale. Sie wurde grob in zwei Typen unterteilt: Der erste Typ G1 ist die halbkugelige Schale mit leicht eingezogenem Rand (Taf. 2, 22) und runder bis leicht spitz zulaufender Lippe. Die Echinusschale vom Typ G1 hat einen Ringstandfuß, dessen Form variieren kann ${ }^{77}$. Als eher singulär ist ein Knick in der Außenwandung zu betrachten. Die Randdurchmesser können zwischen 6 und $16 \mathrm{~cm}$ liegen. Andernorts wird dieser Typ als >halbkugelige Fußschale klassifiziert $^{78}$. In Wohneinheit 7 ist der Typ, dem 85 Fragmente zuzuschreiben sind, in jedem Stratum belegt.

Zu G2, dem zweiten Typus, gehören 81 Fragmente (Taf. 2, 23). Diese Schale steht ebenfalls auf einem Ringstandfuß, doch besitzt sie einen viel stärker eingezogenen Rand, welcher häufig einen Wandknick an der Stelle des maximalen Durchmessers des Gefäßes aufweist. Die Lippe erhält dadurch einen Winkel von 90-100'; sie ist häufiger spitz zulaufend als rund. Die Maße von G2 schwanken sehr: So liegen die Randdurchmesser zwischen 4,5 und $21 \mathrm{~cm}$, wobei der Großteil zwischen 10 und $12 \mathrm{~cm}$ anzusetzen ist. Die sehr große Bandbreite der Randdurchmesser weist auf eine Set-Fabrikation ${ }^{79}$. G2 wird von V. Mitsopoulos-Leon vor allem in das 2. Jahrhundert v. Chr. datiert, H. Liko schränkt durch den Vergleich mit Paphos auf die erste Hälfte des 2. Jahrhunderts v. Chr. ein $^{80}$.

\subsubsection{Skyphoi}

Drei Arten von Skyphoi konnten im vorliegenden Material festgestellt werden (Taf. 2, 29-35). Zum einen gibt es die sog. Knidischen Schalen, welche jeweils einen Henkel zu beiden Seiten des Gefäßes haben. Die Höhe der Henkel übersteigt nicht die des Gesamtgefäßes, das somit kein Kantharos ist, sondern die Henkel gehen knapp unterhalb der Lippe vertikal vom Gefäßkörper ab. Dabei können sie einen leichten Bogen beschreiben, wie es z. B. bei G9 (Taf. 2, 32) der Fall ist. Zum anderen gibt es Skyphoi mit leicht nach innen gewölbter Wandung, verdickter Lippe und Profilierung, hier repräsentiert von Typ G10 mit seinen zwei Varianten (Taf. 2, 33-35). Zuletzt ist eine Skyphosform mit einer innen verdickten Lippe zu verzeichnen, wie sie bei den Typen G33 und G34 (Taf. 4, 58. 59) zu finden ist.

Die $>$ Knidische Schale ${ }^{81}$ ist eine sehr langlebige Form, die schon ab dem Ende des 3. Jahrhunderts v. Chr. in Erscheinung tritt und bis in die mittlere Kaiserzeit läuft ${ }^{82}$. Sie gilt als Leitform der knidischen Kera-

\footnotetext{
75 s. dazu auch Gassner 1997, 40.

${ }^{76}$ Eiring 2000, 57. Die sehr scharfen Farbränder sind auf die Stapeltechnik im Brennofen zurückzuführen.

77 s. u.

${ }^{78}$ Ladstätter 2003a, K 100; Ladstätter 2005a, K 106. 107.

79 Das gilt für die Echinus-, Knickwand- und für die >feine Schaleく in Delos und Athen. s. dazu Rogl 2003, 177.

${ }^{80}$ Liko 2001, 84 mit Anm. 14.

${ }^{81}$ Auch als Koan/Knidian Cup oder Wein-/Trinkschale mit П-förmigen Henkeln bekannt. Kögler 1996, 64; Rogl 2003 b, $196-204$.

${ }^{82}$ Ladstätter 2003a, 31; Kögler 1996, 64; Gassner 1997, 49.
} 
mik und wurde früh im Mittel- und Schwarzmeergebiet vertrieben. Ohne umfassende naturwissenschaftliche Analysen lässt sich letztendlich nicht klären, ob die Fundstücke aus unserem Fundkomplex Importe oder lokal produzierte Waren sind. Allerdings hat die mikroskopische Untersuchung von Stichproben gezeigt, dass der Gefäßtypus in den ephesischen Produktionskatalog übernommen und im hauseigenen Ton produziert wurde ${ }^{83}$. Meistens ist der Überzug außen schwarz und innen rot. Die für Knidos typischen Dekorelemente, die erst im Späthellenismus auftreten ${ }^{84}$, sind - bis auf den Kerbdekor bei Typ I16 (Kat. 154) - bei dem ephesischen Material nicht zu beobachten. Die Grundform zeigt einen Knick im unteren Bauchbereich des Skyphos, dann verläuft die Wandung vertikal oder leicht schräg. Selten ist die Lippe nach außen gestellt, was bei nur einem der vier Typen zutrifft (G6, Taf. 2, 29); eher ist sie leicht nach innen gestellt (G7, G8 und G9, Taf. 2, 30-32). Die Henkel, deren Form P. Kögler als П-ähnlich beschreibt, liegen seitlich gegenüber ${ }^{85}$. An den Gefäßfragmenten konnten zwar nur Henkelansätze festgestellt werden, trotzdem ließ sich diese Art der Henkel in Form einzelner Fragmente im Fundmaterial nachweisen.

Es sind 32 Fragmente des Typs \Knidische Schaleく im Fundkomplex enthalten. Typologisch ist für den Fundkomplex anzunehmen, dass G7 einer der frühesten Vertreter ist, da er über den gesamten Zeitraum präsent bleibt. Charakteristisch ist bei diesem Typ die lange Wandung, die in einer leicht zugespitzten und nach innen gestellten Lippe endet. Die Randdurchmesser schwanken zwischen 8 und $16 \mathrm{~cm}$. G6 ist in den Straten 1,2 und 4 vorhanden, die Durchmesser von 10-13 cm sind auch hier vertreten. Die Mündung ist konisch und hat eine spitze Lippe. G9 kommt in den Straten 1, 2 und 3 vor. Bei diesem Typus ist die Wandung stärker gewölbt. Das Gefäß ist mit Randdurchmessern von 10-12 cm im Durchschnitt kleiner als die anderen Skyphosformen. Bei G8, der nur im zweiten Stratum nachzuweisen war, ist der Gefäßumbruch ein eckiger Knick. Die Lippe ist innen verdickt, und die Ränder haben Durchmesser von 10-14 cm.

Die Skyphoi des Typs G10 (A und B, Taf. 2, 33-35) sind im Durchmesser mittelgroß bis weit. Die Wandung ist leicht nach innen gebogen, und der obere Rand mit der Lippe wird häufig durch Profilierungen, in anderen Fundkontexten auch durch Bemalungen im Westabhang-Nachfolgestil betont ${ }^{86}$. An den Seiten besitzen sie zwei Henkel. Die Skyphoi werden vor allem in das 2. Jahrhundert v. Chr. datiert. Aufgrund ihres geringen Aufkommens im Fundkomplex, besonders durch die Absenz in den oberen Straten, sind diese Formen als die letzten Ausläufer zu betrachten.

In Stratum 1 und 2 sind die Skyphosformen G33 und G34 (Taf. 4, 58. 59) zu finden. Beide haben eine vertikale Wandung, sind leicht nach innen gewölbt, und die Lippe ist charakteristischerweise innen stark verdickt. G34 besitzt zusätzlich eine Profilierung unter der Verdickung. Die Henkel sind knapp unter dem Rand angesetzt und führen in einem Bogen nach unten. Diese Skyphosformen treten in Ephesos in augusteischen Fundkomplexen auf ${ }^{87}$.

\subsubsection{Becher}

Becherformen in Glanztonware sind eher selten. Entweder bediente man sich der besonders umfangreichen Auswahl an Relief- und Applikenbechern, der pergamenischen Sigillata oder an den Bechern der Dünnwandigen Ware. Trotzdem wurden neun Fragmente geborgen, die zu Formen von Bechern in Glanztonware zu zählen sind. Es lassen sich drei Formentypen ableiten, die alle in der Beschaffenheit von Fabric und Überzug der ephesischen Glanztonware gleichen.

G11 (Taf. 2, 36) ist eine Form, die sich in jedem Stratum jeweils einmal erhalten hat. Die Stücke weisen alle eine vertikale Wandung auf. Die Mündung ist leicht ausgestellt, was dem Becher eine konische Form gibt. Die Lippe ist rund und nach innen verdickt. Der durchschnittliche Randdurchmesser liegt bei $12 \mathrm{~cm}$. Die Engobe ist rot, grau oder schwarz, wobei sich die äußere Farbe von der inneren unterscheiden kann. Dies wäre auf das wechselseitige Phänomen des reduzierenden und oxidierenden Stapelbrandes zurückzuführen. Bei Typ G12 (Taf. 2, 37) handelt es sich um vier Randfragmente mit Randdurchmessern zwischen 8 und $13 \mathrm{~cm}$. Die Wandung ist vertikal und endet in einer runden, etwas verjüngten Lippe. Die Form erin-

\footnotetext{
${ }^{83}$ In der Brunnenfüllung 2 im Hanghaus 1 sind zwei von drei Fragmente lokal hergestellt. Ladstätter 2003a, 31.

${ }^{84}$ Kerbmuster, vegetabile oder figürliche Stempelungen oder Froschappliken im Innern des Gefäßes. Kögler 1996, 64.

${ }^{85}$ Kögler 1996, 64.

${ }^{86}$ Mitsopoulos-Leon 1991, für G10: B 42. B 53; für G10 A: B 30. B 36. B 49; für G10 B: B 32. B 48-49.

${ }^{87}$ Ladstätter 2005a-c, K 86 (aber kleiner und dünnwandiger); zur Form: Meyer-Schlichtmann 1988, S 3.
} 
nert an die >ionischen Reliefbecher`, jedoch unterscheidet sich die Optik. Der Überzug kann matt bis matt glänzend sein und rot oder grau bis schwarz. Die Oberfläche ist nicht geglättet, sondern als fein-rau zu bezeichnen. Auffallend ist ebenfalls, dass sich der innere Überzug von dem äußeren unterscheidet: Er kann innen schwarz und außen rot sein oder auch umgekehrt. Das Bodenfragment G13 (Taf. 2, 38) ist von einem Becher, dessen Tonzusammensetzung der Glanztonware, wie oben beschrieben, entspricht. Der Überzug ist rötlich und matt, die Oberfläche recht kompakt, doch feinkörnig. Die Standfläche ist sehr flach, nur auf einem ganz leicht angedeuteten Standring erhebt sich ein konischer Bauch. Das Fragment wurde in der frühen Schicht 4 gefunden, seine Form ist als Einzelstück zu bezeichnen.

\subsubsection{Kannen und Krüge}

Fragmente von Kannen und Krügen der Glanztonware sind eher selten im Fundkomplex der Sondage B6, wie auch andernorts in Ephesos und beispielsweise auch in Korinth ${ }^{88}$. V. Gassner postuliert, dass die Gefäßform vor allem in Metall umgesetzt worden und zudem die Präsenz der feinen Gebrauchskeramik, der Weißgrundigen sowie der Dünnwandigen Ware nicht zu unterschätzen sei, die mit ihren Krugformen verdeutlichen, dass Substitute keineswegs nur in nichtkeramischem Material zu suchen seien ${ }^{89}$.

Drei Formen sind als Kannentypen zu bestimmen. Bei der stratigraphisch älteren Form G14 (Taf. 3, 39) liegen die Randdurchmesser zwischen 6 und $12 \mathrm{~cm}$. Der Überzug ist matt bis matt glänzend und erscheint in den Farbtönen rot, grau und schwarz. Den fünf Randfragmenten ist ein enger Hals mit einer weit ausladenden Mündung gemeinsam, die sich leicht nach innen wölbt. Im Profil sieht es aus, als ob die Mündung eine schräg nach hinten gelegte S-Form bildet. Die Form tritt in Stratum 2, 3 und 4 auf ${ }^{90}$. Nur in den Straten 1 und 2 findet sich jeweils ein Randfragment des Kannentyps G15 (Taf. 3, 40). Es handelt sich dabei um eine birnenförmige Kanne, deren Rand nach außen gebogen ist. Die Lippe läuft spitz zu und hängt leicht nach unten. Bei beiden Fragmenten der Kanne G15 beträgt der Durchmesser $9 \mathrm{~cm}$, eines ist mit einer glänzend schwarzen, das andere mit einer matten roten Engobe überzogen. Parallelen sind aus Ephesos und Paphos bekannt ${ }^{91}$. Zuletzt ist aus Stratum 2 die Oinochoe G32 (Taf. 4, 57) belegt. Die Mündung der kleinen Kanne hat einen Randdurchmesser von $6 \mathrm{~cm}$, ihre Lippe ist innen nach unten abgestrichen.

\subsubsection{Teller}

Mit $20 \%$ haben die Teller unter den Gefäßgattungen der Glanztonware den zweitgrößten Anteil, überdies weisen sie die reichste Formvielfalt der Keramikgattung auf. Wie bei der Glanztonware üblich, ist ein fleckiger Brand in verschiedenen Stärkegraden zu beobachten. Die Teller sind in allen Farben zwischen rot, braun über grau bis zu schwarz vertreten; bei dunkelfarbigen Tellern (braun, grau, schwarz) tritt der metallische Glanz besonders zum Vorschein.

Sieben Randtypen sowie drei gesicherte und drei eventuell zu Tellern passende Bodentypen wurden konstatiert (Taf. 3, 41-47). Der früheste Typ ist wohl der Fischteller G17 (Taf. 3, 42), der als Einzelstück zu betrachten ist ${ }^{92}$. Bei ihm handelt es sich um einen schwarzen, matt glänzenden Teller mit einem Standring und einer charakteristischen runden Vertiefung in der Mitte der Innenseite ${ }^{93}$; es war nicht möglich, ein zu diesem Teller passendes Randfragment zu finden. Das Bodenfragment weist einen Randdurchmesser von $10 \mathrm{~cm}$ auf. Der Standring ist recht niedrig und als eher fein zu bezeichnen, was zur konstant dünnen Wandung passt ${ }^{94}$. Jedoch ist er nicht profiliert, wie beispielsweise frühe Vertreter von der Athener Agora ${ }^{95}$,

\footnotetext{
${ }^{88}$ In den Publikationen von V. Mitsopoulos-Leon und R. Meriç fehlen diese Formen völlig. Andernorts sind sie in geringen Mengen vorhanden, vgl. Liko 2001, 85 und Gassner 1997, 55.

${ }^{89}$ Gassner 1997, 55 mit Anm. 53. Zu den Krugformen s. u.

${ }^{90}$ Ein ähnliches Randstück einer Kanne mit Trichtermündung kommt aus dem Stratum 2. Es hat einen RDm von $5 \mathrm{~cm}$, der Überzug ist schwarz und matt glänzend. Hier sind die Formen doch etwas dicklicher und runder geprägt. Ein zu erwartender Siebeinsatz konnte nicht nachgewiesen werden. Ein vergleichbares Fragment mit identischem Durchmesser und Überzug ist von der Tetragonos Agora bekannt: Gassner 1997, 55 Kat. 148 Taf. 8.

${ }_{91}$ Liko 2001, 38; Hayes 1991a, Nr. 52 Abb. 16, 8.

92 Ein weiteres Fragment (Inv. 99/643.43) aus dem Stratum 1 ist nicht eindeutig als Fischteller zu identifizieren.

${ }_{93}$ Diese diente wohl dazu, Soße aufzunehmen. Sparkes - Talcott 1970, 147.

${ }^{94}$ Oftmals wechselt die Stärke der Wandung spontan, s. dazu Sparkes - Talcott 1970, 148 Abb. 10, 1061. 1066. 1075.

${ }_{95}$ Sparkes - Talcott 1970, 148 Abb. 10, 1061-1066.
} 
sondern schlicht gehalten. In Ephesos wurden diese Teller überwiegend lokal produziert ${ }^{96}$, V. MitsopoulosLeon grenzt ihre Laufzeit zwischen der zweiten Hälfte des 2. Jahrhunderts v. Chr. und dem 1. Jahrhundert v. Chr. ein. Fischteller in ESA sind aus Paphos bekannt, wurden aber von J. W. Hayes in das 2. Jahrhundert v. Chr. datiert, da ihm keine weiteren Beispiele aus dem 1. Jahrhundert v. Chr. bekannt waren ${ }^{97}$. Aufgrund der geographischen Lage an der Küste und der damit verbundenen Speisegewohnheiten verwundert es nicht, dass diese Keramikform in Ephesos noch bis in das 1. Jahrhundert v. Chr. nachzuweisen ist ${ }^{98}$. Vielmehr ist zu fragen, in welchen Formen sich dieser Gefäßtyp z. B. in der Glanztonware, in der ESA oder der Grauen Ware mit schwarzem Überzug widerspiegelt.

Nachfolger der Fischteller können in den Tellern mit >gedrechseltem Rand`, wie er hier als Typ G18 beschrieben ist, gesehen werden ${ }^{99}$. G18 (Taf. 3, 43) ist ein Teller mit verdicktem und stark unterschnittenem Rand, unter dem jeweils zwei Profilrillen folgen ${ }^{100}$. Von diesem Typ sind Fragmente von 16 Gefäßen erhalten, wobei der Großteil in Stratum 1 zu finden ist. Der Teller mit beidseitig verdickter Lippe (G19, Taf. 3, 44) erscheint regelmäßig in späthellenistischen Fundkomplexen in Ephesos ${ }^{101}$. Diese Tellerform bildet sich schon ab dem 3. Jahrhundert v. Chr. in Athen aus und wird in Kleinasien zügig adaptiert ${ }^{102}$, in Tarsus entwickelte sie sich zur zweitbeliebtesten Tellerform ${ }^{103}$. Die Randdurchmesser der Teller rangieren zwischen 16 und $24 \mathrm{~cm}$. Typ G19 ist in jedem Stratum unseres Fundkomplexes vertreten und ist die dritthäufigste Tellerform. Eine Variante bildet G19 A, dessen Lippengestaltung kleiner, fast simpler und abgerundeter wirkt, und der während des 2. Jahrhunderts v. Chr. aus den Fundkomplexen verschwindet ${ }^{104}$. G21, ein Teller mit überhängender Lippe, tritt am häufigsten auf, was darauf zurückzuführen ist, dass seine Varianten sehr vielfältig sein können ${ }^{105}$. So ist er manchmal dünnwandig, dann wieder dickwandig. Seine Lippe kann schräg, aber auch vertikal hängen, sie kann fein geschwungen und spitz zulaufend oder dick und rund sein. Der Bodendurchmesser liegt bei ca. $10 \mathrm{~cm}$, die Randdurchmesser liegen zwischen 16 und $25 \mathrm{~cm}$. Die Randtypen G19 und G21 ähneln sehr den Randformen der Fischteller bei V. Mitsopoulos-Leon oder J. W. Crowfoot ${ }^{106}$. Da jedoch keine weiteren Bodenfragmente zutage kamen, die eine Vertiefung aufweisen, kann es sich dabei um die direkten Nachfolger der Fischteller handeln. Zwar zeigen sie die gleichen Randformen, aber in der Mitte werden statt der Vertiefung nur noch Profilrillen angedeutet ${ }^{107}$. Die Teller mit eingerollter Lippe (G20, Taf. 3, 45) treten schon früh im Athen des 4. Jahrhunderts v. Chr. auf, reichen bis zum Anfang des 1. Jahrhunderts n. Chr. ${ }^{108}$ und verbreiten sich bis nach Antiochia am Orontes ${ }^{109}$. Im Gegensatz zu den attischen Exemplaren sind die Teller in Ephesos aber eher flach und weitmundig. Der Tellertyp erscheint vereinzelt in den ephesischen Komplexen ${ }^{110}$. Für Typ G20 sind Fragmente von sieben Tellern erhalten, die sich in Stratum 4 konzentrieren; lediglich ein Fragment wurde in Stratum 1 gefunden. Als Einzelstück ist der Teller G22 (Taf. 3, 47) zu betrachten, der sich durch eine nach außen geschwungene Wandung und einen besonders profilierten Rand auszeichnet. Die Tellerform ist im ephesischen Hanghaus $2^{111}$ sowie in Pergamon, hier

\footnotetext{
${ }^{96}$ Mitsopoulos-Leon 1972, 498.

${ }^{97}$ Hayes 1991a, 33 und Taf. 46, 14.

${ }_{98}$ Die Frage nach der Verwendung wird bei N. Kunisch ausführlich diskutiert. Er kommt zwar zu keinem definitiven Urteil, räumt aber ein, dass der Teller wohl primär als Fischteller, daneben aber auch für andere Speisen vorkommt; Kunisch 1989, 43-48.

${ }^{99}$ Mitsopoulos 1991, 23; Liko 2001, 85.

100 Gassner 1997, 46 f.

${ }^{101}$ Ladstätter 2003b, K 17. K 161-171; Ladstätter 2005a, K 112; Gassner 1997, Nr. 107; Meriç 2002, K 14-20; Mitsopoulos-Leon 1991, A 56.

102 Mitsopoulos-Leon 1991, 24.

${ }^{103}$ Crowfoot 1957, 222.

${ }^{104}$ Ladstätter 2006, Nr. 7; Mitsopoulos-Leon 1991, A 42. A 44 Taf. 8-9; A 63 Taf. 13; Crowfoot 1957, Nr. 8 Taf. 37; Goldman 1959, Form T 1, Nr. 27-38.

${ }^{105}$ Formenvielfalt und -veränderung sind gut bestimmbar. Eine übergreifende Typologisierung der Teller ist ein Desiderat.

106 Mitsopoulos-Leon 1991, 20 Taf. 8. 9; Crowfoot 1957, 221 f. Abb. 37 Nr. 1-13. Der Durchmesser allein ist kein ausschlaggebendes Kriterium, da z. B. manche Schale einen größeren Randdurchmesser als ein Teller haben kann.

${ }^{107}$ Gassner 1997, 44-46.

${ }^{108}$ Ladstätter 2003a, 24 mit Anm. 36.

109 Gassner 1997, Nr. 108, Parallelen.

110 Brunnenfüllung 1 im Hanghaus 1: Ladstätter 2003a, 24 K 18; Tetragonos Agora: Gassner 1997, Nr. 108 Taf. 6.

111 Ladstätter 2005a, K 117.
} 
jedoch in Grauer Ware mit schwarzem Überzug, belegt ${ }^{112}$. Der Teller G16 (Taf. 3, 41) mit beidseitig verdickter Lippe tritt lediglich einmal in Stratum 4 auf. Diese Tellerform wird zum Ende des 3. Jahrhunderts v. Chr. aus Athen übernommen ${ }^{113}$ und besonders gern in Tarsus benutzt ${ }^{114}$. Ein letztes singuläres Beispiel ist Typ G36 (Taf. 4, 61). Der aus Stratum 3 geborgene Teller hat eine steile Wand mit hohem Rand, der leicht nach innen gewölbt ist. Die Form wird während des 1. Jahrhunderts v. Chr. an mehreren Orten verwendet ${ }^{115}$.

\subsubsection{Nicht näher definierbare Böden}

Eine größere Anzahl von Bodenfragmenten konnte nicht sicher einer bestimmten Gefäßform zugewiesen werden (Taf. 3, 51; 4, 52-54) $)^{116}$. Es sind vier Formen voneinander zu unterscheiden: Typ G26-G29.

Bei allen Bodenfragmenten handelt es sich um Ringstandfüße. G27 ist eine in allen Straten oft vertretene Form $^{117}$. Der Ring ist schlauchförmig, die Randdurchmesser liegen zwischen 6 und $13 \mathrm{~cm}$; die Fragmente sind in allen Farben zwischen rot und schwarz anzutreffen. Parallelen lassen sich in Ephesos in mehreren späthellenistischen Komplexen finden ${ }^{118}$. G26 ist ein kleiner, quadratischer Fuß. Die Seiten sind nach innen hoch gestrichen, bei dem Übergang vom Fuß zum Körper ist eine Einkehlung angebracht, wodurch der im Durchschnitt kleinere Boden feiner gestaltet wirkt. Vermutlich diente er vornehmlich Skyphoi oder Bechern zum Stand. Die 46 Fragmente des Typs G28 sind regelmäßig über alle Straten verteilt. Charakteristikum ist der hohe Standring, welcher schräg gestellt ist. Proportional zu der Größe des Durchmessers (zwischen 4,6 und $11 \mathrm{~cm}$ ) ist auch die dünne Wandung. Einige Beispiele belegen, dass G28 im späthellenistischen Ephesos eine beliebte Fußform für jegliche Art von Tischgeschirr war ${ }^{119}$. Typ G29 ähnelt zwar sehr G28, jedoch ist sein Ringfuß senkrecht gestellt und im Übergang zur Wandung profiliert. Dieser Typ ist seit dem 2. Jahrhundert v. Chr. sowohl in Athen als auch an der Westküste Kleinasiens bekannt und bis zur Mitte des 1. Jahrhunderts v. Chr. belegt ${ }^{120}$. Im vorliegenden Komplex tritt er in den zwei oberen Straten, die etwas später datiert werden, jeweils einmal auf. Bei Ganzformen sind im ephesischen Fundmaterial sowohl für Schalen als auch für Teller immer wieder hohe Ringstandfüße beschrieben, die unprofiliert sind ${ }^{121}$.

\subsection{Ware im Westabhang-Nachfolgestil (WAN)}

Die Ware im Westabhang-Nachfolgestil wird ähnlich wie die Glanztonware hergestellt ${ }^{122}$. In Tonzusammensetzung und Überzugstechnik sind beide gleich ${ }^{123}$, allerdings wird die WAN durch ihre Verzierung, den Schlicker- und Ritzdekor, bestimmt, weswegen sie an dieser Stelle gesondert besprochen wird.

Der Scherben ist orangefarben bis braun. Er bricht hart und enthält außer Glimmer kaum Einschlüsse. Die Textur ist feinporös. Die Oberfläche ist glatt, und der Überzug wurde dicht und geschlossen aufgetragen. Die schwarzen Engoben sind schwach glänzend, während rote eher von minderer Qualität und matt sind. Der Farbdekor ist mit weißem, dicklichem Schlicker aufgetragen, der in seiner Deckungskraft unterschiedlich ist je nach Konsistenz kann er durchscheinend oder deckend weiß sein ${ }^{124}$. Vegetabiles, wie Blätter und Knospen, wurde mit Farbschlicker aufgetragen. Dabei stellte man meist Efeuranken oder Tänien mit an ihnen

112 De Luca - Radt 1999, 49 Kat. 239.

113 Mitsopoulos-Leon 1991, 24.

114 Dort war es die zweitbeliebteste Tellerform; Goldman 1959, Form T 1, Nr. 27-38. Parallelen lassen sich jedoch auch in Ephesos finden: Ladstätter 2006, Nr. 7; Mitsopoulos-Leon 1991, A 42. A 44 Taf. 8-9; A 63 Taf. 13 und Samaria Sebaste: Crowfoot 1957, Nr. 8 Taf. 37.

${ }_{115}$ Hayes 1985, Atlante 14; Ladstätter 2005a, K 69; Conspectus 1990, Form 4.6.1 (Fundorte: Korinth, Berenice, Bolsena, Conimbriga, Kempten, Tessin, Tipasa).

$116 \mathrm{Zu}$ diesem allgemein bekannten Problem s. Conspectus 1990, 153.

117 Insgesamt 33 Fragmente.

${ }_{118}$ Ladstätter 2003b, Taf. 16-17; Ladstätter 2005a, K 22; Liko 2001, Taf. 56 Nr. 44.

119 Ladstätter 2003b, Taf. 17; Ladstätter 2005a, K 122; Meriç 2002, K 12.

${ }^{120}$ Outschar 1996, Nr. 9; Ladstätter 2002, K 12. K 370; Rotroff 1997, Taf. 64 Nr. 1044; Hayes 1997, Troja, Nr. 40.

${ }^{121}$ Ladstätter 2003a, 32. 33. 34.

122 Zum Begriff s. Rotroff 1997, 39; Schäfer 1968, 45.

123 Dies gilt für lokal produzierte Gefäße.

${ }^{124}$ D. Behr geht davon aus, dass die Farbe absichtlich nuanciert verwendet wurde, um die Gefäße plastisch wirken zu lassen. Behr 1988, 105 f. Bei dem vorliegenden Material geht es meist um kleine Punktdekore, daher kann man von einer diesbezüglichen Interpretation absehen; s. hier Abb. 6. 


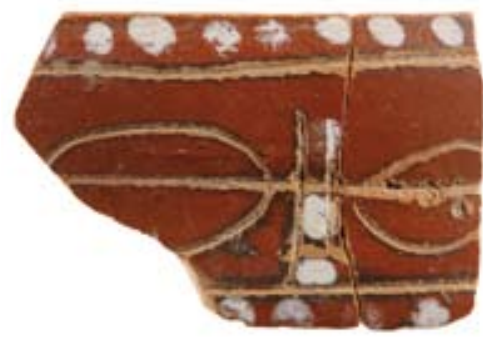

7 Geometrische Formenmuster und Punktreihe auf Kat. 66 (W4)

hängenden Knospen, auch als >Bommelkette $<$ bekannt ${ }^{125}$, dar. Besonders beliebt waren zudem Punktreihen oder sog. Tupfenketten (Abb. 7) ${ }^{126}$ : Die kleinen Punkte beginnen auf der vorausgehenden Westabhangware schon in der zweiten Hälfte des 3. Jahrhunderts v. Chr. und sind noch bis ca. 10 v. Chr. in Athen belegt. Sie dienten als Begrenzung oder wurden in die Girlanden integriert. Beim vorliegenden Material ist besonders bei der roten Ware im WAN dieser Punktdekor immer vorhanden. Entweder liegt er wie ein Band knapp unterhalb der Lippe an oder begrenzt geometrisch verzierte Feldeinheiten. $\mathrm{Zu}$ dem Farbauftrag kommt noch der Ritzdekor: Bei den vegetabilen Mustern ersetzte man vor allem Stiele und Stängel durch Ritzungen, entweder um das Blattwerk plastisch zu gestalten ${ }^{127}$ oder um eine Aufmalung zu vermeiden.

Darüber hinaus benutzte man für die Betonung des tektonischen Gefäßaufbaus abstrakte Formenmuster (Abb. 7). Die Entfaltung der geometrischen Motive entwickelte sich zeitgleich mit dem Aufkommen der Reliefbecher ${ }^{128}$, bis die Skyphoi und Kantharoi im WAN um 175-150 v. Chr. langsam von den Bechern abgelöst wurden ${ }^{129}$.

Vor allem Trinkgefäße sind bei dieser Warengattung beliebt ${ }^{130}$. Das bezeugen $u$. a. die im Fundmaterial vielfach vertretenen Rotellenhenkel, die zu den Skyphoi zählen ${ }^{131}$. Der früheste Typ W1 (Taf. 4, 62) ist ein Skyphos mit leicht einwärts biegender Lippe, die zudem profiliert und leicht abgesetzt ist. Außen ist der Überzug schwarz und metallisch glänzend, innen rot und glänzend. Zahlreiche Beispiele dieses Typs sind aus ephesischen Fundkomplexen des 2. Jahrhunderts v. Chr. belegt, wo sie meist mit Efeublättern als vegetabilem Dekor verziert sind ${ }^{132}$. Der Typ kam in Sondage B6 selten (drei Randfragmente) und nur in Stratum 1 und 4 zutage.

In Stratum 3 wurde das Fragment eines Skyphos (W3, Taf. 4, 64) mit gerader, rund abgestrichener Lippe und mehrfacher Außenprofilierung gefunden, das Schlickerdekor, aber keinen sichtbaren Ritzdekor aufweist. Vergleichsbeispiele innerhalb von Ephesos sind selten belegt ${ }^{133}$, jedoch findet sich eine ähnliche Form in Pergamon in >hauseigener Sigillata wieder und wird von der Mitte des 1. Jahrhunderts v. bis zur Mitte des 1. Jahrhunderts n. Chr. datiert ${ }^{134}$. Weitere Analogien sind in der Gattung der Westabhangware in Samaria-Sebaste und Tarsus des 2.-1. Jahrhunderts v. Chr. anzutreffen ${ }^{135}$. Ob es sich bei dem vorliegenden Objekt um Westabhangware oder ein Gefäß im WAN handelt, ist letztendlich nicht eindeutig zu bestimmen. Beim Skyphos des Typs W4 (Taf. 4, 65) kann als gesichert gelten, dass er dem WAN angehört. Alle sieben Belege des Typs W4 weisen den typischen Schlicker- und Ritzdekor auf. W4 zählt zu den größeren Skyphoi, deren Randdurchmesser von 9,6 bis zu $17 \mathrm{~cm}$ betragen können. Der Dekor zeigt die bekannte >Tupfenkette< am Lippenrand, unter der sich, durch eine horizontale Leiste getrennt, ein schwungvoller Blätterdekor mit Ritzungen befindet. Der Typ ist in Ephesos vom 1. Jahrhundert v. Chr. bis in das frühe 1. Jahrhundert n. Chr. gebräuchlich ${ }^{136}$. In Stratum 4 ist er nicht enthalten. Beim Typ W5 (Taf. 4, 67) handelt es sich ebenfalls um eine Skyphosform. Das Gefäß ist leicht kugelig. Die Lippengestaltung steht mit der innen verdickten Lippe in hellenistischer Tradition ${ }^{137}$; der Rand ist gerade. Unterhalb des Randes ist eine Profilleiste ange-

${ }_{125}$ Mitsopoulos-Leon 1991, 32.

126 Schäfer 1968, 52.

127 Behr 1988, 106.

${ }^{128}$ Eine Beziehung zwischen den Dekoren der Ware im WAN und den Reliefbechern wurde bei V. Mitsopoulos-Leon angesprochen. Sie geht davon aus, dass ein bestimmender `Zeitgeist auf die Motivwahl Einfluss hatte. Mitsopoulos-Leon 1978, 118.

${ }^{129}$ Ladstätter - Lang-Auinger 2001, 73 f. mit Anm. 13. 14.

${ }^{130}$ Das gilt für Ephesos: Mitsopoulos-Leon 1978, 115 wie auch für Pergamon: Behr 1988, 101. 107.

131 Sie wurden unter der Rubrik »Henkel« nur in der Gesamtstatistik aufgeführt. s. auch Behr 1988, 105.

132 Ladstätter 2003c, K 287; Ladstätter 2005a, K 7; Outschar 1996a, Nr. 48; Mitsopoulos-Leon 1991, B 41-79; Gassner 1997, Nr. 170-173; Liko 2001, Taf. 57 Nr. 48.

${ }_{133}$ Mitsopoulos-Leon 1978, Taf. 41 Nr. 9.

134 Meyer-Schlichtmann 1988, S4 Kat. 15 Taf. 7.

${ }_{135}$ Crowfoot 1957, Form Samaria 3, Abb. 46 Nr. 5; Goldman 1959, Form Tarsus 1, 159 Abb. 170 B, Nr. 102. 107. 110.

${ }^{136}$ Ladstätter 2005a, K 94; Meriç 2002, K 39; Mitsopoulos-Leon 1991, B 140.

${ }^{137}$ Mündliche Mitteilung S. Ladstätter. 

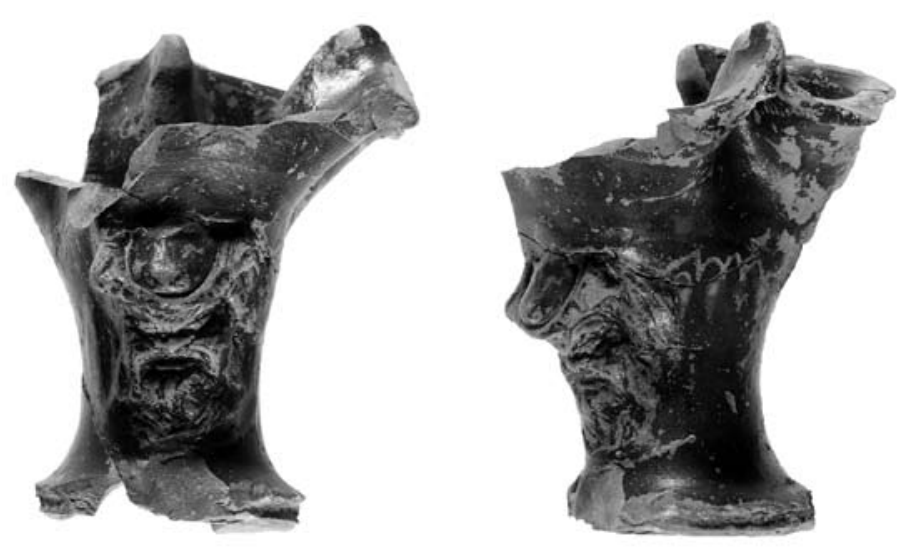

8 a. b Oinochoe Kat. 63 mit Silenskopf-Applik (W2), Front- und Seitenansicht

bracht. Die Henkel setzen vertikal am Körper an und beschreiben dabei einen leichten Bogen nach oben. Mit Randdurchmessern zwischen 8 und $11 \mathrm{~cm}$ ist $\mathrm{W} 5$ ein kleinerer Vertreter seiner Form.

Der letzte Typ, W2, beschreibt das Halsfragment einer Oinochoe aus Stratum 2 (Kat. 63 Abb. 8 a.b). Es zeigt eine Mischung aus appliziertem Relief und Schlickerdekor, wie sie z. B. von den ephesischen Medaillonschalen bekannt ist ${ }^{138}$. Unterhalb der Henkelpartie ist auf dem Hals eine reliefierte Plakette aufgesetzt, deren Ränder abgeschnitten und mit der Wandung verstrichen sind. Sie zeigt einen Silenskopf mit den typischen wulstigen Augenbrauen, der dicken

Nase und den hervorstehenden Wangenpartien. Dem schon etwas älteren Silen fehlt beinahe das gesamte Deckhaar, das restliche Haar fällt seitlich herab. Um den Kopf trägt er eine dicke Symposiumsbinde, die auf den Einsatz des Gefäßes hinweist. Dieser Typus des Papposilen ist von den ptolemäischen Oinochoen aus Alexandria, die D. B. Thompson in die Zeit Arsinoes II. setzt, bekannt ${ }^{139}$ und auf einer Terrakottagruppe aus Myrina des späten 2. Jahrhunderts v. Chr. belegt. Kurz danach muss unser Gefäß entstanden sein, denn eine Laufzeit der Keramik mit aufgesetztem Relief ist nur bis in die 60er Jahre des 1. Jahrhunderts v. Chr. belegt ${ }^{140}$.

Plastischer Schmuck auf Westabhangkeramik ist in Pergamon vertreten, wobei Satyrmasken, die in der Henkelzone oder auf freien Endflächen angebracht wurden, eine besondere Rarität darstellen ${ }^{141}$. Es ist allerdings nicht ungewöhnlich, dass auch auf einem Gefäß im WAN eine Applik erscheint, ist doch die nächste Parallele im Hanghaus 2 in Ephesos selbst zu finden ${ }^{142}$.

\subsection{Applikenware}

In der Sondage sind lediglich sieben Objekte definitiv zur Applikenware zu zählen, wobei ein Halsfragment aufgrund seiner Dekorierung im WAN schon unter W2 aufgeführt wurde. Da zwei Objekte mit Efeuapplik pergamenischer Herkunft (Typ I3, s. u.) sind, werden sie hier nicht berücksichtigt. Bei den übrigen Fragmenten handelt es sich um eine Muschel, einen Jünglingskopf und ein nicht eindeutig zu identifizierendes Fragment. Man muss davon ausgehen, dass Rand- oder Bodenfragmente aufgrund der fehlenden Applik nicht mehr als der Applikenware zugehörig identifiziert werden konnten und so der Glanztonware zugeordnet wurden.

Die hemisphärische Schale G31 (Kat. 56) gehört zur Gruppe der Medaillonschalen ${ }^{143}$. Auf der inneren Bodenmitte ist eine Applik angebracht, deren Umrandung durch Profilrillen betont wird. Zusätzlich besitzt die Trinkschale am äußeren oberen Rand Profilierungen, die bei dieser Gefäßform üblich sind (Abb. 9 a) ${ }^{144}$. Die zentrale Applik zeigt zwei nebeneinander stehende Figuren (Abb. 9 b). Bei der rechten handelt es sich um einen Mann mit um die Hüfte geschlungenem und am Oberbauch gebauschtem Hymation. Sein Oberkörper ist frei. Der Mann steht ponderiert auf seinem linken Bein und stützt sich gleichzeitig auf seinen Stock, den eine Schlange umschlingt. Das rechte Bein hat er locker nach rechts angewinkelt, seinen Kopf dreht er ebenfalls nach rechts in Richtung seiner Bildpartnerin. Die weibliche Figur trägt ein schweres Gewand, über das sie noch einen Mantel geworfen hat. Das Mantelende ist über ihren linken Arm gelegt. Beide Arme

\footnotetext{
138 Mitsopoulos 1991, 55 f. Taf. 64; Rogl 2003b, 187-195.

139 Thompson 1973, 4. 45: 275-270 v. Chr.

${ }_{140}$ LIMC VIII Suppl. 1 (1997) 1116, Nr. 48-50 Taf. 754 s. v. Silenoi (E. Simon). Zur Datierung s. Mitsopoulos 1991, 62.

${ }_{141}$ Behr 1988, 106 Anm. 46. Zwei ähnliche Beispiele aus Piräus: Watzinger 1901, 78 f. Anm. 2, Nr. 25. 26.

${ }_{142}$ Ladstätter 2005a, 234. Die Applik war abgeplatzt.

143 Rotroff 1997, 110-117.

144 Mitsopoulos-Leon 1991, 56.
} 

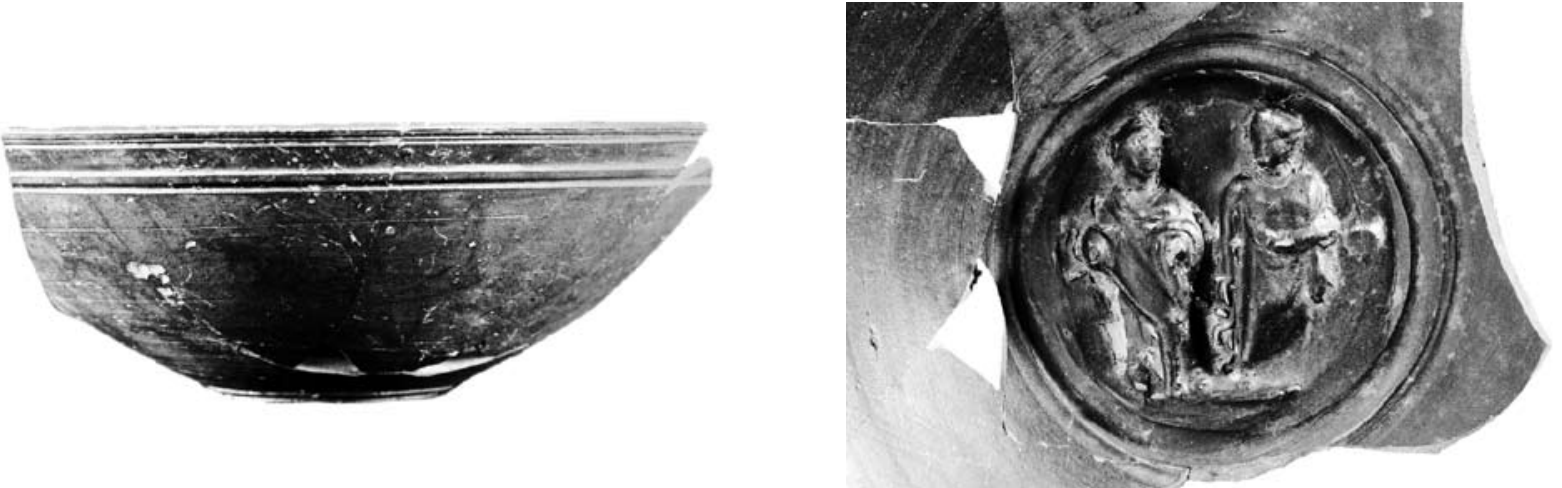

9 a. b Medaillonschale Kat. 56 (G31) mit zentraler Applik (Asklepios und Hygeia)

sind angewinkelt und es scheint, als ob sie etwas in Händen gehalten hat, von dem aufgrund des Erhaltungszustandes nichts mehr zu sehen ist. Die Frau blickt ebenfalls zur Bildmitte. Ikonographisch entspricht die Darstellung Asklepios und seiner Tochter Hygeia. Das Bildthema ist in der Keramik singulär, denn zumeist werden auf Medaillonschalen mythologische, besonders dionysische Themen in Form von Porträtbüsten (z. B. Dionysos, Satyrn, Medusen und Mänaden) dargestellt, weshalb Schalen als Trinkgeschirr oder für Libationen im häuslichen Ritus interpretiert werden ${ }^{145}$. Diese Medaillonschale wurde im Lehmstratum der Baugrube zur hellenistischen Südmauer gefunden, weshalb sie einen terminus post quem für die Mauer am Ende des 2. Jahrhunderts v. Chr. geben kann.

Appliken waren im Hellenismus eine beliebte Verzierungsform ${ }^{146}$. Als Umkehr zu den zentralen Appliken in der Schale wurden Becher, Kannen, aber auch Schalen außen dekoriert. Die Schale G30 ist mit $21 \mathrm{~cm}$ im Randdurchmesser recht groß. Die Wandung ist nach innen gewölbt und die Lippe innen stark verdickt. An der Wandaußenseite war ursprünglich eine Applik angebracht, die nicht mehr erhalten ist. G30 entspricht dem pergamenischen Typus I Form 2, wie er von G. Hübner beschrieben wird. Weitere Parallelen lassen sich in der späthellenistischen Brunnenfüllung 1 des Hanghauses 1 finden ${ }^{147}$. Pergamon, wo diese Gattung ihre Blütezeit zwischen 170 und $130 \mathrm{v}$. Chr. hatte, widmete sich dieser Technik besonders stark und exportierte die Ware, jedoch stellten die importierenden Städte die Gefäße bald selbst her ${ }^{148}$ : Chemische Analysen belegen auch für Ephesos eine Eigenproduktion ${ }^{149}$. Trotzdem ist nur ein minimaler Anteil an lokaler Applikenware im Fundkomplex enthalten. Vorbilder aus der Toreutik werden mittlerweile ausgeschlossen und auch ein alleiniger Bezug auf den Gebrauch im Herrscherkult der Attaliden als Programmträger, wie er noch von G. Hübner postuliert wurde, kann widerlegt werden ${ }^{150}$. Es sind Symplegmata ${ }^{151}$ und vegetabile Themen zu finden, das Beispiel der Oinochoe W2 zeigt darüber hinaus eine mythologische Darstellung.

\subsection{Graue Ware mit schwarzem Überzug}

Die Leitform dieser Gattung sind unbestritten der Teller und die Platte, doch umfasst die Graue Ware mit schwarzem Überzug ein wesentlich komplexeres Formenspektrum als bisher angenommen ${ }^{152}$. In ihrer mineralogischen Zusammensetzung gleicht die Ware den reduzierend gebrannten Reliefbechern ${ }^{153}$ und den

\footnotetext{
145 s. Rotroff 1997, 115; Rotroff - Oliver 2003, 167 und Mitsopoulos-Leon 1991, 56.

146 Ladstätter 2005b, 202. Zum applizierten Emblemgebrauch s. Rotroff - Oliver 2003, 166 f.

${ }_{147} \mathrm{Zu}$ Typus und Parallelen: Ladstätter 2003a, 24 K15 mit Anm. 32 und 33.

${ }^{148}$ Im Fundmaterial der Sondage B6 wurden in den oberen Schichten, die zum Mosaik gehören, ein Fragment in pergamenischer Optik, d. h. gleiche Überzugsfarbe und Dekor, aber in lokalem Fabric gefunden sowie ein lokal gefertigtes Becherfragment mit einer Applik, die eine Zeus-Ganymed-Darstellung zeigt. Aufgrund der Geschlossenheit des Komplexes konnten diese jedoch nicht berücksichtigt werden.

149 Zabehlicky-Scheffenegger - Schneider 2000, 105.

${ }^{150}$ Schwarzer 1999, 298.

${ }^{151}$ In Pergamon konnten allein neun verschiedene Typen von Symplegma-Darstellungen charakterisiert werden. Trümpler-Ries 1982, 40 .

152 s. auch Ladstätter 2005a, 234.

153 Auch \Megarischeく oder ionische (Relief-)Becher genannt.
} 
Ephesos-Lampen, die aber trotzdem nicht zur selben Gattung gezählt werden können ${ }^{154}$, da sich besonders der Überzug unterscheidet.

Die Graue Ware mit schwarzem Überzug ist von zahlreichen Fundorten vor allem der Nord- und Westküste Kleinasiens bis in das nordsyrische Binnenland bekannt ${ }^{155}$. Ein einzelner Ursprungsort konnte nicht eruiert werden, und in Anbetracht der Verschiedenheit der Fabrics und der benutzten Morphologie sollte man auch nicht von einem einzelnen Ursprungsort ausgehen. Ähnlich der Sigillata wurde eine Gattung geschaffen, die zwar in sich grundsätzliche Ähnlichkeiten aufweist, deren Gefäße sich jedoch durch lokale Gegebenheiten wiederum voneinander unterscheiden ${ }^{156}$. So kann man Graue Ware mit schwarzem Überzug in Anlehnung an K. Warner Slane ${ }^{157}$ als nordsyrische, kyprische, pergamenische, ephesische, knidische und delische Produktionsserien klassifizieren. Allen Fundorten ist das Einsetzen der Produktion der Grauen Ware mit schwarzem Überzug um 200 v. Chr. gemein. Schon W. Radt und G. De Luca bestätigten, dass die Ware in Pergamon bereits vor dem Bau des Großen Altars auftrat ${ }^{158}$. Sie entwickelte sich aus der $>$ Grauen Ware/ Keramikı, die schon in vorhellenistischer Zeit weite Verbreitung in Aizanoi, Pergamon, Dorylaion, Daskylaion, Gordion und Sardes fand ${ }^{159}$.

Da sich die Ware in ihren Formen gut den Eastern Sigillata-Formen gegenüberstellen lässt, wurde sie in dieselbe Zeit datiert ${ }^{160}$. Obwohl eine parallele Existenz als gesichert gilt, setzt die Graue Ware mit schwarzem Überzug im vorliegenden Fundkomplex vor der ESA ein ${ }^{161}$. Für Ephesos ist ein Ende der Grauen Ware mit schwarzem Überzug in der frühen Kaiserzeit (tiberisch) anzunehmen ${ }^{162}$. Es liegt nahe, dass sie von der reduzierend gebrannten ESB abgelöst wurde ${ }^{163}$.

\subsubsection{Teller und Platten}

Die Teller und Platten in Grauer Ware mit schwarzem Überzug zeigen bei drei von vier Randformen einen runden, einwärts biegenden Rand mit runder Lippe. Lediglich ein Typ (GW4, Taf. 5, 71) hat eine nach außen schwingende Wandung mit einer beidseitig verdickten Lippe, wie sie von Typ G19 hinreichend bekannt ist. Unterschiede, die chronologisch zu bewerten sind, zeigen sich in Höhe oder Ausprägung der Wandung. Die frühe Form GW7 (Taf. 5, 74), übrigens die einzige Ganzform eines Tellers, aus Stratum 4 ähnelt den ESA-Tellern Atlante 3/4. Der Teller steht auf einem erhöhten Ringstandfuß, über dem sich eine Einkehlung befindet. Die Wandung steigt leicht schräg an, die Lippe biegt rund um und läuft nahezu senkrecht. Im inneren Zentrum befindet sich eine Palmettenstempelung, die von zwei Roulettierungen eingekreist wird. GW5 (Taf. 5, 72) entspricht der Form $1 \mathrm{~b}$ bei S. Zabehlicky-Scheffenegger ${ }^{164}$. Es handelt sich um eine runde Platte mit niedriger Wandung, deren verdickter Wulstrand aufgestellt und nach innen gebogen ist. Diese Form hat einen Randdurchmesser von ca. $26 \mathrm{~cm}$ und ist mit einem Anteil von insgesamt 14\% an der Warengattung in allen Schichten vertreten. Besonders auffallend ist, dass die Unterseite der Platte nicht mit einer Engobe überzogen wurde. Der Typ tritt häufig in ephesischen Kontexten auf und wird in die zweite Hälfte des 1. Jahrhunderts v. Chr. bis in das frühe 1. Jahrhundert $\mathrm{n}$. Chr. gesetzt ${ }^{165}$. Während die eckigen oder halbkreisförmigen Exemplare dieses Plattentyps in eine Form gestrichen wurden, konnten die runden wie üblich auf der Töpferscheibe gedreht werden, wie dies die feinen Drehrillen auf den nichtüberzogenen Partien, etwa auf der Unter- und der Standringinnenseite, bestätigen. In der Sondage B6 ist kein einziges Fragment der eckigen oder halbkreisförmigen Platten gefunden worden, was die These von S. Zabehlicky-Scheffenegger

${ }^{154}$ Es gibt keinen chemischen, aber einen petrographischen Unterschied (Brenngrad, Schwermineralzusammensetzung). s. dazu Zabehlicky-Scheffenegger u. a. 1996, 49. U. Outschar verweist auf die »frappante« Ähnlichkeit von Überzug, Ton und Dekor der Reliefbecher mit den Ephesischen Lampen, Outschar 1996b, 37.

155 Dikbaş 2002, $8 \mathrm{f}$.

156 Die da wären: italische, arretinische, östliche, gallische, afrikanische usw.

157 Warner Slane 1997, 364-366.

${ }^{158}$ Ladstätter - Lang-Auinger 2001, 77.

159 Rotroff - Oliver 2003, $31 \mathrm{f}$.

160 J. W. Hayes konstatiert visuelle Ähnlichkeiten: Hayes 1991a, 8.

${ }^{161}$ s. Typ GW7 und GW5. So auch auf Zypern, s. Dikbaş 2002, 12 und Hayes 1985, 79 f.

162 Mitsopoulos-Leon 1991, 78; Meriç 2002, 39.

163 s. dazu: Ladstätter 2005b, 201-204.

164 Zabehlicky-Scheffenegger u. a. 1996, 42 f. Taf. 11, 3.

${ }^{165}$ Ladstätter 2005a, K 127; Mitsopoulos-Leon 1991, F 10; Meriç 2002, K 97-100. 
unterstützt, dass diese erst in spätaugusteischer Zeit entstanden sind ${ }^{166}$. Überzug und Fabric von einem Fragment des Typs GW5 sind komplett braunrötlich gefärbt. Ein weiteres Beispiel, GW10 (Taf. 9, 77), ist fleckig gebrannt, wobei hier nicht mit letzter Sicherheit gesagt werden kann, ob es sich um sekundär verbrannte Stücke handelt ${ }^{167}$, oder ob es Resultate von handwerklich schlechter Qualität oder Experimentierfreude der ephesischen Töpfer im ausgehenden 1. Jahrhundert v. Chr. sind ${ }^{168}$. GW6 (Taf. 5, 73) ist ein Teller mit hohem, einwärts biegendem Rand und rund abgestrichener Lippe. Die Rand kann zwischen 19 und $32 \mathrm{~cm}$ Durchmesser haben. Die Form erscheint relativ häufig (acht Fragmente) in den oberen drei Straten, jedoch konnten keine passenden Parallelen in Ephesos gefunden werden. GW4 ist mit $14 \mathrm{~cm}$ Randdurchmesser ein kleiner Teller. Er stammt aus Stratum 2 und wird durch ephesische Fundkontexte von der Mitte des 1. Jahrhunderts v. Chr. bis $20-30$ n. Chr. datiert. Eine Analogie in ESA ist aus dem Hanghaus 2 belegt $^{169}$. GW6 stellt stratigraphisch die jüngste Tellerform des Fundkomplexes aus Wohneinheit 7 dar.

Vier Bodentypen konnten erkannt werden, wobei GW9 und GW10 (Taf. 5, 76. 77) einander in ihrer Formsprache ähneln. Beide haben einen sehr niedrigen und breiten Ringfuß. Bei GW9 ist allerdings eine Tendenz zu fließenden Übergängen der Form zu beobachten. Auch ist die Innenseite des Fußes rund nach oben hin abgestrichen, während GW10 im Profil rechteckig wirkt. Die Wandung von GW10 steigt nach auBen leicht an, während sich das Zentrum bei GW9 leicht erhebt. Beide Typen kombinieren im Gefäßinneren konzentrische Kreise mit einer Roulettierung. Zusätzlich sind Einzelstempel in Form von Palmetten oder auch Rauten in radialer Anordnung gruppiert ${ }^{170}$.

GW8 (Taf. 5, 75) besitzt zwar auch einen Ringstandfuß, doch ist dieser hoch und außen eingekehlt. Im Inneren sind, wie bei GW9, konzentrische Rillen angebracht. Der Typus erscheint in Ephesos in der zweiten Hälfte des 1. Jahrhunderts v. Chr. ${ }^{171}$, in Aizanoi beispielsweise ist es ein sehr häufig vorkommender Typus ${ }^{172}$. Bei GW11 (Taf. 5, 78) handelt es sich um einen Teller mit sehr breitem Ringstandfuß (16 cm im RDm), der im Profil viereckig ist und außen leichte Rillen besitzt. Innen ist er mit einer Raute, die dem Stempel auf Typ GW10 entspricht, gestempelt. Formparallelen ließen sich nicht feststellen.

\subsubsection{Sonstige Formen}

Wie schon erwähnt, setzt die Gattung der Grauen Ware mit schwarzem Überzug ihren Formenschwerpunkt auf Teller und Platten. Und obwohl eine große Formenvielfalt in Ephesos und andernorts bestätigt ist ${ }^{173}$, existieren in unserem Fundkomplex nur sehr wenig variierende Gefäßformen. Aus Stratum 1 ist ein Bodenfragment einer Schale von $6 \mathrm{~cm}$ im Randdurchmesser erhalten (GW1, Taf. 5, 68). Der Ringstandfuß ist außen eingekehlt und innen schräg nach oben abgestrichen. In der Formgebung ähnelt die Schale der ESB-Atlanteform 24 bei J. W. Hayes ${ }^{174}$. Imitationen von Sigillata in Grauer Ware mit schwarzem Überzug sind keineswegs ungewöhnlich. Beim Aufkommen der Sigillataformen im 2. Jahrhundert v. Chr. entstehen z. B. in Aizanoi sogleich die dazu passenden Hybride ${ }^{175}$. Eine weitere Nachahmung von Sigillata ist das ebenfalls aus Stratum 1 stammende Bodenfragment GW2 (Taf. 5, 69). Seine Wandung ist gerade und nur leicht schräg nach außen gestellt, und der niedrige, innen schräg nach oben abgestrichene Standring wird durch eine Einkehlung abgesetzt. Der Durchmesser von GW2 beträgt $11 \mathrm{~cm}$. Typologisch entspricht die Form dem ESA-Becher Atlante $42^{176}$, eine weitere Analogie im Fabric der Dünnwandigen Ware stammt aus der Wohneinheit 4 im Hanghaus $2^{177}$. GW12 (Taf. 5, 79) zeigt einen Becher mit vertikaler Wandung sowie

166 Zabehlicky-Scheffenegger u. a. 1996, 45.

167 Vgl. die Stücke vom Magdalensberg: Zabehlicky-Scheffenegger u. a. 1996, 41.

168 Ladstätter 2005a, 234; Ladstätter 2005b, 201.

169 Mitsopoulos-Leon 1972, 505 Abb. 4, D (mit Dekor). In ESA: Ladstätter 2005a, K 53.

170 S. Ladstätter vermutete, dass diese Art von Dekor zwischen dem ausgehenden 2. Jh. v. Chr. bis zum fortgeschrittenen 1. Jh. v. Chr. in Ephesos »kurzfristig aus der Mode gekommen sei«. Ladstätter 2005b, $203 \mathrm{f}$.

171 Ladstätter 2005a, K 133.

172 Mündliche Mitteilung G. Dikbaş.

173 Meriç 2002, 39-42; Mitsopoulos-Leon 1991, 78-85; Gassner 1997, 152 f.; Ladstätter 2005a, 234; Dikbaş 2002, passim; Warner Slane 1997, 269-272.

174 Hayes 1985, 24; Meriç 2002, K 123. 124.

175 Dikbaş 2002, $62 \mathrm{f}$.

176 Hayes 1985, forma 42.

177 Ladstätter 2005a, K 174. 
leicht ausbiegender und runder Lippe. Unter dem Rand sind zwei leichte Profilierungen erkennbar. Der Randdurchmesser ist mit $16 \mathrm{~cm}$ eher groß, und auffallend ist auch die Dickwandigkeit des Gefäßes. Dem Typ GW3 (Taf. 5, 70) sind zwei Fragmente zuzuschreiben, die aus den Straten 1 und 3 kommen. Bei beiden handelt es sich jeweils um ein Bodenfragment von 5 bzw. $9 \mathrm{~cm}$ im Randdurchmesser. Die Wandung ist dick und geschwungen, sodass der Körper hemisphärisch wirkt. Der Ringstandfuß ist hoch und setzt breit auf. Die kleinere Form besaß vermutlich eine enge Mündung oder war geschlossen, zumal das Gefäß innen nicht komplett überzogen ist, sondern lediglich Rinnspuren zu beobachten sind ${ }^{178}$. Bei der größeren Form kann es sich um eine »halbkugelige Schale mit Profilierung « handeln, wie bei C. Rogl beschrieben ${ }^{179}$. Der letzte Typ ist GW13 (Taf. 5, 80), eine dickwandige Schale mit ausbiegender Lippe, Profilierungen und abknickender Wandung. Der Randdurchmesser beträgt $14 \mathrm{~cm}$, und der Überzug ist verhältnismäßig hell. Parallelen konnten nicht eruiert werden.

\section{Reliefbecher/>Megarische Becher}

Die reliefverzierten, reduziert gebrannten Becher sind seit dem 3. Jahrhundert v. Chr. von der Athener Agora bekannt ${ }^{180}$. V. Gassner unterscheidet zwei Arten des Fabric, die sich ebenfalls im vorliegenden Material widerspiegeln: ein orangerosa bis braunfarbener Scherben mit einem rotbraunen oder auch zweifarbigen (rot und braun, rot und schwarz, braun und schwarz) Überzug. A. Laumonier sieht diese zur MonogrammistenWerkstatt zugehörig ${ }^{181}$. Die zweite Gruppe wird durch einen grauen Scherben mit grauschwarzem Überzug definiert. Die Beschaffenheit und Tonzusammensetzung des zweiten Fabric entspricht den Ephesischen Lampen und der Grauen Ware mit schwarzem Überzug ${ }^{182}$. L. L. Neuru konstatiert eine Ähnlichkeit in der Tonzusammensetzung zur ESB ${ }^{183}$. Wie oben beschrieben variiert die Engobe stark in ihrer Farblichkeit. Der meist matte bis matt glänzende Überzug kann zwischen rötlich und schwarz liegen. Lediglich $15 \%$ haben einen (metallisch) glänzenden Überzug, wobei die metallisch glänzenden Gefäße durchweg reduzierend gebrannt sind. Bei den Bechern mit glänzendem Überzug ist eines der vier Beispiele oxidierend gebrannt und stammt aus der frühesten Schicht ${ }^{184}$. Bei der Engobe konnten aufgrund des Abreibungsverhältnisses verschiedene Qualitäten erkannt werden; besonders die rötlichen Überzüge sind oft kreidig und von minderer Qualität.

Zur Fertigung der Becher ${ }^{185}$ benützte man Model, die über einen längeren Zeitraum eingesetzt wurden. Somit ergeben sich zwar für einzelne Dekorformen lange Laufzeiten ${ }^{186}$, die Randgestaltung konnte sich jedoch kurzfristig ändern, da diese von der jeweiligen Werkstatt oder dem jeweiligen Töpfer abhing. Aus diesem Grund gestaltet sich die Erstellung einer Typologie anhand der Randformen - wie auch bei anderen Gefäßen - schwierig. Trotzdem sollen der Vollständigkeit halber die hier auftretenden sechs Typen (R1-R6 Kat. 81-86) beschrieben werden.

In der Forschung werden Becher mit nach außen gebogener Lippe und nach unten zu dicker werdendem Körper als zum griechischen Festland gehörig angesehen. Nach innen gebogene Ränder und ein eher steiler Körper hingegen werden den Töpfern auf Delos zugeschrieben ${ }^{187}$. Diese Typenbeschreibungen passen nicht auf die ephesischen Becher. So haben besonders häufig Schildbecher, einige Male aber auch Netz- und

\footnotetext{
178 Es könnte sich dabei um ein Tintenfässchen oder eine kleine Kanne handeln, die benutzt wurde, um Pinsel abzustellen oder in Farbe zu tauchen. Freundliche Mitteilung von S. Ladstätter.

${ }^{179} \operatorname{Rogl} 2004, \mathrm{~K} 17$.

180 Neuru 1991, 13 mit Anm. 30; S. Rotroff vermutet, gestützt auf die Chronologie der Amphorenstempel von der Agora, dass die Reliefbecher im Jahr 224/223 v. Chr. aus Anlass der Feiern für Ptolemaios III. Euergetes eingeführt worden seien. s. Rotroff 2006, 359.

181 Gassner 1997, 71 mit Anm. 99.

182 Gassner 1997, 71; Rogl 2001b, 103; Meriç 2002, 33.

183 Neuru 1991, 13

184 Inv. 99/715.139, zu Typ R 9 gehörig.

${ }^{185}$ Zur Herstellung in Modeln s. Rotroff 2006, 368. Model wurden weit verstreut im Gebiet von Ephesos geborgen. Bouzek $2005,56$. Diese Model wurden als Matrizen direkt von Metallgefäßen abgenommen.

${ }^{186}$ Eine Sammlung kleinasiatischer Modelformen ist in den 60er und 70er Jahren des 20. Jhs. in deutsche Museen gekommen. S. Künzl behandelte die 76 Model aus dem Römisch-Germanischen Zentralmuseum in Mainz: Künzl 2002, passim.

187 Künzl 2002, 4; Dereboylu 2001, 29.
} 
Buckelbecher eine nach außen geschwungene Lippe. Bei Typ R2 aus der Sondage B6 ist die Lippe ebenfalls nach außen umgebogen, die übrigen Ränder sind nach innen gewendet oder vertikal (wie z. B. R3).

R1 (Taf. 5, 81) kann als typischer halbkugeliger Reliefbecher mit rund abgestrichener Lippe angesprochen werden. Der Rand macht etwa ein Drittel des Gefäßes aus. Er steigt gerade an und wird undekoriert belassen. Nach einer Rille tritt eine Bordüre, beispielsweise das beliebte ionische Kymation, auf. Dieser Typ kam in allen Straten zutage, doch vermehrt in den oberen zwei Schichten. R2 (Taf. 5, 82) ähnelt in seiner Form R1, jedoch steht der Rand vertikal, die Lippe ist kleiner und die Wandung dafür in ihrer Biegung dicker. Wie bei R1 bleibt auch hier die Randpartie ohne Verzierung, doch nimmt sie eine breitere Fläche ein, nämlich etwa die Hälfte des Gefäßes. Nach einer feinen Rille setzt ein >liegendesく lesbisches Kymation $e^{e i n}{ }^{188}$. Das Aufkommen von R2 ist in der Sondage B6 nur sehr mäßig. R3 (Taf. 5, 83) besitzt eine besondere Form: Der Rand ist gerade, die Lippe jedoch biegt mit einem Knick leicht nach außen. Die mikroskopischen Untersuchungen ergaben, dass es sich um eine lokal produzierte Randform handelt. Am Ende des Randes, der höchstens ein Drittel des Gefäßes ausmacht, sind mehrere Profilierungen zu finden. Leider ist der weitere Wandverlauf der Becherform nicht zu erkennen, sodass wenig über Form und Dekor ausgesagt werden kann. Es ist die zweithäufigste Randform im Fundkomplex der Wohneinheit 7, die auch in allen Straten anzutreffen ist. Bei R4 (Taf. 5, 84) lässt die starke Wölbung des Gefäßes auf eine niedrige Becherform schließen. Die Lippe ist nach innen gestellt, leicht verdickt und rund abgestrichen. Die Randbreite ist relativ gering. Diese Form setzt erst im zweiten Stratum ein. R5 (Taf. 6, 85) ist ein dünnwandiger Becher mit nach innen gestellter Mündung und rund abgestrichener Lippe. R6 (Taf. Taf. 6, 86) ist eine recht einfache Form: Nach einer Profilierung wurde ein vertikaler Rand aufgesetzt, dessen Lippe spitz zuläuft. Eine Konzentration des Typs liegt in Stratum 3 vor. Aufgrund der sehr fragmentarischen Erhaltung können im Fundkomplex keine weiteren Formen als die beschriebenen Becherformen erkannt werden ${ }^{189}$.

Da es spekulativ ist, anhand solch kleiner Fragmente auf bestimmte Werkstätten zu schließen, werden im Folgenden die Dekore grob in vegetabil, geometrisch und figürlich eingeteilt (R7-R9, Taf. 6, 99.100; 10, 91-98).

Im Fundkomplex wurden 91 Gefäßindividuen bei den Reliefbechern gezählt. Davon gehören 30 Beispiele zu R7 (Kat. 90. 94-96. 100) und weisen den in der hellenistischen Koiné beliebten vegetabilen Dekor auf, etwa Blätter und Rosetten ${ }^{190}$. In Stratum 1 sind 7 von 34 Gefäßindividuen mit Pinienzapfenbuckeln, spitzen Blattschuppen, zweimal sechs-, sieben- und achtblättrigen Rosetten, Lotus (nymphaea nelumbo) und Zungenblättern verziert. Für die 8 Gefäßindividuen mit geometrischem Dekor sind lesbische und ionische Kymatien, Rauten, Noppen und Riefen belegt. Lediglich ein Fragment ist mit einer Tierdarstellung (Hund, Kat. 101) erhalten, wie sie auch andernorts in Ephesos vorkommt ${ }^{191}$. In Stratum 2 sind insgesamt 27 Gefäßindividuen zu verzeichnen, von denen 8 vegetabile Dekore, wie Zungenblätter, sieben- und zwölfblättrige Rosetten, Pinienzapfenbuckel, Blätter und die Philonblüte (Kat. 87) aufweisen. Für die 5 Beispiele mit geometrischer Verzierung sind ionische und >liegende` lesbische Kymatien, Mäander mit Binnenstern, liegende S-Spiralen, vertikale Punktreihen und Wellen, die nach unten zeigen ( $($ Laufender Hund $)$, belegt. Ein Fragment (Kat. 89) zeigt die rechte untere Körperhälfte eines Jünglings (?) im Ausfallschritt, der mit einem knielangen Gewand bekleidet ist und in seiner Rechten eine Fackel trägt. Hinter ihm ist ein Fisch dargestellt (Abb. 10).

In Stratum 3 sind 10 von 21 Gefäßindividuen u. a. mit Zungenblättern, spitzen Blattschuppen, Rosetten, Langblättern und der Philonblüte verziert. Drei Fragmente zeigen Noppen, Punktreihen, ein ionisches und ein herzförmiges lesbisches Kymation. Figürliche Darstellungen fehlen gänzlich. Dafür sind in Stratum 4 ein Fragment mit laufenden Hunden und ein weiteres mit einer bewegten Figur (Jüngling?, Kat. 99) vorhanden.

${ }^{188}$ Laumonier 1977, 9. Es ließen sich nur zwei Parallelen bei A. Laumonier für solch einen Dekor finden, sie gehören seiner Gruppe V an.

189 Aus Ephesos ist bekannt, dass die hemisphärischen Becher in ihrer Form nicht allein standen, sondern eher als Basis genutzt wurden. Durch das Ansetzen von Henkeln, Tüllen o. Ä. wurde das Formenspektrum erweitert. So können kleine Kannen, Trichterbecher und Schüsseln hinzugezählt werden: Gassner 1997, 72; Ladstätter 2003a, 26; Rogl 2001b, 100. Andernorts wird das Repertoire um Gutti, Amphoren, Lekythen, Pyxiden und Kratere ergänzt: Künzl 2002, 2.

${ }^{190}$ Eine repräsentative Auswahl regionaler tönerner Stempel ist im Museum von Aydın ausgestellt. s. ebenso Rotroff - Oliver 2003, 104 Nr. 422 Taf. 70.

${ }^{191}$ Gassner 1997, Taf. 14, 213. 


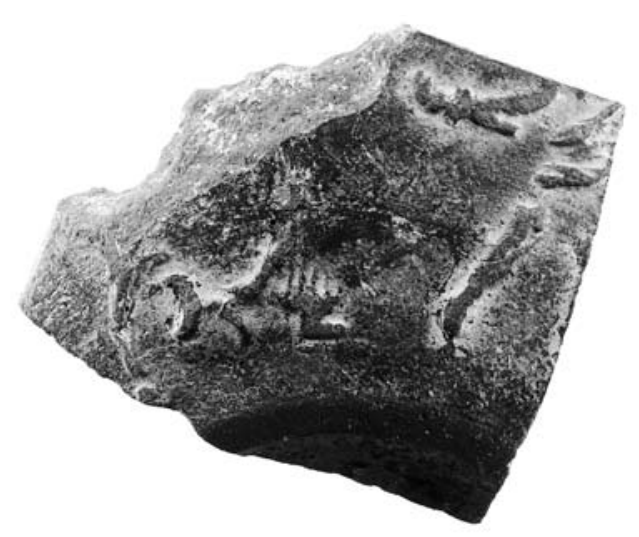

10 Fisch und Teil einer Figur auf dem ionischen Reliefbecher Kat. 89 (R9)

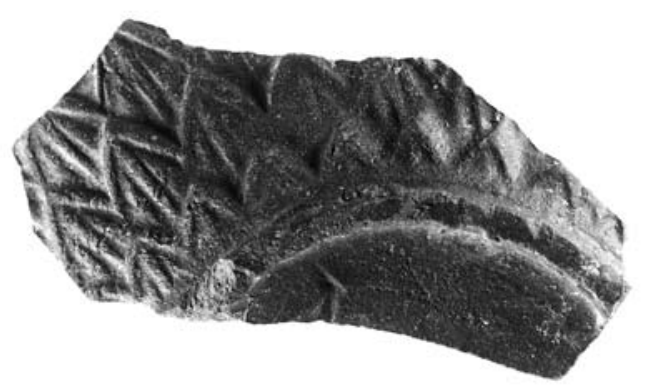

12 Signatur des Töpfers Athenaios auf dem Becher Kat. 90 (R7)

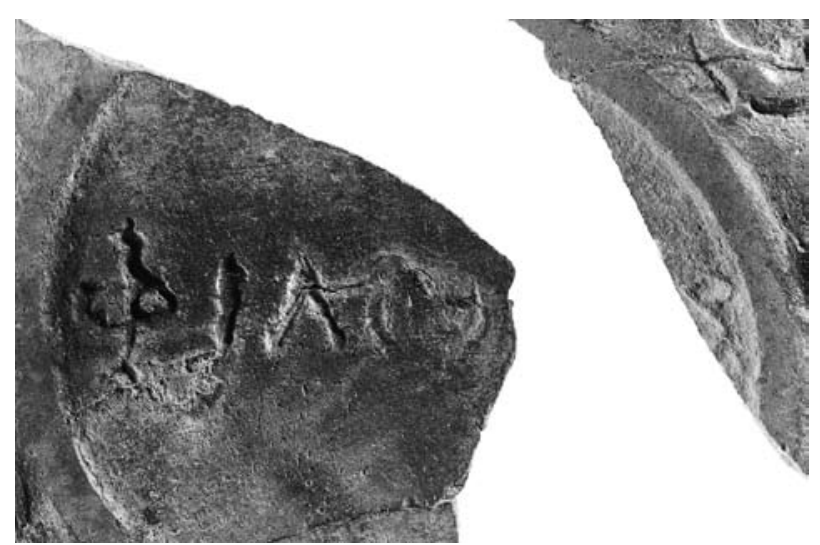

11 Signatur des Töpfers Philon auf dem Becher Kat. 87 (R7)

Die geringe Anzahl von neun Bechern zeigt drei vegetabile (Zungenblatt, Blüten und Weinrebe) und zwei geometrische Dekore (ionisches Kymation und Noppen). Auffallend ist das Fehlen von Netzwerkbechern in allen Straten.

An wenigen Objekten konnten die Signaturen des Philon und Athenaios erkannt werden. Während Philon zu den früheren Werkstätten am Anfang des 1. Jahrhunderts v. Chr. gehört, ist Athenaios eher der zweiten Hälfte des 1. Jahrhunderts v. Chr. zuzuordnen (Abb. 11. 12).

Keine Fragmente konnten gesichert der MonogrammWerkstatt zugesprochen werden, die als größter Exporteur Kleinasiens von Ephesos aus agierte ${ }^{192}$. Hinweise auf eine Werkstatt fehlen zwar bis dato, doch fand man Model in ganz Ephesos. Eine besonders starke Konzentration, die auf einen lokal ansässigen Töpferbetrieb schließen lässt, wurde hierbei im Bereich des Magnesischen Tors beobachtet ${ }^{193}$. Die Produktion in Ephesos beginnt zwar etwas später als in Athen, liegt aber trotzdem um das Jahr 200 v. Chr., wie die jüngere Forschung gezeigt hat ${ }^{194}$. Zur Blütezeit der Produktion um 180 v. Chr. wurde dann der Fernhandel mit den ephesischen Reliefbechern über Delos aufgenommen ${ }^{195}$; aber nicht nur die Gefäße selbst, sondern auch die Punzen und Model wurden weithin gehandelt. Dies ist wohl eine der Ursachen, warum Imitationen schon sehr früh nach den ersten Exporten einsetzten ${ }^{196}$, wofür sich viele Parallelen im gesamten Mittelmeerraum anführen lassen ${ }^{197}$. Obwohl die meisten kleinasiatischen Städte ihre eigenen kleinen Ateliers für Reliefbecher hatten, importierten sie dennoch ephesische Ware, wie sogar Pergamon, für das eine große Eigenproduktion qualitäts-

192 Der geographische wie auch geo-ökonomische Vorteil der Stadt bildete im 2. und frühen 1. Jh. v. Chr. die Grundlage einer optimalen Stellung für den Vertrieb. s. dazu: Guldager Bilde 1993, 200.

193 Allein 68 Model kamen beim Magnesischen Tor zutage: Bouzek 2005, 56; ebenso Mitsopoulos-Leon 1991, 17 mit Anm. 23 und Liko 2001, 86 mit Anm. 39.

194 Gürler 2003, 12 mit Anm. 45. Im Gegensatz zu J. Bouzek, der gestützt auf A. Laumonier den Beginn im 2.-3. Drittel des 2. Jhs. v. Chr. sieht. Bouzek 2005, 61.

${ }^{195}$ Einen terminus post quem bietet das Schiffswrack Grand Congloué von Marseille: Kenrick 2000, 264. Zu Delos: Rogl 2001b, 104.

${ }^{196}$ Günay Tuluk 2001, 52. Aus einigen Orten, beispielsweise in der Nähe von Bukarest, s. Bouzek 2005, 59, sind Imitationen ephesischer Werkstattypen bekannt. Als (günstigere?) Variante wurden sie tonfarben belassen.

197 Es sind Exemplare aus der >A dans carrée〈-Werkstatt von Gallien (Toulouse) bis in die Provinz Syria (heutiges Van) und Antiochia am Orontes gekommen; dazu die Distributionskarte bei Bouzek 2005, 63 Abb. 9; Guldager Bilde 1993, passim, Abb. 1; Rogl 2001b, 103 f. bes. Anm. 28. 
voller Schöpfungen belegt ist ${ }^{198}$. Das Ende der Becherproduktion wird in Ephesos für die zweite Hälfte des 1. Jahrhunderts v. Chr. angenommen ${ }^{199}$.

\subsection{Tongrundige Ware}

Bei der Tongrundigen Ware handelt es sich um eine Gattung, die im Fundkomplex mit nur einem geringen Anteil von $1 \%$ vertreten ist. Die Keramik zeichnet sich durch einen feinen Ton, ähnlich der Glanztonware, aus. Der Scherben ist ebenfalls feinporös und mittelhart bis sehr hart gebrannt. Das Fabric ist rötlich und besitzt neben Glimmerpartikeln feine bis mittlere weiße Einschlüsse. Über das Gefäß wurde ein dünner Tonschlicker aufgetragen, welcher der Zusammensetzung des Fabrics entspricht, wodurch das Gefäß tongrundig bleibt. Vier Formen konnten unterschieden werden.

Von Typ T1 (Taf. 6, 102), einer kleinen, flachen Schale mit überhängender Lippe ${ }^{200}$, ist lediglich ein Fragment aus dem obersten Stratum erhalten. Seine Dickwandigkeit trug wohl dazu bei, dass die halbe Schale in einem Stück erhalten blieb, wodurch die Ganzform rekonstruiert werden konnte. Sie ist sehr klein ( $4 \mathrm{~cm}$ im RDm) und hat einen hohen, nach innen steil abgestrichenen Standring. Typ T2 (Taf. 6, 103) ist eine weit ausladende Schale mit dicker, runder Lippe. Von dieser Gefäßform sind nur zwei Fragmente aus Stratum 1 und 2 bekannt.

Neben der Schalenform stellte man auch die im Hellenismus beliebte Skyphosform in Tongrundiger Ware her. T3 (Taf. 6, 104) ist ein flacher Skyphos, bei V. Gassner auch »gedrungenes Schälchen « genannt ${ }^{201}$. Die Wandung knickt ab, und der Rand verläuft gerade, manchmal sogar leicht nach innen gestellt; er kann facettiert sein. Knapp unterhalb der Lippe sind kleine Halterungen als Henkel an die Wandung geklebt. Der Randdurchmesser des Skyphos liegt zwischen 8 und $12 \mathrm{~cm}$. Vergleichsbeispiele stammen aus dem kretischen Mochlos $^{202}$. Bei T4 (Taf. 6, 105) handelt es sich wahrscheinlich um einen Krug mit einem Randdurchmesser von $8,2-10 \mathrm{~cm}$. Sein Rand schwingt nach außen hoch, seine Lippe ist rund abgestrichen. Es sind drei Fragmente aus den Straten 1, 2 und 3 erhalten. Die Tongrundige Ware kann nur schwer datiert werden, da sie in der Forschung bislang wenig beachtet wurde und sich keine Parallelen finden. Eine Anlehnung an die Formen mit Glanztonüberzug wäre chronologisch jedoch durchaus vertretbar.

\subsection{Dünnwandige Ware ${ }^{203}$}

Die Dünnwandige Ware ist ab späthellenistischer/spätrepublikanischer Zeit eine beliebte Materialgattung für Becher. Das Fabric der Dünnwandigen Ware ist mithilfe hoher Brenngrade sehr hart gebrannt ${ }^{204}$, der Scherben ist überaus fein gemagert. So lassen sich nur sehr feine weiße Einschlüsse, bei einigen Formen zusätzlich dunkelgraue oder rote Partikel finden. Bei fast allen Objekten konnte Glimmer festgestellt werden ${ }^{205}$. Scherben und Überzug sind m. E. in drei Gruppen ${ }^{206}$ einzuteilen, wobei vorab zu bemerken ist, dass es sich bei den Überzügen um keine Glanztonengobe handelt, sondern um dünne Tonschlicker ohne farbgebende Zusätze $^{207}$. Die erste Gruppe hat einen orangefarbenen Scherben mit grauem Kern ${ }^{208}$. Der Überzug ist flächig

${ }^{198}$ Im Ketios-Tal konnten Überreste eines (hellenistischen?) Töpferateliers, u. a. mit Modelformen der ionischen Reliefbecher, geborgen werden; Hausmann 1996, $104 \mathrm{f}$.

199 Pülz - Ladstätter 2006, 81.

${ }^{200}$ Für die Information, dass es sich um ein Spendenschälchen handeln kann, sei hier S. Ladstätter gedankt. Zur Diskussion der Verwendung von >Spendennäpfchen` im häuslichen Bereich s. Ladstätter 2003a, 33.

201 Gassner 1997, Kat. 279 Taf. 21.

202 Eiring 2000, 58 Taf. 29 b, 1-3.

${ }^{203}$ Der Begriff >Dünnwandige Ware` wird vom englischen >Thin-Walled Ware` abgeleitet. Bezeichnungen wie `Eierschalenware`, `Dünnwandige Hartware $<$ (S. Japp) oder lediglich 〉Feinware (V. Gassner) sind nach Meinung der Verfasserin entweder zu spezifisch oder zu umfassend und können zu Missverständnissen führen.

204 s. dazu auch Japp 1999, 302 f.

${ }^{205}$ Glimmer wurde vor Ort mit dem freien Auge und unter Streiflicht, in einzelnen Fällen mit einem Mikroskop festgestellt.

${ }^{206}$ In Pergamon ließ sich die Dünnwandige Ware ebenfalls in mehrere Gruppen einteilen. Die dortige zweite Gruppe besteht aus schwarzen und hochglänzenden Gefäßen, die jedoch nicht in Ephesos nachgewiesen werden konnten. Dies spricht für eine lokalpergamenische Produktion, möglicherweise in Anlehnung an die späthellenistische Sigillata. s. dazu: Japp 1999, 304.

${ }^{207}$ Die Verschiedenfarbigkeit ist somit auf den Brand zurückzuführen. M. T. Marabini-Moevs sieht den Ursprung der Technik in der Eisenzeit: Marabini-Moevs 1973, 36.

${ }^{208}$ Dies ist auf die unterschiedliche Brennung zurückzuführen, s. Mitsopoulos-Leon 1991, 131. 
aufgetragen: Innen ist er orange, außen durch den Brand vor allem bei den sich am breitesten ausdehnenden Gefäßpartien gräulich ${ }^{209}$. Die Oberfläche ist leicht rau. Das Fabric der zweiten Gruppe ist beige. Der Überzug changiert zwischen beige bis beigegräulichen Nuancen. Die Oberfläche ist etwas poliert und glatter als bei Gruppe 1, trotzdem ist sie noch als leicht rau zu bezeichnen. In der Literatur spricht man zutreffend von der >egg-shell-ware〈 oder `Eierschalenware ${ }^{210}$. Die Farbgebung der dritten Gruppe schwankt von dunkelrot bis violett. Das Fabric ist nicht so fein geschlämmt und eher mittelporös, es ähnelt in der Textur der Glanztonware. Der Bruch ist mittelhart bis hart, und der Überzug entspricht der Farbe des Scherbens. Die Oberfläche ist körniger, also nicht so kompakt wie bei den Gruppen 1 und 2, auch ist die Wandung oftmals dicker. Meines Erachtens handelt es sich dabei um eine Nachahmung der qualitätsvollen dünnwandigen Ware: Man versuchte, auf traditionellem Weg, also in der Machart der typisch hellenistischen Glanztonware, ein ähnliches Fabrikat wie das der Dünnwandigen Ware herzustellen ${ }^{211}$.

Mit ihren Wandungsstärken von 0,5-3 mm ist die Dünnwandige Ware - wie schon erwähnt - meist als Trinkgefäß oder als Behälter für Flüssigkeiten benutzt worden ${ }^{212}$. Die Herstellungstechnik dieser äußerst fragilen Ware ist nicht ganz geklärt. Möglich wäre beispielsweise, dass ein sehr dünner, also besonders fein geschlämmter Ton in einem Gipsmodel geschwenkt wurde. Durch das Schwenken entstanden die charakteristischen Rillen auf der Innenwandung. Nachdem das Gefäß angetrocknet war, wurde es bei sehr hohen Temperaturen gebrannt ${ }^{213}$. Aufgrund der diffizilen Herstellungsweise könnten als Formen vorzugsweise offene Gefäße benutzt worden sein, nämlich Becher und Schalen ${ }^{214}$. Auffallend sind bei sich nach oben verjüngenden Bechern die dickeren Ränder, welche auf eine spätere, separate Ansetzung hinweisen könnten. Allerdings trifft man auch auf andere Gefäße wie Krüge oder kleine Kannen. Für diese ist noch nicht ausreichend geklärt, wie man sie herstellte.

Die Gattung der Dünnwandigen Ware kann nicht zur Küchenware gezählt werden, denn dafür ist sie zu fein und teilweise zu aufwendig dekoriert. Demnach gehörte sie wohl zum Tischgeschirr, möglicherweise substituierte sie das zu jener Zeit eher selten verwendete Glas. Nur $4 \%$ der vorliegenden Dünnwandigen Ware wurden mit einem Dekor versehen, bei dem sich zwei Arten unterscheiden lassen: die Barbotine-Technik und die sog. Thorn Ware.

Die Dünnwandige Ware tritt in mehreren Regionen auf und wurde je nach lokalen Gegebenheiten auch unterschiedlich hergestellt ${ }^{215}$. Nachdem ein hohes Aufkommen Dünnwandiger Ware auch in ephesischen Fundkomplexen beobachtet werden konnte, ist hier von einer lokalen Produktion auszugehen ${ }^{216}$. Im Rahmen der Bearbeitung konnten insgesamt drei Keramikproben genommen werden, die am Institut für Silikatchemie und Archäometrie der Hochschule für angewandte Kunst in Wien von R. Sauer analysiert worden sind (Abb. 27). Von dem Typ D9 wurden zwei Proben jeweils aus den Fabric-Gruppen 1 und 2 genommen. Die petrographisch-mineralogischen Untersuchungen ergaben, dass beide Waren lokal hergestellt worden waren. Für die Gruppe 1 konnte sogar das Mäandertal als Produktionsort nachgewiesen werden. Die dritte Probe,

${ }^{209}$ V. Mitsopoulos-Leon verweist auf die Technik, bei der die Gefäße mit einem trockenen Schlicker überzogen werden, der durch das Ineinanderstapeln beim Brand eine unterschiedliche Färbung erhalten kann, Mitsopoulos-Leon 1991, 131. S. Japp geht davon aus, dass die Verschiedenfarbigkeit des Überzugs durch die Konditionen im Ofen (verschiedene oxidierende und reduzierende Phasen, Sauerstoff- und Hitzeverhältnisse) und die individuelle Positionierung zustande kommt. Als weitere Option führt sie eine sog. Eigen-Engobe an, die durch das Glattstreichen der Außenoberfläche mit von Tonschlicker genässten Töpferhänden entsteht. s. dazu Japp 1999, 303.

${ }^{210}$ Vor allem in der pergamenischen Terminologie. Japp 1999, 303.

${ }^{211}$ Diese These stimmt nicht mit der Typisierung der nabatäischen Ware von S. G. Schmid überein, meint er doch im Gegenteil, dass der gröbere Typ auch der früher zu datierende sei: Schmid 1996, $131 \mathrm{f}$.

${ }^{212}$ Montana u. a. 2003, 375: erinnert an Glasgefäße.

${ }^{213}$ Hayes 1997, 68.

${ }^{214}$ Montana u. a. 2003, passim gehen davon aus, dass offene Gefäßformen mehr Profit versprächen und einfacher zu transportieren seien. Für den von ihnen untersuchten Ort Segesta ergaben die petrographischen und chemischen Analysen, dass die Dünnwandige Ware, wie auch schon für die Amphoren belegt, lokal produziert worden ist. 12\% konnten als Importe deklariert werden. In anderen antiken Stätten auf Sizilien ist diese Warengattung jedoch nur in geringem Ausmaß belegt. Dies spricht dafür, dass zumindest Sizilien kein zentrales Produktionszentrum und daher auch nicht der Ursprungsort der Dünnwandigen Keramik war.

${ }^{215}$ Zur nabatäischen Dünnwandigen Keramik: Schmid 2000, passim; zur pergamenischen Dünnwandigen Ware: Japp 1999 und 2003, passim; für Priene: Fenn 2008, passim; für Stobi: Anderson 1977, 112. 116 Nr. 136a Abb. 56; für Çandarlı: Loeschcke 1912, 392; und für Ephesos: Mitsopoulos-Leon 1991, 131-137.

216 Eine lokale Produktion wird ebenfalls von C. Rogl vermutet: Rogl 2007, 188 mit Anm. 54. 
von Typ D21, die ebenfalls zur Fabric-Gruppe 1 gehört, ist ein Import. Für einen Teil der Dünnwandigen Ware ist somit eine Herstellung mit verschiedenen Fabrics in Ephesos und Umgebung im 1. Jahrhundert v. Chr. belegt.

\subsubsection{Becher}

Bei der Dünnwandigen Ware zählen $97 \%$ aller Gefäßformen zu den Bechern. Dabei kann man anhand der Ränder vier Basisformen unterscheiden: konische oder trichterförmige Becher, Becher mit verengter Mündung, halbkugelige Becher und Becher mit ausgestellter Lippe. Die durchschnittlichen Randdurchmesser liegen bei allen Gruppen bei ca. $9 \mathrm{~cm}$.

Mit einem 40\%-igem Anteil tritt der konische Becher am häufigsten auf. Zu dieser Gruppe zählen fünf Typen, deren Parallelen alle eher spät datiert werden: ab dem 1. Jahrhundert v. Chr. bis in die claudische Zeit. Während D3 (Taf. 6, 108) eine vereinfachte Form mit gerader, leicht nach außen geschwungener Wandung und runder Lippe darstellt, haben D9 und D11 (Taf. 6, 114. 116) eine leicht gewölbte Wandung. Die Lippe ist innen verdickt. D11 weist zusätzlich eine leichte Einkehlung am Lippenrand auf. Bei dem Einzelstück D12 (Taf. 6, 117) (Stratum 3) fällt die sehr kantige Form auf: Die Lippe macht einen starken Knick nach innen und läuft sehr spitz zu. Mit $8 \mathrm{~cm}$ Randdurchmesser zählt dieses Becherfragment zu den kleineren Vertretern. D7 (Taf. 6, 112), ebenfalls aus Stratum 3, erinnert wieder an die Form von D9 und D11. Allerdings ist die Lippe nicht verdickt, sondern rund abgestrichen. Am äußeren oberen Rand ist eine leichte, schwarz eingefärbte Facettierung zu sehen. Der bisher aus anderen Fundkomplexen in Ephesos als augusteisch datierte Becher ist also bichrom. Alle fünf Typen treten in den Straten 2 und 3 auf, D9 auch im ersten Stratum.

Die Becher mit verengter Mündung machen $25 \%$ der Gefäßgattung aus. Sie kommen alle aus dem zweiten und dritten Stratum. D4 (Taf. 6, 109) ist ein Becher mit gerader Wandung; darauf folgt ein Absatz nach innen und die hohe, rund abgestrichene Lippe läuft vertikal. Der Absatz wird durch Profilrillen betont. M. T. Marabini-Moevs datiert diese Form in Cosa in die spätrepublikanische Zeit ${ }^{217}$. Bei D2 (Taf. 6, 107) ist der Gefäßkörper halbkugelig, die Mündung ist jedoch nach innen gezogen. Die Lippe ist innen leicht verdickt und biegt nach außen um. In Tarent wird die dort seltene Form in die zweite Hälfte des 2. Jahrhunderts v. Chr. datiert ${ }^{218}$. In ephesischen Kontexten tritt sie bisher erst im dritten Viertel des 1. Jahrhunderts v. Chr. auf ${ }^{219}$. D10 (Taf. 6, 115) ähnelt D2, allerdings ist die Wandung viel schräger nach innen gestellt und die Lippe nach außen verdickt.

Halbkugelige Becher sind in der Sondage B6 in Wohneinheit 7 des Hanghauses 2 in Ephesos am dritthäufigsten vertreten. Auch ihr Vorkommen beschränkt sich auf die Straten 2 und 3, und es gibt nur einen Typ (D5, Taf. 6, 110), der von recht einfacher Form ist: halbkugelig mit rund abgestrichener Lippe. D5 existiert in ephesischen Fundkomplexen der Jahre 25 v. -25 n. Chr. ${ }^{220}$.

Die Becher mit ausgestellter Lippe kommen mit $15 \%$ am seltensten vor. Von den drei Typen sind D1 (Taf. 6, 106; Stratum 2) und D8 (Taf. 6, 113; Stratum 3) einander sehr ähnlich. Bei beiden handelt es sich um die bei R. Meriç als »Becher mit kleiner Lippe« beschriebenen Gefäße, die von ihm in flavische Zeit datiert werden $^{221}$. Allerdings befindet sich bei D1 außen ein kleiner Wulst an der Stelle des Umbruchs, der bei D8 nicht existiert. Dafür ist D8 im Dekor der sog. Thorn Ware verziert. Vom letzten Typ, D6 (Taf. 6, 111), aus Stratum 2 und 3, der ein hoher, ovaler Becher mit ausgestellter Mündung und nach innen geschwungener Lippe ist, sind zwar nur sehr kleine Fragmente erhalten, jedoch lassen sich für die Ganzform gute Parallelen finden, die vom späten 1. Jahrhundert v. Chr. bis in die Mitte des 1. Jahrhunderts n. Chr. datiert werden ${ }^{222}$.

\footnotetext{
217 Marabini-Moevs 1973, Form XXXII, Nr. 163 Taf. 15.

${ }^{218}$ Hempel 2000, Form 626b, Nr. 8. Auch für Cosa: Marabini-Moevs 1973, Form VIII.

219 Meriç 2002, K 342-345 (Atlante 1/27); Ladstätter 2005a, K 156. K 327.

220 Meriç 2002, K 385; Mitsopoulos-Leon 1991, K 18.

221 Meriç 2002, 74.

${ }^{222}$ Meriç 2002, K 359 (Atlante 1/78); Ladstätter 2005a, K 159-162 f.
} 


\subsubsection{Sonstige Randfragmente}

Von anderen Gefäßformen wie Schalen, Skyphoi und Krügen ist jeweils ein Randfragment erhalten. Die Schale D13 aus Stratum 2 kennzeichnet eine eingeschnürte Wandung. Die Lippe ist innen verdickt. Vergleichsbeispiele lassen sich sowohl in Ephesos ${ }^{223}$ als auch im Westen ${ }^{224}$ finden, datiert werden sie von spätrepublikanisch bis tiberisch. Der Skyphos D14 aus Stratum 1 fällt durch seine konische Form und spitze Lippe auf. Durch eine Verdickung der Wand wird die Lippe sogar betont abgesetzt. Der Henkelansatz scheint sehr tief am Gefäß zu beginnen. Für den Skyphos der Fabric-Gruppe 1 sind keine Parallelen zu finden. D15 ist ein kleiner Krug mit 6,4 cm im Randdurchmesser. Die Mündung ist nach innen gewölbt und die Lippe spitz. Eine Parallele aus dem Hanghaus 2 wird in das 1.-3. Jahrhundert n. Chr. datiert ${ }^{225}$.

\subsubsection{Bodenformen}

Aufliegende, flache Böden wie bei Typ D20 (Taf. 7, 125) sind in allen Straten vertreten, allerdings kann dieser Typ ohne Wandung kaum als Datierungskriterium herangezogen werden. Die Durchmesser rangieren zwischen 3,4 und 9,2 cm, die augusteisch datierte Form ist relativ gebräuchlich und lässt sich mehrfach nachweisen ${ }^{226}$. D18 und D21 (Taf. 6, 123 und 7, 126) ähneln einander sehr. Der Boden ist durch einen im Profil dreieckigen Ringfuß gekennzeichnet. Beide Typen kommen in den Straten 1-3 vor. D18 wird in das 1. Jahrhundert v. Chr. datiert, D21 viel später in das 1. Jahrhundert n. Chr. D21 ist im Durchschnitt kleiner als D18 und wird zudem als >Scheinfuß tion und nur durch die Fabrikation zu erklären ist ${ }^{227}$. D19 (Taf. 6, 124) ist ein flacher, abgerundeter Boden mit Profilierungen. Seine Form findet eine Analogie in der Glanztonware, die in das erste Viertel des 1. Jahrhunderts v. Chr. -25 n. Chr. datiert wird ${ }^{228}$. Das Einzelstück D16 (Taf. 6, 121) aus Stratum 3 beschreibt eine besondere Form. Es ist ein hoher, nach innen gewölbter Standfuß, der zur ersten Fabric-Gruppe gehört und einen Durchmesser von 6,8 cm hat. Dieser Typ tritt im Westen schon um die Mitte des 2. Jahrhunderts v. Chr. auf und hat eine lange Laufzeit, nämlich bis in das dritte Viertel des 1. Jahrhunderts n. Chr.

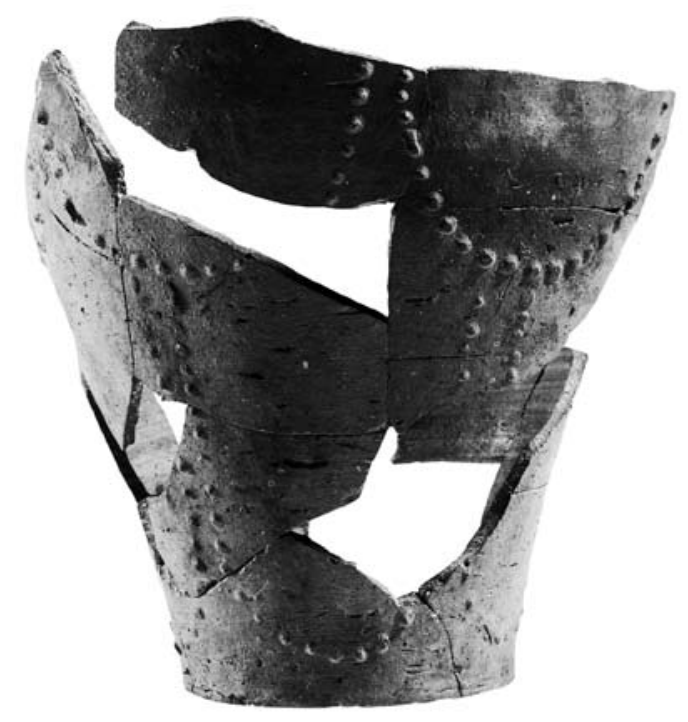

13 Dünnwandiger Becher Kat. 122 mit BarbotineDekor (D17)

\subsubsection{Barbotine-Dekor}

23 Wand- und 3 Bodenfragmente aus Stratum 4 konnten zu einer fast vollständigen Becherform rekonstruiert werden (D17, Kat. 122 Abb. 13); leider fehlt die Mündung. Das Fabric ähnelt Gruppe 1, allerdings laufen die Farben Orange und Grau innen abwechselnd spiralenförmig zusammen. Zudem sind im Scherben mit dem Mikroskop vulkanische Einschlüsse sichtbar, die nicht ephesischer Herkunft sein können $^{229}$. Der Becher hat eine hohe, lang gezogene und ovale Form. Sein Boden ist einfach abgerundet und liegt flach auf. Kleine Tonperlen wurden aneinandergereiht in Form einer Girlande auf die Außenwandung aufgetragen, sodass sie sich fast über die gesamte Becherhöhe erstrecken; nur die obere Randzone wurde ausgelassen. Man kann davon ausgehen, dass dieser Becher ein frühes Importstück darstellt. Anhand von Parallelen lässt er sich in den Zeitraum zwischen 150 und 75 v. Chr. datieren ${ }^{230}$.

\footnotetext{
${ }^{223}$ Meriç 2002, K 382 (Atlante 2/232. 2/405); Mitsopoulos-Leon 1991, K 18.

${ }^{224}$ Mayet 1980, Form 33; Marabini-Moevs 1973, Nr. 142 Taf. 13.

${ }^{225}$ Ladstätter 2005a, K 538.

${ }^{226}$ Mitsopoulos-Leon 1991, K 3; Ladstätter 2005a, K 170. K 178; Marabini-Moevs 1973, Form I, Nr. 6 Taf. 1.

${ }^{227}$ Conspectus 1990, 153.

${ }_{228}$ Meriç 2002, K 462 Taf. 38; vgl. mit G15.

229 Sauer 1995, passim.

${ }^{230}$ Marabini-Moevs, Form I, Nr. 3 Taf. 1; zur Form: Ladstätter 2005a, K 171 (dort ohne Dekor und augusteisch datiert).
} 


\subsubsection{Sog. Thorn Ware, Kommaregen-Dekor, Grätendekor oder Spachtelkeramik ${ }^{231}$}

Schon die Vielfalt der Bezeichnungen zeigt, dass sich die Forschung nicht einig ist, wie man diese Verzierungsform benennen soll. Meist wurden die Funde aus verschiedenen Regionen auch nicht als eine Gattung betrachtet, trotz augenscheinlicher Parallelen.

Für diesen Dekor wurden Tonstreifen vermutlich mit einem scharfen Gegenstand, etwa einem Messer, von unten nach oben vertikal auf das Gefäß aufgestrichen und ein weiteres Mal von der anderen Langseite nach oben gestrichen, sodass sich in der Mitte ein scharfer Grat bildete. Sein oberes Ende steht etwas von der Gefäßwandung ab und endet in leichten Rundungen. Die untere Partie ist grob mit der Wandung verstrichen (Abb. 14).

Dieser Dekor wird ausschließlich in der Fabric-Gruppe 1 verwendet. Er tritt auf den oben beschriebenen Bechertypen D18 und D8 auf. In Ephesos sind Parallelen aus dem Hanghaus 2 selbst $^{232}$, aus der Basilika am Staatsmarkt und von der Tetragonos Agora ${ }^{233}$ bekannt. Allerdings werden diese erst ab claudischer Zeit bis in das 2. Jahrhundert $n$. Chr. datiert. Es gab aber durchaus eine weite Verbreitung in Kleinasien

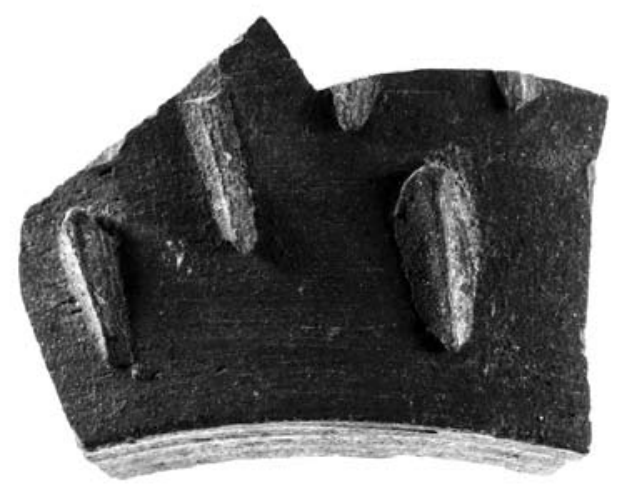

14 Thorn-Ware, Bodenfragment Inv. 99/649 B.16; Form wie D18 (Kat. 123) bereits während des 1. Jahrhunderts v. Chr. Eine Herkunft oder ein Produktionszentrum für die sog. Thorn Ware kann mit jetzigen Forschungsstand nicht eruiert werden.

\subsection{Weißßgrundige/>Lagynos-Ware ${ }^{234}$}

Die Weißgrundige Ware ist in späthellenistischen Fundkomplexen des Mittelmeerraumes eine immer wieder auftretende Gattung ${ }^{235}$, jedoch ist ihr Aufkommen gegenüber anderen Waren meist geringer. Die Ware bewahrt ihren Traditionsreichtum - das Haften an wenigen Formen -, der bis in die Klassik zurückreicht. Der Scherben ist hart gebrannt und feinporös, seine Farbe ist meist rötlich beige. Mit bloßem Auge sind Glimmerpartikel und weiße, feine Einschlüsse sichtbar. Der leicht rosa- bis gelbweißliche Überzug, der auf die Außenseiten und die Randinnenseite dick aufgetragen wurde, ist charakteristisch für diese Gattung, wobei sich jedoch verschiedene Qualitäten feststellen lassen ${ }^{236}$. Meist ist der Überzug matt bis matt glänzend, bei wenigen Beispielen wurde er dicker und kompakter aufgetragen. Manchmal wurde die Oberfläche leicht geglättet, sodass der Überzug gelegentlich glänzt - bei dem hier vorliegenden Fundmaterial eher die Ausnahme. In den meisten Fällen wurde der Tonschlicker zu dünn aufgetragen, wodurch er kreidig wirkt und sich gut abreiben lässt, was vor allem im unteren Gefäßteil zu beobachten ist. Der Standring wurde häufig komplett ausgespart und tonfarben belassen. Der Dekor wurde noch vor dem Brand aufgetragen ${ }^{237}$ : Bauch- und Schulterbereich sind meist kompakter überzogen, auf ihnen befinden sich häufig orangerote bis bräunliche Dekore. Die Gefäßformen und besonders die Umbrüche, wie z. B. die kantige Schulter oder die verdickte Lippe am Ende des röhrenförmigen, langen Halses bei der Lagynos, werden durch umlaufende Bänder deutlich betont. Im Allgemeinen sind diese Gefäße mit vegetabilen oder ornamentalen Dekorformen übersät. Beim pflanzlichen Dekor herrschen Blattmotive oder Ranken vor, der ornamentale Dekor bedient sich Bänder in den verschiedensten Formen und Größen sowie einiger Punktverzierungsarten. Leider sind signifikante Stücke nur sehr fragmentarisch erhalten und eine großflächige Rekonstruktion daher nicht möglich,

\footnotetext{
${ }^{231}$ Die Dekorart erhielt in der Forschung sehr unterschiedliche Namen: K. Warner Slane nennt sie Thorn Ware, S. G. Schmid wählt die illustrative Bezeichnung Kommaregen-Dekor, V. Mitsopoulos-Leon nennt sie Grätchendekor, während S. Japp Spachtelkeramik dazu sagen möchte. Im Folgenden soll der Terminus >Thorn Ware benutzt werden.

${ }^{232}$ Ladstätter 2005a, K 164.

233 Mitsopoulos-Leon 1991, 132; Gassner 1997, 155.

${ }^{234}$ Dieser Ausdruck ist auf die am häufigsten benutzte Gefäßform in dieser Gattung, die Lagynos, eine einhenkelige Kanne oder ein Krug mit bikonischem oder sphärischem Bauch, zurückzuführen.

235 Vgl. dazu Rogl 2007, passim.

${ }^{236}$ Lediglich zwei Beispiele weisen einen glänzenden Überzug auf.

${ }^{237}$ Dereboylu 2001, 21.
} 


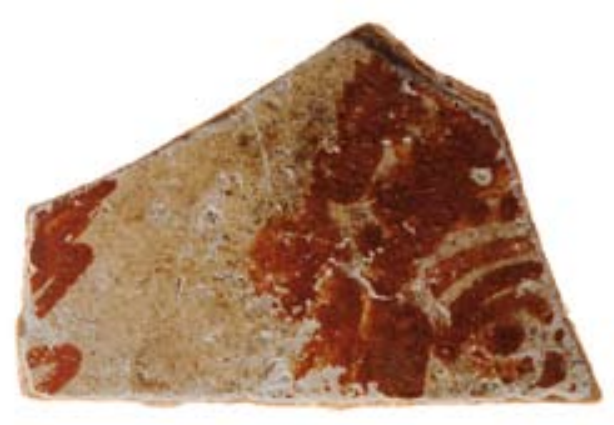

15

Lagynos Kat. 137 mit dem Teil eines Gesichtes auf Weißgrundiger Ware (Dionysos?)

jedoch lassen sich für den Dekor Parallelen aus Ephesos heranziehen ${ }^{238}$. Eine inhaltliche Verbindung des Dekors mit dem Verwendungszweck der Gefäße scheint gegeben, zumal dionysische Motive benutzt wurden ${ }^{239}$. Auf dem Fragment Kat. 137 aus Stratum 2 ist ein figürliches Motiv zu sehen (Abb. 15). Das rechte Auge und die rechte obere Kopfhälfte bis zum Ohr sind vorhanden. Es handelt sich um einen Mann mit kurzem, gelocktem Haar und einem Kranz aus Weinblättern darin, wahrscheinlich der Gott Dionysos ${ }^{240}$.

Aufgrund der schlechten Haftung des Überzugs geht R. Zahn davon aus, dass diese Gefäße nicht täglich gebraucht wurden. Eher sieht er sie in einem festlichen Kontext ${ }^{241}$, da es sich bei den Lagynoi ${ }^{242}$ um Krüge mit breiten und flachen Schultern, langem, engem Hals sowie bikonischem Körper handelt, die man zum Ausschenken von Wein benützte. Sie haben lange, vertikale Henkel, die knapp unter der Lippe ansetzen, bis auf die Schulter laufen und sich im Querschnitt langoval oder rechteckig mit abgerundeten Ecken darstellen. Farblich gesehen sind die Henkel recht schlicht gehalten, d. h. weißgrundig. Ihre Verzierung ist eine Tordierung ${ }^{243}$. Drei Rand- (L1, L3 und L4, Taf. 7, 127. 129. 130) und zwei Bodenformen (L6 und L5, Taf. 7, 131. 132) konnten sicher zu den Krügen gezählt werden, wobei L1 und L3 zu den einhenkligen Krügen gehören. L1 entspricht dem mehrmals überlieferten Typ mit langer, runder Lippe, die durch einen Knick, bei dem sich das Gefäß nach außen verbreitert, vom Hals abgesetzt wird. Dadurch erhält die Mündung im Profil eine S-Form. Die Lippenwandung steht leicht schräg nach innen, die Lippe selber ist rund und schmal wie die Wandung selbst. Der Mündungsdurchmesser beträgt 3,4 cm. L3 hingegen hat eine sehr enge Mündung, die Lippe ist nur in Ansätzen vorhanden. Wandung und Henkel sind recht dick. Für L3 konnte kein Vergleich innerhalb der Gattung gefunden werden. L4 hat einen sehr charakteristischen Rand: Die Mündung ist weit ausgestellt, sodass der Rand nach außen schwingen und überhängen kann. Die Form wird von R. Meriç als »zweihenkeliger Krug« bezeichnet.

Bei den Bodenfragmenten können zwei Typen unterschieden werden. Beide stehen auf einem niedrigen Standring und beide sehen im Querschnitt eckig aus. Bei Typ L6 geht der Körper in eine bauchige oder birnenähnliche Form über, die sowohl in Ephesos als auch außerhalb gebräuchlich ist und für die sich reichlich Parallelen finden lassen ${ }^{244}$. Die Wandung von Typ L5 biegt nach dem Standring nach außen, sodass seine Form hoch und oval und nicht kugelig oder bauchig werden kann. Eine vergleichbare hohe Lagynos stammt aus Tarent und wird in die zweite Hälfte des 2. Jahrhunderts v. Chr. datiert ${ }^{245}$.

Zur Weißgrundigen Ware gehören neben den Lagynoi (ein- oder zweihenkelig) noch Thymiaterien, Becher, Schalen und Teller. Daraus ergibt sich eine Vielzahl verschiedener Gefäßformen, die sich zu einem Service zusammenstellen lässt. Von den Schalen oder Tellern ist Typ L9 (Taf. 7, 135) aus Stratum 2 zu nennen, von dem fünf Fragmente erhalten sind. Es handelt sich um ein flaches, weit ausladendes Gefäß mit einem größeren Randdurchmesser $(21 \mathrm{~cm})$. Der Rand ist, nach einem kleinen Absatz an der äußeren Lippe, überhängend, was sowohl auf eine flache Schale als auch auf einen Teller deuten könnte. Ferner sind

${ }^{238}$ Dereboylu 2001, Taf. 10, 11-25; 11, 26-33; Mitsopoulos-Leon 1991, Taf. 89.

239 R. Zahn verweist auf den Gebrauch bacchischer Verzierungselemente, z. B. Girlanden, aber auch Syrinx, Harfe, Lagobolon, Dreizack mit Tänien, Vögel und Delphine; Zahn 1904, 399. V. Mitsopoulos-Leon erweitert dies um Efeu und Lorbeer: MitsopoulosLeon 1991, 75 mit Anm. 376. Zusätzlich sind bei G. Leroux zwei Inschriften auf Gefäßen erhalten, die einen bacchischen Bezug nahelegen; Leroux 1913, 73.

${ }^{240}$ Eine Ähnlichkeit in der Haar-, Kranz- und Augengestaltung ist zum Dionysos Fufluns auf einem Stamnos zu erkennen. LIMC III 1 (1986) 534 E, b, 37 Taf. 422 s. v. Dionysos/Fufluns (M. Cristofani).

${ }^{241}$ Zahn 1904, 399.

${ }^{242}$ Zur Herstellungstechnik der Lagynoi s. Dereboylu 2001, 22.

${ }^{243}$ Zwei Tonwürste werden umeinander gedreht. Dann setzt man sie auf Lippe und Schulter und verstreicht die Enden mit dem Gefäß.

${ }^{244}$ Für Ephesos: Dereboylu 2001, 1.a. Kat. 1-29; Mitsopoulos-Leon 1991, 75-77; Gassner 1997, 69 f. Kat. 206; Meriç 2002, 34-39. Für Knidos: Mandel u. a. 1996, 61 f. Für Priene: Zahn 1904, 399 f.; Hübner 2000, 161-173.

${ }^{245}$ Hempel 2000, 430. 432. 
ein Rand- und zwei Wandfragmente von einem Gefäß (Typ L2, Taf. 7, 128) erhalten, welches einen Randdurchmesser von $10 \mathrm{~cm}$ aufweist. Da dies für eine Lagynosmündung zu groß ist, kann es sich nur um einen Becher handeln. Die Lippe ist rund und leicht nach außen gebogen. E. Dereboylu führt unter dem Punkt "geschlossene Gefäße« ein passendes Vergleichsbeispiel an, geht aber nicht näher auf dessen Form ein ${ }^{246}$. In derselben Gruppe ist das Bodenfragment L7 (Taf. 7, 133) aufgeführt, bei dem es sich um einen etwas höheren, aber auch im Randdurchmesser kleinen $(6 \mathrm{~cm})$, schlauchförmigen Ringfuß handelt. Die Wandung ist relativ dünn. Des Weiteren konnten Fragmente von Thymiaterien, wie z. B. vom Bodentyp L8 (Taf. 7 , 134) oder von dem Deckelknauftyp L10 (Taf. 7, 136), aufgenommen werden. L8 stammt aus dem obersten Stratum, ein Vergleichsbeispiel wird von R. Meriç als der »spätere Typ« beschrieben und in frühflavische Zeit datiert ${ }^{247}$.

Die im Scherben enthaltenen Glimmerpartikel würden für eine lokale Produktion sprechen, jedoch konnte keine konkrete Produktionsstätte eruiert werden ${ }^{248}$. Es wird eine ionische Herkunft mit den Reliefbechern gleichem distributivem Handelsweg in die Mittelmeerregionen postuliert ${ }^{249}$.

\subsection{Sonstige Importe}

Bei den Importen lässt sich eine große Gruppe pergamenischer Ware feststellen. Zwei Fragmente stammen aus Knidos, ein weiteres konnte nicht sicher bestimmt werden. Die als pergamenisch gesicherten Typen zählen farblich zu der von C. Meyer-Schlichtmann definierten Tongruppe 3, welche den Hauptanteil der pergamenischen Sigillata stellt und die er vom letzten Drittel des 1. Jahrhunderts v. Chr. bis in die Mitte des 2. Jahrhunderts n. Chr. ansetzt ${ }^{250}$.

Im obersten Stratum der Sondage B6 ist die größte Vielfalt an Formen aufgetreten: zwei Schalen, drei Skyphoi, zwei Becher und ein Krug. Die Schalen I6 und I7 (Taf. 7, 144. 145) sind in ihrer Randgestaltung sehr unterschiedlich. Die Lippe vom Typ I6, der nur einmal in Stratum 1 belegt ist, schwingt weit nach außen, unterhalb der Lippe befinden sich zwei Einkehlungen. Parallelen sind in pergamenischen Kontexten vom zweiten Viertel des 1. Jahrhunderts v. Chr. bis zum Anfang des 1. Jahrhunderts n. Chr. zu finden ${ }^{251}$. I7 ist eine hohe Schale mit leicht schräg nach außen gestellter Wandung. Die Lippe ist eingekehlt, verdickt sich außen und schließt vertikal ab. Vier Fragmente, die nicht zum selben Gefäß gehören, stammen aus den Straten 1 und 2. Datiert wurde die Form von C. Meyer-Schlichtmann zwischen der Mitte des 1. Jahrhunderts v. Chr. bis zum ersten Viertel des 2. Jahrhunderts n. Chr. ${ }^{252}$. Die drei Skyphosformen I1, I2 und I5 (Taf. 7, 138. 139. 143) passen zu dem Schema der pergamenischen Trinkgefäße. Die Füße sind breit, jedoch nicht so hoch ${ }^{253}$ und werden darüber hinaus durch mehrfache Profilierungen gekennzeichnet. Bei I1, aus den Straten 1 und 3, handelt es sich um die in Pergamon gebräuchliche Skyphosform S $8^{254}$. Der gleiche Fuß ist bei J. W. Hayes als Atlante 24 angeführt und wird von ihm zwischen das letzte Viertel des 2. Jahrhunderts v. Chr. und die Mitte des 1 . Jahrhunderts v. Chr. datiert ${ }^{255}$. I2 ist eine langlebigere Form und wird von der Mitte des 2. Jahrhunderts v. Chr. bis zum Anfang des 1 . Jahrhunderts n. Chr. datiert ${ }^{256}$. Für I5, dessen Rand innen hochgezogen wurde, ließen sich keine passenden Vergleiche finden. Die Becher I10 und I11 (Taf. 8, 148. 149) haben eine gerade Wandung und eine rund abgestrichene Lippe, die bei I10 jedoch leicht nach innen, bei I11 hingegen nach außen geschwungen ist. Eine Herkunft aus Pergamon ist aufgrund des Fabrics und des Überzugs sehr wahrscheinlich, direkte Parallelen konnten aber nicht gefunden werden. Die einzige Krugform in Stratum 1 ist I13 (Taf. 8, 151), dessen an der Innenseite facettierte Lippe ebenfalls nach außen

${ }^{246}$ Dereboylu 2001, 25 f., 1.c. Kat. 6 Taf. 12, 42.

${ }^{247}$ Meriç 2002, 36 K 90 Taf. 10.

${ }^{248}$ Es werden mindestens ein, aber auch mehrere Zentren in Kleinasien vermutet. Entgegen E. Dereboylu ist allerdings von einer Produktion in Ephesos auszugehen; vgl. Dereboylu 2001, 28.

${ }^{249}$ Ionien, Griechenland und seine Inseln, Alexandria, Westitalien, Spanien, Karthago und das tunesische Uzita. s. dazu Neuru 1991, 13; Hayes 1991a, 20; Dereboylu 2001, 22.

${ }^{250}$ Meyer-Schlichtmann 1988, $13 \mathrm{f}$.

251 Meyer-Schlichtmann 1988, N 37 Kat. 179 Taf. 13; ebenso B 7 Kat. 65 Taf. 9.

${ }^{252}$ Meyer-Schlichtmann 1988, Form Sü 5 Kat. 337 Taf. 20.

${ }^{253}$ Meyer-Schlichtmann 1988, 63.

${ }_{254}$ Meyer-Schlichtmann 1988, S 8 Kat. 30 Taf. 29.

${ }^{255}$ Hayes 1985, 24 Taf. 12, 19.

${ }^{256}$ Meyer-Schlichtmann 1988, S 1 Taf. 7 Abb. 1. 
geschwungen ist; darunter befindet sich eine Rille. Entsprechungen finden sich vom 1. Jahrhundert v. Chr. bis in das 2. Jahrhundert $\mathrm{n}$. Chr. ${ }^{257}$.

In Stratum 2 sind, zusätzlich zu den schon besprochenen Typen I7 und I10, die Schalenform I8 (Taf. 8, 146), die Skyphosform I2 A (Taf. 7, 140) und die einzige pergamenische Tellerform I14 (Taf. 8, 152) vertreten. I8 ist eine tiefe Schale mit ausgestellter, gerader Wandung und runder Lippe. Die Form wird in Pergamon grob von der Mitte des 1. Jahrhunderts v. Chr. bis in das 2. Jahrhundert n. Chr. datiert ${ }^{258}$; Analogien in ESA lassen sich in Tarsus, Samaria Sebaste und Athen finden ${ }^{259}$. Bei der in Stratum 2 einmalig auftretenden Skyphosform handelt es sich um einen profilierten Standfuß, wie er schon von I2 bekannt ist und weswegen er auch hier als Variante aufgefasst wurde. I2 A entspricht der pergamenischen Sigillataform S 2 und datiert zwischen dem Ende des 2. Jahrhunderts v. Chr. und dem Anfang des 1. Jahrhunderts n. Chr. ${ }^{260}$. Der Teller I14 mit Steilrand und runder Lippe ist ab dem Ende des 2./Anfang des 1. Jahrhunderts v. Chr. bis zum Anfang des 1. Jahrhunderts n. Chr. vorzufinden. Mehrere Parallelen und Analogien in Sigillata zeigen, dass die Form ausgesprochen beliebt war ${ }^{261}$.

Ein früher Import ist durch die drei Skyphosformen I1, I3 und I4 (Taf. 7, 138. 141. 142), die in Pergamon eine beliebte Trinkgefäßform darstellen, in Stratum 3 belegt. Auf dem Skyphos Typ I3 mit geradem Rand und verdickter Innenlippe ist ein Efeurelief appliziert ${ }^{262}$. Die etwa fünf bis sieben Appliken wurden aus Negativ-Matrizen entnommen und vor dem Auftrag der Engobe mit etwas Schlicker kettenartig auf die Gefäße aufgeklebt ${ }^{263}$. Efeusträußchen sind das häufigste Blattmotiv, welches die Töpfer versuchten, zumindest proportional, naturnah zu fertigen ${ }^{264}$. Die typologische Entwicklung der Gefäßform wird von C. MeyerSchlichtmann sehr eng datiert. Er geht davon aus, dass sie etwa im zweiten Viertel des 1. Jahrhunderts v. Chr. importiert und angepasst worden sei und in dieser Art bis zum beginnenden 1. Jahrhundert $\mathrm{n}$. Chr. produziert wurde ${ }^{265}$. Typ I4, ein Skyphos mit gerader, schräg nach außen gestellter Mündung wird später, am Ende des 1. Jahrhunderts v. Chr., angesetzt. Die bisher gefundenen Exemplare in Pergamon und auch Tarsos sind im unteren Drittel mit Sand beworfen - ein Dekor, der sich erst im späten 1. Jahrhundert v. Chr. entwickelte ${ }^{266}$. Als letzte und früheste pergamenische Form in unserem Fundkomplex ist die Schale I9 aus Stratum $4 \mathrm{zu}$ nennen. Die dünnwandige Schale hat einen ausladenden Rand und eine runde Lippe. O. Bounegru identifiziert die >Lokalpergamenische $<$ Ware oder auch \Pergamenische Sigillata als die bisher bekannte >Çandarlı Wareく. Er vermutet, dass die Ware von Çandarlı aus in die gesamte ägäische Welt und das nordöstliche Pontusgebiet exportiert wurde ${ }^{267}$.

Die Herkunft der Typen I12 und I15 konnte nicht eindeutig bestimmt werden. I12 aus Stratum 2 ist ein halbkugeliger Becher mit leicht eingezogener, spitzer Lippe. Das Fabric ist hart und feinporös. Feiner Glimmer sowie feine, rote Partikel und Quarzeinschlüsse lassen sich mit freiem Auge erkennen. Der flächig aufgetragene Überzug ist schwarzgrau und wirkt matt. I15 aus Stratum 3 ist ein größeres Fragment mit Henkel. Die Form eines einhenkeligen Kruges mit gerader Wand und stark umbiegender Lippe ist daraus abzuleiten ${ }^{268}$. Der Henkel ist in der Mitte länglich eingekehlt und wird an einer Stelle von einem Band umschlossen. Unter dem Henkel verläuft eine Roulettierung, die von je zwei Profilrillen flankiert wird. Das Fabric ist wie bei I12 gräulich, jedoch feiner in seiner Porösität. Es konnten nur feine, weiße Partikel festgestellt werden. Die Engobe ist blaugrau und glänzt. Sowohl I12 als auch I15 könnten aufgrund des Fabrics und des Überzugs aus dem knidischen Raum stammen, passende Vergleichsbeispiele konnten bisher aber nicht eruiert werden.

\footnotetext{
${ }_{257}$ Meyer-Schlichtmann 1988, Kr 2 Kat. 382 Taf. 33.

258 Zelle 1997, Abb. 16, 182; Meyer-Schlichtmann 1988, N 24 Taf. 31 Abb. 153. 154.

${ }^{259}$ Meyer-Schlichtmann 1988, 104.

${ }^{260}$ Meyer-Schlichtmann 1988, 64 S 2.

${ }^{261}$ Meyer-Schlichtmann 1988, T 2 Taf. 16 Abb. 248; Weiterhin belegt in Tarsos, Hama, Antiochia, Samaria Sebaste, Athen, Korinth (in ESA), Stobi (lokal) und auf dem Magdalensberg (in TS).

${ }^{262}$ Meyer-Schlichtmann 1988, 65 S 3 Kat. 12-14 Taf. 7. 29.

${ }^{263}$ Zur Technik: Hübner 1993, 33.

${ }^{264}$ Hübner 1993, 64-68.

${ }^{265}$ Meyer-Schlichtmann 1988, 65 S 3 Kat. 12-14 Taf. 7. 29.

${ }^{266}$ C. Meyer-Schlichtmann kennt kein Beispiel ohne Sandbewurf. Meyer-Schlichtmann 1988, 66 S 5b Kat. 18 Taf. 8.

${ }^{267}$ Bounegru 1996, 106.

${ }^{268}$ Freundliche Mitteilung G. Dikbas.
} 
Einzig das Wandstück Typ I16 kann dem knidischen Herkunftsraum sicher zugerechnet werden. Das Fabric ist beigegrau und hart gebrannt. Der nur partiell aufgetragene Überzug ist schwarzbraun und matt. Anhand dieses Wandstücks lässt sich keine gesicherte Form feststellen, jedoch sind die Dickwandigkeit und Wölbung der Scherbe auffallend. Eine Profilierung, die von der Engobe ausgespart worden ist, deutet auf einen Fußbereich mit Standring. Da Kerben als vegetabiles Blattmotiv eingeschnitten wurden, lässt dies auf einen halbkugeligen Becher mit Kerbdekor schließen, wie er für Knidos belegt ist ${ }^{269}$.

\subsection{Lampen}

Die Lampen des Fundkomplexes wurden, bis auf ein Exemplar, typischerweise in Matrizen hergestellt ${ }^{270}$. Drei Fragmente aus Stratum 1 und zwei aus Stratum 2 zeigen nicht den üblichen schwarz bis schwarzblaugrauen Überzug, sondern sind tongrundig oder rötlich (fleckig). Es kann sich entweder um ein 〉Experiment eine mit Absicht oxidierende Brennung handeln ${ }^{271}$, oder der Farbgebung könnte ein Nach- bzw. Fehlbrand zugrunde liegen ${ }^{272}$.

Ephesische Lampen stehen den Reliefbechern in der Dekorierung in nichts nach. Die mannigfaltigen Kombinationsmöglichkeiten von Motivelementen sind aufgrund der Verwendung von Einzelstempeln unerschöpflich, wodurch es aber leider auch schwerfällt, einzelne Werkstätten zu unterscheiden. Zusätzlich muss davon ausgegangen werden, dass die Ateliers Einzelstempel untereinander tauschten, um noch mehr Dekorvielfalt zu erhalten ${ }^{273}$. Konkrete Werkstatthinweise liefern daher allein die Töpfersignaturen und Monogramme auf den Bodenunterseiten der Lampe. Im vorliegenden Fundkomplex kommt die Signatur des Töpfers Philon ${ }^{274}$ vor, die schon von den Reliefbechern bekannt ist. Weiterhin konnte ein Monogramm des Archetimos (?) eruiert werden. Dieser Töpfer wirkte vom Ende des 2. bis in das 1. Jahrhundert v. Chr. in Ephesos und veräußerte seine Ware u. a. nach Priene ${ }^{275}$.

Die Verzierung der Lampen lässt sich wie bei den Reliefbechern in vegetabilen, ornamentalen und figürlichen Dekor trennen. Die Unterschiedlichkeit in der Ausarbeitung der einzelnen Dekorelemente dokumentiert, dass für Lampenmodel und Reliefbecher andere Punzen benutzt wurden. Der vegetabile Dekor zeigt Blätter-, Langblatt-, Palmetten- und Rosettenmotive, die aber nicht so lebendig gestaltet sind wie bei den Reliefbechern, sondern eher schematisch ausgearbeitet wurden. Beim ornamentalen Dekor bediente man sich anderer Elemente, wie Zapfen, SSpiralen, Punktreihen oder Rauten. Einige Lampen tragen auf dem Hals auch Darstellungen von Gefäßen, stilisierten Bukranien und Masken.

Es wurden in den vier Straten insgesamt 100 Lampenfragmente (Wandstücke, Schnauzen, Diskusfragmente) gefunden, von denen 76 verziert waren. In Stratum 1 sind sechs von fünfzehn verzierten Fragmenten mit vegetabilem Dekor (Pinienzapfen, Zungenblätter, Palmetten, Dreiblattsträußchen mit Fruchtständen, Lotus, Farn und abwechselnde Blattarten) belegt. Demgegenüber stehen fünf ornamentale Verzierungen,

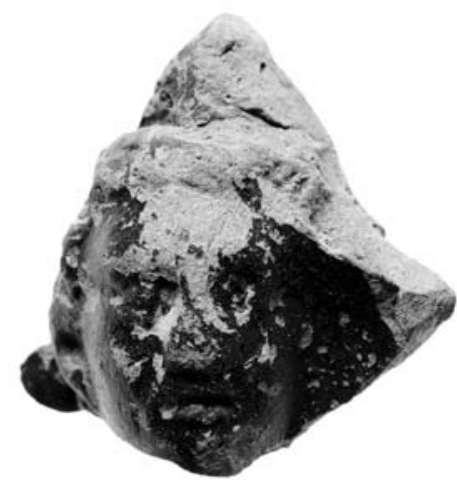

16 Lampenfragment Kat. 169 mit Jünglingskopf die Kringel, Punktreihen, Strahlen, Noppen, Rauten, Wellen (`Laufender Hund $)$ und ein ionisches Kymation zeigen. Zwei Appliken mit der Darstellung von Jünglingsköpfen sind zu den figürlichen Motiven zu zählen (Kat. 169 Abb. 16). Acht Fragmente tragen keinen Dekor.

In Stratum 2 verlagert sich der Schwerpunkt hin zum ornamentalen Dekor (14 von 21 verzierten Fragmenten). Bevorzugt werden vor allem Punktverzierungen, Perl- und Eierstäbe, Rauten, Noppen, Spiralen und liegende-S Dekore. Acht Fragmente zeigen vier- und sechsblättrige Rosetten, Zungenblätter, z. T. mit Punktreihen kombiniert, Ranken, spitze Blätter mit Punkten dazwischen und Palmetten. Zwei Beispiele

$269 \operatorname{Rogl} 2007,185$.

${ }^{270}$ Zur genauen Technik s. Scheibler 1976, 133-139.

${ }^{271}$ Mündliche Mitteilung S. Ladstätter.

272 Mündliche Mitteilung C. Höpken.

273 Giuliani 2001, 46; Giuliani 2007, 178.

${ }^{274}$ Rogl 2001c, 144; Laumonier 1977, RB 9340. 4620.

${ }^{275}$ Giuliani 2004, 153 Abb. 3 a, 6 mit weiterführender Literatur. 

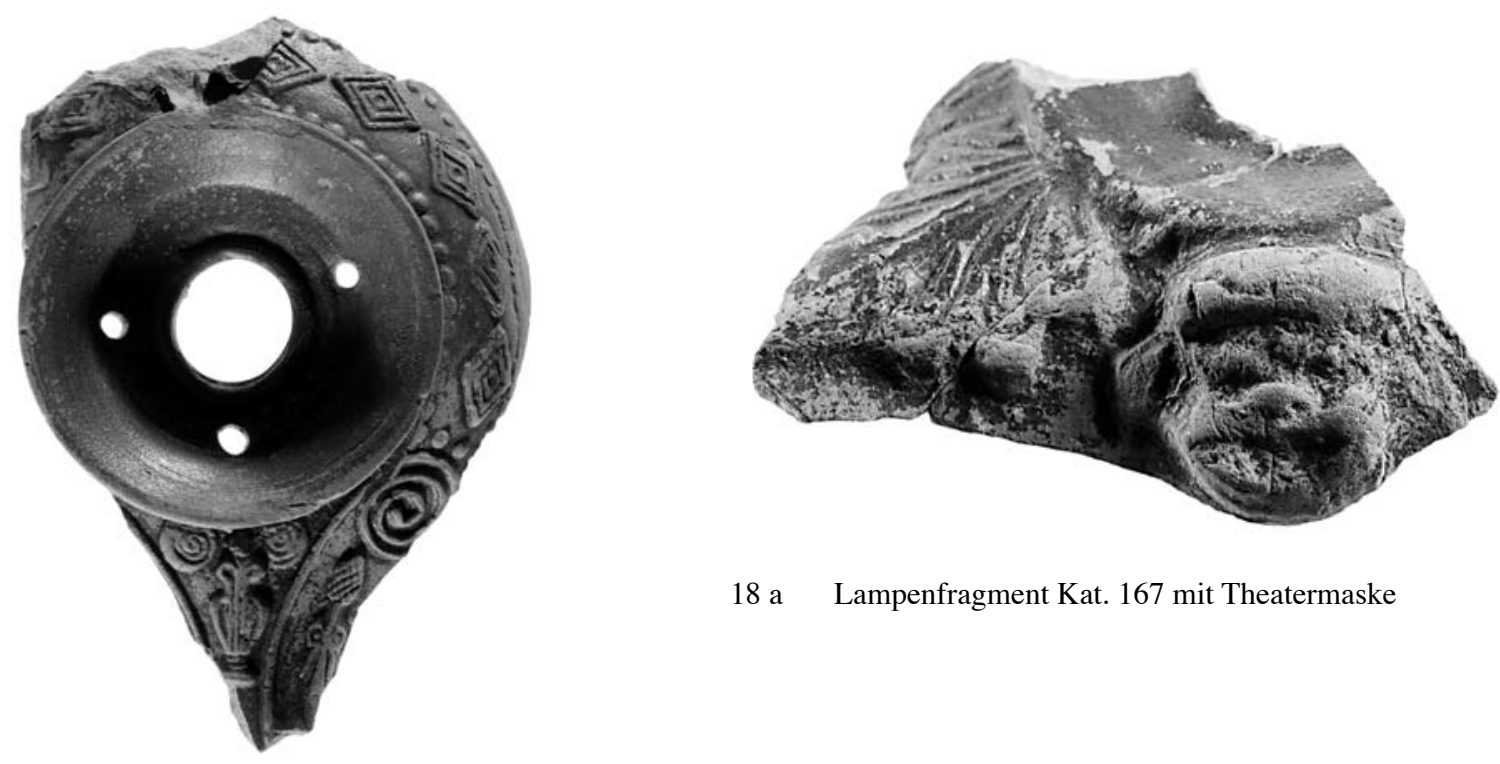

18 a Lampenfragment Kat. 167 mit Theatermaske

17 Lagynos auf dem Schnauzengang der Lampe Kat. 156
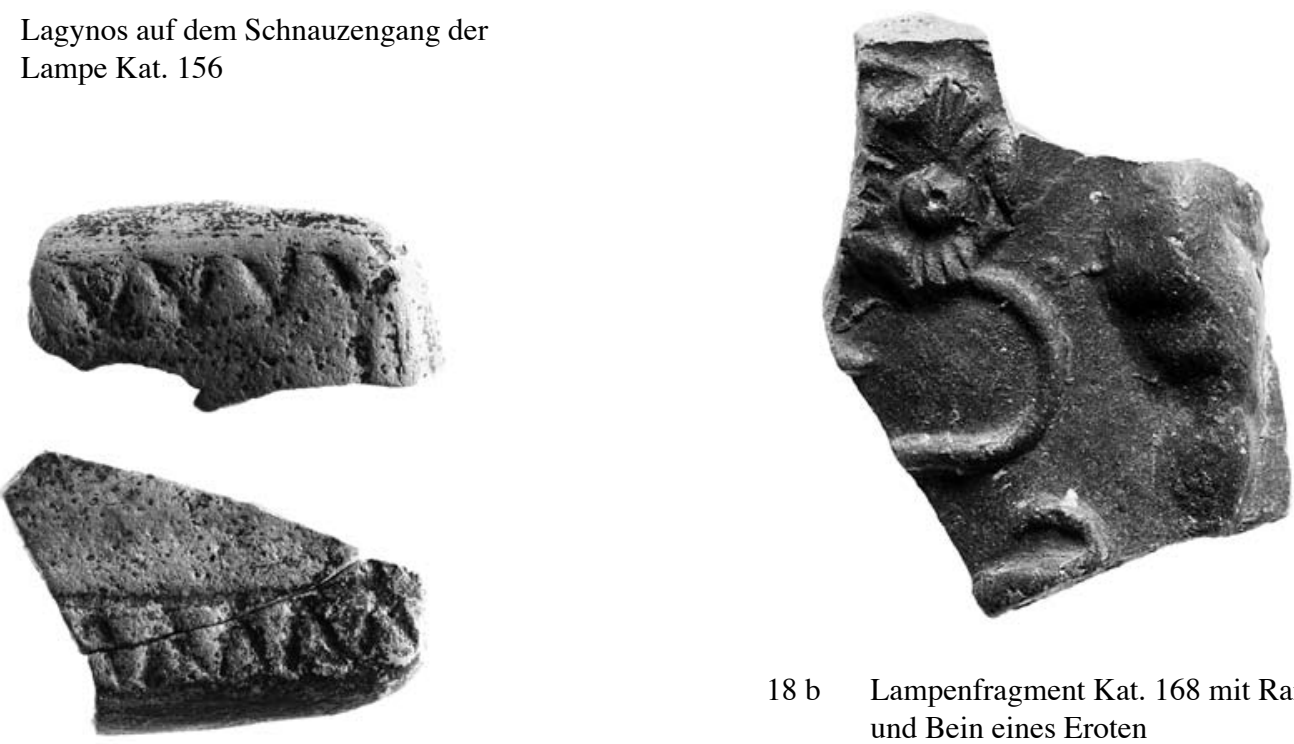

18 b Lampenfragment Kat. 168 mit Ranke und Bein eines Eroten

19 Dreiecksmuster auf rechteckigen Lampenfragmenten Kat. 166
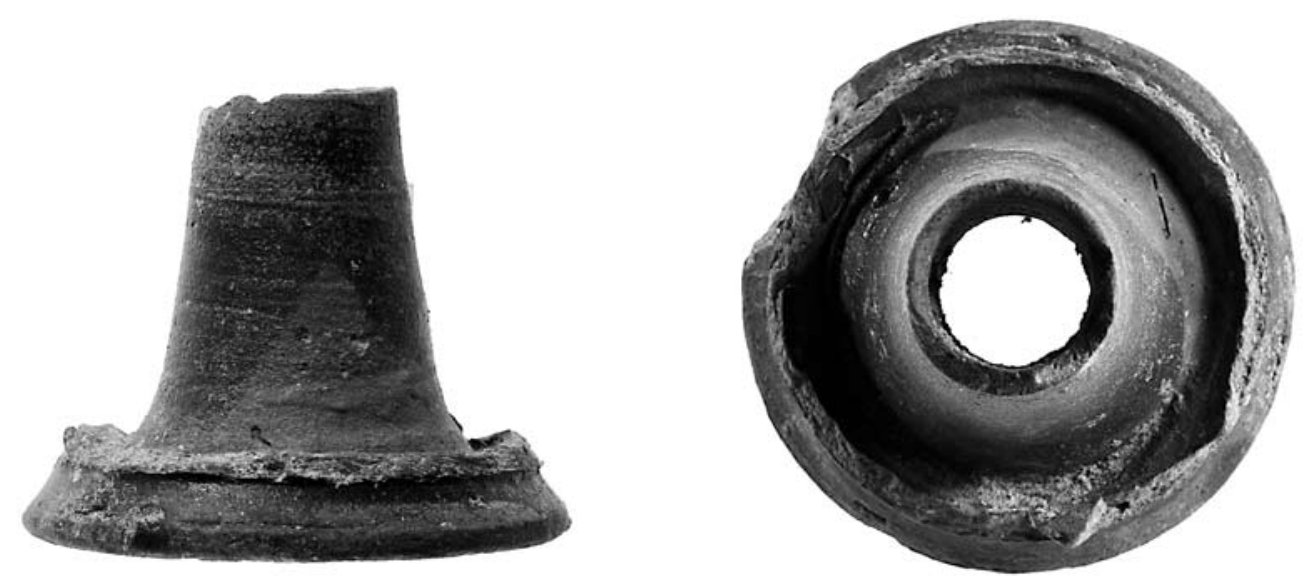

20 a. b Fragment der Stocklampe Kat. 170, Seitenansicht und Aufsicht 
zeigen eine Lagynos-Darstellung auf dem Schnauzengang (Kat. 156 Abb. 17); zehn Fragmente sind unverziert.

In Stratum 3 wird der Anteil an Lampenfragmenten geringer. Von zehn verzierten Beispielen besitzen vier vegetabilen Dekor wie Palmetten, Lilien, Blumen und Efeublätter. Das Ornamentale besteht aus den üblichen Punktverzierungen, Rauten, Flechtbändern, Mäandern ( $>$ Laufender Hund $\varsigma$ ) sowie dem stehenden S-Dekor. Der figürliche Dekor ist eher außergewöhnlich, so finden sich eine Theatermaske und das rechte Bein eines Eroten neben einer Ranke (Kat. 167. 168 Abb. 18 a. b). Zusätzlich wurden vier unverzierte Fragmente gezählt.

Aus Stratum 4 sind fünf dekorierte Fragmente geborgen worden, die vornehmlich vegetabilen Dekor wie achtblättrige Rosetten, Dreiblattsträußchen mit Fruchtständen und Zungenblätter zeigen. Auf dem Fragment einer Lampe in rechteckiger Form ist ein Dreiecksmuster zu sehen (Kat. 166 Abb. 19), ein weiteres Fragment zeigt zusätzlich zum vegetabilen Dekor eine stilisierte Bukranie auf dem Schnauzengang (Taf. 9, 159).

Ein erstes Aufkommen der Lampen ist in Ephesos für die Mitte des 2. Jahrhunderts v. Chr. belegtt ${ }^{276}$. Vor allem um das Ende des 2. bis zum 1. Jahrhundert v. Chr. haben sie sich in das Töpferrepertoire integriert ${ }^{277}$. Entgegen J. Bouzek konnte die Produktion nicht um die Mitte des 1. Jahrhunderts v. Chr. enden ${ }^{278}$, sondern muss aufgrund der hohen Fundzahl in frühkaiserzeitlichen Kontexten, zumindest in Ephesos, in die erste Hälfte des 1. Jahrhunderts n. Chr. datiert werden ${ }^{279}$.

$\mathrm{Zu}$ den auf der Scheibe gedrehten Lampen zählt das Fragment einer Stocklampe (Kat. 170 Abb. 20 a. b). Da solche Lampen bedingt durch ihre Konstruktion meist nur fragmentarisch erhalten sind, ist eine genaue typologische Zuweisung schwierig. Das vorliegende Beispiel entspricht im Profil der Form L61 der Basilikafunde, deren Parallele aus Athen in das 4. Jahrhundert v. Chr. datiert wird ${ }^{280}$, jedoch sind Fabric und Überzug in der Machart der späthellenistischen `Ephesos-Lampen` gestaltet.

\subsection{Tönerne Webgewichte}

Es wurden insgesamt zehn tönerne Webgewichte geborgen, von denen neun linsenförmig sind und nur ein einziges zylinderförmig ist. Das zylinderförmige Gewicht ist 7,9 cm hoch und besitzt ein Aufhängeloch. Die runden Gewichte haben einen Randdurchmesser zwischen 2,7 und 6,5 cm. Sie besitzen jeweils zwei durchgehende Löcher für die Aufhängung, die im oberen Teil platziert werden. Drei Webgewichte sind definitiv und zwei möglicherweise mit einem Gemmenring gestempelt ${ }^{281}$. Die Stempelungen wurden unterhalb der Aufhängelöcher, und zwar in der Mitte der Oberfläche angesetzt. Leider sind sie sehr verwaschen, was auf eine lange Benutzungsphase hinweist ${ }^{282}$ und ein etwaiges Motiv nicht mehr deutlich erkennen lässt ${ }^{283}$. Die Produktion der Webgewichte ist lokal, das Fabric weist die für Ephesos typische Tonzusammensetzung auf.

\subsection{Terrakotten}

Es wurden Fragmente von sieben verschiedenen Terrakotten geborgen ${ }^{284}$. Das Bein eines Eroten, erhalten vom Gluteus bis zum Fußgelenk mit weißer und orangefarbener Bemalung, kommt aus Stratum $3^{285}$. Zudem gibt es eine hohe, viereckige Basis mit weißbemalten Zehen eines (männlichen?) rechten Fußes ${ }^{286}$. Das dritte Fragment ist ein weiblicher Kopf mit einer Krone oder einem Diadem (Ceres?). Die Haare sind in der Mitte der Stirn gescheitelt und in gerollten Strähnen am Hinterkopf befestigt (〉Melonenfrisur`). An der linken Schläfe ist eine gelockte Strähne im Ansatz erhalten.

\footnotetext{
276 Giuliani 2003, passim; Giuliani 2007, 173 (3. Viertel 2. Jh. v. Chr.).

277 Gassner 1997, 193.

278 J. Bouzek setzt das Ende der Lampen in das 2. Drittel. Das würde bedeuten, dass die Lampen lediglich drei bis vier Dekaden gehandelt worden wären.

279 Gassner 1997, 193 mit Anm. 313; Ladstätter 2005a, 235; Pülz - Ladstätter 2006, 83; Giuliani 2007, 176.

${ }^{280}$ Mitsopoulos-Leon 2007, 73 Taf. 21.

${ }^{281}$ Stempelungen wurden durch Gemmenringe, aber auch Metallringe und Münzen angebracht.

${ }^{282}$ Auch die geringe Anzahl an Webgewichtfunden lässt vermuten, dass sie über lange Zeit benutzt wurden. Für jeden Webstuhl werden ca. 65-70 Gewichte verschiedener Größen veranschlagt.

283 Zur Motivauswahl s. Mitsopoulos-Leon 2007, 114-116 Taf. 34-38.

${ }^{284} \mathrm{Zu}$ Werkstätten s. Lang-Auinger 2007, 125. 126; zur Herstellung: Lang-Auinger 2003, 209-212.

${ }^{285}$ Lang-Auinger 2007, 136-138 bes. TK 24 Taf. 42.

286 Vgl. Lang-Auinger 2007, 162 TK 99 Taf. 53.
} 

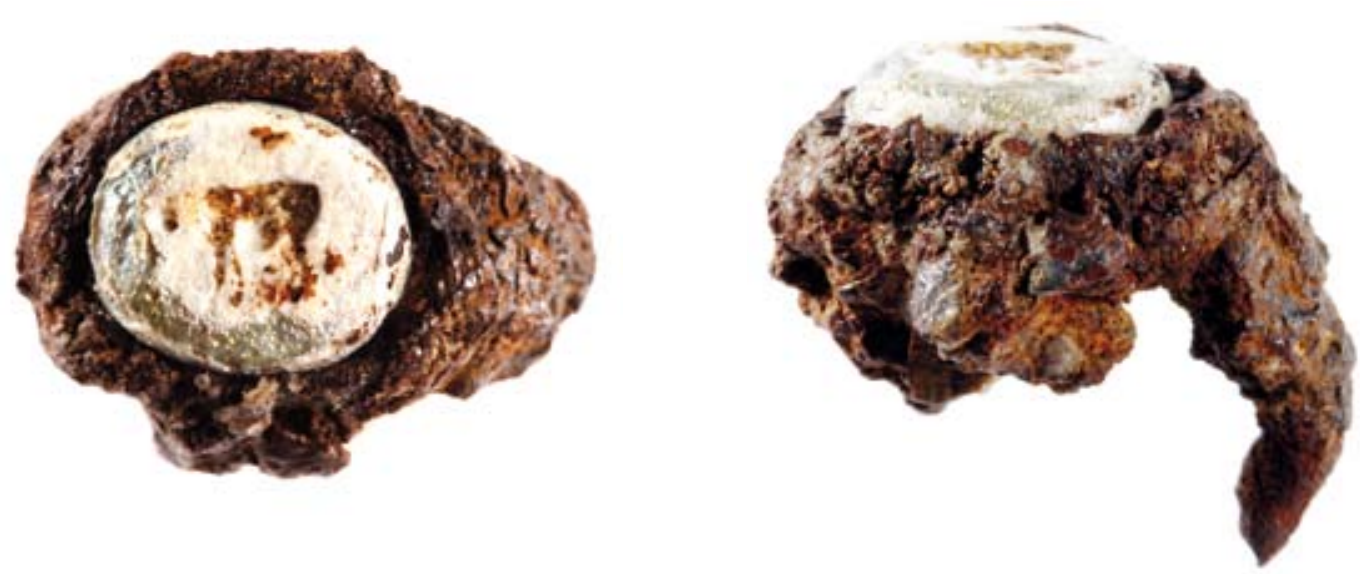

21 a. b Ring Kat. 193 mit Gemmenstein, Seitenansicht und Aufsicht

Aus Stratum 2 stammen zwei Entenköpfe. Sie sind flach, weiß bemalt, die Augen wurden extra aufgesetzt (Taf. 10, 180). Für die Enten ließen sich keine Parallelen in den Hanghäusern oder der Basilika finden. Ebenfalls aus Stratum 2 ist ein Fragment mit lockigem Kopfhaar und Blätterkranz erhalten (Dionysos?), ein weiteres Fragment ist undefinierbar. Eine Produktion der Stücke in Ephesos ist wahrscheinlich. Augrund des starken Fragmentierunsgzustandes sind genauere Datierungen aber nicht möglich.

\section{Sonstige Kleinfunde}

\subsection{Glas}

Zwei Fragmente zählen zu Glasgefäßen. Das milchig weiße Randstück gehört zu einer konischen Schale mit $12 \mathrm{~cm}$ im Randdurchmesser (Taf. 10, 185) ${ }^{287}$. Die weit ausgestellte Lippe ist gerundet und außen profiliert. Das zweite Fragment ist ein stark korrodiertes Wandstück mit bräunlicher Farbe. Beide Fragmente zeichnen sich durch ihre Dickwandigkeit und feine Schliffrillen im Innern aus, weshalb man sie als geformte Schalen identifizieren $\mathrm{kann}^{288}$. Zudem wurden drei Glassteine von Ringfassungen inventarisiert. Zwei Ringsteine aus Stratum 3 sind ovalförmig, auf einer Seite flach und auf der anderen gewölbt. Bei einem Ring (Kat. 187 Abb. 21 a. b) ist die eiserne Fassung in einem stark korrodierten Zustand erhalten. Der Ring zeigt eine Darstellung eines größeren Tieres (Kuh, Hirsch?). Ein hellgrüner Ringstein aus Stratum 1 besitzt die gleiche Form wie die anderen zwei Beispiele, hat jedoch bräunliche Flecken.

\subsection{Beinobjekte}

Es wurden drei Objekte aus Bein geborgen: eine Beinperle, bei der es sich um einen Spinnwirtel handeln kann $^{289}$, ein profiliertes Beinobjekt mit einer Bruchstelle, an dem etwas Röhrenförmiges angesetzt gewesen sein musste, und eine dicke, kurze Haarnadel (Taf. 10, 189) ${ }^{290}$.

\subsection{Metall}

Im Stratum 4 wurde ein Henkel aus Silber gefunden, der Teil eines Skyphos war. Der vertikale Henkel ist nicht geschlossen und an seiner oberen Auflagefläche (〉Daumenplatte $)$ mit Voluten verziert (Abb. 22 a. b).

\footnotetext{
${ }^{287}$ Czurda-Ruth 2007, Taf. 1. 2.

${ }^{288}$ Czurda-Ruth 2007, 24.

289 Trinkl 2003, 323 T 20 Taf. 153.

${ }^{290}$ Zum Gebrauch der Haarnadeln s. Jilek 2003, 259.
} 

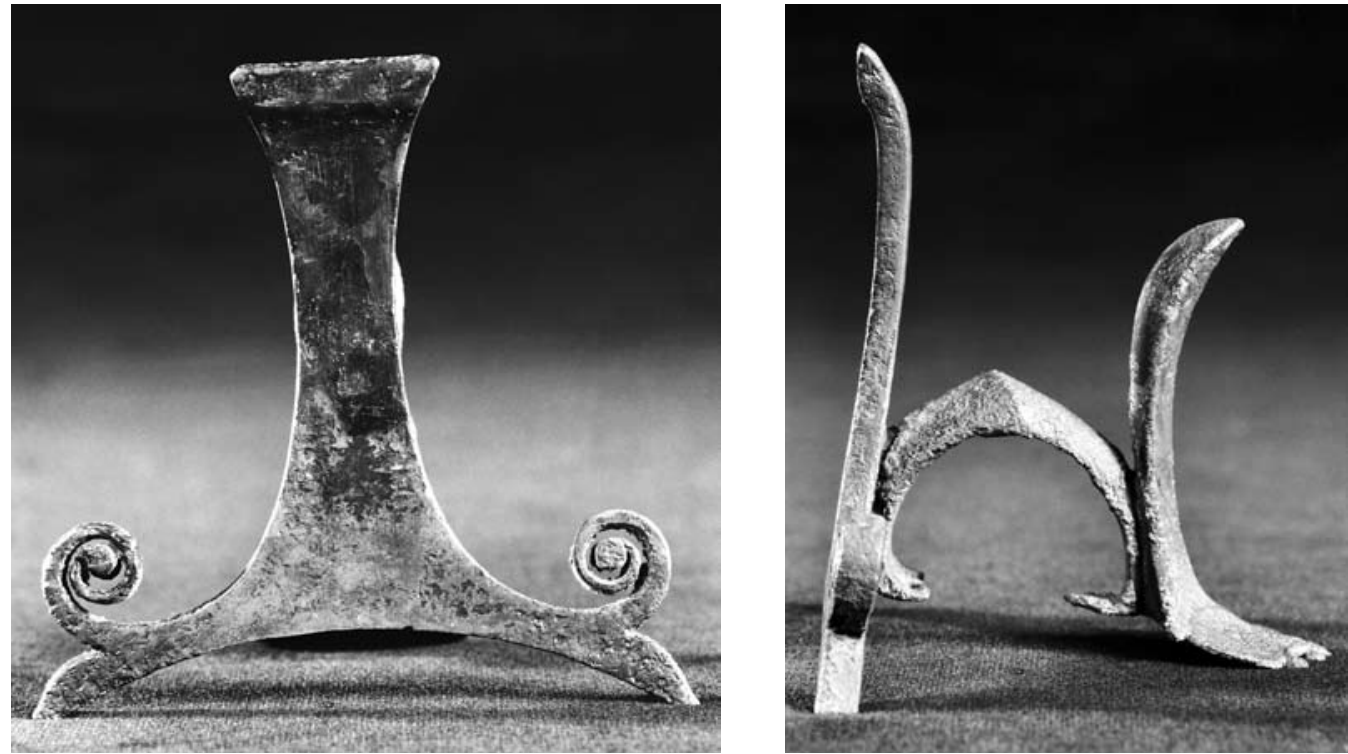

22 a. b Silberner Skyphoshenkel Kat. 192, Aufsicht und Seitenansicht

Solche Skyphoshenkel sind aus dem Hellenismus bekannt, keramische Analogien finden sich beispielsweise in Pergamon ${ }^{291}$.

Als weiteres Metallobjekt ist ein pyramidales Bleigewicht mit rechteckiger Grundfläche erhalten (Taf. 10, 171), das oben zwei Aufhängelöcher aufweist ${ }^{292}$. An der Unterseite lässt sich möglicherweise eine Abbildung vermuten, die jedoch aufgrund des schlechten Erhaltungszustandes nicht interpretiert werden kann.

\subsection{Wandmalerei}

Im Fundkomplex wurden kleinste Fragmente von Wandmalerei gefunden, die zwischen 1,4 und 5,5 cm groß sind. Es handelt sich dabei um Stuckplatten, die sich besonders durch ihren kompakten, hellen Mörtel und die geglättete Oberfläche auszeichnen ${ }^{293}$. Nach einer stichprobenartigen Sichtung des Materials wurden sie von B. Tober durchweg in die späthellenistische Periode datiert. Die Fragmente werden durch ihre Farben (lindgrün, weiß, schwarz, gelb, rosa) und besonders durch ihre Kanten charakterisiert: Sie gehören dem ১Östlichen Ersten Stil an ${ }^{294}$.

\section{Analyse}

Die Auswertung der Stratigraphie lässt erkennen, dass die vier Straten einen geschlossenen und nicht vom kaiserzeitlichen Bodenhorizont gestörten Komplex bilden. Für die grobe Datierung werden die Münzfunde, für die allerdings eine lange Laufzeit vorausgesetzt werden muss, herangezogen. Das erhaltene keramische Material liefert zwar konkretere, aber eben nur relativchronologische Indikatoren, durch welche der Fundkomplex in den Späthellenismus datiert werden kann ${ }^{295}$. Letztmöglicher Zeitpunkt für die Datierung ist die Errichtung des Hanghauses 2 in augusteisch-tiberischer Zeit. Als grobe Eckdaten für die vier Straten dient also der Zeitraum zwischen 150 v. Chr. bis zum ersten Viertel des 1. Jahrhunderts n. Chr. (Abb. 23).

\footnotetext{
291 Hübner 1993, Taf. 6, Nr. 47.

292 In Ton: Trinkl 2003, T 11. T 19 Taf. 152.

293 Vergleichsmaterial ist in nächster Nähe, im Nordumgang des Peristylhofs 31a, bei den Grabungen des Jahres 2004 zutage gekommen. Ladstätter 2005c, 269 Abb. 28.

${ }^{294}$ Vgl. dazu: Ladstätter 2005c, 247-276; Zimmermann u. a. (in Druck).

${ }^{295}$ Beispielsweise ist das Aufkommen von Grauer Ware mit schwarzem Überzug und Sigillata in den frühsten Schichten ein Indikator dafür.
} 


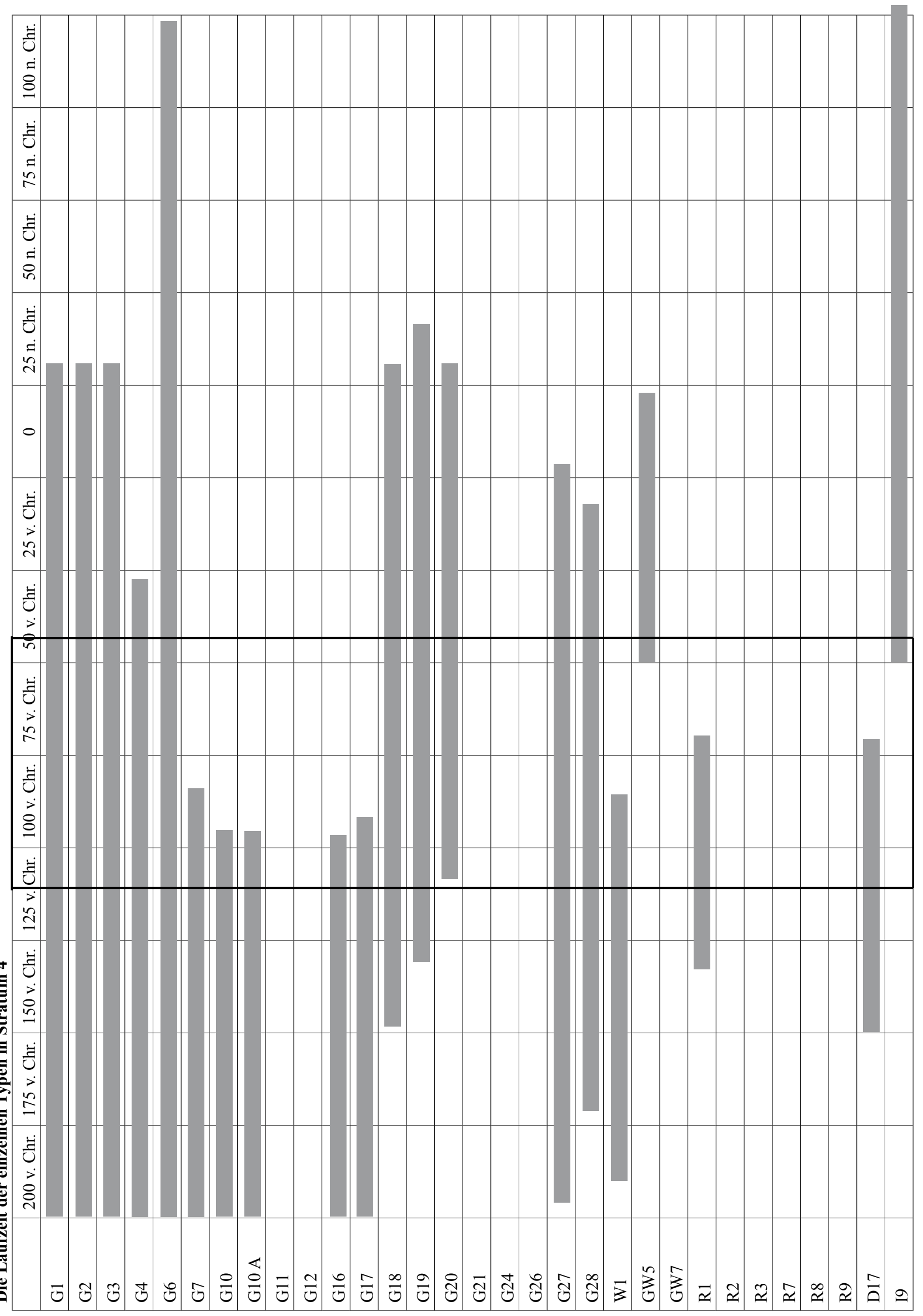




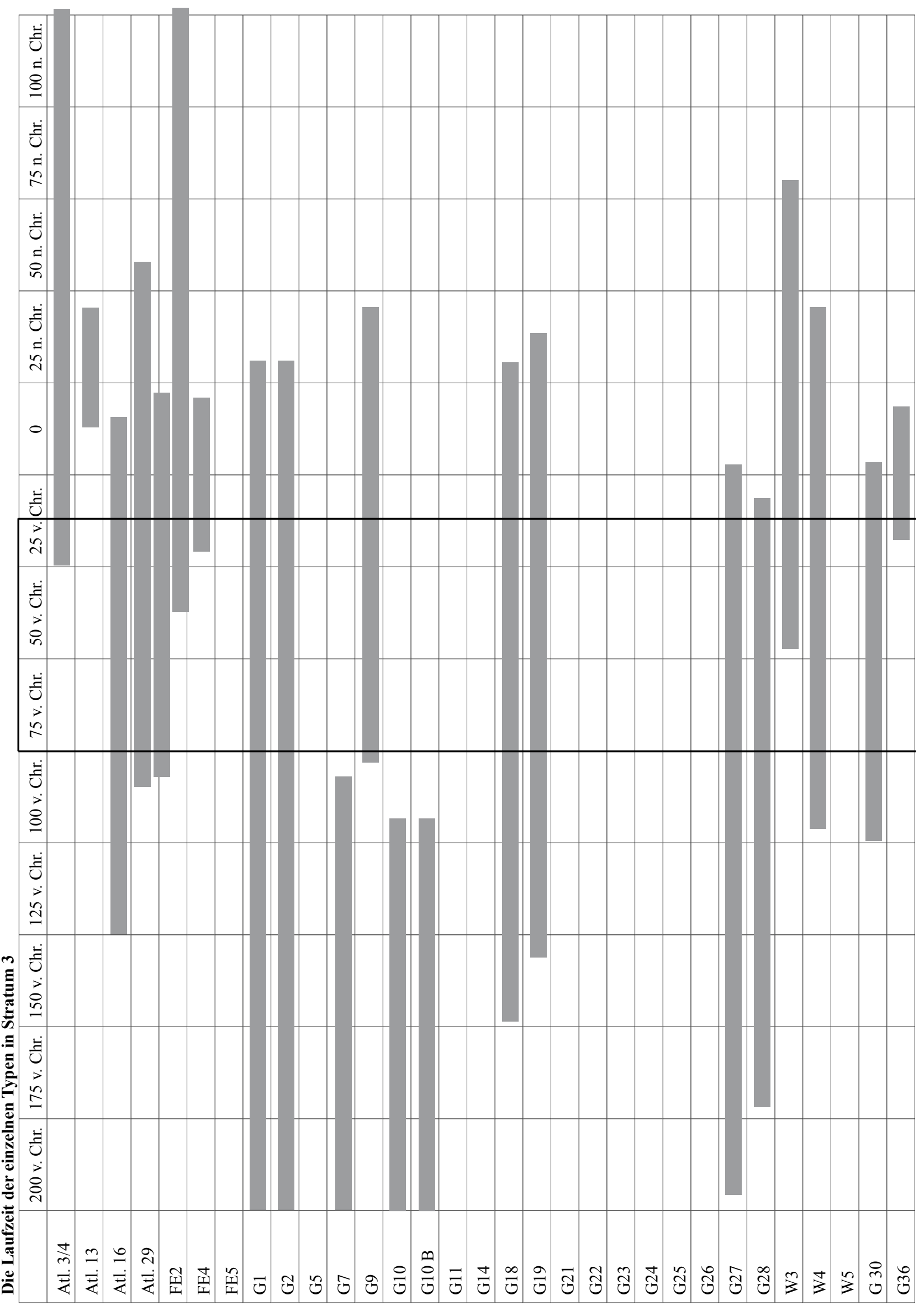




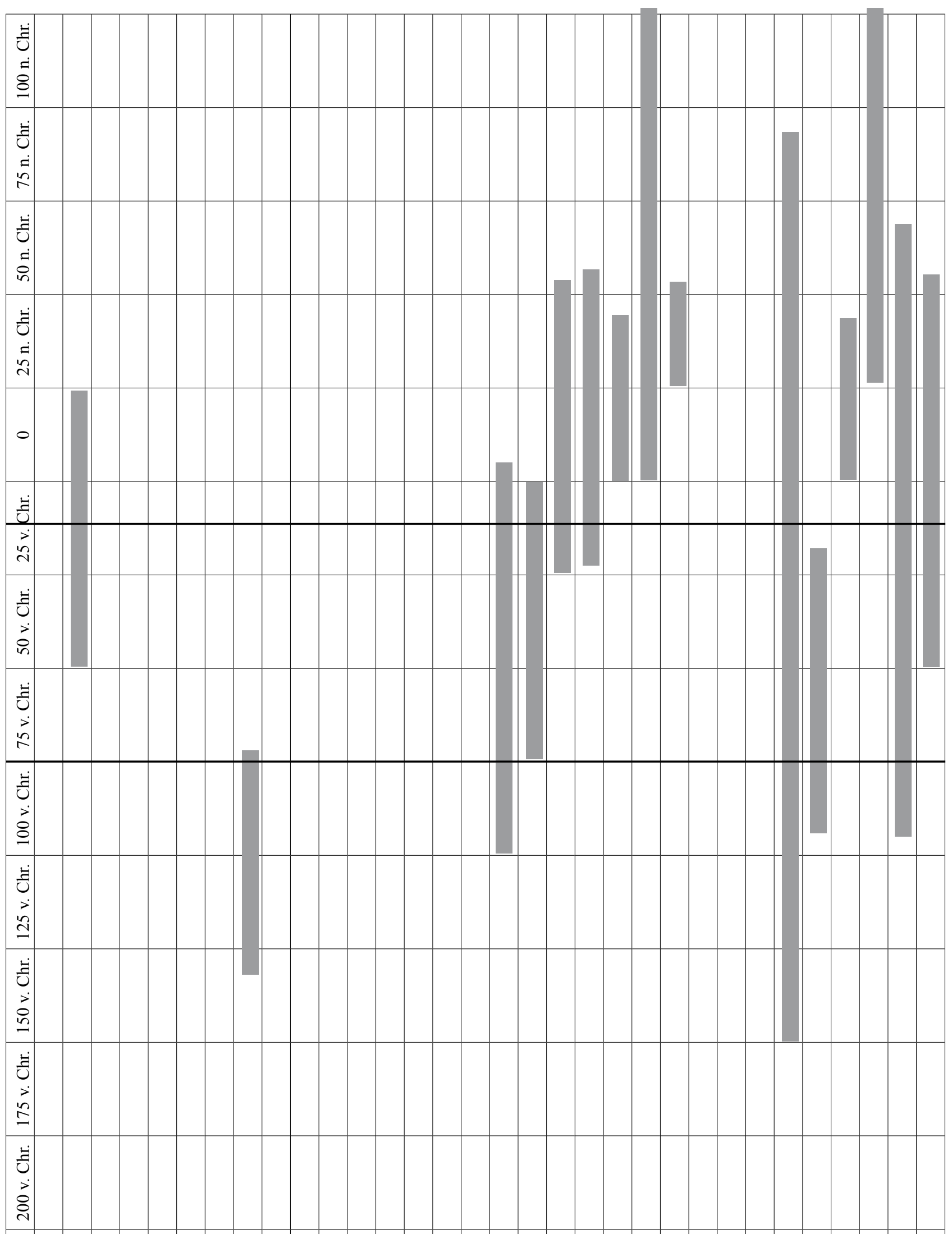

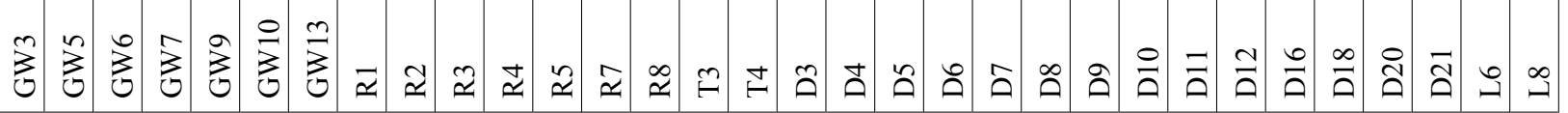




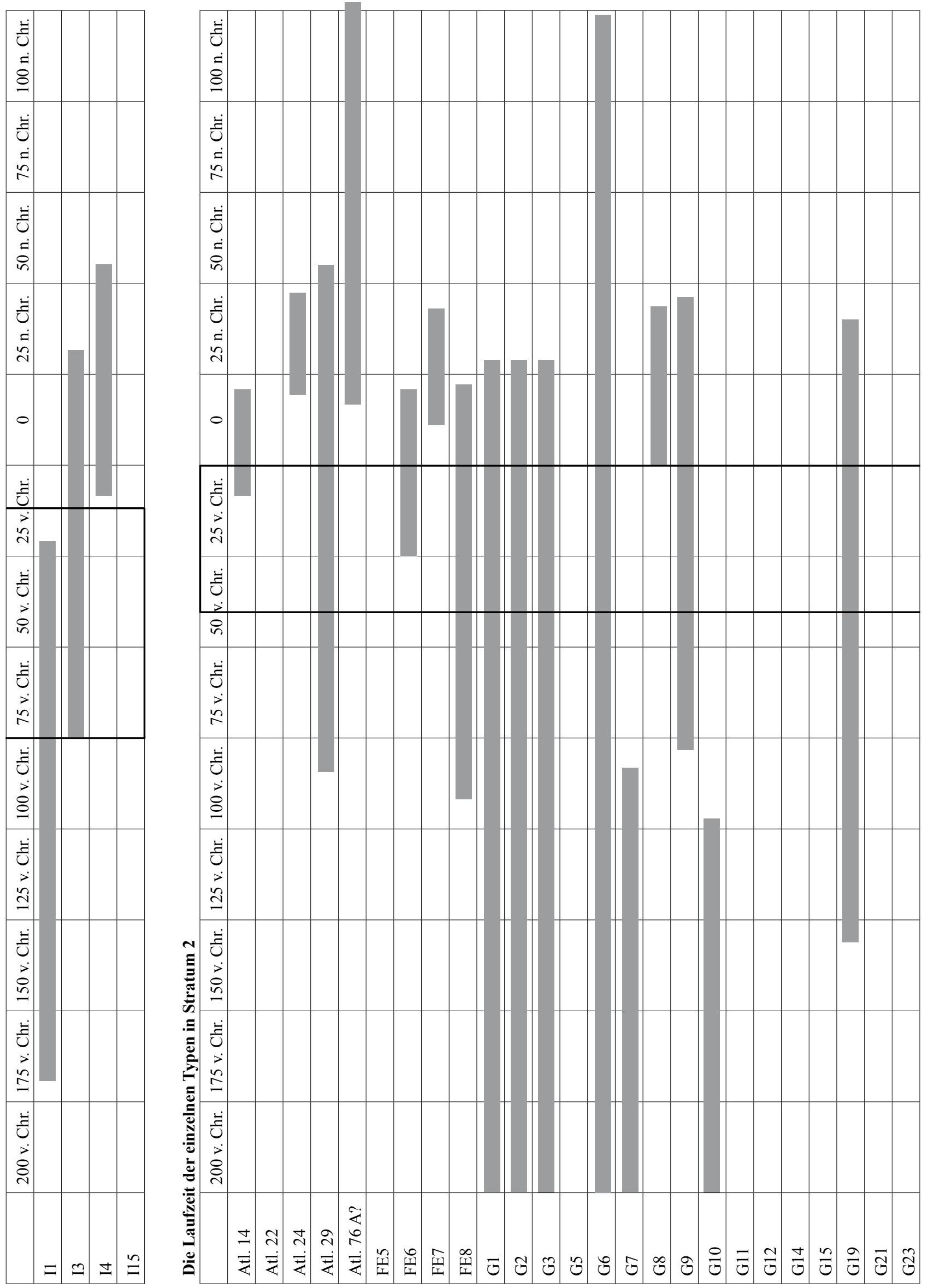




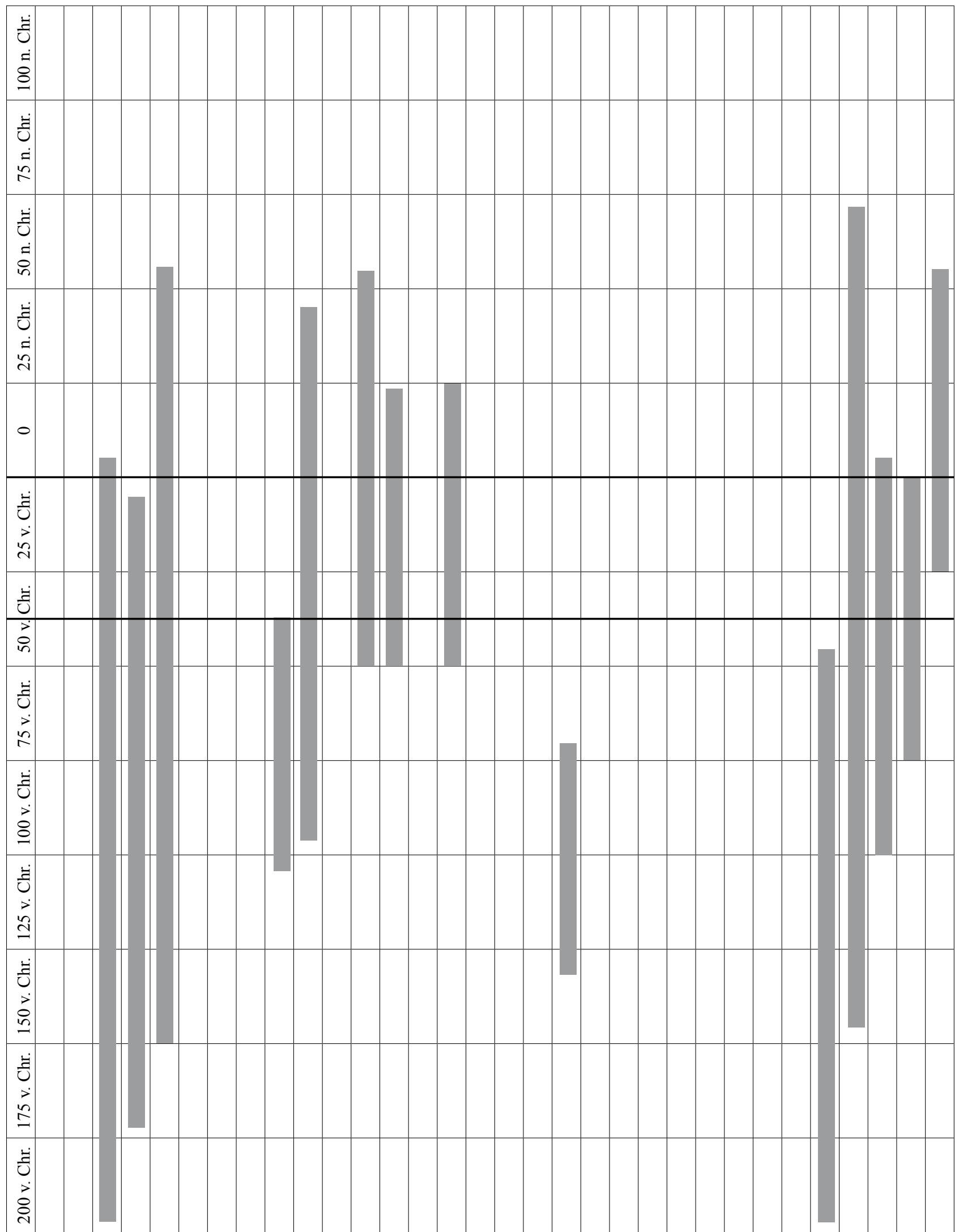

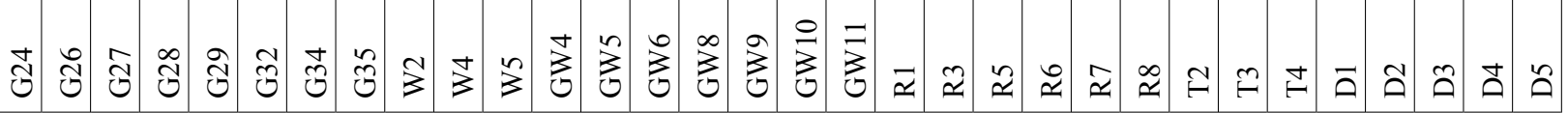



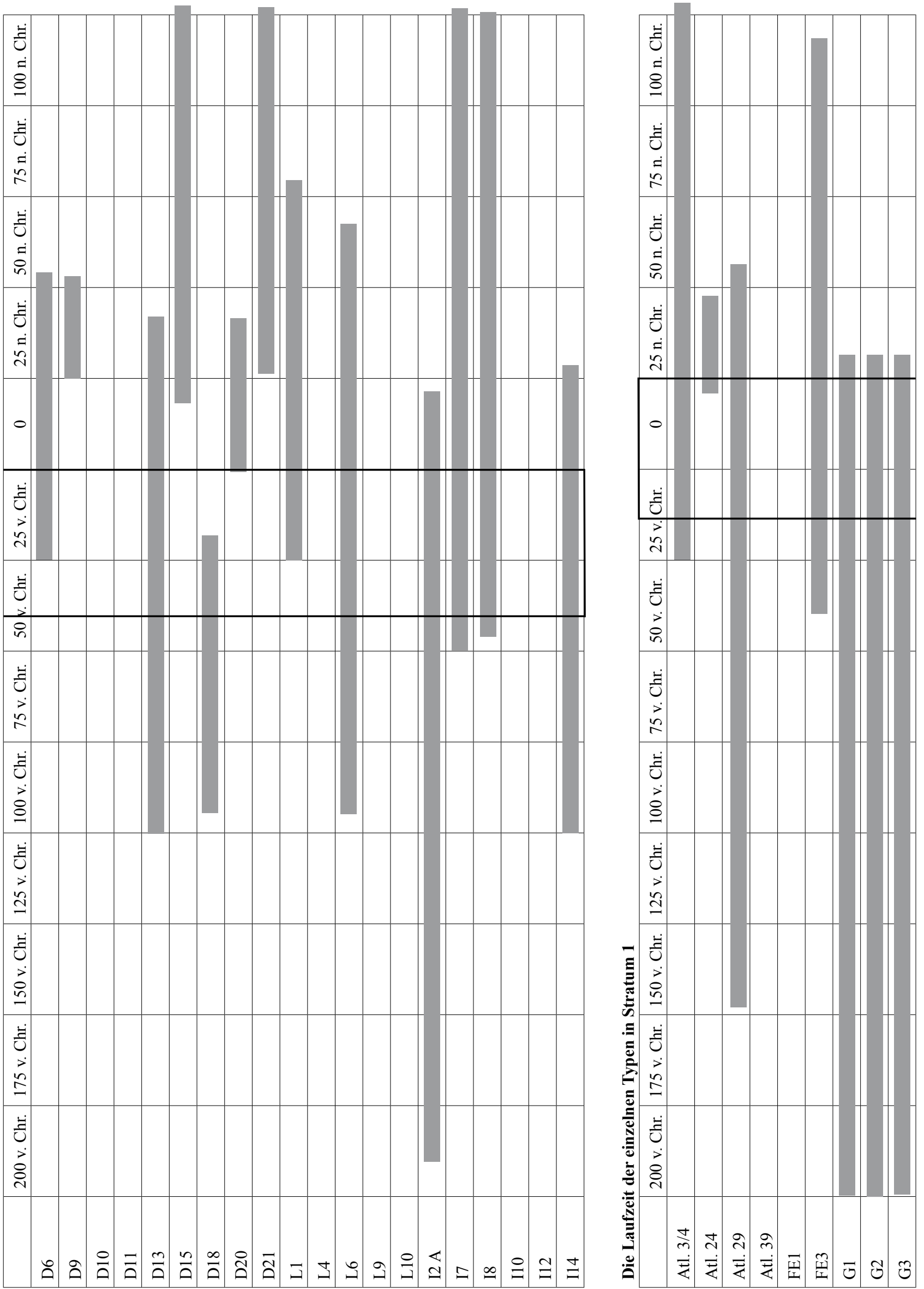


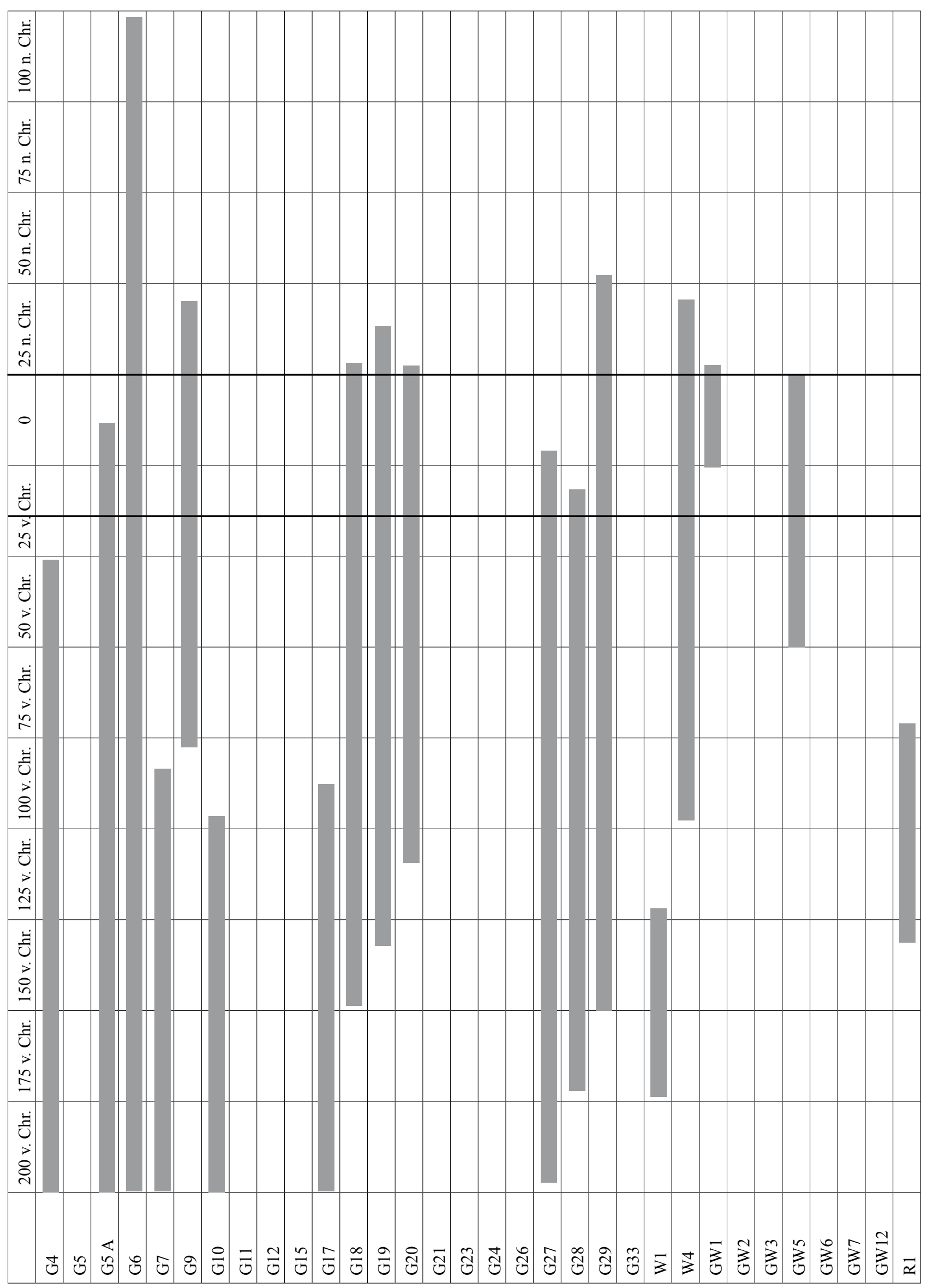




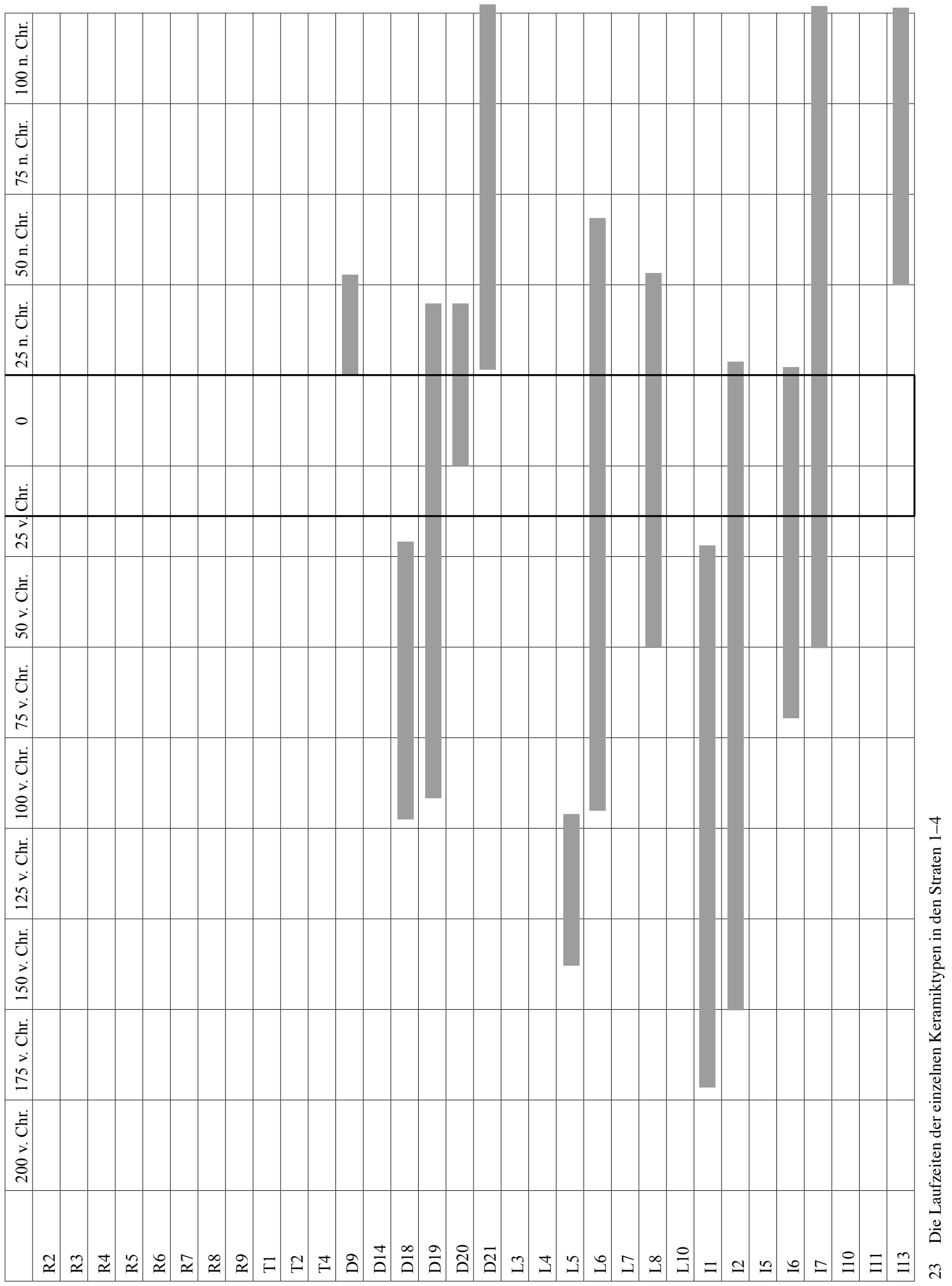


Beginnend mit Stratum 4 weisen einige Indikatoren dieses in das letzte Viertel des 2. Jahrhunderts v. Chr.: das Einsetzen des Tellers mit eingerollter Lippe (G20), der importierte, dünnwandige Becher mit Barbotinedekor, das Verschwinden der Tellerform G16, vor allem aber das geringe Aufkommen von Grauer Ware mit schwarzem Überzug und der `Ephesos-Lampen` sowie das Fehlen von ESA. Die numismatischen Funde deuten in die erste Hälfte des 3. Jahrhunderts v. Chr. Dies spricht jedoch aufgrund der gegebenen langen Laufzeit bei Geldmitteln nicht gegen die vorgeschlagene Datierung. Die Qualität der Schicht, wie sie oben beschrieben ist, deutet auf keinen langen Zeithorizont. Als Endpunkt ist die Mitte des 1. Jahrhunderts v. Chr. zu betrachten. Die Laufzeit zweier Typen beginnt gerade erst: Es handelt sich um die importierte Schale 19, welche in Pergamon erst in späteren Komplexen auftritt, und um Typ GW5, der seine späte Datierung aus Fundkomplexen in Ephesos und vom Magdalensberg erhalten hat.

Bei den beiden mittleren Straten handelt es sich um Auffüllschichten, die wahrscheinlich im Zuge einer Fundamentierung, gegebenenfalls auch für deren Ausbesserung, umgelagert wurden. Dies passierte in einer Zeitspanne zwischen dem dritten und dem letzten Viertel des 1. Jahrhunderts v. Chr. ${ }^{296}$. Das Fundmaterial ist sich sehr ähnlich, weshalb es unmöglich scheint, gut fundierte Fixpunkte als zeitliche Trennungslinie zu setzen; Abbildung 23 veranschaulicht, dass die Schnittmengen miteinander verschwimmen.

Ein Umbruch, der sich besonders bei den Trinkgefäßen manifestiert, ist bei der Wahl des Tischgeschirrs zu erkennen. Während in Stratum 4 sieben Becherformen verschiedener Gattungen vorhanden sind, setzen im dritten Stratum vierzehn Bechertypen allein der Dünnwandigen Ware ein. Davon sind zehn Typen jeweils einmal belegt, was auf ein erstes Auftreten der Form hinweist. Da die Typen in Ephesos zumeist in späteren Fundkontexten belegt sind, scheinen ein früherer Zeitansatz sowie die lokale Produktion für die Dünnwandige Ware in Ephesos evident. Neben den dünnwandigen Bechern wird das Repertoire durch häufiger in Erscheinung tretende Reliefbecher, Knidische Schalen, Skyphoi in WAN und den pergamenischen Skyphos I3 mit Efeusträußchen, der in Pergamon ab 75 v. Chr. produziert wurde, bereichert. Die vermehrt auftretenden Platten in Grauer Ware teilen sich den Anteil an Tellerformen mit den quantitativ stark abnehmenden Tellern in Glanztonware. Als chronologischer Indikator ist das Einsetzen von ESA-Formen zu werten. Die einzige bestimmbare Münze, die zwischen 202 und 133 v. Chr. emittiert worden ist, spricht, wie schon die Münzen von Stratum 4, nicht gegen eine Datierung dieses Stratums in das dritte bis letzte Viertel des 1. Jahrhunderts v. Chr.

Aus den Schnittstellen in Abbildung 23 ergibt sich für Stratum 2 die Zeitspanne der zweiten Hälfte des 1. Jahrhunderts v. Chr. Dass die römische Präsenz zunehmend verstärkt wurde, bemerkt man in der Zunahme von Gefäßformen in östlicher Sigillata. In Stratum 2 steht die ESB mit der Frühen ESB zwar quantitativ hinter Stratum 3, jedoch wird hier die größte Formenvielfalt erreicht. Zudem ist der vermehrte Rückgriff auf importierte Waren auffallend. Engere Datierungsindikatoren sind die hohe Schale I8 aus Pergamon, die ab der Mitte des 1. Jahrhunderts v. Chr. produziert wurde, die Teller GW8 und GW4, die in Ephesos um die Mitte des 1. Jahrhunderts v. Chr. vorkommen, und die Oinochoe mit Applik, die aufgrund der Maskengestaltung spätestens bis in die 60er Jahre des 1. Jahrhunderts v. Chr. datiert wird.

Stratum 1 unterscheidet sich in seiner keramischen Vergesellschaftung von Stratum 2. Das Spektrum der Glanztonware ist zwar annähernd gleich, jedoch existiert kaum Sigillata; ebenso gehen WAN, Graue und Dünnwandige Ware zurück. Im Gegensatz dazu steigen Lampen, Reliefbecher und Importe z. T. beträchtlich an. Hervorzuheben ist, dass hier nicht von einem plötzlichen Wandel des Gattungsrepertoires auszugehen ist, vielmehr sind die Gründe dieser Entwicklung in der Funktion der Schicht zu sehen: Stratum 1 besteht zu 90\% aus grobem Baumaterial, das im Zuge der Erbauung des Hanghauses 2 verfüllt wurde. Dementsprechend zeigt die Keramik den neuesten >Müll aus der Umgebung. Durch zwei frühaugusteische Münzen (Mü 22 und Mü 24) kann ein terminus post quem für das Stratum mit dem Jahr 25 v. Chr. angegeben werden. Endpunkt ist die Errichtung des Hanghauses 2 in augusteisch-tiberischer Zeit.

Nach der Klassifizierung und zeitlichen Einordnung des Materials soll an dieser Stelle auch auf statistische Fragen eingegangen werden, da sich mittels tabellarisch dargestellter Quantitäten Rückschlüsse über Verteilung und Häufigkeit der Gattungen oder Typen ziehen lassen.

In Abbildung 24 wird die Gesamtverteilung der Feinkeramik des Fundkomplexes dargestellt. Daraus ist klar ersichtlich, dass die Glanztonware eine herausragende Stellung einnimmt. Die übrigen Gattungen

\footnotetext{
${ }^{296}$ Ein Indiz für die Datierung vor dem letzten Viertel des 1. Jhs. v. Chr. könnte das Fehlen jeglicher Augustus-Prägungen sein.
} 


\begin{tabular}{|l|c|c|}
\hline \multicolumn{3}{|l|}{ Verteilung der Warengattungen - Insgesamt (Individuen) } \\
\hline ESA & 27 & $3 \%$ \\
\hline ESB & 19 & $2 \%$ \\
\hline Frühe ESB & 10 & $1 \%$ \\
\hline Glanztonware & 448 & $48 \%$ \\
\hline WAN & 38 & $4 \%$ \\
\hline Graue Ware & 51 & $5 \%$ \\
\hline Reliefbecher & 91 & $10 \%$ \\
\hline Tongrundig & 14 & $1 \%$ \\
\hline Dünnwandig & 91 & $10 \%$ \\
\hline Weißgrundig & 34 & $4 \%$ \\
\hline Import & 33 & $4 \%$ \\
\hline Lampe & 79 & $8 \%$ \\
\hline
\end{tabular}

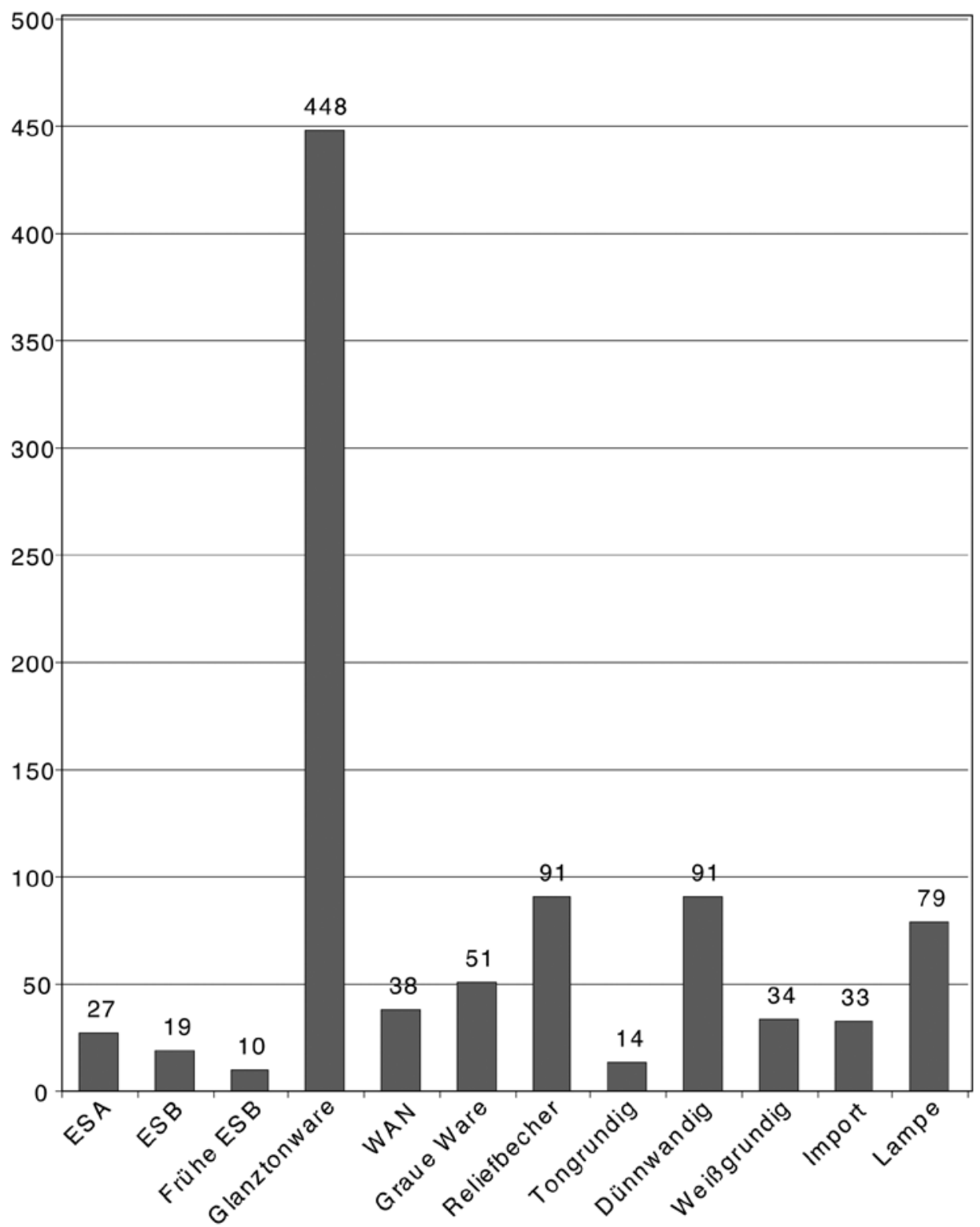

24 Gesamtverteilung der Feinkeramik des Fundkomplexes 
teilen sich den Restanteil relativ gleichmäßig auf. Auch bei anderen Fundkomplexen der kleinasiatischen Westküste - z. B. Samos, Delos und Knidos ${ }^{297}$ - trifft man auf ähnliche Verteilungen. Abbildung 25 zeigt eine genauere Analyse durch die separate Darstellung der einzelnen Straten. Stratum 4 setzt sich mit $81 \%$ Glanztonware vom Spektrum der anderen Straten, die zwischen $38 \%$ und $45 \%$ liegen, ab. Es wird vermehrt der ionische Reliefbecher (7\%) als Tischgeschirrergänzung bevorzugt. Der geringe Anteil an Typen der Dünnwandigen Ware, ESB und der Grauen Ware mit schwarzem Überzug lässt darauf schließen, dass sich diese Gattungen im Stadium ihrer frühesten Genese befanden. Tongrundige Ware und ESA treten hingegen noch gar nicht auf. Aufgrund des gehäuften Auftretens (Tab. 5) lassen sich für das Ende des 2. Jahrhunderts v. Chr./den Anfang 1. Jahrhunderts v. Chr. die Echinusschalen G1 und G2 sowie die Teller G 20 und G21 als feste Bestandteile eines Speiseservices rekonstruieren.

Tabelle 5: Häufigkeit der Gefäßtypen in den einzelnen Straten

\begin{tabular}{|c|c|c|c|c|}
\hline Тур & Stratum 1 & Stratum 2 & Stratum 3 & Stratum 4 \\
\hline Atl. 3/4 & 5 & 3 & 4 & \\
\hline Atl. 13 & & 1 & 3 & \\
\hline Atl. 14 & & 1 & 1 & \\
\hline Atl. 16 & & & 1 & \\
\hline Atl. 22 & & 6 & 6 & \\
\hline Atl. 24 & 1 & 3 & & \\
\hline Atl. 29 & 1 & 2 & & \\
\hline Atl. 36 & & 1 & & \\
\hline Atl. 39 & 2 & 1 & & \\
\hline $\begin{array}{l}\text { Atl. } \\
76 \text { A (?) }\end{array}$ & & 1 & & \\
\hline FE1 & 1 & & & \\
\hline FE2 & & & 1 & \\
\hline FE3 & 1 & & & \\
\hline FE4 & & & 1 & \\
\hline FE5 & & 1 & 2 & \\
\hline FE6 & & 1 & & \\
\hline FE7 & & 1 & & \\
\hline FE8 & & 1 & & \\
\hline G1 & 9 & 39 & 12 & 18 \\
\hline G2 & 12 & 11 & 3 & 31 \\
\hline G3 & 2 & 2 & & 7 \\
\hline G4 & 1 & & & 1 \\
\hline G5 & 1 & 2 & 1 & \\
\hline G5 A & 1 & & & 2 \\
\hline G5 B & & & & 1 \\
\hline G6 & 1 & 1 & & 1 \\
\hline G7 & 6 & 3 & 8 & 1 \\
\hline G8 & & 2 & & \\
\hline G9 & 3 & 4 & 2 & \\
\hline G10 & 2 & 3 & 2 & 3 \\
\hline G10A & & & & 1 \\
\hline G10 B & & & 1 & \\
\hline G11 & 1 & 1 & 1 & 1 \\
\hline G12 & 1 & 2 & & 1 \\
\hline G13 & & & & 1 \\
\hline
\end{tabular}

\begin{tabular}{|l|c|c|c|c|}
\hline Typ & Stratum 1 & Stratum 2 & Stratum 3 & Stratum 4 \\
\hline GW7 & 2 & & 1 & 1 \\
\hline GW8 & & 1 & & \\
\hline GW9 & & & 2 & 1 \\
\hline GW10 & & & 3 & 1 \\
\hline GW11 & & 1 & & \\
\hline GW12 & 1 & & & \\
\hline GW13 & & & 1 & \\
\hline R1 & 5 & 75 & 3 & 2 \\
\hline R2 & 1 & & 1 & 1 \\
\hline R3 & 4 & 7 & 1 & 1 \\
\hline R4 & 2 & & 6 & \\
\hline R5 & 2 & 2 & 1 & \\
\hline R6 & 2 & 1 & & \\
\hline R7 & 9 & 8 & 10 & 3 \\
\hline R8 & 6 & 5 & 3 & 2 \\
\hline R9 & 1 & 1 & & 2 \\
\hline T1 & 1 & & & \\
\hline T2 & 1 & 1 & & \\
\hline T3 & & 2 & 2 & \\
\hline T4 & 1 & 1 & 1 & \\
\hline D1 & & 3 & & \\
\hline D2 & & 1 & & \\
\hline D3 & & 1 & 1 & \\
\hline D4 & & 3 & & \\
\hline D5 & & 3 & 4 & \\
\hline D6 & & 1 & 1 & \\
\hline D7 & & & & \\
\hline D8 & & & & \\
\hline D9 & 1 & 4 & 5 & \\
\hline D10 & & & & \\
\hline D11 & & & & \\
\hline D12 & & & & \\
\hline D13 & & & & \\
\hline D14 & 1 & & & \\
\hline D15 & & & & \\
\hline
\end{tabular}

$\overline{{ }^{297} \text { Inventaraufstellungen bei } \operatorname{Rog} 12007,183-188 .}$ 
Tabelle 5 (Fortsetzung): Häufigkeit der Gefäßtypen in den einzelnen Straten

\begin{tabular}{|c|c|c|c|c|c|c|c|c|c|}
\hline Typ & Stratum 1 & Stratum 2 & Stratum 3 & Stratum 4 & \begin{tabular}{|l|} 
Typ \\
\end{tabular} & Stratum 1 & Stratum 2 & Stratum 3 & Stratum 4 \\
\hline G14 & & 2 & 2 & 1 & D16 & & & 1 & \\
\hline G15 & 1 & 1 & & & D17 & & & & 1 \\
\hline G16 & & & & 1 & D18 & 2 & 13 & 5 & \\
\hline G17 & $1 ?$ & & & 1 & D19 & 1 & & & \\
\hline G18 & 8 & & 4 & 4 & D20 & 4 & 4 & 4 & \\
\hline G19 & 5 & 2 & 2 & 1 & D21 & 3 & 3 & 1 & \\
\hline G20 & 1 & & & 6 & L1 & & 1 & & \\
\hline G21 & 5 & 2 & 2 & 18 & L2 & & & & 3 \\
\hline G22 & & & 1 & & L3 & 1 & & & \\
\hline G23 & 3 & 5 & 2 & & L4 & 1 & 1 & & \\
\hline G24 & 3 & 11 & 2 & 1 & L5 & 1 & & & \\
\hline G25 & & & 2 & & L6 & 3 & 2 & 1 & \\
\hline G26 & 5 & 5 & 2 & 1 & L7 & 1 & & & \\
\hline G27 & 13 & 7 & 5 & 6 & L8 & 1 & & 1 & \\
\hline G28 & 20 & 15 & 9 & 2 & L9 & & 5 & & \\
\hline G29 & 1 & 1 & & & L10 & 1 & 1 & & \\
\hline G30 & & & 1 & & I1 & 1 & & 1 & \\
\hline G31 & & & & 1 & I2 & 1 & & & \\
\hline G32 & & 1 & & & $\mathrm{I} 2 \mathrm{~A}$ & & 1 & & \\
\hline G33 & 1 & & & & I3 & & & 2 & \\
\hline G34 & & 1 & & & I4 & & & 1 & \\
\hline G35 & & 1 & & & I5 & 1 & & & \\
\hline G36 & & & 1 & & I6 & 1 & & & \\
\hline W1 & 2 & & & 1 & I7 & 3 & 1 & & \\
\hline W2 & & 1 & & & I8 & & 2 & & \\
\hline W3 & & & 1 & & I9 & & & & 1 \\
\hline W4 & 2 & 3 & 2 & & I10 & 1 & 1 & & \\
\hline W5 & & 4 & 1 & & I11 & 1 & & & \\
\hline GW1 & 1 & & & & I12 & & 1 & & \\
\hline GW2 & 1 & & & & I13 & 1 & & & \\
\hline GW3 & 1 & & 1 & & I14 & & 1 & & \\
\hline GW4 & & 1 & & & I15 & & & 1 & \\
\hline GW5 & 2 & 5 & 2 & 1 & I16 & & 1 & & \\
\hline GW6 & 1 & 5 & 3 & & Lampe & 23 & 34 & 13 & 5 \\
\hline
\end{tabular}

Verteilung der Gefäßindividuen anhand der Warengattungen und getrennt nach Straten Stratum 1

\begin{tabular}{|l|c|c|c|c|c|c|c|c|c|c|c|c|}
\hline \hline & ESA & ESB & Frühe ESB & Glanzton & WAN & Graue W & RB & Tongrundig & Dünnwandig & Weißgrundig & Import & Lampen \\
\hline Gesamt & 5 & 3 & 2 & 114 & 9 & 12 & 34 & 4 & 16 & 14 & 12 & 23 \\
\hline
\end{tabular}

\section{Stratum 2}

\begin{tabular}{|c|c|c|c|c|c|c|c|c|c|c|c|c|}
\hline \hline & ESA & ESB & Frühe ESB & Glanzton & WAN & Graue W & RB & Tongrundig & Dünnwandig & Weißgrundig & Import & Lampen \\
\hline Gesamt & 11 & 11 & 4 & 141 & 17 & 27 & 27 & 7 & 46 & 14 & 11 & 34 \\
\hline
\end{tabular}

Stratum 3

\begin{tabular}{|l|c|c|c|c|c|c|c|c|c|c|c|c|}
\hline Gesamt & ESA & ESB & Frühe ESB & Glanzton & WAN & Graue W & RB & Tongrundig & Dünnwandig & Weißgrundig & Import & Lampen \\
Stratum 4 4 & 5 & 4 & 82 & 10 & 10 & 21 & 3 & 28 & 5 & 9 & 14 \\
\hline \hline & ESA & ESB & Frühe ESB & Glanzton & WAN & Graue W & RB & Tongrundig & Dünnwandig & Weißgrundig & Import & Lampen \\
\hline Gesamt & 0 & 0 & 0 & 111 & 2 & 2 & 9 & 0 & 1 & 1 & 1 & 8 \\
\hline
\end{tabular}

25a Verteilung der Warengattungen nach Straten 

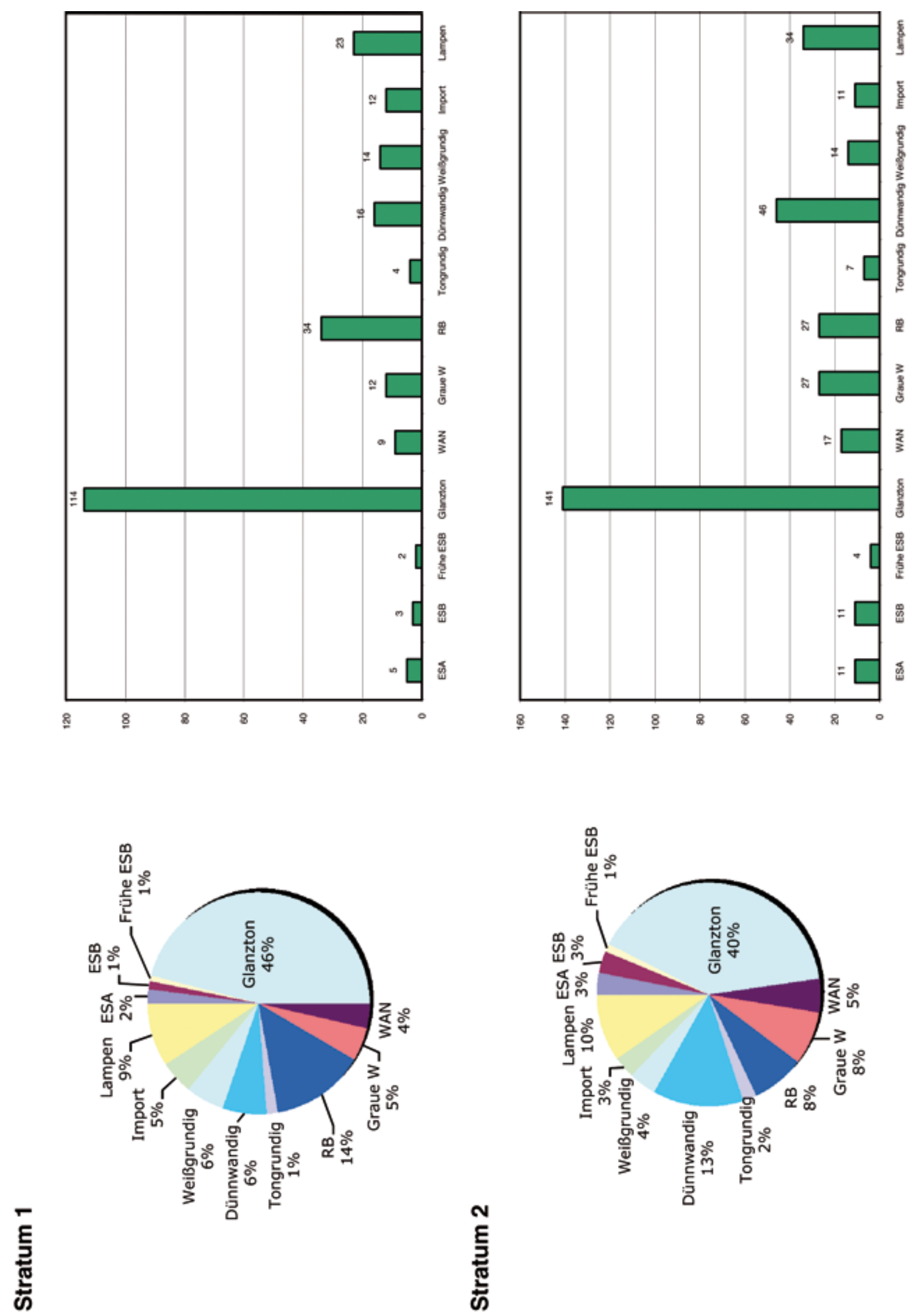

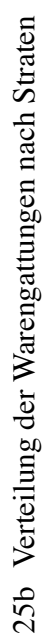



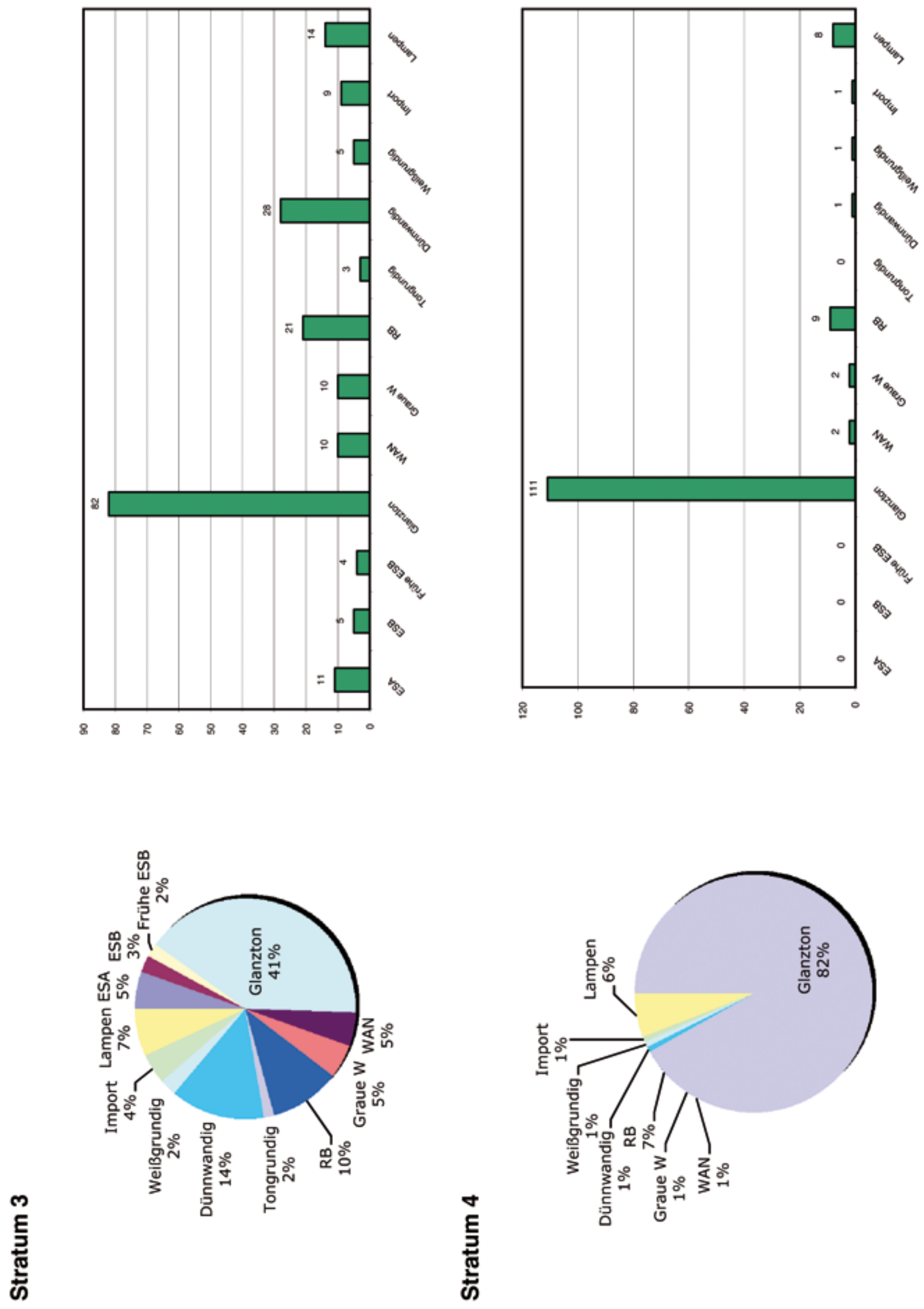

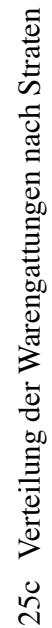


Im dritten Stratum sind zwar alle Warengattungen vertreten, jedoch liegt der Schwerpunkt auf den rot engobierten Sigillaten und der Dünnwandigen Ware. Die Bechertypen finden sich in beträchtlicher Anzahl, anscheinend festigen sie ihre Position bei Tisch. Die Erweiterung des Reliefbecher- und Lampenrepertoires spiegelt die Etablierung der Matrizentechnik wider. Eine klare Veränderung macht sich bei den Trinkgewohnheiten bemerkbar: Der Skyphos mit weiter Mündung (G10), wie er im 2. Jahrhundert v. Chr. sehr beliebt war, läuft aus und wird durch den Typ (G7) der Knidischen Schale und die Reliefbecher ersetzt. Die Trinkgefäße aus Irdenware werden nun auch zahlenmäßig stärker. Entweder wurden vorher mehr Schalen mit geraden oder ausbiegenden Rändern zum Trinken benutzt oder, was wahrscheinlicher ist, die metallenen Vorbilder wurden ersetzt. Dahinter steckt wohl kein ökonomischer Abstieg, sondern ein Prinzip, dass bis zum heutigen Tag angewandt wird, bei dem günstige, doch nicht qualitätslose Ware in Massen hergestellt und überaus gern vom Endkonsumenten aufgenommen wird - dadurch wird ein viel größerer Markt geschaffen. Die ESB nimmt in der Menge und auch in der Formvielfalt anteilig stark zu. Während man im Späthellenismus Ware mit schwarzem und rotem Glanztonüberzug produzierte, deren rote Engobe immer etwas matter als die schwarze blieb, änderte sich dies mit der Sigillata. Es scheint eine neue technische Errungenschaft zu sein, den Überzug glasig und glänzend herzustellen.

Typ G1 erlebt in Stratum 2 noch einmal einen immensen Aufschwung, hingegen sind die Teller der Glanztonware dürftig vorhanden und werden durch die Graue Ware substituiert. Im Allgemeinen lässt sich ein Rückgang von Tellerformen und ihren Mengen verzeichnen. Nur G18, der Teller mit unterschnittenem Rand, wird in Stratum 1 anteilsmäßig wieder stärker. Die dünnwandigen Becher nehmen im Vergleich zu Stratum 2 in Stratum 1 wieder um die Hälfte ab, allerdings ist ein leichter Anstieg von Weißgrundiger Ware zu beobachten. Sie behält ihre Bedeutung bei häuslichen Riten, ihre Leitformen sind die Lagynos und das Thymiaterion (Abb. 26).

\section{Zusammenfassung}

Zusammenfassend lässt sich festhalten, dass Ephesos im Späthellenismus sehr stark von der lokalen Produktion abhängig war. Das frühe keramische Tischgeschirr ist in seiner Formensprache den hellenistischen Traditionen verhaftet ${ }^{298}$ und noch nicht so vielfältig wie in der augusteischen Epoche. Bevorzugt wurden einfache Schalen und Teller. Bei den Schalen ist die besondere Form der Echinusschale zum Charakteristikum für den gesamten Späthellenismus geworden. Sie verändert sich nicht formtypologisch, sondern in ihrem Dekor, der durch Stapeltechnik und die abwechselnd oxidierende und reduzierende Brenntechnik erreicht wird. Im 1. Jahrhundert v. Chr. wandelt sich das Keramikrepertoire langsam, aber stetig durch Zusätze, vor allem aus anderen Warengattungen. Eine entscheidende Wende in der Tellerform tritt durch das Aufkommen der Grauen Ware mit schwarzem Überzug am Ende des 2. Jahrhunderts v. Chr. (Stratum 4) ein. Die Teller sind nun mit einem dickeren, schwarz glänzenden Überzug versehen, der eine neue Qualität einleitet. Ihr Dekor entspricht den hellenistischen Verzierungen mit Stempeln von Palmetten oder Rauten, die schon auf der Glanztonware zu finden waren, ihre Form allerdings lehnt sich an die ESA-Teller an. Anscheinend war den ephesischen Töpfern schon früh die Ware aus dem syrischen Raum bekannt, die sie dann auch recht bald für ihre neu entwickelte Graue Ware mit schwarzem Überzug adaptierten. Die >Grauen Teller` erfreuen sich während des 1 . Jahrhunderts v. Chr. großer Beliebtheit, gleichzeitig verringert sich die Produktion von Tellern in Glanztonware und die jahrhundertelang gebräuchlichen Fischteller verschwinden vollständig. Die Graue Ware mit schwarzem Überzug entwickelt zwar weitere Gefäßformen, doch bleibt diese Gattung vornehmlich den Tellern und Platten vorbehalten. Diese >Grauen Platten`waren ein Aushängeschild von Ephesos und man verhandelte sie u. a. bis auf den norischen Magdalensberg.

Eine weitere Spezialität ephesischer Töpfer waren die Reliefbecher, die ebenfalls reduzierend gebrannt wurden und in ihrer Tonbeschaffenheit der Grauen Ware entsprechen. Einen ähnlichen Vergleich zieht L. Cornell für die Reliefbecher aus Tel Anafa, welche sie der ESA respektive der von K. Warner Slane `BSP (genannten Ware, die der Grauen Ware mit schwarzem Überzug entspricht ${ }^{299}$, gegenüberstellt.

${ }^{298}$ Ladstätter 2007, 206; Rogl 2007, 189.

299 Cornell 1997, 407. 


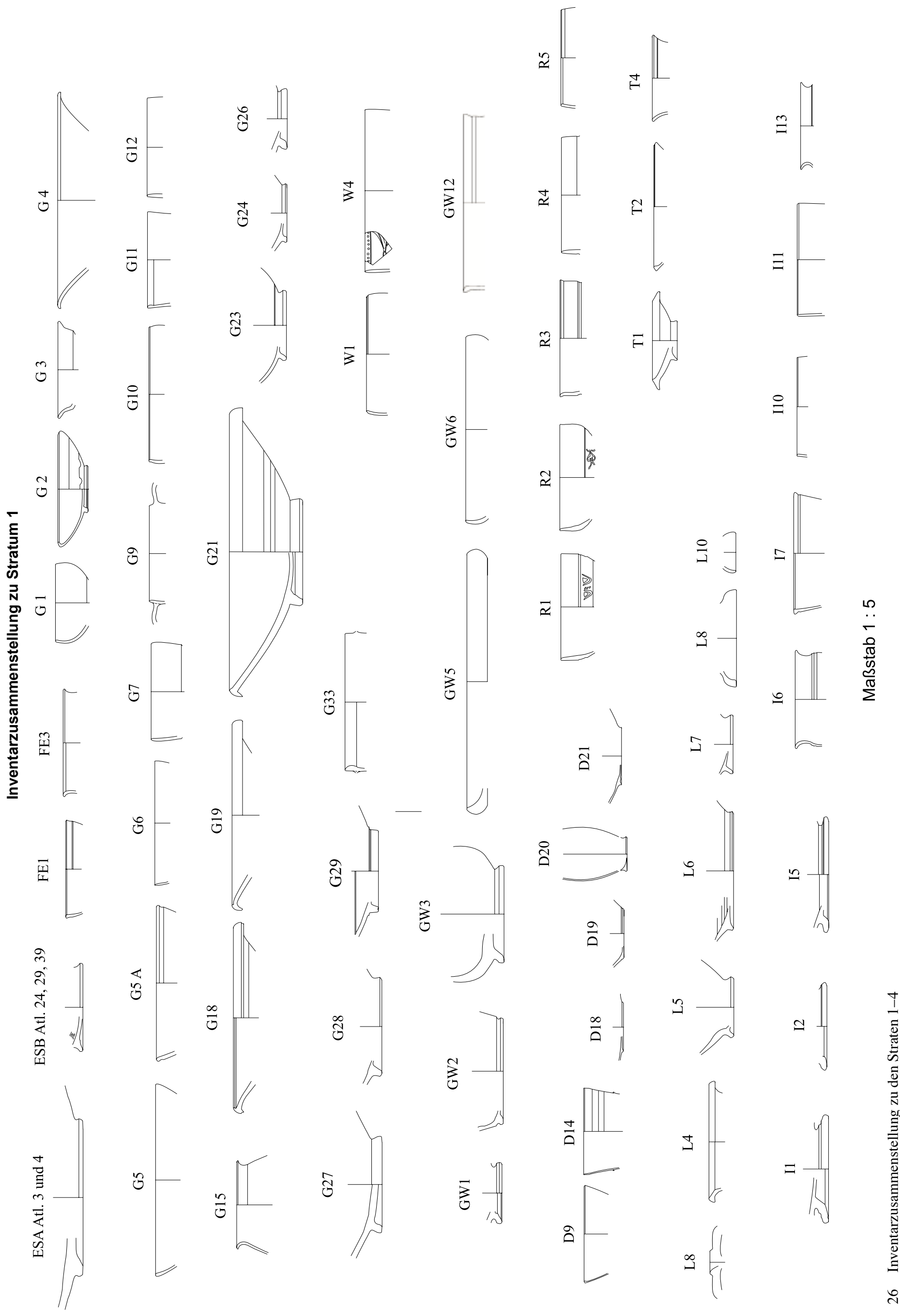




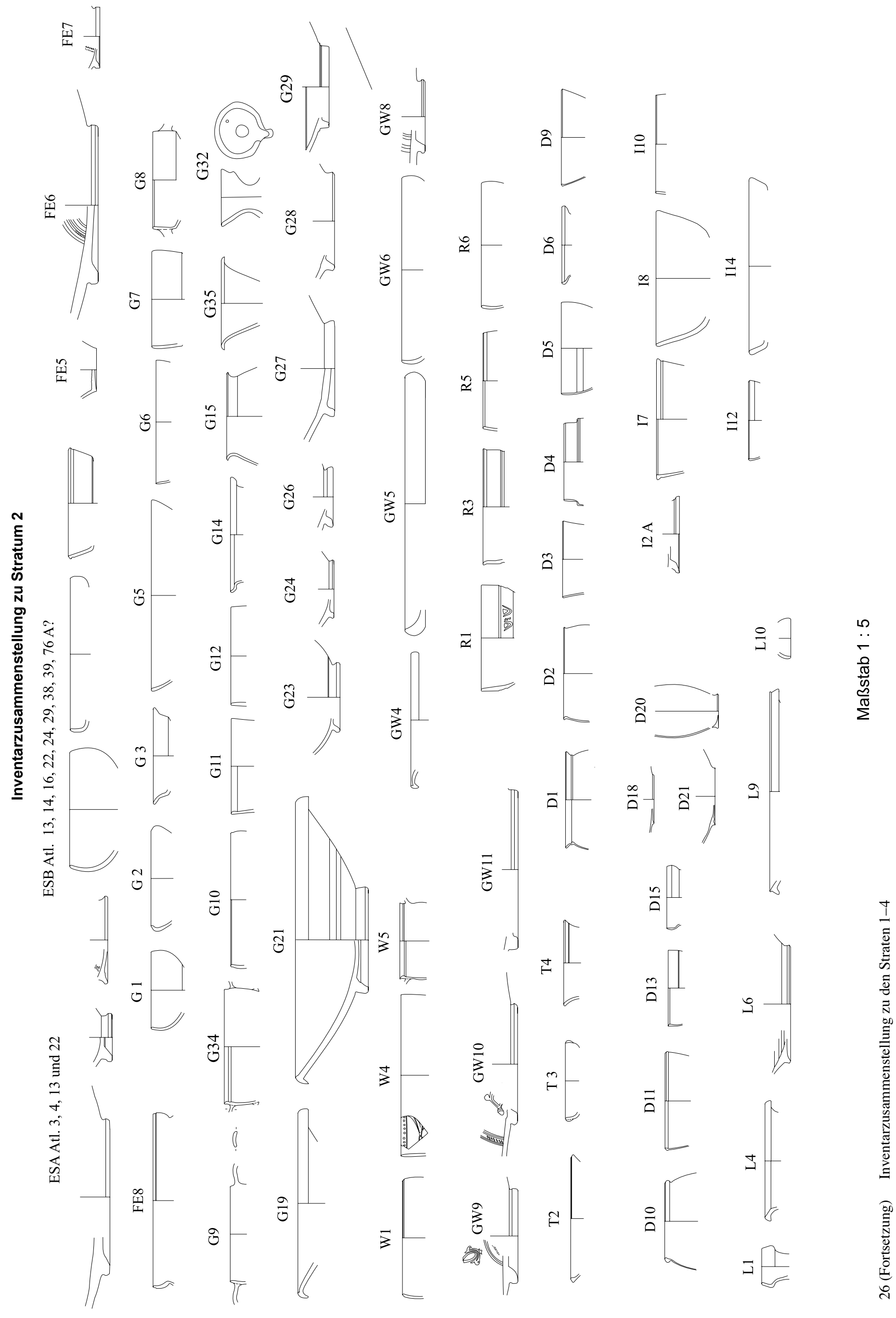




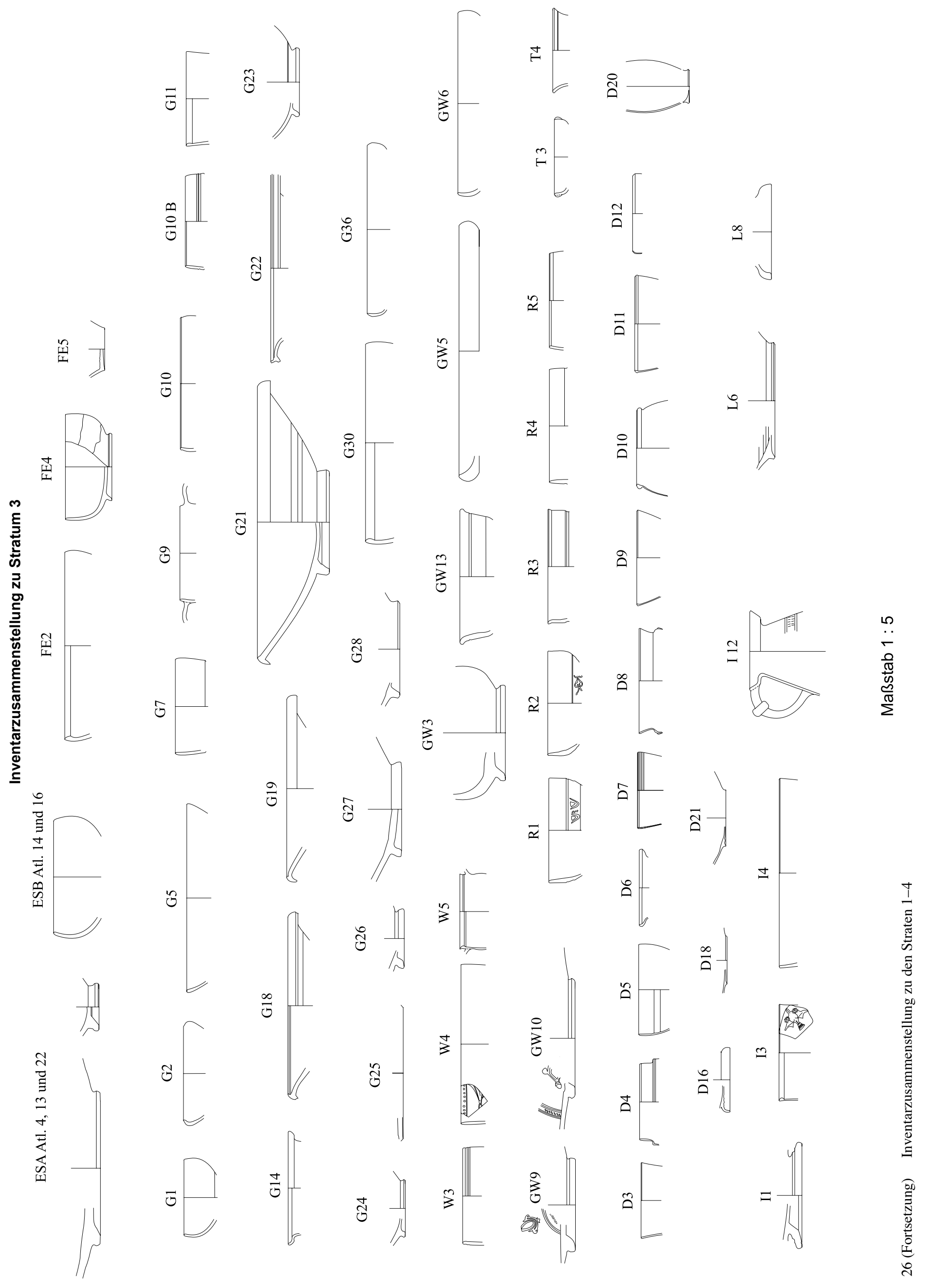




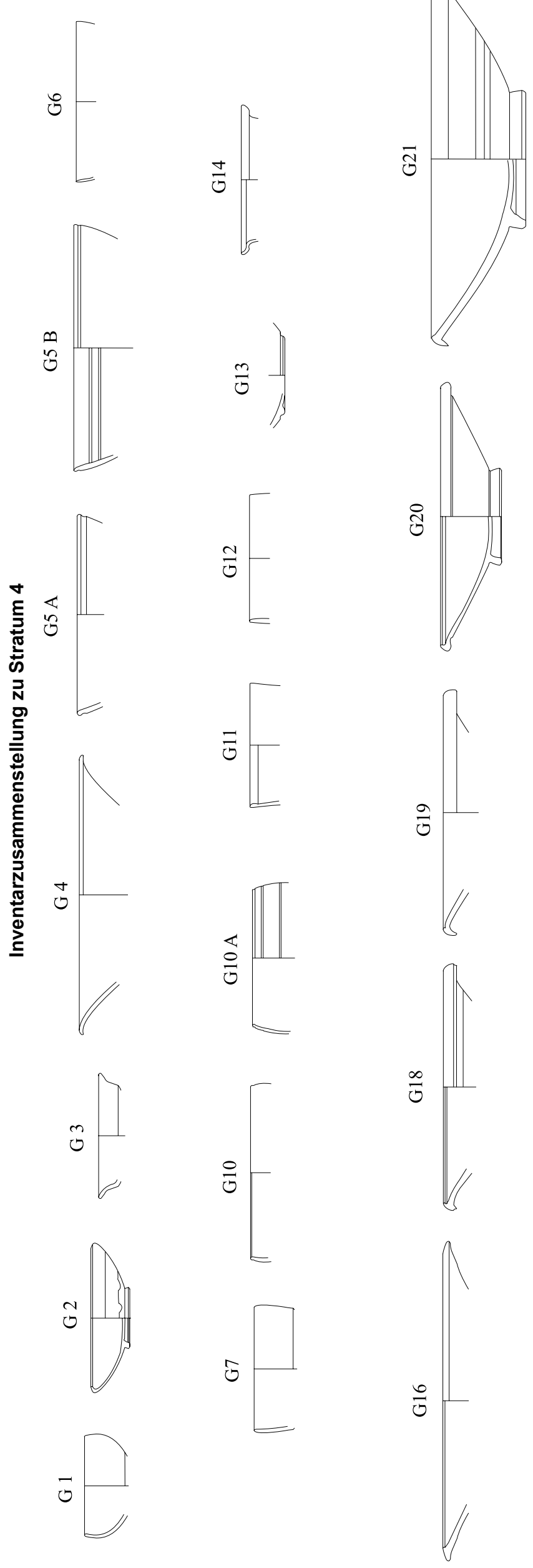

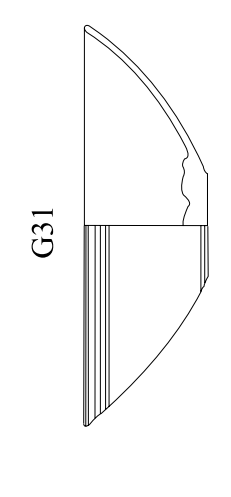
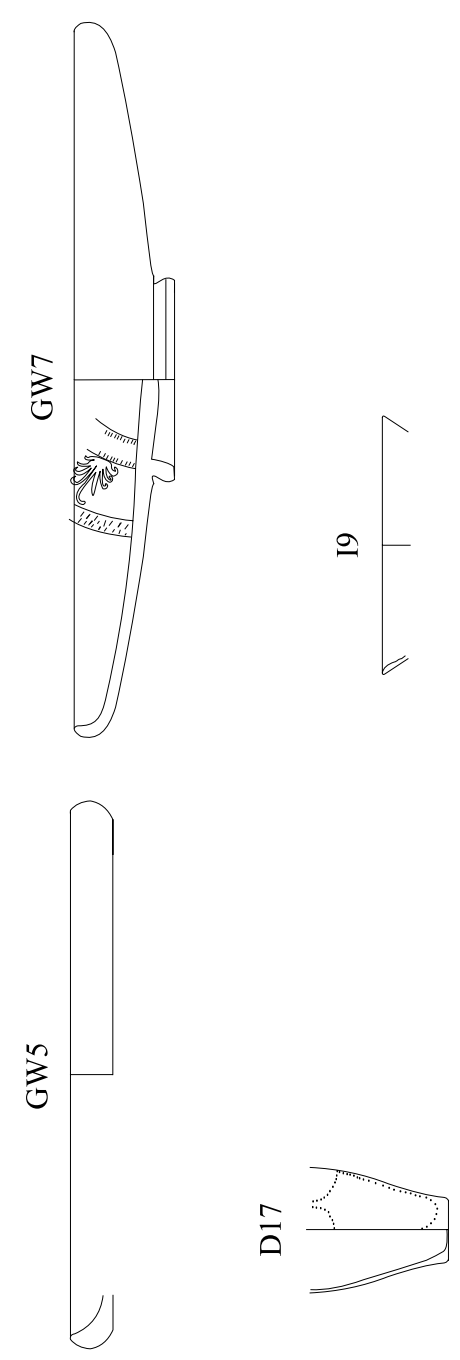

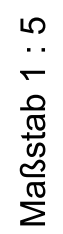

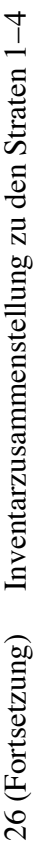


Als besonders innovativ ist die Kombination altbekannter Herstellungstechnik - die Becher werden in Modeln geformt - mit italischem Formenrepertoire anzusehen ${ }^{300}$. Das Herausragende ist dabei der Dekor, welcher durch Negativstempelung in der Matrize erzielt wird. Diese Technik erlaubt eine Massenproduktion der äußerst aufwendig dekorierten Ware. Die Gattung etabliert sich im ionischen Raum zu Anfang des 2. Jahrhunderts v. Chr. und erreicht einen weiten Exportradius. Sie entwickelt sich geradezu zu einem Exportschlager. Erste Filialbetriebe für die Produktion werden auf Samos gegründet ${ }^{301}$, und auch in Pergamon beginnen die dort ansässigen Töpfer, die Ware zu imitieren. In derselben Fabrikationstechnik entstehen auch die >Ephesos-Lampen<. Trotz unterschiedlicher Funktionen und trotz unterschiedlicher Punzenstempel gleichen die beiden Gattungen einander in der Dekorauswahl sehr. Generell werden bei beiden vegetabile oder ornamentale Motive favorisiert. Die `Ephesos-Lampen< setzten mit ihrer Produktion später ein und werden dann, wie die Reliefbecher, über den Hafen in Delos vertrieben. Der Export barg einen immensen ökonomischen Faktor für die Stadt Ephesos: Bis in das 1. Jahrhundert v. Chr. war damit eine bedeutende Einnahmequelle gesichert, die erst mit dem vermehrten Einsetzen der Sigillata und der italischen Lampen (z. B. Importe oder Red-on-White-Lampen) in der frühen Kaiserzeit langsam versiegte. Um die Mitte des 1. Jahrhunderts v. Chr. eröffnete schließlich die Sigillata einen neuen, großen Absatzmarkt. Als frühste Sigillata, die sich in das kleinasiatische Keramikrepertoire integrierte, kann die ESA genannt werden. In unserem Fundkomplex ist eine Zurückhaltung gegenüber der ESA, die sich erst langsam durchsetzte, zu bemerken. Allein die Teller Atlante 3/4 werden konstant genutzt.

Im Gegensatz dazu scheint die lokal produzierte ESB sehr schnell akzeptiert worden zu sein. Man kann davon ausgehen, dass sie nicht, wie ursprünglich angenommen, als Nachfolger der ESA hergestellt wurde, sondern sich selbstständig aus dem hellenistischen Formengut entwickelte. Anhand des Materials aus dem vorliegenden Fundkomplex muss der Beginn der ESB entgegen J. W. Hayes, der ihn an das Ende des 1. Jahrhunderts v. Chr. setzt, in das letzte Drittel des 1 . Jahrhunderts v. Chr. korrigiert werden ${ }^{302}$. Die Töpfer befanden sich offenbar in einer kurzen Experimentierphase, in der sie erstens die neue Technik an traditionellen Formen anwandten und zweitens die innovativen Gefäßtypen auf traditionelle Weise fertigten. Das Material zeigt jedoch, dass die lokalen Handwerker eher versucht waren, Sigillata, vor allem ESB, in ihrem optischen Erscheinungsbild zu imitieren. Im späten 1. Jahrhundert v. Chr. wurde das hellenistische Formengut weitestgehend belassen und die Töpfer orientierten sich vornehmlich am italischen Repertoire.

Es kamen verschiedene Mischformen zustande, die bis jetzt in keiner Katalogisierung zu finden sind. J. W. Hayes legte einen guten »Zwischenstand der Forschung $\aleph^{303}$ vor, doch die meisten Parallelen der Atlanteformen stammen aus Korinth. Da jedoch eine frühere ESB-Produktion in Ephesos belegt is $\mathrm{t}^{304}$, ist es unumgänglich, eine neue Klassifizierung, Typologisierung und Datierung für die Gattung zu erstellen. Die im Atlante beschriebenen ESB-Formen manifestieren sich erst in der frühen Kaiserzeit zu festen Typen. Für die Zeit davor kann die Benennung einer eigenen Gattung sinnvoll erscheinen, obwohl noch nicht absehbar ist, inwieweit sich eine eigene Morphologie ausgebildet hat. Die Phase des Experimentierens bildet einen kritischen Faktor in der Definition der ESB, weswegen die Klassifizierung einer eigenen Gattung mit dem Namen >Frühe ESB « empfohlen wird ${ }^{305}$. Die Produktion der Frühen ESB und der ESB sind in der Umgebung von Ephesos anzusiedeln.

Die Herkunft der Dünnwandigen Ware ist nicht eindeutig geklärt. Die meisten Forschungsmeinungen plädieren für eine Genese im Westen, mit einem Hauptproduktionsort auf Sizilien, doch lassen sich neuerdings Vermutungen über eine östliche Herkunft fassen ${ }^{306}$. Auffallend ist in Ephesos das zahlreiche Aufkommen an Typen, die zudem in verschiedenen Fabric-Gruppen erscheinen. Die petrographisch-mineralogischen Analysen haben ergeben, dass zwei von drei verschiedenen Fabrics tatsächlich aus lokalem Ton gefertigt sind, womit die Produktion der Dünnwandigen Ware im 1. Jahrhundert v. Chr. in der Umgebung von Ephesos

${ }^{300}$ Ladstätter 2007, 205.

301 Rogl 2007, 182.

302 Zelle 1997, 13; Ladstätter 2005a, 233.

303 Zelle 1997, 12.

304 Ladstätter 2007, 208.

305 Die Empfehlung geht auf S. Ladstätter zurück.

306 Für eine westliche Herkunft (Sizilien): Marabini-Moevs 1973, 35; Japp 1999, 306 und Warner Slane 1999, 349; östliche Herkunft: Rogl 2007, 188 mit Anm. 54 und Peignard-Giros 2000, 131-133. 


\section{Magerungsgehalt in \%}

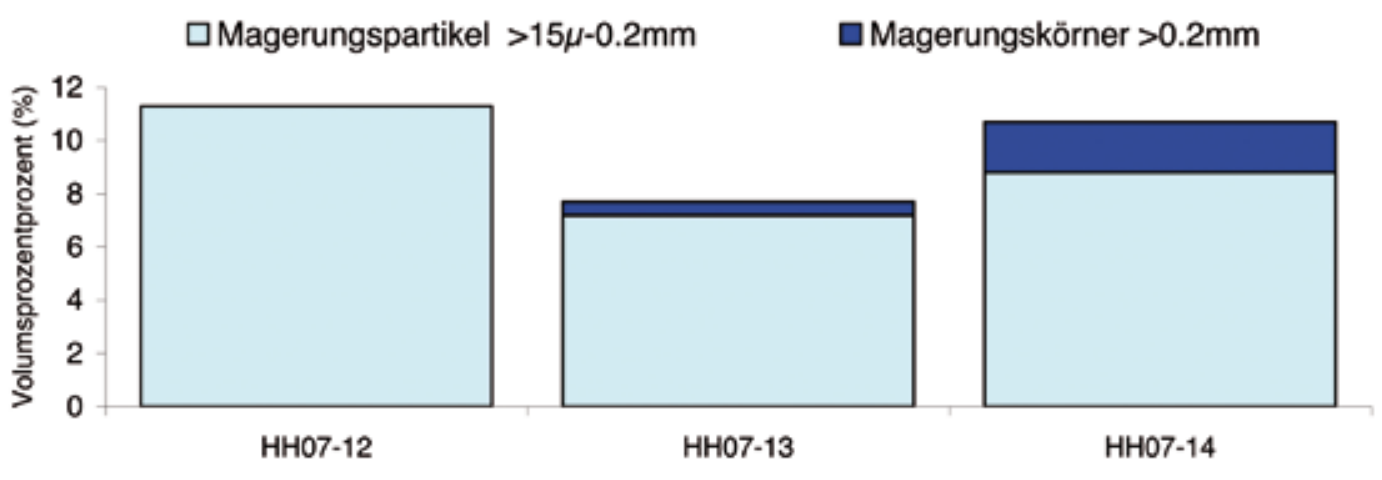

Zusammensetzung der Magerungspartikel

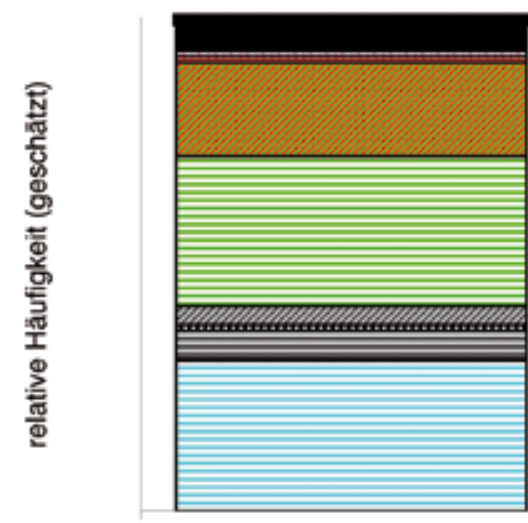

HH07-12

日Monokristalliner Quarz 早Hornstein

III Plagioklas

日Muskovit

Karbonat

Foraminiferen

kieselige Biogene

Kristallinbruchstücke

Opake Substanz

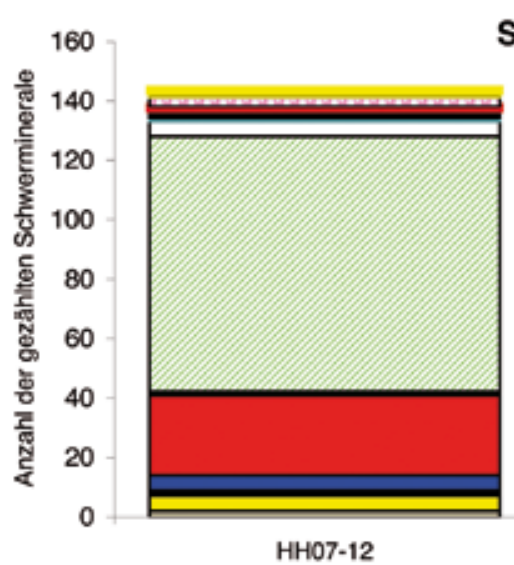

$\square$ Zirkon

四 Titanit

$\square$ Staurolith

$\square$ Hornblende

田Klinopyroxen (augitisch)

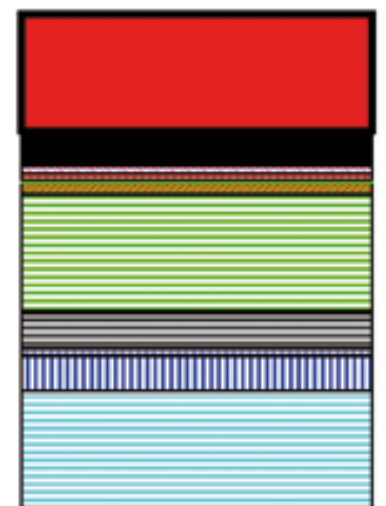

HH07-13

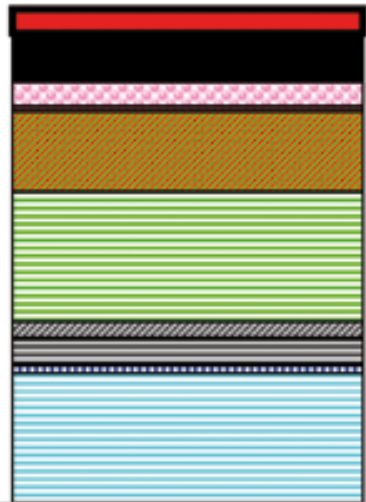

HH07-14

m Polykristalliner Quarz

Alkalifeldspat

Albit

oxidierte Schichtsilik.+Phlog. +Biotit

Karbonatpseudomorphosen

ㅈarbonatische Biogene

Pflanzenreste

Schwermineralien

Eisenoxidkonkretionen

Schwermineralzusammensetzung

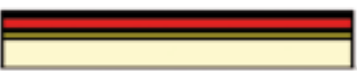

HH07-13

Rutil

Turmalin

घDisthen

준 Chloritoid

Korund

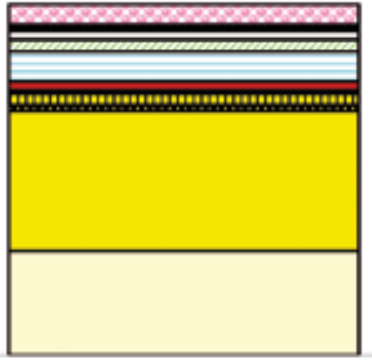

HH07-14

田Brookit/Anatas

-Granat

口Epidot/Klinozoisit

四 Sillimanit

ㅁ?

27 Chemische Analyse der Keramikproben aus Sondage B6 
bewiesen ist. Eine Reziprozität in der Formsprache zwischen Ost und West soll dabei aber nicht außer Acht gelassen werden.

Noch vor der Mitte des 1. Jahrhunderts v. Chr. öffnete sich die Stadt für umgebende Märkte und importierte Waren aus Pergamon und Knidos nehmen zu. Besonders die Pergamenische Sigillata mit Appliken erfreute sich großer Beliebtheit, sodass sie in augusteischer Zeit in kleinen Mengen im lokalen Fabric imitiert wird. Dennoch ist zu beobachten, dass die Konnektivität und der Austausch unter den Zentren gering blieben $^{307}$.

Festzuhalten bleibt, dass Ephesos in seiner Keramikproduktion und -versorgung weitgehend autark $w^{2}{ }^{308}$. Die Menge an Keramik, die für die Metropole Ephesos und den überregionalen Export produziert worden ist, weist auf den hohen technologischen Standard einer Massenfabrik mit Arbeitsteilung, auf eine ausgeprägte Infrastruktur und auf das fundierte Know-how der Töpfer hin.

Obwohl es sich bei dem Fundkomplex aus Sondage B6 in der Wohneinheit 7 des Hanghauses 2 nur um einen kleinen Auszug aus dem Keramikrepertoire des späthellenistischen-frührömischen Ephesos handelt und »one more excavated deposit could change impressions $« 309$, sind neben der Vorstellung einer Typenreihe auch übergreifende Erkenntnisse gewonnen worden.

\section{Katalog}

Im Katalog werden folgende zusätzliche Abkürzungen verwendet:

$\begin{array}{llll}\text { AO } & \text { Aufbewahrungsort } & \text { Hfrgt(e). } & \text { Halsfragment(e) } \\ \text { Atl. } & \text { Atlante } & \text { Mü } & \text { Münze } \\ \text { Dat. } & \text { Datierung } & \text { BDm/RDm } & \text { Boden-/Randdurchmesser } \\ \text { Bfrgt(e). } & \text { Bodenfragment(e) } & \text { Rfrgt(e). } & \text { Randfragment(e) } \\ \text { Dfrgt(e). } & \text { Diskusfragment(e) } & \text { TS } & \text { Terra Sigillata } \\ \text { erh. } & \text { erhalten } & \text { Wfrgt(e). } & \text { Wandfragment(e) }\end{array}$

Eastern Sigillata A

Kat. 1

Taf. 1, 1

Kat. 2

ohne Abb.

Teller

Teller

AO: Depot des österreichischen Grabungshauses Inv. 99/690.01

FO: Stratum 2

Fabric: 10 R 8/3; hart, fein, feinporös, feiner Glimmer, mittel-sel-

AO: Depot des österreichischen Grabungshauses Inv. 99/675.03 FO: Stratum 2

Fabric:10 R 8/3; hart, fein, feinporös, feiner Glimmer, selten

Überzug: 10 R 4/6, mattglänzend

Dekor: Palmettenstempel, Roulettierungen

Überzug: $10 \mathrm{R}$ 4/6, mattglänzend

Maße: RDm $16 \mathrm{~cm}$

Erh.: 1 Rfrgt.

Dat. nach Stück: letztes Drittel 1. Jh. v. Chr.

Dat. nach Kontext: 2. Hälfte 1. Jh. v. Chr.

Parallelen: Hayes 1985, Atlante 3.

Maße: RDm $14 \mathrm{~cm}$

Erh.: 1 Bfrgt.

Dat. nach Stück: letztes Drittel 1. Jh. v. Chr.

Dat. nach Kontext: 2. Hälfte 1. Jh. v. Chr.

Parallelen: Hayes 1985, Atlante 4 A, Abb. 9.

$307 \operatorname{Rogl} 2007,189$.

${ }^{308}$ Die Töpfereien siedelten nicht in unmittelbarer Nähe der Stadt, weil die Tonaufkommen dort nicht verwertbar genug waren und man gerade für Reliefbecher, Lampen und applikenverzierte Ware einen plastischen, gut formbaren Ton benötigte. Mineralogische Untersuchungen sowie mikroskopische Betrachtungen der Fabrics wurde von N. Kun, Institut für Geologisches Ingenieurswesen der 9 Eylül Universität in Izmir, durchgeführt. Er fand heraus, dass der Ton aus Lagerstätten nahe dem heutigen Yeniköy (ca. 15 km vom antiken Ephesos entfernt) genommen wurde. s. dazu Gürler 2003, 16.

${ }^{309}$ Eiring 2000, 201. 
Kat. 3

Teller

AO: Depot des österreichischen Grabungshauses Inv. 99/696.01

FO: Stratum 1, Bauschutt

Fabric: 5 YR 8/4; hart, fein, feinporös, feiner Glimmer, selten

Überzug: 10 R 4/6, mattglänzend

Maße: ?

Dekor: Palmettenstempel

Erh.: 1 Wfrgt.

Dat. nach Stück: letztes Drittel 1. Jh. v. Chr.

Dat. nach Kontext: augusteisch-tiberisch

Parallelen: Hayes 1985, Atlante 3/4.

\section{Kat. 4}

Taf. 1, 4

\section{Schale}

AO: Depot des österreichischen Grabungshauses Inv. 99/702.01 FO: Stratum 2

Fabric:10 YR 8/3; hart, fein, feinporös, sehr feiner Glimmer, selten

Überzug:10 R 4/6, mattglänzend

Maße: RDm 4, $8 \mathrm{~cm}$

Erh.:1 Bfrgt.

Dat. nach Stück: augusteisch

Dat. nach Kontext: 2. Hälfte 1. Jh. v. Chr.

Parallelen: Hayes 1985, Atlante 22 B.

Eastern Sigillata B

\section{Kat. 5}

Taf. 1, 5

Schale

AO: Depot des österreichischen Grabungshauses Inv. 99/705.17 FO: Stratum 3

Fabric:10 YR 6/3; hart, sehr fein, feinporös, sehr feiner Glimmer, selten

Überzug: 2.5 YR 4/8 und 3/3, glänzend

Dekor: Roulettierung

Maße: RDm $9 \mathrm{~cm}$

Erh.: 2 Bfrgte.

Dat. nach Stück: 1. Viertel 1. Jh. n. Chr. (augusteisch)

Dat. nach Kontext: 3.-4. Viertel 1. Jh. v. Chr.

Parallelen: Hayes 1985, Atlante 13 und 24; Ladstätter 2005a, K

83; Ladstätter 2007, Abb. 5 (r. u.).

Kat. 6

ohne Abb.

Schale

AO: Depot des österreichischen Grabungshauses Inv. 99/675.06 FO: Stratum 2

Fabric: 10 YR 6/3; hart, fein, feinporös, feiner Glimmer, selten Überzug: 2.5 YR 4/8, glänzend

Maße: RDm $8 \mathrm{~cm}$

Erh.: 2 Rfgrte.

Dat. nach Stück: letztes Viertel des 1. Jhs. v. Chr.

Dat. nach Kontext: 3.-4. Viertel 1. Jh. v. Chr.

Parallelen: Hayes 1985, Atlante 14.

Kat. 7

Taf. 1, 7; 9,7

Schale

AO: Depot des österreichischen Grabungshauses Inv. 99/641.01 FO: Stratum 3
Fabric: 7.5 YR 6/4-5/8, hart, fein, feinporös, feiner Glimmer, selten

Überzug: 2.5 YR 5/8, teilweise abgeplatzt, glänzend

Maße: RDm $12 \mathrm{~cm}$

Erh.: 2 Rfrgte., 1 Wfrgt.

Dat. nach Stück: späthellenistisch-augusteisch

Dat. nach Kontext: 3.-4. Viertel 1. Jh. v. Chr.

Parallelen: Hayes 1985, Atlante 16 (53?).

Kat. 8

ohne Abb.

Schale

AO: Depot des österreichischen Grabungshauses Inv. 99/643.16 FO: Stratum 1, Bauschutt

Fabric:10 YR 6/3; hart, fein, feinporös, feiner Glimmer, mittel-selten

Überzug: 2.5 YR 6/6, glänzend

Dekor: Roulettierung

Maße: RDm $7 \mathrm{~cm}$

Erh.: 1 Bfrgt.

Dat. nach Stück: 1. Viertel 1. Jh. n. Chr.

Dat. nach Kontext: augusteisch-tiberisch

Parallelen: Hayes 1985, Atlante 24.

Kat. 9

ohne Abb.

Becher

AO: Depot des österreichischen Grabungshauses Inv. 99/679.02 FO: Stratum 1, Bauschutt

Fabric: 7.5 YR 5/8; hart, fein, feinporös, feiner Glimmer, selten Überzug: 2.5 YR 5/8, glänzend

Dekor: Roulettierung

Maße: RDm 6,4 cm

Erh.: 1 Bfrgt.

Dat. nach Stück: 2. Drittel 2. Jh. v. Chr. - 1. Drittel 1. Jh. n. Chr.

Dat. nach Kontext: augusteisch-tiberisch

Parallelen: Hayes 1985, Atlante 29

Kat. 10

Taf. 1, 10

Schale

AO: Depot des österreichischen Grabungshauses Inv. 99/690.03 FO: Stratum 2

Fabric: 2.5 YR 5/8; hart, fein, feinporös, feiner Glimmer, mittel Überzug: 2.5 YR 5/6, mattglänzend

Maße: RDm $16 \mathrm{~cm}$

Erh.: 1 Rfgrt.

Dat. nach Stück: Mitte 1. Jh. n. Chr.

Dat. nach Kontext: 2. Hälfte 1. Jh. v. Chr.

Parallelen: Hayes 1985, Atlante 36; Ladstätter 2007, Abb. 5 (1., 2. von oben).

Kat. 11

ohne Abb.

Krater

AO: Depot des österreichischen Grabungshauses Inv. 99/708.06 FO: Stratum 3

Fabric: 7.5 YR 6/3; hart, fein, feinporös, feiner Glimmer, mittel Überzug: 2.5 YR 5/8, glänzend

Maße: RDm $20 \mathrm{~cm}$

Erh.: 1 Rfrgt. 
Dat. nach Stück: 1. Jh. v. Chr.

Dat. nach Kontext: 3.-4. Viertel 1. Jh. v. Chr.

Parallelen: Hayes 1985, Atlante 38 (15).

Kat. 12

ohne Abb.

Schale

AO: Depot des österreichischen Grabungshauses Inv. 99/643.15 FO: Stratum 1, Bauschutt

Fabric: 2.5 YR 6/4; hart, fein, feinporös, feiner Glimmer, mittel-selten

Überzug: 2.5 YR 6/6, mattglänzend

Maße: RDm $10 \mathrm{~cm}$

Erh.: 2 Rfrgt.

Dat. nach Stück: -

Dat. nach Kontext: augusteisch-tiberisch

Parallelen: Hayes 1985, Atlante 39.

Kat. 13

Taf. 1, 13

Schale

AO: Depot des österreichischen Grabungshauses Inv. 99/649B.09
FO: Stratum 2

Fabric: 10 R 5/8; hart, fein, feinporös, Glimmer, weiße feine Einschlüsse, mittel, graue feine Einschlüsse, vereinzelt

Überzug: 10 R 5/8, glänzend

Maße: RDm $11 \mathrm{~cm}$

Erh.: 1 Rfrgt.

Dat. nach Stück: 1./2. Jh. n. Chr.

Dat. nach Kontext: 2. Hälfte 1. Jh. v. Chr

Parallelen: Hayes 1985, Atlante 76 A (?), Taf. 15, Abb. 10.

Kat. 14

Abb. 5; Taf. 1, 14

Becher mit eingeschnürter Wand, Typ FE1

Gattung: unbestimmmte Sigillata

AO: Depot des österreichischen Grabungshauses Inv. 99/679.01

FO: Stratum 1, Bauschutt

Fabric: 2.5 YR 6/6; hart, sehr fein, feinporös, Glimmer sehr fein, weiße Einschlüsse, fein

Überzug: 2.5 YR 5/8, glänzend

Maße: RDm $10 \mathrm{~cm}$

Erh.: 1 Rfrgt.

Dat. nach Stück: -

Dat. nach Kontext: augusteisch-tiberisch

Parallelen:-

\section{Frühe Eastern Sigillata B}

\section{Kat. 15}

Schale Typ FE2

AO: Depot des österreichischen Grabungshauses Inv. 99/732.07

FO: Stratum 3

Fabric: 2.5 YR 4/2; hart, sehr fein, feinporös, feiner Glimmer, selten

Überzug: 2.5 YR 4/6-2.5/1, glänzend

Maße: RDm $20 \mathrm{~cm}$

Erh.: 1 Rfrgt.

Dat. nach Stück: Mitte 1. Jh. v. Chr. - 2. Jh. n. Chr.

Dat. nach Kontext: 3.-4. Viertel 1. Jh. v. Chr.

Parallelen: zur Form: Meyer-Schlichtmann 1988, Sa 8 Kat. 203

Taf. 14.

\section{Kat. 16}

Taf. 1, 16

Becher Typ FE3

AO: Depot des österreichischen Grabungshauses Inv. 99/651.05

FO: Stratum 1

Fabric: 2.5 YR 6/8; hart, sehr fein, feinporös, Glimmer

Überzug: 2.5 YR 4/8, glänzend

Maße: RDm $11 \mathrm{~cm}$

Erh.: 1 Rfrgt.

Dat. nach Stück: 2. Hälfte 1. Jh. v. Chr. - Anfang 1. Jh. n. Chr.

Dat. nach Kontext: augusteisch-tiberisch

Parallelen: Hayes 1985, Atlante 13 B, 27, 49, rara a (Taf. 11, 3);

Bruneau 1970, 246 Abb. 126, D 48.

Kat. 17

Taf. 1, 17

Schale Typ FE4

AO: Depot des österreichischen Grabungshauses Inv. 99/708.01
FO: Stratum 3

Fabric: 10 YR 6/3; hart, sehr fein, feinporös, rötliche, sehr feine Einschlüsse, vereinzelt

Überzug: 2.5 YR 4/8, 10 YR 5/3, 5 YR 6/6, glänzend

Maße: RDm 11,2 cm; BDm $7 \mathrm{~cm}$

Erh.: 1 Frgt.

Dat. nach Stück: frühaugusteisch-tiberisch

Dat. nach Kontext: 3.-4. Viertel 1. Jh. v. Chr.

Parallelen: Conspectus 1990, Form 36.4.4.

Kat. 18

Taf. 1, 18

Becher Typ FE5

Gattung: unbestimmte Sigillata

AO: Depot des österreichischen Grabungshauses Inv. 99/705.06

FO: Stratum 3

Fabric: 2.5 YR 6/8, Kern 7.5 YR 6/3; hart, sehr fein, feinporös, sehr feiner Glimmer, selten, weiße feine Einschlüsse, vereinzelt Überzug: außen 2.5 YR 5/8, innen tonfarbig, glänzend

Maße: RDm 4,4 cm

Erh.: 1 Bfrgt.

Dat. nach Stück: -

Dat. nach Kontext: 3.-4. Viertel 1. Jh. v. Chr.

Parallelen: unbekannt

Kat. 19

Taf. 1, 19

Teller ESA-Imitat, Typ FE6

AO: Depot des österreichischen Grabungshauses Inv. 99/731.01

FO: Stratum 2

Fabric:2.5 YR 5/6; hart, fein, feinporös, feiner Glimmer, mittel, weiße und graue feine Einschlüsse, selten 
Überzug:10 R 5/8 außen fleckig mit 10 R 4/4, glänzend

Dekor: Roulettierung

Maße: RDm 16,4 cm

Erh.: 1 Bfrgt.

Dat. nach Stück: letztes Drittel 1. Jh. v. Chr.

Dat. nach Kontext: 2. Hälfte 1. Jh. v. Chr.

Parallelen: Hayes 1985, Atlante 3/4.

\section{Kat. 20}

Taf. 1, 20

Schale Typ FE7

AO: Depot des österreichischen Grabungshauses Inv. 99/704.02 FO: Stratum 2

Fabric: 2.5 YR 6/8; hart, fein, feinporös, sehr feiner Glimmer, häufig, Quarz, fein, selten, weiße Einschlüsse, fein, häufig

Überzug: 10 R 5/8, glänzend

Dekor: Roulettierung

Maße: RDm 6,4 cm

Erh.: 1 Bfrgt.
Dat. nach Stück: 1. Viertel 1. Jh. n. Chr.

Dat. nach Kontext: 2. Hälfte 1. Jh. v. Chr.

Parallelen: Ladstätter 2007, Abb. 5 (r. o.).

Kat. 21

Taf. 1, 21

Krater Typ FE8

AO: Depot des österreichischen Grabungshauses Inv. 99/702.04 FO: Stratum 2

Fabric: 5 YR 5/8; hart, fein, feinporös, sehr feiner Glimmer, selten, weiße Einschlüsse, fein, mittel, Quarz, fein, mittel, rote Einschlüsse, fein, selten

Überzug: 2.5 YR 4/8, glänzend

Maße: RDm $18 \mathrm{~cm}$

Erh.: 1 Rfrgt.

Dat. nach Stück: 1. Jh. v. Chr.

Dat. nach Kontext: 2. Hälfte 1. Jh. v. Chr.

Parallelen: Hayes 1985, Atlante 38, 61 (auch mit Dekor im WAN).

\section{Glanztonware}

\section{Kat. 22}

Taf. 2, 22

Echinusschale Typ G1

AO: Depot des österreichischen Grabungshauses Inv. 99/702.23

FO: Stratum 2

Fabric: 5 YR 5/6; hart, fein, feinporös, weiße Einschlüsse, feinmittel, häufig

Überzug: $10 \mathrm{R}$ 4/6, mattglänzend

Maße: RDm $8 \mathrm{~cm}$

Erh.: 1 Rfrgt.

Dat. nach Stück: 1. Hälfte 2. Jh. v. Chr. - augusteisch

Dat. nach Kontext: 2. Hälfte 1. Jh. v. Chr.

Parallelen: Ladstätter 2003a, K 11-14; Meriç 2002, K2. 4. 5. 10.

12; Gassner 1997, Nr. 63-66; Thompson 1934, D 9; Rogl 2007, 192 Abb. 3; Zelle 2007, 200 Abb. 4.

\section{Kat. 23}

Taf. 2, 23

Bichrome Echinusschale Typ G2

AO: Depot des österreichischen Grabungshauses Inv. 99/715.35 FO: Stratum 4

Fabric: 2.5 YR 6/8; hart, fein, feinporös, Glimmer, weiße feine Einschlüsse, selten, feine Quarzeinschlüsse, vereinzelt, hellgraue feine Einschlüsse, mittel

Überzug: 10 R 2.5/1 und 2.5 YR 5/6, mattglänzend

Maße: RDm $9 \mathrm{~cm}$

Erh.: 1 Rfgrt., 3 Bfrgte., 2 Wfrgte.

Dat. nach Stück: 2./1. Jh. v. Chr.

Dat. nach Kontext: Ende 2. Jh. - Mitte 1. Jh. v. Chr.

Parallelen: Ladstätter 2005a, K 309; Gassner 1997, Nr. 65; Crowfoot 1957, 223; Goldman 1950, 157; Gassner 1997, Nr. 67-71; Meriç 2002, K1. 7. 8.

\section{Kat. 24}

Taf. 2, 24

Schale mit geschwungener Wand Typ G3

AO: Depot des österreichischen Grabungshauses Inv. 99/666.19 FO: Stratum 4

Fabric:7.5 YR 6/4; hart, fein, feinporös, Glimmer, weiße sehr feine Einschlüsse, mittel

Überzug: außen 2.5 YR 4/3; innen: 2.5 YR 4/6, glänzend

Maße: RDm $10 \mathrm{~cm}$

Erh.: 1 Rfgrt.

Dat. nach Stück: 2./1. Jh. v. Chr.

Dat. nach Kontext: Ende 2. Jh. - Mitte 1. Jh. v. Chr.

Parallelen: Ladstätter 2003a, K 98-110; Ladstätter 2005a, K 313.

\section{Kat. 25}

Taf. 2, 25

Trichterförmige Schale Typ G4

AO: Depot des österreichischen Grabungshauses Inv. 99/715.43 FO: Stratum 4

Fabric: 5 YR 4/6; hart, fein, feinporös, feiner Glimmer, häufig, feine Quarzeinschlüsse, selten, hellgraue feine Einschlüsse, mittel, schwarze feine Einschlüsse, vereinzelt, rote feine Einschlüsse, vereinzelt

Überzug: 2.5 YR 3/1 und 2.5 YR 4/6, mattglänzend Maße: RDm $22 \mathrm{~cm}$

Erh.: 9 Rfrgte.

Dat. nach Stück: 2. Jh. v. Chr.

Dat. nach Kontext: Ende 2. Jh. - Mitte 1. Jh. v. Chr.

Parallelen: Mitsopoulos-Leon 1991, A 18.

Kat. 26

Taf. 2, 26

Weit ausladende Schale Typ G5

AO: Depot des österreichischen Grabungshauses Inv. 99/651.20 FO: Stratum 1

Fabric: 7.5 YR 5/6, hart, fein, feinporös, feiner Glimmer, selten Überzug: außen 5 YR 5/6; innen 10 R 4/6, matt

Maße: RDm $20 \mathrm{~cm}$

Erh.: 1 Rfgrt.

Dat. nach Stück: -

Dat. nach Kontext: augusteisch-tiberisch

Parallelen: Mitsopoulos-Leon 1991, B 80. 


\section{Kat. 27}

Taf. 2, 27

Konische Schale Typ G5 A

AO: Depot des österreichischen Grabungshauses Inv. 99/666.25 FO: Stratum 4

Fabric: 5 YR 7/4; hart, fein, feinporös, Glimmer, weiße feine Einschlüsse, mittel

Überzug: 2.5 YR 2.5/1 und 4/8, matt

Maße: RDm $16 \mathrm{~cm}$

Erh.: 1 Rfrgt.

Dat. nach Stück: 3.-1. Jh. v. Chr

Dat. nach Kontext: Ende 2. Jh. - Mitte 1. Jh. v. Chr.

Parallelen: Gassner 1997, Nr. 123-125; Mitsopoulos-Leon 1991, B 81; Ladstätter 2005a, K 367 (in Sigillata).

\section{Kat. 28}

Taf. 2, 28

Mastos mit Profilierung Typ G5 B

AO: Depot des österreichischen Grabungshauses Inv. 99/715.77 FO: Stratum 4

Fabric: 2.5 YR 7/4; hart, fein, feinporös, feiner Glimmer, selten Überzug: 2.5 YR 2.5/1, matt

Maße: RDm $20 \mathrm{~cm}$

Erh.: 1 Rfrgt.

Dat. nach Stück: 3. Jh. v. Chr. - 1. Jh. n. Chr

Dat. nach Kontext: Ende 2. Jh. - Mitte 1. Jh. v. Chr.

Parallelen: Mitsopoulos-Leon 1991, B 86; Gassner 1997, Nr. 124; Rogl 2003, Nr. 10 Abb. 198 Taf. 58; Ladstätter 2003a, K 72; Ladstätter 2005a, K 134 (in Grauer Ware); Ladstätter 2005a, K 65 (in ESA); Ladstätter 2005a, K 367 (in unbestimmter Sigillata).

\section{Kat. 29}

Taf. 2, 29

\Knidische Schale< Typ G6

AO: Depot des österreichischen Grabungshauses Inv. 99/702.31 FO: Stratum 2

Fabric: 7.5 YR 5/6, hart, fein, feinporös, feiner Glimmer, mittel Überzug: außen 5 YR 3/4, Lippe 2.5 YR 2.5/1; innen 2.5 YR 4/8, glänzend

Maße: RDm $13 \mathrm{~cm}$

Erh.: 1 Rfrgt.

Dat. nach Stück: 2. Jh. v. Chr. - 1. Jh. n. Chr.

Dat. nach Kontext: 2. Hälfte 1. Jh. v. Chr

Parallelen: Ladstätter 2005a, K 372; Zelle 2007, 200 Abb. 4.

Kat. 30

Taf. 2, 30

$>$ Knidische Schale< Typ G7

AO: Depot des österreichischen Grabungshauses Inv. 99/641.18 FO: Stratum 3

Fabric: 5 YR 5/6, hart, fein, feinporös, feiner Glimmer, mittel Überzug: außen 10 R 3/1; innen 10 R 5/8, metallisch glänzend Maße: RDm $10 \mathrm{~cm}$

Erh.: 1 Rfrgt.

Dat. nach Stück: 2. Jh. v. Chr. - 1. Jh. v. Chr.

Dat. nach Kontext: 3.-4. Viertel 1. Jh. v. Chr.

Parallelen: Meriç 2002, K 30; Ladstätter 2007, Abb. 11.
Kat. 31

Taf. 2, 31

Skyphos \Knidische Schale $<$ Typ G8

AO: Depot des österreichischen Grabungshauses Inv. 99/691.09

FO: Stratum 2

Fabric: 5 YR 5/8; hart, fein, feinporös, feiner Glimmer, mittel Überzug: 2.5 YR 4/6-3/1, fleckig, glänzend

Maße: RDm $10 \mathrm{~cm}$

Erh.:1 Rfrgt. mit Henkelansatz

Dat. nach Stück: 1. Viertel 1. Jh. n. Chr.

Dat. nach Kontext: 2. Hälfte 1. Jh. v. Chr.

Parallelen: Meriç 2002, K 29. 35 Taf. 3; Ladstätter 2005a, K 109

Taf. 152; K 349 Taf. 169; Warner Slane 1997, FW 541; Rogl 2007, 192 Abb. 5.

Kat. 32

Taf. 2, 32

\Knidische Schale` Typ G9

AO: Depot des österreichischen Grabungshauses Inv. 99/634.01

FO: Stratum 1, Bauschutt

Fabric: 5 YR 5/6; hart, fein, feinporös, Glimmer, mittel

Überzug: außen 10 R 3/1; innen 10 R 4/4, metallisch glänzend Maße: RDm $10 \mathrm{~cm}$

Erh.: 1 Rfrgt. mit Henkel

Dat. nach Stück: spätes 2. Jh. v. Chr. - frühes 1. Jh. n. Chr.

Dat. nach Kontext: augusteisch-tiberisch

Parallelen: Ladstätter 2003a, K 108; Ladstätter 2005a, K 108. 109

Kat. 33

Taf. 2, 33

Skyphos Typ G10

AO: Depot des österreichischen Grabungshauses Inv. 99/702.30

FO: Stratum 2

Fabric: 7.5 YR 5/6

Überzug:außen 5 YR 5/6; innen 10 R 5/8, matt

Maße: RDm $14 \mathrm{~cm}$

Erh.: 1 Rfrgt.

Dat. nach Stück: 2. Jh. v. Chr.

Dat. nach Kontext: letztes Viertel 1. Jh. v. Chr

Parallelen: Mitsopoulos-Leon 1991, B 42. 53.

Kat. 34

Taf. 2, 34

Skyphos mit Profilierungen Typ G10 A

AO: Depot des österreichischen Grabungshauses Inv. 99/733.01

FO: Stratum 4

Fabric: 10 YR 6/3; hart, fein, feinporös, feine Quarzeinschlüsse, selten, feine weiße, schwarze und gelbe Einschlüsse, vereinzelt Überzug: 2.5 Y 3/1, matt

Maße: RDm $6 \mathrm{~cm}$

Erh.: 3 Rfrgte., 1 Wfrgt.

Dat. nach Stück: 2. Jh. v. Chr.

Dat. nach Kontext: Ende 2. Jh. - Mitte 1. Jh. v. Chr. Parallelen: Mitsopoulos-Leon 1991, B 30. 36. 49. 


\section{Kat. 35}

Skyphos mit Profilierung Typ G10 B

AO: Depot des österreichischen Grabungshauses Inv. 99/639.08 FO: Stratum 3

Fabric: 5 YR 5/6; hart, fein, feinporös, sehr feiner Glimmer, mittel, weiße feine Einschlüsse, mittel, feine Quarzeinschlüsse, selten

Überzug: 2.5 YR 4/8 und 3/1, glänzend

Maße: RDm 9,6 cm

Erh.: 1 Rfrgt.

Dat. nach Stück: 2. Jh. v. Chr.

Dat. nach Kontext: 3.-4. Viertel 1. Jh. v. Chr.

Parallelen: Mitsopoulos-Leon 1991, B 32. 48-49.

\section{Kat. 36}

Taf. 2, 36

Becher mit verdickter Lippe Typ G11

AO: Depot des österreichischen Grabungshauses Inv. 99/679.21

FO: Stratum 1, Bauschutt

Fabric: 5 YR 5/6, hart, fein, feinporös, feiner Glimmer, mittel

Überzug: außen und Lippe innen 2.5 YR 3/1; innen 10 R 4/8, metallisch glänzend

Maße: RDm $10 \mathrm{~cm}$

Erh.: 1 Rfrgt.

Dat. nach Stück: -

Dat. nach Kontext: augusteisch-tiberisch

Parallelen: -

\section{Kat. 37}

Taf. 2, 37

Becher mit vertikaler Mündung Typ G12

AO: Depot des österreichischen Grabungshauses Inv. 99/702.32 FO: Stratum 2

Fabric: 7.5 YR 6/6, hart, fein, feinporös, feiner Glimmer, selten Überzug: 7.5 YR 2.5/1-3/2, matt

Maße: RDm $10 \mathrm{~cm}$

Erh.: 1 Rfrgt.

Dat. nach Stück: -

Dat. nach Kontext: 2. Hälfte 1. Jh. v. Chr.

Parallelen: -

\section{Kat. 38}

Taf. 2, 38

Becher Typ G13

AO: Depot des österreichischen Grabungshauses Inv. 99/715.101

FO: Stratum 4

Fabric: 5 YR 5/6; hart, fein, feinporös, feiner Glimmer, mittel, weiße, sehr feine Einschlüsse, häufig, schwarze feine Einschlüsse, mittel

Überzug: $10 \mathrm{R} 4 / 6$, matt

Maße: RDm $6 \mathrm{~cm}$

Erh.: 1 Bfrgt.

Dat. nach Stück: -

Dat. nach Kontext: Ende 2. Jh. - Mitte 1. Jh. v. Chr.

Parallelen: -

Kat. 39

Taf. 3, 39

Kanne Typ G14

AO: Depot des österreichischen Grabungshauses Inv. 99/732.06
FO: Stratum 3

Fabric: 10 YR4/1; hart, fein, feinporös, feiner Glimmer, selten, weiße und dunkelgraue feine Einschlüsse, selten

Überzug: 7.5 YR 4/1, glänzend

Maße: RDm $12 \mathrm{~cm}$

Erh.: 1 Rfrgt.

Dat. nach Stück: -

Dat. nach Kontext: 3.-4. Viertel 1. Jh. v. Chr.

Parallelen: -

Kat. 40

Taf. 3, 40

Dünnwandiger Krug Typ G15

AO: Depot des österreichischen Grabungshauses Inv. 99/675.16 FO: Stratum 2

Fabric: 2.5 YR 7/6; hart, fein, feinporös, feiner Glimmer, vereinzelt

Überzug: 2.5 YR 6/6, matt

Maße: RDm $9 \mathrm{~cm}$

Erh.: 1 Rfrgt.

Dat. nach Stück: -

Dat. nach Kontext: 2. Hälfte 1. Jh. v. Chr.

Parallelen: Liko 2001, 38; Hayes 1991a, Nr. 52 Abb. 16, 8.

Kat. 41

Taf. 3, 41

Teller mit beidseitig verdickter Lippe Typ G16

AO: Depot des österreichischen Grabungshauses Inv. 99/715.50 FO: Stratum 4

Fabric: 5 YR 5/6; hart, fein, feinporös, feiner Glimmer, mittel, weiße feine Einschlüsse, selten, feine Quarzeinschlüsse, mittel, dunkelgraue feine Einschlüsse, vereinzelt, rote feine Einschlüsse, vereinzelt

Überzug: 7.5 YR 7/4, matt

Maße: RDm $24 \mathrm{~cm}$

Erh.: 3 Rfrgte.

Dat. nach Stück: 2. Jh. v. Chr.

Dat. nach Kontext: Ende 2. Jh. - Mitte 1. Jh. v. Chr.

Parallelen: Ladstätter 2006, Nr. 7; Mitsopoulos-Leon 1991, A 42. A 44 Taf. 8-9; A 63 Taf. 13; Crowfoot 1957, Nr. 8 Taf. 37; Goldman 1959, Form T 1, Nr. 27-38.

Kat. 42

Taf. 3, 42

Fischteller Typ G17

AO: Depot des österreichischen Grabungshauses Inv. 99/ 715.132

FO: Stratum 4

Fabric: 2.5 YR 5/6; hart, fein, feinporös, feiner Glimmer, mittel, feine Quarzeinschlüsse, mittel, schwarze feine Einschlüsse, mittel

Überzug: 7.5 YR 2.5/1, mattglänzend

Maße: RDm $10 \mathrm{~cm}$

Erh.: 1 Bfrgt.

Dat. nach Stück: frühes 3. Jh. n. Chr. - frühes 1. Jh. v. Chr.

Dat. nach Kontext: Ende 2. Jh. - Mitte 1. Jh. v. Chr.

Parallelen: Mitsopoulos-Leon 1991, A 37-41 Taf. 7. 8; Rotroff 1997, Taf. 51; Gassner 1997, Nr. 92-93; Ladstätter 2003a, K 283. 


\section{Kat. 43}

Taf. 3, 43

Teller mit unterschnittenem Rand Typ G18

AO: Depot des österreichischen Grabungshauses Inv. 99/715.70 FO: Stratum 4

Fabric: 5 YR 7/6; hart, fein, feinporös, feiner Glimmer, mittel, mittlere Quarzeinschlüsse, selten, schwarze mittlere Einschlüsse, mittel

Überzug:2.5 YR 2.5/1, metallisch glänzend

Maße: RDm $19 \mathrm{~cm}$

Erh.: 2 Rfrgt.

Dat. nach Stück: 2. Hälfte des 2. Jhs. v. Chr. (150) -25 n. Chr.

Dat. nach Kontext: Ende 2. Jh. - Mitte 1. Jh. v. Chr.

Parallelen: Mitsopoulos-Leon 1991, A 56-59 Taf. 11; Goldman 1959, Form T 1, B, C, Abb. 178; G, D, Abb. 179.

\section{Kat. 44}

Taf. 3, 44

Teller mit beidseitig verdickter Lippe Typ G19

AO: Depot des österreichischen Grabungshauses Inv. 99/652.22

FO: Stratum 3

Fabric: 2.5 YR 5/8; hart, fein, feinporös, feiner Glimmer, mittel, feine weiße Einschlüsse, vereinzelt, gelbe feine Einschlüsse, vereinzelt

Überzug:10 R 4/4, matt

Maße: RDm $19 \mathrm{~cm}$

Erh.: 1 Rfrgt.

Dat. nach Stück: spätes 2. Jh. v. Chr. - frühes 1. Jh. n. Chr.

Dat. nach Kontext: 3.-4. Viertel 1. Jh. v. Chr.

Parallelen: Ladstätter 2003a, K 17. 161-171; Ladstätter 2005a, K112; Gassner 1997, Nr. 107; Meriç 2002, K 14-20; Mitsopoulos-Leon 1991, A 56.

\section{Kat. 45}

Taf. 3, 45

Teller mit eingerollter Lippe Typ G20

AO: Depot des österreichischen Grabungshauses Inv. 99/715.156

FO: Stratum 4

Fabric: 2.5 YR 4/1; hart, fein, feinporös, feiner Glimmer, mittel, feine Quarzeinschlüsse, selten, schwarze feine Einschlüsse, mittel

Überzug: 2.5 YR 2.5/1, metallisch glänzend

Maße: RDm $21 \mathrm{~cm}$; BDm: 7,4 cm

Erh.: 5 Rfrgte., 4 Bfrgte., 11 Wfrgte.

Dat. nach Stück: spätes 2. Jh. v. Chr. - frühes 1. Jh. n. Chr.

Dat. nach Kontext: Ende 2. Jh. - Mitte 1. Jh. v. Chr.

Parallelen: Ladstätter 2005, K 111; Mitsopoulos-Leon 1991, A 60 Taf. 12.

\section{Kat. 46}

Taf. 3, 46

Teller mit überhängender Lippe Typ G21

AO: Depot des österreichischen Grabungshauses Inv. 99/715.157

FO: Stratum 4

Fabric: 7.5 YR 4/1; hart, fein, feinporös, feiner Glimmer, mittel, feine Quarzeinschlüsse, selten, schwarze feine Einschlüsse, selten

Überzug: 2.5 YR 4/1-2.5/1, matt

Maße: RDm $23 \mathrm{~cm}$; BDm 9,5 cm

Erh.: 9 Rfrgte., 4 Bfrgte., 9 Wfrgte.
Dat. nach Stück: -

Dat. nach Kontext: Ende 2. Jh. - Mitte 1. Jh. v. Chr.

Parallelen: Mitsopoulos-Leon 1991, A 61-75 Taf. 12-16.

Kat. 47

Taf. 3, 47

Teller mit profiliertem Rand Typ G22

AO: Depot des österreichischen Grabungshauses Inv. 99/672.09 FO: Stratum 3

Fabric: 7.5 YR 5/6; hart, sehr fein, feinporös, feiner Glimmer, vereinzelt, weiße feine Einschlüsse, selten

Überzug: 7.5 YR 3/1, fleckig, glänzend

Maße: RDm $20 \mathrm{~cm}$

Erh.: 1 Rfrgt.

Dat. nach Stück: -

Dat. nach Kontext: 3.-4. Viertel 1. Jh. v. Chr.

Parallelen: De Luca - Radt 1999, 49 Kat. 239 (in Grauer Ware); Kat. 318. 319; Ladstätter 2005a, K 117.

Kat. 48

Taf. 3, 48

Schale Typ G23

AO: Depot des österreichischen Grabungshauses Inv. 99/632.16 FO: Stratum 1

Fabric: 7.5 YR 5/6; hart, fein, feinporös, feiner Glimmer, vereinzelt

Überzug: 7.5 YR 3/1, matt

Maße: RDm 6,6 cm

Erh.: 1 Bfrgt.

Dat. nach Stück: -

Dat. nach Kontext: augusteisch-tiberisch

Parallelen:-

Kat. 49

Taf. 3, 49

Schale Typ G24

AO: Depot des österreichischen Grabungshauses Inv. 99/702.41

FO: Stratum 2

Fabric: 5 YR 5/8; hart, fein, feinporös, feiner Glimmer, selten

Überzug: 2.5 YR 5/6, mattglänzend

Maße: RDm $6 \mathrm{~cm}$

Erh.: 1 Bfrgt.

Dat. nach Stück: -

Dat. nach Kontext: 2. Hälfte 1. Jh. v. Chr.

Parallelen: -

Kat. 50

Taf. 3, 50

Schale mit flachem Boden Typ G 25

AO: Depot des österreichischen Grabungshauses Inv. 99/641.23

FO: Stratum 3

Fabric: 5 Y 4/1; hart, fein, feinporös, feiner Glimmer, vereinzelt Überzug: 2.5 YR 5/4 und 7.5 YR 3/1, mattglänzend

Maße: RDm $14 \mathrm{~cm}$

Erh.: 1 Bfrgt.

Dat. nach Stück: -

Dat. nach Kontext: 3.-4. Viertel 1. Jh. v. Chr.

Parallelen:- 


\section{Kat. 51}

Taf. 3, 51

Schale Typ G26

AO: Depot des österreichischen Grabungshauses Inv. 99/632.13 FO: Stratum 1

Fabric: 2.5 YR 5/8; hart, fein, feinporös, feiner Glimmer, selten Überzug: innen 10 R 5/6, matt

Maße: RDm $6 \mathrm{~cm}$

Erh.: 1 Bfrgt.

Dat. nach Stück: -

Dat. nach Kontext: augusteisch-tiberisch

Parallelen: -

\section{Kat. 52}

Taf. 4, 52

Teller Typ G27

AO: Depot des österreichischen Grabungshauses Inv. 99/690.21

FO: Stratum 2

Fabric: 2.5 YR 8/4; hart, fein, feinporös, feiner Glimmer, häufig, feine Quarzeinschlüsse, selten

Überzug: 2.5 YR 5/8, matt

Maße: RDm 8,2 cm

Erh.: 1 Bfrgt.

Dat. nach Stück: 2./1. Jh. v. Chr.

Dat. nach Kontext: 2. Hälfte 1. Jh. v. Chr.

Parallelen: Ladstätter 2003a, Taf. 16-17; Ladstätter 2005a, K 22; Liko 2001, 44 Taf. 56.

\section{Kat. 53}

Taf. 4,53

Teller Typ G28

AO: Depot des österreichischen Grabungshauses Inv. 99/702.40 FO: Stratum 2

Fabric: 7.5 YR 6/6; hart, fein, feinporös, feiner Glimmer, mittel Überzug: 10 R 5/6, matt

Maße: RDm $10 \mathrm{~cm}$

Erh.: 1 Bfrgt.

Dat. nach Stück: 2. Viertel 2. Jh. v. Chr. - 4. Viertel 1. Jh. v. Chr.

Dat. nach Kontext: 2. Hälfte 1. Jh. v. Chr.

Parallelen: Ladstätter 2003a, Taf. 17; Ladstätter 2005a, K 122;

Meriç 2002, K 12.

\section{Kat. 54}

Taf. 4,54

Teller Typ G29

AO: Depot des österreichischen Grabungshauses Inv. 99/702.36

FO: Stratum 2

Fabric: 2.5 Y 4/2; hart, fein, feinporös, feiner Glimmer, mittel

Überzug: 5 Y 2.5/1, fleckig, matt

Maße: RDm $8 \mathrm{~cm}$

Erh.: 1 Bfrgt.

Dat. nach Stück: Mitte 2. Jh. v. Chr. - Mitte 1. Jh. n. Chr.

Dat. nach Kontext: 2. Hälfte 1. Jh. v. Chr.

Parallelen: Outschar 1996a, Nr. 9; Ladstätter 2005a, K 12. K 370; Rotroff 1997, Taf. 64 Nr. 1044; Hayes 1991b, Nr. 40.

\section{Kat. 55}

Taf. 4, 55

Applikenschale Typ G30

AO: Depot des österreichischen Grabungshauses Inv. 99/705.03 FO: Stratum 3
Fabric: 2.5 YR 5/8; hart, sehr fein, feinporös, feine weiße Einschlüsse, selten, feiner Glimmer

Überzug: 2.5 YR 4/6, glänzend

Maße: RDm $21 \mathrm{~cm}$

Erh.: 1 Rfrgt.

Dat. nach Stück: 1. Jh. v. Chr.

Dat. nach Kontext: 3.-4. Viertel 1. Jh. v. Chr.

Parallelen: Ladstätter 2003a, K 15.

Kat. 56

Abb. 9 a. b; Taf. 4, 56

Medaillonschale Typ G31

AO: Depot des Efes Müzesi Selçuk Inv. 99/737.01

FO: Stratum 4

Fabric: ?

Überzug: ?

Dekor: Medaillon auf der Innenseite des Bodens mit Darstellung der Hygeia und des Asklepios

Maße: RDm?

Erh.: mehrere R-, B- und Wfrgte.

Dat. nach Stück: Mitte 2. Jh. v. Chr.

Dat. nach Kontext: Ende 2. Jh. - Mitte 1. Jh. v. Chr.

Parallelen: Mitsopoulos-Leon 1991, 55-56 Taf. 64-66, C1-12; Rotroff 1997, 110-117 Abb. 21-22, 362; Rotroff - Oliver 2003, 167-169.

Kat. 57

Taf. 4, 57

Oinochoe Typ G32

AO: Depot des österreichischen Grabungshauses Inv. 99/691.02 FO: Stratum 2

Fabric: 2.5 YR 6/6-5/1; hart, fein, feinporös, feiner Glimmer, häufig

Überzug: 2.5 YR 5/1, mattglänzend

Maße: RDm $6 \mathrm{~cm}$

Erh.: 1 Rfrgt.

Dat. nach Stück: -

Dat. nach Kontext: 2. Hälfte 1. Jh. v. Chr.

Parallelen: -

Kat. 58

Taf. 4, 58

Skyphos Typ G33

AO: Depot des österreichischen Grabungshauses Inv. 99/696.05 FO: Stratum 1, Bauschutt

Fabric: 5 YR 5/6; hart, fein, feinporös, sehr feiner Glimmer, selten

Überzug: 2.5 YR 4/6, glänzend

Maße: RDm 14,2 cm

Erh.: 1 Rfrgt.

Dat. nach Stück: -

Dat. nach Kontext: augusteisch-tiberisch

Parallelen: -

Kat. 59

Taf. 4, 59

Skyphos Typ G34

AO: Depot des österreichischen Grabungshauses Inv. 99/649B.07

FO: Stratum 2

Fabric: 5 YR 6/6; hart, sehr fein, feinporös, feiner Glimmer, 
selten

Überzug: 2.5 YR 5/6, glänzend

Maße: RDm $12 \mathrm{~cm}$

Erh.: 1 Rfrgt. mit Henkelansatz

Dat. nach Stück: augusteisch

Dat. nach Kontext: 2. Hälfte 1. Jh. v. Chr.

Parallelen: Ähnlich Ladstätter 2005a-c, K 86 (aber kleiner und dünnwandiger); (zur Form) Meyer-Schlichtmann 1988, S 3.

Kat. 60

Taf. 4, 60

Schale Typ G35

AO: Depot des österreichischen Grabungshauses Inv. 99/702.03 FO: Stratum 2

Fabric: 2.5 YR 5/8; hart fein, feinporös, feiner Glimmer, häufig Überzug: 2.5 YR 5/6, mattglänzend

Maße: RDm $9 \mathrm{~cm}$

Erh.: 1 Rfrgt.

Dat. nach Stück: -

Dat. nach Kontext: 2. Hälfte 1. Jh. v. Chr.

Parallelen: Hayes 1985, (Napfform) 34; Ladstätter 2007, Abb. 9 ,

Nr. 12 (in Grauer Ware mit schwarzem Überzug).

\section{Kat. 61}

Taf. 4, 61

Teller mit steil aufgebogener Wand Typ G36

AO: Depot des österreichischen Grabungshauses Inv. 99/695.09

FO: Stratum 3

Fabric: 7.5 YR 5/6; hart, fein, feinporös, feiner Glimmer, selten, rote Einschlüsse, fein, selten, weiße Einschlüsse, fein, selten, Quarz, fein-mittel, vereinzelt

Überzug: 2.5 YR 6/6, mattglänzend

Maße: RDm $18 \mathrm{~cm}$

Erh.: 1 Rfrgt.

Dat. nach Stück: letztes Viertel 1. Jh. v. Chr.

Dat. nach Kontext: 3.-4. Viertel 1. Jh. v. Chr.

Parallelen: Hayes 1985, Atlante 14; Ladstätter 2005a, K 69; Conspectus 1990, Form 4.6.1 (Fundorte in Korinth, Berenice, Bolsena, Conimbriga, Kempten, Tessin, Tipasa).

Westabhang-Nachfolgestil

\section{Kat. 62}

Taf. 4, 62

Skyphos mit Außenprofilierung Typ W1

AO: Depot des österreichischen Grabungshauses Inv. 99/736.04 FO: Stratum 1

Fabric: 5 YR 5/8; hart, fein, feinporös, feiner Glimmer, mittel Überzug: außen GLEY1 3/1; innen 10 R 4/6, metallisch glänzend

Maße: RDm $12 \mathrm{~cm}$

Erh.: 1 Rfrgt.

Dat. nach Stück: 2. Jh. v. Chr.

Dat. nach Kontext: augusteisch-tiberisch

Parallelen: Ladstätter 2003a, K 287; Ladstätter 2005a, K 7; Mitsopoulos-Leon 1991, B 41-79; Gassner 1997, Nr. 170-173; Liko 2001, Taf. 57, Nr. 48.

\section{Kat. 63}

Abb. 8 a. b; Taf. 4, 63

Oinochoe Typ W2

AO: Depot des österreichischen Grabungshauses Inv. 99/729.01
FO: Stratum 2

Fabric: 5 YR 7/4; hart, fein, feinporös, feiner Glimmer, vereinzelt, feine weiße Einschlüsse, mittel

Überzug: 5 YR 3/3, 5 YR 8/1, glänzend

Dekor: Silenskopf (Applik), Efeuranken

Maße: RDm 7,4 cm

Erh.: 1 Hfrgt.

Dat. nach Stück: spätes 2. Jh. v. Chr. - 60er Jahre des 1. Jhs. v. Chr.

Dat. nach Kontext: 2. Hälfte 1. Jh. v. Chr.

Parallelen: Mitsopoulos-Leon 1991, 55-60 B 27 Taf. 27; C 1 Taf. 64; LIMC VIII 2 (1997) 754 s. v. Silenoi 48 (E. Simon).

\section{Kat. 64}

Taf. 4, 64

Skyphos mit Profilierung Typ W3

AO: Depot des österreichischen Grabungshauses Inv. 99/695.05 FO: Stratum 3

Fabric: 7.5 YR 4/1; hart, fein, feinporös, sehr feiner Glimmer, vereinzelt, graue feine Einschlüsse, vereinzelt

Überzug: 5 YR 3/3, glänzend

Dekor: Schlickerdekor

Maße: RDm $10 \mathrm{~cm}$

Erh.: 1 Rfrgt.

Dat. nach Stück: 2.-1. Jh. v. Chr./Mitte 1. Jh. v. Chr. - Mitte 1. Jh. n. Chr.

Dat. nach Kontext: 3.-4. Viertel 1. Jh. v. Chr.

Parallelen: Mitsopoulos-Leon 1978, Taf. 41, Nr. 9; zur Form: Meyer-Schlichtmann 1988, S4 Kat. 15 Taf. 7.

\section{Kat. 65}

Skyphos $>$ Knidische Schale $<$ Typ W4

Abb. 7; Taf. 4, 65

AO: Depot des österreichischen Grabungshauses Inv. 99/641.17 FO: Stratum 3

Fabric: 5 YR 7/4; hart, fein, feinporös, feiner Glimmer, vereinzelt, weiße feine Einschlüsse, vereinzelt

Überzug: außen 2.5 YR 4/4-3/2; innen 2.5 YR 4/6; Punkte: 2.5

YR 8/1, mattglänzend

Dekor: Schlicker- und Ritzdekor

Maße: RDm $17 \mathrm{~cm}$

Erh.: 1 Rfrgt.

Dat. nach Stück: 1. Jh. v. Chr. - frühes 1. Jh. n. Chr.

Dat. nach Kontext: 3.-4. Viertel 1. Jh. v. Chr.

Parallelen: Ladstätter 2005a, K 94; Meriç 2002, K 39; Mitsopoulos-Leon 1991, B 140.

Kat. 66

Abb. 7

Becher Typ W4

AO: Depot des österreichischen Grabungshauses Inv. 99/729.17

FO: Stratum 2

Fabric: 5 YR 8/4; hart, fein, feinporös, feiner Glimmer, mittel, weiße feine Einschlüsse, selten

Überzug: 2.5 YR 6/6, mattglänzend

Dekor: Ritz- und Schlickerdekor

Maße: RDm $10 \mathrm{~cm}$

Erh.: 2 Rfrgte.

Dat. nach Stück: -

Dat. nach Kontext: 2. Hälfte 1. Jh. v. Chr.

Parallelen:- 


\section{Kat. 67}

Skyphos Typ W5

AO: Depot des österreichischen Grabungshauses Inv. 99/629.01 FO: Stratum 3

Fabric: 2.5 YR 6/8; hart, fein, feinporös, weiße feine Einschlüsse, vereinzelt

Taf. 4,67
Überzug: außen 2.5 YR 3/1; innen 2.5 YR 5/8, mattglänzend Dekor: Ritzdekor

Maße: RDm $8 \mathrm{~cm}$

Erh.: 1 Rfrgt.

Dat. nach Stück: -

Dat. nach Kontext: 3.-4. Viertel 1. Jh. v. Chr.

Parallelen: -

\section{Graue Ware mit schwarzem Überzug}

\section{Kat. 68}

Taf. 5, 68

Schale Typ GW1

AO: Depot des österreichischen Grabungshauses Inv. 99/651.25 FO: Stratum 1

Fabric: 7.5 YR 7/3; hart, fein, feinporös, feiner Glimmer, mittel-selten

Überzug: GLEY1 2.5/N, glänzend

Maße: RDm 6 (?) cm

Erh.: 1 Bfrgt.

Dat. nach Stück: 1. Viertel 1. Jh. n. Chr. -25 n. Chr.

Dat. nach Kontext: augusteisch-tiberisch

Parallelen: Meriç 2002, K 123. 124 Taf. 12; Hayes 1985, Atlante 24 (in ESB).

\section{Kat. 69}

Taf. 5, 69

Becher Typ GW2

AO: Depot des österreichischen Grabungshauses Inv. 99/663.08 FO: Stratum 1, Bauschutt

Fabric: 5 Y 5/1; hart, fein, feinporös, Glimmer, weiße feine Einschlüsse, vereinzelt

Überzug: 5 Y $5 / 1$ bis $6 / 1$, mattglänzend

Maße: RDm $11 \mathrm{~cm}$

Erh.: 1 Bfrgt.

Dat. nach Stück: -

Dat. nach Kontext: augusteisch-tiberisch

Parallelen: zur Form: Hayes 1985, Atlante 42 (in ESA); Ladstätter 2005a, K 174 (in dünnwandiger Ware).

\section{Kat. 70}

Taf. 5, 70

Tintenfäßchen oder Kanne Typ GW3

AO: Depot des österreichischen Grabungshauses Inv. 99/652.01 FO: Stratum 3

Fabric: GLEY1 5/N; hart, fein, feinporös, Glimmer, fein, selten, graue feine Einschlüsse, mittel

Überzug: GLEY1 2.5/N, glänzend

Maße: RDm $5 \mathrm{~cm}$

Erh.:1 Bfrgt.

Dat. nach Stück: -

Dat. nach Kontext: 3.-4. Viertel 1. Jh. v. Chr.

Parallelen: Conspectus 1990, Form 51.3.1, Taf. 45.

\section{Kat. 71}

Taf. 5, 71

Teller mit beidseitig verdickter Lippe Typ GW4

AO: Depot des österreichischen Grabungshauses Inv. 99/655.08 FO: Stratum 2

Fabric: 10 YR 4/2; sehr hart, fein, feinporös, feiner Glimmer, feine weiße Einschlüsse, selten

Überzug: GLEY1 2.5/N, glänzend

Maße: RDm $14 \mathrm{~cm}$

Erh.: 1 Rfrgt.

Dat. nach Stück: Mitte 1. Jh. v. Chr. $-20-30$ n. Chr.

Dat. nach Kontext: 2. Hälfte 1. Jh. v. Chr.

Parallelen: Mitsopoulos-Leon 1972, 505 Abb. 4, D (mit Dekor); Ladstätter 2005a, K 53 (in ESA).

Kat. 72

Taf. 5, 72

Platte Typ GW5

AO: Depot des österreichischen Grabungshauses Inv. 99/708.15B

FO: Stratum 3

Fabric: 7.5 YR 5/4; hart, fein, feinporös, sehr feiner Glimmer, häufig, weiße feine Einschlüße, selten

Überzug: 7.5 YR $5 / 3$ bis 4/1, glänzend

Maße: RDm $26 \mathrm{~cm}$

Erh.: 1 Rfrgt.

Dat. nach Stück: 2. Hälfte 1. Jh. v. Chr. - frühes 1. Jh. n. Chr

Dat. nach Kontext: 3.-4. Viertel 1. Jh. v. Chr.

Parallelen: Zabehlicky-Scheffenegger u. a. 1996, 42 f. Taf. 11, 3; Ladstätter 2005a, K 127; Mitsopoulos-Leon 1991, F 10; Meriç 2002, K 97-100.

Kat. 73

Taf. 5, 73

Teller mit hohem Rand Typ GW6

AO: Depot des österreichischen Grabungshauses Inv. 99/702.07 FO: Stratum 2

Fabric: 2.5 Y 5/2; hart, fein, feinporös, feiner Glimmer, vereinzelt

Überzug: 5 Y 2.5/1, glänzend

Maße: RDm $19 \mathrm{~cm}$

Erh.: 1 Rfrgt.

Dat. nach Stück: späthellenistisch

Dat. nach Kontext: 2. Hälfte 1. Jh. v. Chr.

Parallelen: -

Kat. 74

Taf. 5, 74

Teller Typ GW7

AO: Depot des österreichischen Grabungshauses Inv. 99/715.158

FO: Stratum 4

Fabric: 10 YR 5/3, (Rand) 7.5 YR 3/1; mittel-hart, fein, feinporös, Glimmer, weiße feine Einschlüsse, selten, feine Quarzeinschlüsse, selten, rote, sehr feine Einschlüsse, vereinzelt, dunkel- 
graue feine Einschlüsse, selten Überzug: 2.5 YR 2.5/1, glänzend

Dekor: Palmettenstempel, Roulettierung

Maße: RDm $36 \mathrm{~cm}$; BDm $10 \mathrm{~cm}$

Erh.: 13 Rfrgte., 3 Bfrgte., 27 Wfrgte.

Dat. nach Stück: späthellenistisch

Dat. nach Kontext: Ende 2. Jh. - Mitte 1. Jh. v. Chr. Parallelen:-

\section{Kat. 75}

Taf. 5, 75

Teller Typ GW8

AO: Depot des österreichischen Grabungshauses Inv. 99/649.11

FO: Stratum 2

Fabric: 2.5 Y 4/1; hart, fein, feinporös, sehr feiner Glimmer, mittel, weiße feine und mittlere Einschlüsse, vereinzelt

Überzug: 2.5 Y 2.5/1, mattglänzend

Maße: RDm 10,2 cm

Erh.: 1 Bfrgt.

Dat. nach Stück: 2. Hälfte 1. Jh. v. Chr. - frühes 1. Jh. n. Chr.

Dat. nach Kontext: 2. Hälfte 1. Jh. v. Chr.

Parallelen: Ladstätter 2005a, K 133.

Kat. 76

Taf. 5,76

Platte Typ GW9

AO: Depot des österreichischen Grabungshauses Inv. 99/708.14

FO: Stratum 3

Fabric: 10 YR 4/3; hart, fein, feinporös, Glimmer, mittel, weiße feine Einschlüsse, selten

Überzug: GLEY1 2.5/N, glänzend

Dekor: Palmettenstempel, Roulettierung

Maße: RDm 9,6 cm

Erh.: 1 Bfrgt.

Dat. nach Stück: -

Dat. nach Kontext: 3.-4. Viertel 1. Jh. v. Chr.

Parallelen: Mitsopoulos-Leon 1991, F 46.

Kat. 77

Taf. 5, 77

Platte Typ GW10

AO: Depot des österreichischen Grabungshauses Inv. 99/641.10

FO: Stratum 3

Fabric: 5 YR 6/6-4/1; hart, fein, feinporös, feiner Glimmer, vereinzelt

Überzug: 5 YR 6/6-2.5/1, Standring ist ausgespart, glänzend

Dekor: Rautenstempel, Roulettierung

Maße: RDm $12 \mathrm{~cm}$
Erh.: 1 Bfrgt.

Dat. nach Stück: -

Dat. nach Kontext: 3.-4. Viertel 1. Jh. v. Chr.

Parallelen: Mitsopoulos-Leon 1991, F 43.

Kat. 78

Taf. 5, 78

Teller Typ GW11

AO: Depot des österreichischen Grabungshauses Inv. 99/649B.12

FO: Stratum 2

Fabric: 10 YR 4/3; mittelhart, fein, feinporös, Glimmer, weiße feine Einschlüsse, selten, rötliche feine Einschlüsse, vereinzelt Überzug: 10 YR 2/1, glänzend

Dekor: Rautenstempel

Maße: RDm $16 \mathrm{~cm}$

Erh.: 1 Bfrgt.

Dat. nach Stück: -

Dat. nach Kontext: 2. Hälfte 1. Jh. v. Chr.

Parallelen:-

Kat. 79

Taf. 5, 79

Becher mit ausgebogenem Rand Typ GW12

AO: Depot des österreichischen Grabungshauses Inv. 99/663.11 FO: Stratum 1, Bauschutt

Fabric: 5 Y 4/1; hart, fein, feinporös, Glimmer, weiße feine Einschlüsse, viel

Überzug: GLEY1 2.5/N, glänzend

Maße: RDm $16 \mathrm{~cm}$

Erh.: 1 Rfrgt.

Dat. nach Stück: -

Dat. nach Kontext: augusteisch-tiberisch

Parallelen: Ladstätter 2003a-c, K 71.

Kat. 80

Taf. 5, 80

Schale Typ GW13

AO: Depot des österreichischen Grabungshauses Inv. 99/695.11 FO: Stratum 3

Fabric: 2.5 Y 6/1; sehr hart, fein, feinporös, sehr feiner Glimmer, vereinzelt

Überzug: 5 YR 4/1, matt

Maße: RDm $14 \mathrm{~cm}$

Erh.: 1 Rfrgt.

Dat. nach Stück: -

Dat. nach Kontext: 3.-4. Viertel 1. Jh. v. Chr.

Parallelen:-

\section{Reliefbecher}

Kat. 81

Becher Typ R1

AO: Depot des österreichischen Grabungshauses Inv. 99/702.18

FO: Stratum 2

Fabric: 5 YR 6/4; hart, fein, feinporös, feiner Glimmer, mittel Überzug: 2.5 YR 2.5/1-5/4, mattglänzend

Dekor: ionisches Kymation

Maße: RDm $11 \mathrm{~cm}$
Erh.: 1 Rfrgt.

Dat. nach Stück: fortgeschrittenes 2. Jh. v. Chr.

Dat. nach Kontext: 2. Hälfte 1. Jh. v. Chr.

Parallelen: Mitsopoulos-Leon 1991, D 35; Ladstätter 2005a, K 13; Dereboylu 2001, Nr. 201; Rogl 2001b, RB 1, Abb. 3. 


\section{Kat. 82}

Taf. 5, 82

Becher Typ R2

AO: Depot des österreichischen Grabungshauses Inv. 99/702.19

FO: Stratum 2

Fabric: GLEY1 5/N; hart, fein, feinporös, feiner Glimmer, mittel

Überzug: GLEY1 3/N, mattglänzend

Dekor: liegendes lesbisches Kymation

Maße: RDm $10 \mathrm{~cm}$

Erh.: 1 Rfrgt.

Dat. nach Stück: -

Dat. nach Kontext: 2. Hälfte 1. Jh. v. Chr.

Parallelen: Mitsopoulos-Leon 1991, D 13 (Randform); D 57

(Dekor); Dereboylu 2001, Nr. 201 Taf. 22.

\section{Kat. 83}

Taf. 5,83

Becher mit nach außen geknickter Lippe Typ R3

AO: Depot des österreichischen Grabungshauses Inv. 99/736.03

FO: Stratum 1

Fabric: 2.5 YR 6/8; hart, fein, feinporös, feiner Glimmer, selten

Überzug: außen 2.5 YR 3/1; innen 2.5 YR 3/2, glänzend

Maße: RDm $12 \mathrm{~cm}$

Erh.: 1 Rfrgt.

Dat. nach Stück: (Südtor-Werkstatt) vor der Mitte des 2. Jhs. v. Chr.

Dat. nach Kontext: augusteisch-tiberisch

Parallelen: Mitsopoulos-Leon 1991, D 44. 52.

\section{Kat. 84}

Taf. 5, 84

Becher Typ R4

AO: Depot des österreichischen Grabungshauses Inv. 99/702.27

FO: Stratum 2

Fabric: 7.5 YR 5/6; hart, fein, feinporös, feiner Glimmer, vereinzelt

Überzug: 2.5 YR 2.5/1, metallisch glänzend

Maße: RDm $12 \mathrm{~cm}$

Erh.: 1 Rfrgt.

Dat. nach Stück: -

Dat. nach Kontext: 2. Hälfte 1. Jh. v. Chr.

Parallelen: Mitsopoulos-Leon 1991, D 55.

\section{Kat. 85}

Taf. 6, 85

Becher Typ R5

AO: Depot des österreichischen Grabungshauses Inv. 99/702.25

FO: Stratum 2

Fabric: 5 YR 6/6; hart, fein, feinporös, feiner Glimmer, vereinzelt

Überzug: 2.5 YR 5/6-3/1, metallisch glänzend

Maße: RDm $10 \mathrm{~cm}$

Erh.: 1 Rfrgt.

Dat. nach Stück:-

Dat. nach Kontext: 2. Hälfte 1. Jh. v. Chr.

Parallelen: Mitsopoulos-Leon 1991, D 41.

\section{Kat. 86}

Taf. 6, 86

Becher Typ R6

AO: Depot des österreichischen Grabungshauses Inv. 99/652.18
FO: Stratum 3

Fabric: 2.5 YR 4/1; hart, fein, feinporös, feiner Glimmer, mittel Überzug: GLEY1 2.5/N, matt

Maße: RDm $13 \mathrm{~cm}$

Erh.: 1 Rfrgt.

Dat. nach Stück: -

Dat. nach Kontext: 3.-4. Viertel 1. Jh. v. Chr.

Parallelen: -

Kat. 87

Abb. 11

Becher des Philon, Typ R7

AO: Depot des österreichischen Grabungshauses Inv. 99/627.07 FO: Stratum 2 und 3

Fabric: GLEY 6/N; hart, fein, feinporös, feiner Glimmer, mittel Überzug: GLEY $16 / \mathrm{N}$ bis $4 / \mathrm{N}$, matt

Dekor: lesbisches Kymation, hohe Blüte, Signatur des Philon

Maße: RDm 4,6 cm

Erh.: 1 Bfrgt., 7 Wfrgte.

Dat. nach Stück: Anfang 1. Jh. v. Chr.

Dat. nach Kontext: 2. Hälfte - letztes Viertel 1. Jh. v. Chr.

Parallelen: Rogl 2001c, 144; Laumonier 1977, RB 9340. 4620.

Kat. 88

ohne Abb.

Becher des Philon (?), Typ R2

AO: Depot des österreichischen Grabungshauses Inv. 99/729.29

FO: Stratum 2

Fabric: 10 YR 7/4; hart, fein, feinporös, feiner Glimmer, mittel Überzug: 10 YR 3/1, matt

Dekor: Laufender Hund (nach unten), Akanthusblatt, vertikale Punktreihe, Philonblüte

Maße: RDm $13 \mathrm{~cm}$

Erh.:1 Rfrgt., 1 Wfrgt.

Dat. nach Stück: Anfang 1. Jh. v. Chr.

Dat. nach Kontext: 2. Hälfte 1. Jh. v. Chr.

Parallelen: -

Kat. 89

Abb. 10

Becher des Philon, Typ R9

AO: Depot des österreichischen Grabungshauses Inv. 99/729.24

FO: Stratum 2

Fabric: GLEY1 4/N; hart, fein, feinporös, feiner Glimmer, mittel, weisse feine Einschlüsse, selten

Überzug: 10 Y 4/1, matt

Dekor: Fisch, Unterkörper von einem Jüngling mit Fackel, Signaturrest Philon am Boden

Maße: $R D m 4,8 \mathrm{~cm}$

Erh.: 1 Bfrgt.

Dat. nach Stück: Anfang 1. Jh. v. Chr.

Dat. nach Kontext: 2. Hälfte 1. Jh. v. Chr.

Parallelen: -

Kat. 90

Abb. 12

Becher des Athenaios, Typ R7

AO: Depot des österreichischen Grabungshauses Inv. 99/643.47 FO: Stratum 1, Bauschutt

Fabric: GLEY 1 5/N; hart, fein, feinporös, feiner Glimmer, mittel 
Überzug: GLEY 1 4/N, matt

Dekor: spitze Blattschuppen, Reste der Signatur des Athenaios Maße: RDm 5,0 cm

Erh.: 1 Bfrgt.

Dat. nach Stück: Ende des 1. Jhs. v. Chr.

Dat. nach Kontext: augusteisch-tiberisch

Parallelen: Laumonier 1977, Taf. 52, Nr. 3431.

Kat. 91

Taf. 10, 91

Becher Typ R2

AO: Depot des österreichischen Grabungshauses Inv. 99/720.04

FO: Stratum 1, Bauschutt

Fabric: 5 YR 5/6; hart, sehr fein, sehr feinporös, feiner Glimmer, mittel

Überzug: 2.5 YR 4/1, matt

Dekor: achtblättrige Rosetten, ionisches Kymation, spitze Blattschuppen

Maße: RDm 12,4 cm

Erh.: 1 Wfrgt.

Dat. nach Stück: Ende 2. - spätes 1. Jh. v. Chr.

Dat. nach Kontext: augusteisch-tiberisch

Parallelen: -

Kat. 92

Taf. 10, 92

Becher Typ R2

AO: Depot des österreichischen Grabungshauses Inv. 99/702.49

FO: Stratum 2

Fabric: GLEY1 4/N; hart, fein, feinporös, feiner Glimmer, selten

Überzug: GLEY1 5/N, matt

Dekor: Zungenblatt, liegende S-Spirale

Maße: RDm $13 \mathrm{~cm}$

Erh.: 1 Rfrgt., 1 Wfrgt.

Dat. nach Stück: Ende 2. - spätes 1. Jh. v. Chr.

Dat. nach Kontext: 2. Hälfte 1. Jh. v. Chr.

Parallelen: -

\section{Kat. 93}

Taf. 10,93

Becher Typ R2

AO: Depot des österreichischen Grabungshauses Inv. 99/663.04

FO: Stratum 1, Bauschutt

Fabric: GLEY1 4/1; hart, fein, feinporös, feiner Glimmer, mittel

Überzug: GLEY1 2.5/N, matt

Dekor: Perlstab, ionisches Kymation, spitze Blattschuppen

Maße: RDm $12 \mathrm{~cm}$

Erh.: 1 Rfrgt.

Dat. nach Stück: -

Dat. nach Kontext: augusteisch-tiberisch

Parallelen: Mitsopoulos-Leon 1991, D 30; Günay Tuluk 2003,

Kat. 20; Laumonier 1977, Taf. $10 \mathrm{u}$.

\section{Kat. 94}

Taf. 10, 94

Becher Typ R7

AO: Depot des österreichischen Grabungshauses Inv. 99/696.08

FO: Stratum 1, Bauschutt

Fabric: 10 YR 5/6; hart, fein, feinporös, feiner Glimmer, mittel
Überzug: 10 R 5/6, mattglänzend

Dekor: Lotusblatt (nymphaea nelumbo)

Erh.: 1 Wfrgt.

Dat. nach Stück: -

Dat. nach Kontext: augusteisch-tiberisch

Parallelen: Rogl 2007, 192 Abb. 2.

Kat. 95

Taf. 10, 95

Becher Typ R7

AO: Depot des österreichischen Grabungshauses Inv. 99/729.28

FO: Stratum 2

Fabric: 10 YR 5/1; hart, fein, feinporös, feiner Glimmer, mittel

Überzug: 10 YR 6/2, matt

Dekor: Pinienzapfen

Maße: RDm 4 cm

Erh.: 1 Bfrgt.

Dat. nach Stück: Ende 2. - 1. Jh. v. Chr.

Dat. nach Kontext: 2. Hälfte 1. Jh. v. Chr.

Parallelen:-

Kat. 96

Taf. 10, 96

Becher Typ R7

AO: Depot des österreichischen Grabungshauses Inv. 99/655.28

FO: Stratum 2

Fabric: 7.5 YR 6/6; hart, fein, feinporös, feiner Glimmer, selten Überzug: 2.5 YR 3/2, matt

Dekor: Pinienzapfenbuckel, 12-blättrige Rosette

Erh.: 2 Wfrgte.

Dat. nach Stück: Ende 2. - spätes 1. Jh. v. Chr.

Dat. nach Kontext: 2. Hälfte 1. Jh. v. Chr.

Parallelen:-

Kat. 97

Taf. 10, 97

Becher Typ R8

AO: Depot des österreichischen Grabungshauses Inv. 99/663.05 FO: Stratum 1, Bauschutt

Fabric: 10 YR 5/6; hart, fein, feinporös, feiner Glimmer, mittel

Überzug: 10 R 5/6, mattglänzend

Dekor: Punktdekor (Noppen)

Erh.: 1 Wfrgt.

Dat. nach Stück: -

Dat. nach Kontext: augusteisch-tiberisch

Parallelen: Rogl 2001b, RB 11 Taf. 67; RB 24 Taf. 65. 69; Günay Tuluk 2003, Kat. 25 Taf. 43.

Kat. 98

Taf. 10, 98

Becher Typ R8

AO: Depot des österreichischen Grabungshauses Inv. 99/649.15

FO: Stratum 2

Fabric: 10 YR 5/6; hart, fein, feinporös, feiner Glimmer, selten

Überzug: GLEY1 4/1, stark abgerieben, matt

Dekor: Mäander mit Binnenstern

Erh.: 1 Wfrgt.

Dat. nach Stück: späthellenistisch

Dat. nach Kontext: 2. Hälfte 1. Jh. v. Chr.

Parallelen: Rogl 2001b, RB 16. 19. 21; Mitsopoulos-Leon 1991, D 34. D 52. 


\section{Kat. 99}

Becher Typ R9

AO: Depot des österreichischen Grabungshauses Inv. 99/715.145

FO: Stratum 4

Fabric: 10 YR 5/6; hart, fein, feinporös, feiner Glimmer, mittel Überzug: 10 R 5/6, mattglänzend

Dekor: bewegte Figur (Jüngling?)

Erh.: 1 Wfrgt.

Dat. nach Stück: voraugusteisch (vor der Bauzeit der Basilika)

Dat. nach Kontext: Ende 2. Jh. - Mitte 1. Jh. v. Chr.

Parallelen: Mitsopoulos-Leon 1991, D 24.

\section{Kat. 100}

Taf. 6, 100

Becher Typ R7

AO: Depot des österreichischen Grabungshauses Inv. 99/715.148

FO: Stratum 4

Gattung: Reliefbecher

Fabric: 7.5 YR 6/6; hart, fein, feinporös, feiner Glimmer, mittel
Überzug: 2.5 YR 5/6, matt

Dekor: Weinrebe

Erh.: 1 Wfrgt.

Dat. nach Stück: -

Dat. nach Kontext: Ende 2. Jh. - Mitte 1. Jh. v. Chr.

Parallelen: -

\section{Kat. 101}

ohne Abb.

Becher Typ R9

AO: Depot des österreichischen Grabungshauses Inv. 99/715.153

FO: Stratum 4

Fabric: GLEY 6/N; hart, fein, feinporös, feiner Glimmer, mittel Überzug: GLEY 2.5/N, metallisch glänzend

Dekor: tierische Darstellung (laufende Hunde)

Erh.: 1 Wfrgt.

Dat. nach Stück: -

Dat. nach Kontext: Ende 2. Jh. - Mitte 1. Jh. v. Chr. Parallelen: Gassner 1997, Taf. 14, 213.

\section{Tongrundige Ware}

\section{Kat. 102}

Spendenschälchen Typ T1

Taf. 6, 102

AO: Depot des österreichischen Grabungshauses Inv. 99/727.01

FO: Stratum 1, Bauschutt

Fabric: 5 YR 4/6; sehr hart, fein, feinporös, feiner Glimmer, mittel, weiße feine Einschlüsse, mittel

Maße: RDm 4 cn

Erh.:1 Frgt.

Dat. nach Stück: -

Dat. nach Kontext: augusteisch-tiberisch

Parallelen: -

\section{Kat. 103}

Taf. 6, 103

Schale Typ T2

AO: Depot des österreichischen Grabungshauses Inv. 99/651.07 FO: Stratum 1

Fabric: 5 YR 5/6; mittelhart, fein, feinporös, feiner Glimmer, selten

Überzug: 7.5 YR 7/3

Maße: RDm 12,8 cm

Erh.: 1 Rfrgt.

Dat. nach Stück: -

Dat. nach Kontext: augusteisch-tiberisch

Parallelen:-
Kat. 104

Skyphos Typ T3

Taf. 6, 104

AO: Depot des österreichischen Grabungshauses Inv. 99/732.11 FO: Stratum 3

Fabric: 2.5 YR 6/8; hart, fein, feinporös, weiße feine Einschlüsse, mittel

Überzug: 2.5 YR 6/8, matt

Maße: RDm $8 \mathrm{~cm}$

Erh.: 1 Rfrgt. mit Henkelansatz

Dat. nach Stück: -

Dat. nach Kontext: 3.-4. Viertel 1. Jh. v. Chr.

Parallelen: -

Kat. 105

Taf. 6, 105

Becher (?) Typ T4

AO: Depot des österreichischen Grabungshauses Inv. 99/652.13 FO: Stratum 3

Fabric: 2.5 YR 6/8; hart, fein, feinporös, Glimmer, weiße feine Einschlüsse, selten

Überzug: 2.5 YR 6/6, matt

Maße: RDm $8,8 \mathrm{~cm}$

Erh.: 1 Rfrgt.

Dat. nach Stück: -

Dat. nach Kontext: 3.-4. Viertel 1. Jh. v. Chr.

Parallelen:- 


\section{Dünnwandige Ware}

\section{Kat. 106}

Becher mit kleiner Lippe Typ D1

AO: Depot des österreichischen Grabungshauses Inv. 99/702.10 FO: Stratum 2

Fabric: 2.5 YR 6/8; hart, fein, feinporös, Glimmer fein, häufig, weiße Einschlüsse, vereinzelt

Überzug: 7.5 YR $6 / 2$ bis 5/2, matt

Maße: RDm $10 \mathrm{~cm}$

Erh.: 1 Rfrgt.

Dat. nach Stück: 2. Jh. v. Chr. - Mitte 1. Jh. v. Chr.

Dat. nach Kontext: 2. Hälfte 1. Jh. v. Chr.

Parallelen: Meriç 2002, K 339-341 (Atlante I, 1).

\section{Kat. 107}

Taf. 6, 107

Becher mit auswärts gebogener Lippe Typ D2

AO: Depot des österreichischen Grabungshauses Inv. 99/691.07 FO: Stratum 2

Fabric: 5 YR 5/6; sehr hart, sehr fein, feinporös, Glimmer, weiße feine Einschlüsse, mittel

Überzug: 5 YR 7/4-4/3

Überzug: 7.5 YR 5/1, matt

Maße: RDm 9,4 cm

Erh.: 1 Rfrgt.

Dat. nach Stück: 2. Hälfte 2. Jh. v. Chr.; 3. Viertel 1. Jh. v. Chr. - neronisch

Dat. nach Kontext: 2. Hälfte 1. Jh. v. Chr.

Parallelen: Hempel 2000, Form 626b, Nr. 8; Meriç 2002, K 342-345 (Atlante I, 27); Ladstätter 2005a, K 156. K 327; Marabini-Moevs 1973, 69. 70 Form VIII Nr. 86 Taf. 8, 60.

\section{Kat. 108}

Taf. 6, 108

Konischer Becher Typ D3

AO: Depot des österreichischen Grabungshauses Inv. 99/695.18 FO: Stratum 3

Fabric: 5 YR 6/4; hart, sehr fein, feinporös, sehr feiner Glimmer, häufig

Maße: RDm $8 \mathrm{~cm}$

Erh.: 1 Rfrgt.

Dat. nach Stück: 1. Jh. v. Chr.

Dat. nach Kontext: 3.-4. Viertel 1. Jh. v. Chr.

Parallelen: Marabini-Moevs 1973, Form VII, Nr. 78 Taf. 7.

Kat. 109

Taf. 6, 109

Becher Typ D4

AO: Depot des österreichischen Grabungshauses Inv. 99/672.07

FO: Stratum 3

Fabric: 7.5 YR 3/1; sehr hart, sehr fein, feinporös

Überzug: 7.5 YR $4 / 1$ bis $4 / 3$, matt

Maße: RDm $8 \mathrm{~cm}$

Erh.: 1 Rfrgt.

Dat. nach Stück: spätrepublikanisch

Dat. nach Kontext: 3.-4. Viertel 1. Jh. v. Chr.

Parallelen: Marabini-Moevs 1973, 101 Form XXXII, Nr. 163 Taf. 15.

\section{Kat. 110}

Taf. 6, 110

Halbkugeliger Becher Typ D5

AO: Depot des österreichischen Grabungshauses Inv. 99/641.07 FO: Stratum 3

Fabric: 2.5 YR 4/8; mittelhart, fein, feinporös, Glimmer Überzug: außen 7.5 YR 5/2; innen 2.5 YR 5/6, fleckig, matt Maße: RDm 9,6 cm

Erh.: 2 Rfrgt.

Dat. nach Stück: 25 v. Chr. -25 n. Chr.

Dat. nach Kontext: 3.-4. Viertel 1. Jh. v. Chr.

Parallelen: Meriç 2002, K 385; Mitsopoulos-Leon 1991, K 18.

\section{Kat. 111}

Taf. 6, 111

Becher Typ D6

AO: Depot des österreichischen Grabungshauses Inv. 99/646.01

FO: Stratum 3

Fabric: 2.5 YR 5/6 und 10 YR 5/1; sehr hart, sehr fein, feinporös, sehr feiner Glimmer, mittel

Überzug: 10 YR 6/2, matt

Maße: RDm $8 \mathrm{~cm}$

Erh.: 1 Rfrgt.

Dat. nach Stück: spätes 1. Jh. v. Chr. - Mitte 1. Jh. n. Chr.

Dat. nach Kontext: 3.-4. Viertel 1. Jh. v. Chr.

Parallelen: Meriç 2002, K 359 (Atlante I/78); Ladstätter 2005a, K 159-162.

Kat. 112

Taf. 6, 112

Trichterförmiger Becher Typ D7

AO: Depot des österreichischen Grabungshauses Inv. 99/652.05 FO: Stratum 3

Fabric: 10 R 5/6, Kern 10 R 4/1; sehr hart, sehr fein, feinporös, feiner Glimmer

Überzug: 10 R 4/6, Rand 10 R 2.5/1

Dekor: Facettierung

Maße: RDm $8 \mathrm{~cm}$

Erh.: 1 Rfrgt.

Dat. nach Stück: augusteisch

Dat. nach Kontext: 3.-4. Viertel 1. Jh. v. Chr.

Parallelen: Ladstätter 2005a, K 153.

Kat. 113

Taf. 6, 113

Becher Typ D8

AO: Depot des österreichischen Grabungshauses Inv.99/708.12 FO: Stratum 3

Fabric: 2.5 YR 5/8; hart, fein, feinporös, sehr feiner Glimmer, häufig

Überzug: 2.5 YR 5/6 bis 4/1, matt

Dekor: applizierte Dornen

Maße: RDm 11,2 cm

Erh.: 1 Rfrgt.

Dat. nach Stück: 1.-3. Jh. n. Chr.

Dat. nach Kontext: 3.-4. Viertel 1. Jh. v. Chr.

Parallelen: Ladstätter 2005a, K 537; zur Form: Meriç 2002, K 350 (Atlante I/3); Mayet 1980, II D. 


\section{Kat. 114}

Becher mit verdickter Lippe Typ D9

AO: Depot des österreichischen Grabungshauses Inv.99/641.09 FO: Stratum 3

Fabric: 2.5 YR 5/6; hart, sehr fein, feinporös, viel Glimmer

Überzug: 10 YR 3/1, matt

Maße: RDm $10 \mathrm{~cm}$

Erh.: 1 Rfrgt.

Dat. nach Stück: tiberisch-frühclaudisch (?)

Dat. nach Kontext: 3.-4. Viertel 1. Jh. v. Chr.

Parallelen: D12. D13; Marabini Moevs 1973, Form LVII, Nr. 300 Taf. 33 (hier kleinere Form).

\section{Kat. 115}

Taf. 6, 115

Becher mit verdickter Lippe Typ D10

AO: Depot des österreichischen Grabungshauses Inv. 99/705.08 FO: Stratum 3

Fabric: 5 YR 5/6, Kern 7.5 YR 6/2; sehr hart, fein, feinporös, Glimmer, sehr feine dunkelgraue Einschlüsse, selten

Überzug: 5 YR 7/4, matt

Maße: RDm $8 \mathrm{~cm}$

Erh.: 1 Rfrgt.

Dat. nach Stück: -

Dat. nach Kontext: 3.-4. Viertel 1. Jh. v. Chr.

Parallelen: -

\section{Kat. 116}

Taf. 6, 116

Konischer Becher Typ D11

AO: Depot des österreichischen Grabungshauses Inv. 99/732.04 FO: Stratum 3

Fabric: 2.5 YR 4/8; hart, fein, feinporös, feiner Glimmer, häufig

Überzug: 2.5 YR 6/6-5/4

Maße: RDm $10 \mathrm{~cm}$

Erh.: 1 Rfrgt.

Dat. nach Stück: -

Dat. nach Kontext: 3.-4. Viertel 1. Jh. v. Chr.

Parallelen: -

\section{Kat. 117}

Taf. 6, 117

Becher mit eingezogenem Rand Typ D12

AO: Depot des österreichischen Grabungshauses Inv. 99/726.04

FO: Stratum 3

Fabric: 2.5 YR 5/8; hart, sehr fein, feinporös, weiße feine Einschlüsse, vereinzelt

Überzug: 2.5 YR 6/6, matt

Maße: RDm $8 \mathrm{~cm}$

Erh.: 1 Rfrgt.

Dat. nach Stück: -

Dat. nach Kontext: 3.-4. Viertel 1. Jh. v. Chr.

Parallelen: -

\section{Kat. 118}

Taf. 6, 118

Schale mit eingeschnürter Wand Typ D13

AO: Depot des österreichischen Grabungshauses Inv. 99/674.06

FO: Stratum 2

Fabric: 5 YR 4/6; sehr hart, sehr fein, feinporös, Glimmer, weiße feine Einschlüsse, mittel

Überzug: 5 YR 7/4 und 6/1

Maße: RDm $8 \mathrm{~cm}$

Erh.: 1 Rfrgt.

Dat. nach Stück: republikanisch-tiberisch

Dat. nach Kontext: 3.-4. Viertel 1. Jh. v. Chr.

Parallelen: Meriç 2002, K 382 (Atlante II/232. II/405); Mitsopoulos-Leon 1991, K 18; Mayet 1980, F 33; Marabini-Moevs 1973, Nr. 142 Taf. 13.

Kat. 119

Taf. 6, 119

Skyphos Typ D14

AO: Depot des österreichischen Grabungshauses Inv. 99/651.08 FO: Stratum 1

Fabric: 7.5 YR 5/6, hart, sehr fein, feinporös

Überzug: 10 YR 4/1, matt

Maße: RDm $9 \mathrm{~cm}$

Erh.: 1 Rfrgt., 1 Wfrgt. mit Henkelansatz

Dat. nach Stück: -

Dat. nach Kontext: augusteisch-tiberisch

Parallelen: -

Kat. 120

Taf. 6, 120

Krug Typ D15

AO: Depot des österreichischen Grabungshauses Inv. 99/702.11 FO: Stratum 2

Fabric: 5 YR 7/8; hart, sehr fein, feinporös

Überzug: 2.5 YR 6/4; Lippe: 5 YR 7/4, matt

Maße: RDm 6,4 cm

Erh.: 1 Rfrgt.

Dat. nach Stück: 1.-3. Jh. n. Chr.

Dat. nach Kontext: 2. Hälfte 1. Jh. v. Chr.

Parallelen: Ladstätter 2005a, K 538.

\section{Kat. 121}

Taf. 6, 121

Becher mit hohem Standring Typ D16

AO: Depot des österreichischen Grabungshauses Inv. 99/708.11 FO: Stratum 3

Fabric: 5 YR 5/6 u. 4/1; hart, sehr fein, feinporös, sehr feiner Glimmer, mittel

Überzug: 5 YR 5/4, matt

Maße: RDm $6,8 \mathrm{~cm}$

Erh.: 1 Bfrgt.

Dat. nach Stück: Mitte 2. Jh. v. Chr. -3 . Viertel des 1. Jhs. n. Chr.

Dat. nach Kontext: 3.-4. Viertel 1. Jh. v. Chr.

Parallelen: Marabini-Moevs 1973, Form XIV, Nr. 101. 103 Taf. 9.

Kat. 122

Abb. 13; Taf. 7, 122

Becher Typ D17

AO: Depot des österreichischen Grabungshauses Inv. 99/715.154

FO: Stratum 4

Fabric: 5 YR 6/8, Kern 5 YR 5/1; sehr hart, fein, feinporös, Glimmer, schwarze Einschlüsse, mittel, selten, Quarzeinschlüsse, fein-mittel, selten, weiße, sehr feine Einschlüsse, selten, rote 
feine Einschlüsse, selten

Überzug: 5 YR 6/6 und 5/2

Dekor: Punktgirlande (Barbotine)

Maße: RDm 3,4 cm

Erh.: 3 Bfgrte., 23 Wfrgte.

Dat. nach Stück: $150-75$ v. Chr.

Dat. nach Kontext: Ende 2. Jh. - Mitte 1. Jh. v. Chr.

Parallelen: Marabini-Moevs 1973, Form I, Nr. 3 Taf. 1; Hempel 2000, Form 626b, Nr. 8; Ladstätter 2005a, K 171 (dort ohne Dekor).

\section{Kat. 123}

Taf. 6, 123

Becher Typ D18

AO: Depot des österreichischen Grabungshauses Inv. 99/702.13 FO: Stratum 2

Fabric: 5 YR 5/8; hart, fein, feinporös

Überzug: 2.5 YR 6/6, matt

Maße: RDm $5 \mathrm{~cm}$

Erh.: 1 Bfrgt.

Dat. nach Stück: Anfang 1. Jh. v. Chr. - 3. Viertel des 1. Jhs. v. Chr.

Dat. nach Kontext: 2. Hälfte 1. Jh. v. Chr.

Parallelen: Meriç 2002, K 475; Marabini-Moevs 1973, Form V-VI, Nr. 153 Taf. 14, 63

\section{Kat. 124}

Taf. 6, 124

Becher Typ D19

AO: Depot des österreichischen Grabungshauses Inv. 99/643.20

FO: Stratum 1, Bauschutt

Fabric: 2.5 Y 4/1; hart, sehr fein, feinporös

Überzug: GLEY1 2.5/N, mattglänzend
Maße: RDm $5 \mathrm{~cm}$

Erh.: 1 Bfrgt.

Dat. nach Stück: 1. Viertel 1. Jh. v. Chr. -25 n. Chr.

Dat. nach Kontext: augusteisch-tiberisch

Parallelen: Meriç 2002, K 462 Taf. 38, G13.

Kat. 125

Taf. 7, 125

Becher Typ D20

AO: Depot des österreichischen Grabungshauses Inv. 99/643.01

FO: Stratum 1, Bauschutt

Fabric: 2.5 YR 5/8; hart, fein, feinporös, Glimmer

Überzug: außen 7.5 YR 3/1 und 6/2; innen 2.5 YR 5/6, matt

Maße: RDm 3,4 cm

Erh.: 1 Bfrgt., 8 Wfrgte.

Dat. nach Stück: -

Dat. nach Kontext: augusteisch-tiberisch

Parallelen: Mitsopoulos-Leon 1991, K 3; Ladstätter 2005a, K 178. K 170; Marabini-Moevs 1973, Form I, Nr. 6 Taf. 1.

Kat. 126

Taf. 7, 126

Becher mit \Scheinfuß< Typ D21

AO: Depot des österreichischen Grabungshauses Inv. 99/696.19

FO: Stratum 1, Bauschutt

Fabric: 2.5 YR 6/6; sehr hart, sehr fein, feinporös, Glimmer

Überzug: 2.5 YR 7/4, matt

Maße: RDm $6 \mathrm{~cm}$

Erh.: 1 Bfrgt.

Dat. nach Stück: 1. Jh. n. Chr.

Dat. nach Kontext: augusteisch-tiberisch

Parallelen: Meriç 2002, 73; Ladstätter 2005a, K 23; Mitsopoulos-Leon 1991, K1.

\section{Weißgrundige Ware}

Kat. 127

Einhenkeliger Krug Typ L1

AO: Depot des österreichischen Grabungshauses Inv. 99/729A.02

FO: Stratum 2

Fabric: 7.5 YR 6/4; hart, fein, feinporös, feiner Glimmer, mittel, weiße feine Einschlüsse, mittel

Überzug: 2.5 YR 8/3, 5 YR 5/6 und 4/6, matt

Maße: RDm 3,4 cm

Erh.: 1 Rfrgt. mit Henkelansatz

Dat. nach Stück: augusteisch - Mitte 1. Jh. n. Chr.

Dat. nach Kontext: 2. Hälfte 1. Jh. v. Chr.

Parallelen: Meriç 2002, K 62; Mitsopoulos-Leon 1991, E 14.

\section{Kat. 128}

Taf. 7, 128

Krug (?) Typ L2

AO: Depot des österreichischen Grabungshauses Inv. 99/666.01 FO: Stratum 4

Fabric: 5 YR 7/4; hart, fein, feinporös, feiner Glimmer, mittel Überzug: 2.5 YR 7/6 und 2.5 YR 8/1, matt

Maße: RDm $10 \mathrm{~cm}$

Erh.: 1 Rfrgt., 2 Wfrgte.

Dat. nach Stück: -
Dat. nach Kontext: Ende 2. Jh. - Mitte 1. Jh. v. Chr. Parallelen: Dereboylu 2001, Kat. 42 Taf. 12.

Kat. 129

Taf. 7, 129

Krug mit tordiertem Henkel Typ L3

AO: Depot des österreichischen Grabungshauses Inv. 99/618.06 FO: Stratum 1, Bauschutt

Fabric: 7.5 YR 5/6; hart, fein, feinporös, feiner Glimmer, mittel, feine weiße Einschlüsse, selten

Überzug: 5 YR 8/1, matt

Maße: RDm $2 \mathrm{~cm}$

Erh.: 1 Rfrgt. mit Henkelansatz

Dat. nach Stück: -

Dat. nach Kontext: augusteisch-tiberisch

Parallelen: -

Kat. 130

Taf. 7, 130

Zweihenkeliger Krug Typ L4

AO: Depot des österreichischen Grabungshauses Inv. 99/704.25 FO: Stratum 2

Fabric: 10 YR 6/4; hart, fein, feinporös, feiner Glimmer, mittel Überzug: 2.5 Y $8 / 2$, matt 
Maße: RDm $12 \mathrm{~cm}$

Erh.: 1 Rfrgt.

Dat. nach Stück: -

Dat. nach Kontext: 2. Hälfte 1. Jh. v. Chr.

Parallelen: Meriç 2002, K 64.

\section{Kat. 131}

Taf. 7, 131

Krug Typ L5

AO: Depot des österreichischen Grabungshauses Inv. 99/663.12

FO: Stratum 1, Bauschutt

Fabric: 2.5 YR 5/6; hart, fein, feinporös, feiner Glimmer, mittel, weiße feine Einschlüsse, häufig, mittlere weiße Einschlüsse, vereinzelt

Überzug: 5 YR 8/1, Rand 5 YR 5/4, matt

Maße: RDm $6 \mathrm{~cm}$

Erh.: 2 Bfrgte.

Dat. nach Stück: 2. Hälfte 2. Jh. v. Chr.

Dat. nach Kontext: augusteisch-tiberisch

Parallelen: Hempel 2000, Form 114: Hübner 2000, Abb. 4 Nr. 9.

\section{Kat. 132}

Taf. 7, 132

Einhenkeliger Krug Typ L6

AO: Depot des österreichischen Grabungshauses Inv. 99/643.04 FO: Stratum 1, Bauschutt

Fabric: 5 YR 5/6; hart, fein, feinporös, feiner Glimmer, mittel, weiße Einschlüsse, fein-mittel, vereinzelt

Überzug: 2.5 Y $8 / 1$, matt

Maße: RDm $12 \mathrm{~cm}$

Erh.: 1 Bfrgt.

Dat. nach Stück:1. Viertel 1. Jh. v. Chr. - Mitte 1. Jh. n. Chr.

Dat. nach Kontext: augusteisch-tiberisch

Parallelen: Meriç 2002, K 54 ; Dereboylu 2001, Kat. 10 Taf. 10; Smetana-Scherrer 1984, 667. 669 Taf. 51; Schäfer 1968, F 11 Taf. 45 .

\section{Kat. 133}

Taf. 7, 133

Unbestimmtes geschlossenes Gefäß Typ L7

AO: Depot des österreichischen Grabungshauses Inv. 99/643.30 FO: Stratum 1, Bauschutt

Fabric: 5 YR 5/6; mittelhart, fein, feinporös, feiner Glimmer, vereinzelt, weiße feine Einschlüsse, selten

Überzug: 5 YR 8/1, 5 YR 6/6, matt

Maße: RDm $6 \mathrm{~cm}$

Erh.: 1 Bfrgt.

Dat. nach Stück: -

Dat. nach Kontext: augusteisch-tiberisch

Parallelen: Dereboylu 2001, Kat. 39 Taf. 11.

\section{Kat. 134}

Taf. 7, 134

Thymiaterion Typ L8

AO: Depot des österreichischen Grabungshauses Inv. 99/727.02

FO: Stratum 1, Bauschutt

Fabric: 10 YR 6/3; hart, fein, feinporös, feiner Glimmer, selten, feine weiße Einschlüsse, vereinzelt

Überzug: 10 YR 8/2, matt

Maße: RDm $10 \mathrm{~cm}$
Erh.: 1 Bfrgt.

Dat. nach Stück: Mitte 1. Jh. v. Chr. - flavisch

Dat. nach Kontext: augusteisch-tiberisch

Parallelen: Meriç 2002, K 90 (später Typ).

\section{Kat. 135}

Taf. 7, 135

Unbestimmtes offenes Gefäß Typ L9

AO: Depot des österreichischen Grabungshauses Inv. 99/655.27 FO: Stratum 2

Fabric: 5 YR 5/4-4/2; hart, fein, feinporös, feiner Glimmer, mittel, weiße feine Einschlüsse, mittel

Überzug: 5 YR 5/4-3/2, 2.5 Y 7/3, matt

Maße: RDm $21 \mathrm{~cm}$

Erh.: 1 Rfrgt., 4 Wfrgte.

Dat. nach Stück: -

Dat. nach Kontext: 2. Hälfte 1. Jh. v. Chr.

Parallelen: Dereboylu 2001, Kat. 44 Taf. 12.

\section{Kat. 136}

Taf. 7, 136

Deckelknauf eines Thymiaterions Typ L10

AO: Depot des österreichischen Grabungshauses Inv. 99/696.10 FO: Stratum 1, Bauschutt

Fabric: 7.5 YR 6/4; hart, fein, feinporös, feiner Glimmer, selten, feine weiße Einschlüsse, mittel

Überzug: 7.5 YR 3/2, 2.5 Y 8/2, matt

Maße: RDm $4 \mathrm{~cm}$

Erh.: 1 Rfrgt.

Dat. nach Stück: -

Dat. nach Kontext: augusteisch-tiberisch

Parallelen: -

Kat. 137

Abb. 15; Taf. 7, 137

Lagynos

AO: Depot des österreichischen Grabungshauses Inv. 99/675.02 FO: Stratum 2

Gattung: Weißgrundige Ware

Fabric: 5 YR 7/4; hart, fein, feinporös, feiner Glimmer, mittel Überzug: 10 R 5/6; 5 YR 8/1, matt

Dekor: Teil eines Gesichtes; Dionysos mit lockigem Haar und Kranz

Erh.: 1 Wfrgt.

Dat. nach Stück: -

Dat. nach Kontext: 2. Hälfte 1. Jh. v. Chr.

Parallelen: LIMC III 1 (1986) 534, E, b, 37 s. v. Dionysos/Fufluns (M. Cristofani). 


\section{Importware}

\section{Kat. 138}

Skyphos mit gekehltem Standfuß Typ I1

AO: Depot des österreichischen Grabungshauses Inv. 99/641.04

FO: Stratum 3

Gattung: pergamenischer Import

Fabric: 10 R 5/6, hart, fein, feinporös, Glimmer, sehr feine bis feine weiße Einschlüsse, mittel

Überzug: 2.5 YR 5/6, mattglänzend

Maße: RDm 10,8 cm

Erh.: 1 Bfrgt.

Dat. nach Stück: letztes Viertel 2. Jh. v. Chr. - Mitte 1. Jh. v. Chr.

Dat. nach Kontext: 3.-4. Viertel 1. Jh. v. Chr.

Parallelen: Meyer-Schlichtmann 1988, S 8 Kat. 30 Taf. 29; Hayes 1985, 19. 24 Taf. 12.

\section{Kat. 139}

Taf. 7, 139

Skyphos Typ I2

AO: Depot des österreichischen Grabungshauses Inv. 99/651.22

FO: Stratum 1

Gattung: pergamenischer Import

Fabric: 10 R 5/6; hart, fein, feinporös, feiner Glimmer, vereinzelt

Überzug: 2.5 YR 5/6-2.5/1, fleckig, glänzend

Maße: RDm $9 \mathrm{~cm}$

Erh.: 1 Bfrgt.

Dat. nach Stück: Mitte 2. Jh. v. Chr. - Anfang 1. Jh. n. Chr

Dat. nach Kontext: augusteisch-tiberisch

Parallelen: Meyer-Schlichtmann 1988, S 1 Taf. 7 Abb. 1.

\section{Kat. 140}

Taf. 7, 140

Skyphos Typ I2 A

AO: Depot des österreichischen Grabungshauses Inv. 99/691.04 FO: Stratum 2

Gattung: pergamenischer Import

Fabric: 2.5 YR 6/8; hart, sehr fein, feinporös, sehr feiner Glimmer, häufig

Überzug: 2.5 YR 4/8, glänzend

Maße: RDm $8 \mathrm{~cm}$

Erh.: 1 Bfrgt.

Dat. nach Stück: 2. Jh. v. Chr. - Anfang 1. Jh. n. Chr.

Dat. nach Kontext: 2. Hälfte 1. Jh. v. Chr.

Parallelen: Meyer-Schlichtmann 1988, S 2; Ladstätter 2007, Abb. 5 (r., 2. von oben).

\section{Kat. 141}

Taf. 7, 141

Skyphos Typ I3

AO: Depot des österreichischen Grabungshauses Inv. 99/641.14

FO: Stratum 3

Gattung: pergamenischer Import

Fabric: 2.5 YR 5/8; hart, fein, feinporös, feiner Glimmer, vereinzelt

Überzug: außen 2.5 YR 4/4-2.5/1; innen 2.5 YR 4/8, fleckig, glänzend

Dekor: Efeusträußchen (Applik)

Maße: RDm $10 \mathrm{~cm}$
Erh.: 1 Rfrgt., 2 Wfrgte.

Dat. nach Stück: 2. Viertel 1. Jh. v. Chr. - Anfang 1. Jh. n. Chr. Dat. nach Kontext: 3.-4. Viertel 1. Jh. v. Chr.

Parallelen: Meyer-Schlichtmann 1988, S 3 Kat. 12 Taf. 7, E 67.

Kat. 142

Taf. 7, 142

Konischer Skyphos Typ I4

AO: Depot des österreichischen Grabungshauses Inv. 99/708.13 FO: Stratum 3

Gattung: pergamenischer Import

Fabric: 5 YR 7/6; hart, fein, feinporös, feiner Glimmer, vereinzelt

Überzug: 2.5 YR 4/8, glänzend

Maße: RDm $20 \mathrm{~cm}$

Erh.: 1 Rfrgt.

Dat. nach Stück: Ende 1. Jh. v. Chr. - Mitte 1. Jh. n. Chr.

Dat. nach Kontext: 3.-4. Viertel 1. Jh. v. Chr

Parallelen: Meyer-Schlichtmann 1988, S 5b Kat. 18 Taf. 8.

Kat. 143

Taf. 7, 143

Skyphos mit profiliertem Standfuß Typ I5

AO: Depot des österreichischen Grabungshauses Inv. 99/696.04

FO: Stratum 1, Bauschutt

Gattung: pergamenischer Import

Fabric: 5 YR 6/8; hart, sehr fein, feinporös, wenig feiner Glimmer, weiße feine Einschlüsse, vereinzelt

Überzug: 2.5 YR 5/6 und 3/1, fleckig, metallisch glänzend

Maße: RDm 11,2 cm

Erh.: 1 Bfrgt.

Dat. nach Stück: -

Dat. nach Kontext: augusteisch-tiberisch

Parallelen:-

Kat. 144

Taf. 7, 144

Schale mit eingekehltem Rand Typ I6

AO: Depot des österreichischen Grabungshauses Inv. 99/720.01 FO: Stratum 1, Bauschutt

Gattung: pergamenischer Import

Fabric: 2.5 YR 6/6; hart, fein, feinporös, weiße feine Einschlüsse, selten

Überzug: außen 10 YR 2.5/1; innen 2.5 YR 5/6, glänzend

Maße: RDm $10 \mathrm{~cm}$

Erh.: 1 Rfrgt.

Dat. nach Stück: 2. Viertel 1. Jh. v. Chr. - Anfang 1. Jh. n. Chr. Dat. nach Kontext: augusteisch-tiberisch

Parallelen: Meyer-Schlichtmann 1988, N 37 Kat. 179 Taf. 13; B

7 Kat. 65 Taf. 9.

Kat. 145

Taf. 7, 145

Schale mit Profilierung Typ I7

AO: Depot des österreichischen Grabungshauses Inv. 99/643.23

FO: Stratum 1, Bauschutt

Gattung: pergamenischer Import

Fabric: 7.5 YR 6/4; mittelhart, fein, feinporös, kein Glimmer, weiße feine Einschlüsse, mittel 
Überzug: GLEY1 2.5/N, stark abgeplatzt, matt

Maße: RDm $12 \mathrm{~cm}$

Erh.: 2 Rfrgte.

Dat. nach Stück: Mitte 1. Jh. v. Chr. -1 . Viertel des 2. Jhs. n. Chr.

Dat. nach Kontext: augusteisch-tiberisch

Parallelen: Meyer-Schlichtmann 1988, Sü 5 Kat. 337 Taf. 20

\section{Kat. 146}

Taf. 8, 146

Schale Typ I8

AO: Depot des österreichischen Grabungshauses Inv. 99/702.02

FO: Stratum 2

Gattung: pergamenischer Import

Fabric: 2.5 YR 6/6; hart, fein, feinporös, feiner Glimmer, mittel Überzug: 2.5 YR 4/8, glänzend

Maße: RDm $14 \mathrm{~cm}$

Erh.: 1Rfrgt.

Dat. nach Stück: Mitte 1. Jh. v. Chr. - 2. Jh. n. Chr.

Dat. nach Kontext: 2. Hälfte 1. Jh. v. Chr.

Parallelen: Zelle 1997, Abb. 16, 182; Meyer-Schlichtmann 1988, N24 Taf. 31 Abb. 153. 154.

\section{Kat. 147}

Taf. 8, 147

Schale mit ausladenem Rand Typ I9

AO: Depot des österreichischen Grabungshauses Inv. 99/666.24 FO: Stratum 4

Gattung: pergamenischer Import

Fabric: 2.5 YR 5/6; hart, fein, feinporös, weiße feine Einschlüsse, häufig

Überzug: 2.5 YR 2.5/1 mit 4/8, fleckig, glänzend

Maße: RDm $13 \mathrm{~cm}$

Erh.: 1 Rfrgt.

Dat. nach Stück: Mitte 1. Jh. v. Chr. - Mitte 2. Jh. n. Chr.

Dat. nach Kontext: Ende 2. Jh. - Mitte 1. Jh. v. Chr.

Parallelen: Meyer-Schlichtmann 1988, N11a Taf. 11 Abb. 132.

\section{Kat. 148}

Taf. 8, 148

Becher Typ I10

AO: Depot des österreichischen Grabungshauses Inv. 99/696.30

FO: Stratum 1, Bauschutt

Gattung: pergamenischer Import

Fabric: 2.5 YR 4/8; hart, fein, feinporös, weiße feine Einschlüsse, mittel

Überzug: außen 2.5 YR 2.5/1; innen 2.5 YR 4/8, glänzend

Maße: RDm 10,2 cm

Erh.: 1 Rfrgt.

Dat. nach Stück: -

Dat. nach Kontext: augusteisch-tiberisch

Parallelen:-

\section{Kat. 149}

Taf. 8, 149

Becher Typ I11

AO: Depot des österreichischen Grabungshauses Inv. 99/696.31

FO: Stratum 1, Bauschutt

Gattung: pergamenischer Import

Fabric: 2.5 YR 4/8; hart, fein, feinporös, weiße feine Einschlüsse, mittel

Überzug: außen 2.5 YR 2.5/1; innen 2.5 YR 4/8
Maße: RDm 11,6 cm

Erh.: 1 Rfrgt.

Dat. nach Stück: -

Dat. nach Kontext: augusteisch-tiberisch

Parallelen: -

\section{Kat. 150}

Taf. 8, 150

Becher Typ I12

AO: Depot des österreichischen Grabungshauses Inv. 99/675.07

FO: Stratum 2

Gattung: Import

Fabric: 5 YR 4/1; hart, fein, feinporös, feiner Glimmer, mittel, feine rote Einschlüsse und feine Quarzeinschlüsse, mittel

Überzug: 5 YR 3/1, matt

Maße: RDm $8 \mathrm{~cm}$

Erh.: 2 Rfrgte.

Dat. nach Stück: -

Dat. nach Kontext: 2. Hälfte 1. Jh. v. Chr.

Parallelen: -

\section{Kat. 151}

Taf. 8, 151

Krug Typ I13

AO: Depot des österreichischen Grabungshauses Inv. 99/643.14

FO: Stratum 1, Bauschutt

Gattung: pergamenischer Import

Fabric: 2.5 YR 6/8; hart, fein, feinporös, weiße feine Einschlüsse, selten

Überzug: 2.5 YR 4/8 bis 3/1, fleckig, glänzend

Dekor: innen facettiert

Maße: RDm $9 \mathrm{~cm}$

Erh.: 1 Rfrgt.

Dat. nach Stück: 1. Jh. v. Chr. -2 . Jh. n. Chr.

Dat. nach Kontext: augusteisch-tiberisch

Parallelen: Meyer-Schlichtmann 1988, Kr 2 Kat. 382 Taf. 33.

\section{Kat. 152}

Taf. 8, 152

Teller mit abknickendem Schrägrand Typ I14

AO: Depot des österreichischen Grabungshauses Inv. 99/704.18

FO: Stratum 2

Gattung: pergamenischer Import

Fabric: 2.5 YR 6/6; hart, fein, feinporös, Glimmer, dunkelgraue feine Einschlüsse, selten

Überzug: 2.5 YR 4/4-2.5/1, glänzend

Maße: RDm $18 \mathrm{~cm}$

Erh.: 1 Rfrgt.

Dat. nach Stück: Ende 2./Anfang 1. Jh. v. Chr. - Anfang 1. Jh. n. Chr.

Dat. nach Kontext: 2. Hälfte 1. Jh. v. Chr.

Parallelen: Meyer-Schlichtmann 1988, T2 Taf. 16 Abb. 248.

Kat. 153

Taf. 8, 153

Einhenkeliger Krug Typ I15

AO: Depot des österreichischen Grabungshauses Inv. 99/708.02 FO: Stratum 3

Gattung: knidischer Import

Fabric: 5 Y 4/1; hart, sehr fein, feinporös, weiße feine Einschlüsse, selten

Überzug: GLEY1 4/1, glänzend 
Dekor: Roulettierung

Maße: RDm $8 \mathrm{~cm}$

Erh.: 1 Rfrgt. mit Henkel

Dat. nach Stück: -

Dat. nach Kontext: 3.-4. Viertel 1. Jh. v. Chr.

Parallelen: -

\section{Kat. 154}

Halbkugeliger Becher Typ I16

AO: Depot des österreichischen Grabungshauses Inv. 99/675.09
FO: Stratum 2

Gattung: knidischer Import

Fabric: 5 YR 7/3; hart, fein, feinporös

Überzug: 5 YR 3/1, matt

Dekor: Kerbschnitt

Maße: -

Erh.: 1 Wfrgt.

Dat. nach Stück: -

Dat. nach Kontext: 2. Hälfte 1. Jh. v. Chr.

Parallelen: Rogl 2007, 185.

\section{Lampen}

\section{Kat. 155}

Dreischnauzige Lampe

AO: Depot des Efes Müzesi Selçuk Inv. 99/623.15

FO: Stratum 1

Fabric: 10 YR 6/1; hart, fein, feinporös; Glimmer, sehr fein, selten, weiße Einschlüsse, fein, wenig

Überzug: GLEY1 3/1, partiell aufgetragen, mattglänzend

Dekor: Einzelne Wellen (>Laufender Hund $`$ ) um den Diskus angeordnet, vegetabile Motive

Maße: RDm 3,9 cm

Erh.: in einem Stück, ohne Henkel

Dat. nach Stück: -

Dat. nach Kontext: augusteisch-tiberisch

Parallelen:-

\section{Kat. 156}

Lampe des Archetimos (?)

AO: Depot des Efes Müzesi Selçuk Inv. 99/70

FO: Stratum 2

Fabric: 10 YR 5/1; hart, fein, feinporös; sehr feiner Glimmer, mittel-selten, dunkelgraue, feine Einschlüsse, selten

Überzug: 10 YR 3/1, fleckig, matt

Dekor: Dreiblattsträußchen mit Fruchtständen, Lagynos auf dem Schnauzengang und Monogramm des Archetimos (?) auf dem Boden

Maße: RDm 4,5 cm

Erh.: ganz, ohne Henkel

Dat. nach Stück: Ende 2.-1. Jh. v. Chr.

Dat. nach Kontext: 2. Hälfte 1. Jh. v. Chr.

Parallelen: Giuliani 2004, 153, III a/6.

\section{Kat. 157}

Taf. 9, 157

Lampe des A (?)

AO: Depot des österreichischen Grabungshauses Inv. 99/729.27

FO: Stratum 2

Fabric: 2.5 Y 4/1; hart, fein, feinporös, feiner Glimmer, mittel, feine weiße Einschlüsse, selten

Überzug: GLEY1 2.5/N, matt

Dekor: Zungenblatt, vertikale Punktreihe, Signaturrest A (?)

Maße: RDm 3,6 cm

Erh.: 1 Bfrgt.

Dat. nach Stück: -

Dat. nach Kontext: 2. Hälfte 1. Jh. v. Chr.

Parallelen: -
Kat. 158

Taf. 8, 158

Ephesos-Lampe

AO: Depot des Efes Müzesi Selçuk Inv. 99/53

FO: Stratum 2

Fabric: 10 YR 3/1; hart, fein, feinporös; mit dunkelgrauen, mittel-feinen Einschlüssen, mittel, feiner Glimmer, mittel

Überzug: GLEY1 4/1, matt

Dekor: Zungenblätter, dazwischen Noppen; auf dem Schnauzengang ein einzelnes Zungenblatt

Maße: RDm $6 \mathrm{~cm}$

Erh.: in 2 Frgte., Henkel abgebrochen

Dat. nach Stück: -

Dat. nach Kontext: 2. Hälfte 1. Jh. v. Chr.

Parallelen: -

Kat. 159

Lampe

AO: Depot des Efes Müzesi Selçuk Inv. 99/42

FO: Stratum 2

Fabric: 2.5 Y 4/1; hart, fein, feinporös, feiner Glimmer, mittel

Überzug: GLEY1 3/1, partiell aufgetragen, Laufnasen, mattglänzend

Dekor: achtblättrige Rosetten um den Diskus, stilisierte Bukranie auf dem Schnauzengang

Maße: RDm 4,5 cm

Erh.: in einem Stück, kein Henkel

Dat. nach Stück: -

Dat. nach Kontext: 2. Hälfte 1. Jh. v. Chr.

Parallelen:-

Kat. 160

Taf. 9, 160

Lampe

AO: Depot des österreichischen Grabungshauses Inv. 99/623.15 FO: Stratum 1

Fabric: 10 YR 6/1; hart, fein, feinporös; Glimmer, sehr fein, selten, weiße Einschlüsse, fein, wenig

Überzug: GLEY 1 7/1-4/1, fleckig, matt

Dekor: Dreiblattsträußchen mit Fruchtständen, Palmette auf dem Schnauzengang

Maße: RDm 4,9 cm

Erh.: 1 Frgt.

Dat. nach Stück: -

Dat. nach Kontext: augusteisch-tiberisch

Parallelen: - 


\section{Kat. 161}

Lampe

AO: Depot des österreichischen Grabungshauses Inv. 99/627.06 FO: Stratum 2

Fabric: 2.5 Y 6/1; hart, fein, feinporös, feiner Glimmer, mittel Überzug: 10 YR 4/1, matt

Dekor: Rauten, Voluten (mit Punkten), Lagynos auf dem Schnauzengang

Maße: RDm 5,5 cm

Erh.:1 Frgt.

Dat. nach Stück: -

Dat. nach Kontext: 2. Hälfte 1. Jh. v. Chr.

Parallelen: -

\section{Kat. 162}

Taf. 9, 162

Lampe

AO: Depot des österreichischen Grabungshauses Inv. 99/647.01

FO: Stratum 2

Fabric: 5 Y 6/1; hart, fein, feinporös, feiner Glimmer, mittel

Überzug: GLEY $15 / 1$, metallisch glänzend

Dekor: Zungenblatt

Maße: RDm 5,6 cm

Erh.: 1 Dfrgt. mit Henkelansatz

Dat. nach Stück: -

Dat. nach Kontext: 2. Hälfte 1. Jh. v. Chr.

Parallelen: -

\section{Kat. 163}

Taf. 9, 163

Lampe

AO: Depot des österreichischen Grabungshauses Inv. 99/732.13 FO: Stratum 3

Fabric: GLEY1 3/1; hart, fein, feinporös, feiner Glimmer, selten

Überzug: GLEY1 2.5/N, mattglänzend

Dekor: Lilien und Punkte

Erh.: 1 Dfrgt.

Dat. nach Stück: -

Dat. nach Kontext: 3.-4. Viertel 1. Jh. v. Chr.

Parallelen: -

\section{Kat. 164}

Taf. 9, 164

Lampe

AO: Depot des österreichischen Grabungshauses Inv. 99/708.33

FO: Stratum 3

Fabric: GLEY1 3/N; hart, fein, feinporös, feiner Glimmer, mittel

Überzug: GLEY1 2.5/N, mattglänzend

Dekor: `Laufender Hund blatt auf dem Schnauzengang

Maße: RDm 1,2 cm

Erh.: 1 Dfrgt.

Dat. nach Stück: -

Dat. nach Kontext: 3.-4. Viertel 1. Jh. v. Chr.

Parallelen: -

Kat. 165

Oxidierend gebrannte Lampe
AO: Depot des österreichischen Grabungshauses Inv. 99/623.02 FO: Stratum 1, Bauschutt

Fabric: 10 YR 6/3; hart, fein, feinporös, weiße feine Einschlüsse, selten

Überzug: 7.5 YR 4/6, matt

Dekor: Strahlen/Riefen um den Diskus, hoher Kragen

Erh.: 1 Dfrgt. mit Henkelansatz

Dat. nach Stück: -

Dat. nach Kontext: augusteisch-tiberisch

Parallelen: -

Kat. 166

Abb. 19

Viereckige Lampe

AO: Depot des österreichischen Grabungshauses Inv. 99/666.42 FO: Stratum 4

Fabric: 2.5 Y 4/1; hart, fein, feinporös, feiner Glimmer, mittel

Überzug: GLEY1 2.5/N, stark abgerieben, matt

Dekor: Dreiecksmuster

Erh.: 4 Frgte.

Dat. nach Stück: -

Dat. nach Kontext: Ende 2. Jh. - Mitte 1. Jh. v. Chr.

Parallelen: -

Kat. 167

Abb. 18 a

Lampe

AO: Depot des österreichischen Grabungshauses Inv. 99/639.02 FO: Stratum 3

Fabric: GLEY1 4/1; hart, fein, feinporös, feiner Glimmer, mittel-selten

Überzug: GLEY1 3/1, matt

Dekor: Palmette, Theatermaske (Applik)

Erh.: 1 Dfrgt.

Dat. nach Stück: -

Dat. nach Kontext: 3.-4. Viertel 1. Jh. v. Chr.

Parallelen: -

Kat. 168

Abb. 18 b

Lampe

AO: Depot des österreichischen Grabungshauses Inv. 99/658.01 FO: Stratum 3

Fabric: GLEY1 4/1; hart, fein, feinporös, feiner Glimmer, selten

Überzug: GLEY1 2.5/N, glänzend

Dekor: Ranken, Rosetten und ein nacktes, rechtes Bein von Gluteus bis Fußknöchel (Erot?)

Erh.: 1 Frgt.

Dat. nach Stück: -

Dat. nach Kontext: 3.-4. Viertel 1. Jh. v. Chr.

Parallelen: -

Kat. 169

Abb. 16

Lampe

AO: Depot des österreichischen Grabungshauses Inv. 99/736.19 FO: Stratum 1

Fabric: GLEY1 4/1; hart, fein, feinporös, feiner Glimmer, mittel

Überzug: GLEY1 2.5/N, mattglänzend 
Dekor: Jünglingskopf in Dreiviertelansicht

Erh.: 1 Frgt.

Dat. nach Stück: -

Dat. nach Kontext: augusteisch-tiberisch

Parallelen: -

\section{Kat. 170}

Stocklampe

AO: Depot des österreichischen Grabungshauses Inv. 99/618.08

FO: Stratum 1, Bauschutt
Fabric: GLEY1 4/1; hart, fein, feinporös, feiner Glimmer, mittel

Überzug: GLEY1 2.5/N, matt

Maße: RDm $4 \mathrm{~cm}$

Erh.: 1 Bfrgt.

Dat. nach Stück: 4. Jh. v. Chr.

Dat. nach Kontext: augusteisch-tiberisch

Parallelen: Mitsopoulos-Leon 2007, 73 L 61 Taf. 21; Howland 1958, Typ 26A.

\section{Webgewichte}

\section{Kat. 171}

Konisches Webgewicht

AO: Depot des Efes Müzesi Selçuk Inv. 99/46

FO: Stratum 4

Fabric: 2.5 YR 7/4, hart, fein, feinporös; sehr feiner Glimmer, häufig, dunkelgraue Einschlüsse, fein, mittel, rötliche Einschlüsse, mittel, selten, Quarzeinschlüsse, fein-mittel, selten

Erh.: leichte Abplatzungen

Dat. nach Stück: -

Dat. nach Kontext: Ende 2. Jh. - Mitte 1. Jh. v. Chr. Parallelen: Mitsopoulos-Leon 2007, 114-116; Trink1 2003, 313-327.

\section{Kat. 172}

Tongrundiges, rundes Webgewicht

AO: Depot des Efes Müzesi Selçuk Inv. 99/80

FO: Stratum 4

Fabric: 2.5 YR 5/2; hart, fein, feinporös, feiner Glimmer, mittel

Maße: RDm 4 cm

Erh.: ganz

Dat. nach Stück: -

Dat. nach Kontext: Ende 2. Jh. - Mitte 1. Jh. v. Chr.

Parallelen: Mitsopoulos-Leon 2007, 114-116.

\section{Kat. 173}

Taf. 10, 173

Tongrundiges Webgewicht

AO: Depot des Efes Müzesi Selçuk Inv. 99/85A

FO: Stratum 4

Fabric: 2.5 YR 7/4; hart, fein, feinporös; Glimmer, fein, selten

Maße: RDm 5,4 cm

Erh.: ganz

Dat. nach Stück: -

Dat. nach Kontext: Ende 2. Jh. - Mitte 1. Jh. v. Chr.

Parallelen: Mitsopoulos-Leon 2007, 114-116; Trinkl 2003, 313-327.

\section{Kat. 174}

Tongrundiges Webgewicht

ohne Abb.

AO: Depot des Efes Müzesi Selçuk Inv. 99/85B

FO: Stratum 4

Fabric: 7.5 YR 4/3; hart, fein, feinporös, feiner Glimmer, mittel, dunkelgraue Einschlüsse, fein, mittel

Maße: RDm 5,9 cm

Erh.: ganz ohne Abb. $\quad$ Dat. nach Stück: -

Dat. nach Kontext: Ende 2. Jh. - Mitte 1. Jh. v. Chr.

Parallelen: Mitsopoulos-Leon 2007, 114-116; Trinkl 2003, 313-327.

\section{Kat. 176}

ohne Abb.

Tongrundiges Webgewicht

AO: Depot des Efes Müzesi Selçuk Inv. 99/81C

FO: Stratum 4

Fabric: 2.5 YR 5/6; hart, fein, feinporös, feiner Glimmer, mittel, dunkelgraue Einschlüsse

Maße: RDm 4,6 cm

Erh.: ganz

Dat. nach Stück:-

Dat. nach Kontext: Ende 2. Jh. - Mitte 1. Jh. v. Chr.

Parallelen: Mitsopoulos-Leon 2007, 114-116; Trinkl 2003, 313-327.

Kat. 177

ohne Abb.

Tongrundiges Webgewicht

AO: Depot des Efes Müzesi Selçuk Inv. 99/81B

FO: Stratum 4

Fabric: 2.5 YR 5/6; hart, fein, feinporös, feiner Glimmer, selten Maße: RDm 6,2 cm

Erh.: ganz

Dat. nach Stück: -

Dat. nach Kontext: Ende 2. Jh. - Mitte 1. Jh. v. Chr.

Parallelen: Mitsopoulos-Leon 2007, 114-116; Trinkl 2003, 313-327. 


\section{Kat. 178}

Tongrundiges Webgewicht

AO: Depot des österreichischen Grabungshauses Inv. 99/81E

FO: Stratum 4

Fabric: 2.5 YR 7/4; hart, sehr fein, feinporös, feiner Glimmer, selten

Maße: RDm 2,7 cm

Erh.: ganz

Dat. nach Stück: -

Dat. nach Kontext: Ende 2. Jh. - Mitte 1. Jh. v. Chr.

Parallelen: Mitsopoulos-Leon 2007, 114-116; Trinkl 2003, 313-327.
Kat. 179

ohne Abb.

Webgewicht

AO: Depot des Efes Müzesi Selçuk Inv. 99/81D

FO: Stratum 4

Fabric: 5 YR 7/4; hart, sehr fein, feinporös, feiner Glimmer, mittel-selten

Maße: RDm 2,8 cm

Erh.: ganz

Dat. nach Stück: -

Dat. nach Kontext: Ende 2. Jh. - Mitte 1. Jh. v. Chr.

Parallelen: Mitsopoulos-Leon 2007, 114-116; Trink1 2003, 313-327.

\section{Terrakotten}

\section{Kat. 180}

Spielzeug, Entenkopf

AO: Depot des Efes Müzesi Selçuk Inv. 54/20/99

FO: Stratum 4

Fabric: 2.5 YR 7/3; hart, fein, feinporös, feiner Glimmer, häufig, weiße, dunkelgraue und rote Einschlüsse, fein-mittel, mittel-selten

Überzug: 7.5 YR 8/2, matt

Erh.: 1 Frgt.

Dat. nach Stück: -

Dat. nach Kontext: Ende 2. Jh. - Mitte 1. Jh. v. Chr.

Parallelen: -

\section{Kat. 181}

ohne Abb.

Spielzeug, Entenkopf

AO: Depot des Efes Müzesi Selçuk Inv. 99/711.02

FO: Stratum 2

Fabric: 5 YR 7/4; hart, fein, feinporös, feiner Glimmer, mittel, weiße, dunkelgraue und rötliche Einschlüsse, fein, mittel-selten

Überzug: 2.5 YR 7/3, matt

Erh.:1 Frgt. (Kopf)

Dat. nach Stück: -

Dat. nach Kontext: 2. Hälfte 1. Jh. v. Chr.

Parallelen: -

\section{Kat. 182}

ohne Abb.

Weiblicher Kopf

AO: Depot des Efes Müzesi Selçuk Inv. 99/76

FO: Stratum 3

Fabric: 5 YR 7/5; hart, fein, feinporös, feiner Glimmer, mittel, feine dunkelgraue Einschlüsse, wenig

Überzug: 2.5 YR 8/1 matt

Dekor: Weiblicher Kopf mit Krone/Diadem. Die Haare sind in der Mitte der Stirn gescheitelt und in eingerollten Strähnen am Hinterkopf befestigt. An der linken Seite ist noch eine gelockte Strähne im Ansatz erhalten (Ceres?).

Maße: RDm $3 \mathrm{~cm}$

Erh.: 1 Frgt.

Dat. nach Stück: 3. Jh. v. - 2. Hälfte 1. Jh. n. Chr.

Dat. nach Kontext: 3.-4. Viertel 1. Jh. v. Chr.

Parallelen: Lang-Auinger 2003, 227 TK 52 Taf. 127; Lang-Auinger 2007, 147 TK 49 Taf. 47.

\section{Kat. 183}

ohne Abb.

Haare mit Kranz

AO: Depot des österreichischen Grabungshauses Inv.99/691.01 FO: Stratum 2

Fabric: 5 YR 7/4; hart, fein, feinporös, feiner Glimmer, mittel, feine dunkelgraue Einschlüsse, wenig

Dekor: Haare mit Blätterkranz (Dionysos?)

Maße: -

Erh.: 1 Frgt.

Dat. nach Stück: -

Dat. nach Kontext: 2. Hälfte 1. Jh. v. Chr.

Parallelen: -

\section{Kat. 184}

ohne Abb.

Basis

AO: Depot des österreichischen Grabungshauses Inv. 99/641.26 FO: Stratum 1, Bauschutt

Fabric: 2.5 YR 7/4-4/1; hart, fein, feinporös, feiner Glimmer, mittel

Überzug: 2.5 YR 8/1, matt

Dekor: Viereckige hohe Basis mit Zehen und Ansatz vom rechten $\mathrm{Fu} \beta$

Erh.: 1 Frgt.

Dat. nach Stück: hellenistisch

Dat. nach Kontext: augusteisch-tiberisch

Parallelen: Lang-Auinger 2003, TK 28 Taf. 126; Lang-Auinger 2007, 162 TK 99 Taf. 53.

\section{Kat. 185}

ohne Abb.

Bein eines Eroten

AO: Depot des österreichischen Grabungshauses Inv. 99/639.05 FO: Stratum 3

Fabric: 2.5 YR 7/5; hart, fein, feinporös, feiner Glimmer, selten Überzug: 2.5 YR 8/1, 10 YR 5/6, matt

Dekor: Gluteus bis Fußgelenk

Maße: RDm 2,8 cm

Erh.: 2 Frgte.

Dat. nach Stück: 1. Hälfte 1.-3. Jh. n. Chr.

Dat. nach Kontext: 3.-4. Viertel 1. Jh. v. Chr

Parallelen: Lang-Auinger 2003, 245 TK 80 Taf. 129; Lang-Auinger 2007, 136. 137 TK 24 Taf. 42. 
Glas

\section{Kat. 186}

Schale Typ GL1

AO: Depot des österreichischen Grabungshauses Inv. 99/715.167

FO: Stratum 4

Überzug: milchig weiß

Maße: RDm $12 \mathrm{~cm}$

Erh.: 1 Rfrgt.

Dat. nach Stück: -

Dat. nach Kontext: Ende 2. Jh. - Mitte 1. Jh. v. Chr.

Parallelen: Czurda-Ruth 2007, 24.

\section{Kat. 187}

Ovaler Ringstein

AO: Depot des Efes Müzesi Selçuk Inv. 99/634.04

FO: Stratum 1

Taf. 10, 187

\section{Taf. 10, 186}

\author{
Maße: RDm 1,4×1,2 ×0,6 cm \\ Erh.: ganz \\ Dat. nach Stück: - \\ Dat. nach Kontext: augusteisch-tiberisch \\ Parallelen: -
}

Überzug: hellgrünes Glas, bräunliche Verfärbung

\section{Kat. 188}

Ringstein

AO: Depot des Efes Müzesi Selçuk Inv. 99/630.07

FO: Stratum 3

Überzug: türkis

Maße: RDm 1,5 × 1,2 × 0,6 cm

Erh.: ganz

Dat. nach Stück: -

Dat. nach Kontext: 3.-4. Viertel 1. Jh. v. Chr.

Parallelen: -

\section{Bein}

\section{Kat. 189}

Taf. 10, 189

Haarnadel

AO: Depot des Efes Müzesi Selçuk Inv. 99/694.05

FO: Stratum 2

Maße: RDm 0,8 cm

Erh.: ganz

Dat. nach Stück: -

Dat. nach Kontext: 2. Hälfte 1. Jh. v. Chr.

Parallelen: -

\section{Kat. 190}

Beinobjekt

AO: Depot des Efes Müzesi Selçuk Inv. 99/666.41

FO: Stratum 4

Dekor: Profilierung

Maße: RDm $2 \mathrm{~cm}$

Erh.: 1 Frgte.

Dat. nach Stück: Parallelen:-

\section{Kat. 191}

Perle oder Spinnwirtel

AO: Depot des Efes Müzesi Selçuk Inv. 99/718.01

FO: Stratum 4

ohne Abb. Maße: RDm 1,8 cm

Erh.: ganz

Dat. nach Stück: Parallelen: Trinkl 2003, 323 T 20 Taf. 153.
Dat. nach Kontext: Ende 2. Jh. - Mitte 1. Jh. v. Chr.

ohne Abb.

Dat. nach Kontext: Ende 2. Jh. - Mitte 1. Jh. v. Chr.

\section{Metall}

Kat. 192

Silberner Henkel eines Skyphos

AO: Depot des Efes Müzesi Selçuk Inv. 99/642.01

FO: Stratum 3

Fabric: AG mattglänzend

Dekor: Voluten

Maße: RDm 5,8 cm

Erh.: 1 Henkel (Daumenplatte)

Dat. nach Stück: 1. Jh. v. Chr.

Dat. nach Kontext: 3.-4. Viertel 1. Jh. v. Chr.

Parallelen: Hübner 1993, Taf. 6 Nr. 47; Schäfer 1968, E 109 (beide in Keramik).

\section{Kat. 193}

Abb. 21 a. b

Ring mit Glasstein

AO: Depot des Efes Müzesi Selçuk Inv. 99/636.04

FO: Stratum 3

Fabric: FE und Glas
Taf. 10, 188

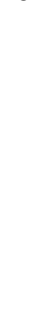


Tafel 1

Eastern Sigillata A
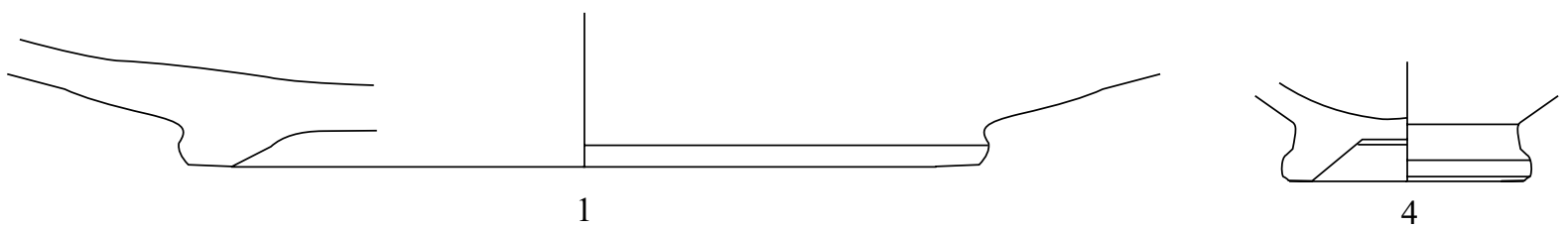

Eastern Sigillata B
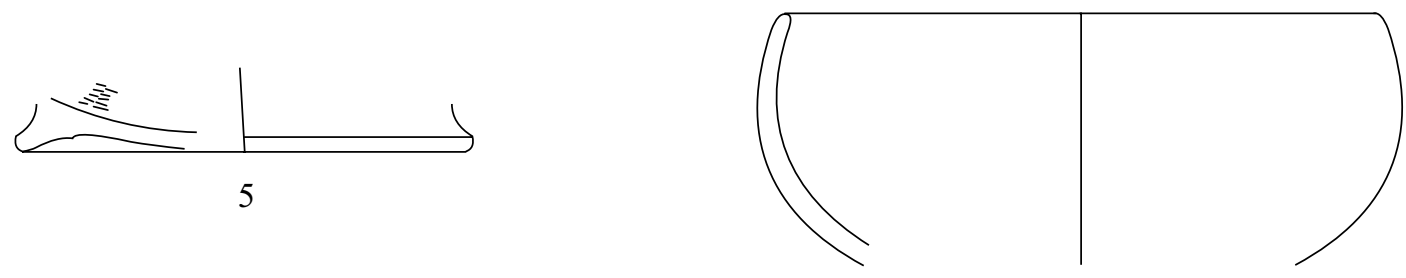

7
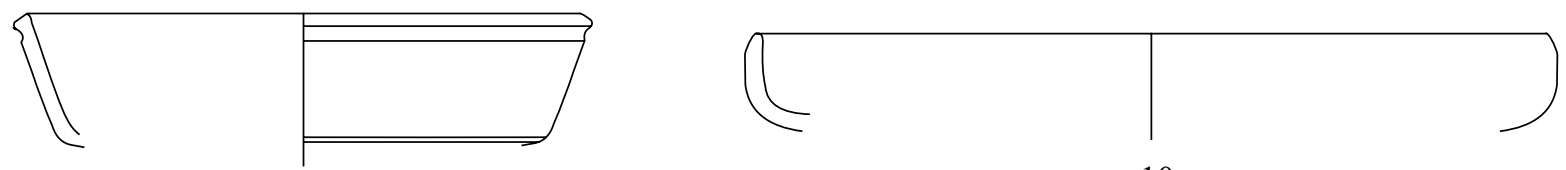

10

13

Mögliche Imitate von Sigillata und Frühe ESB
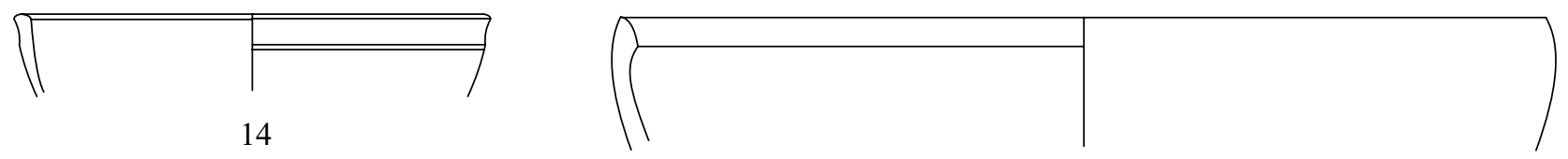

15
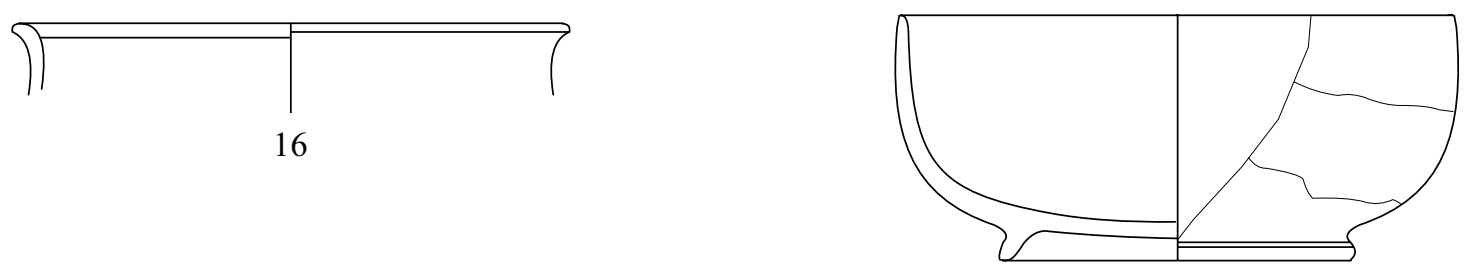

17

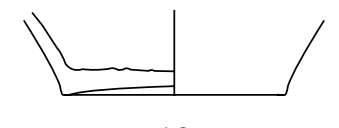

18

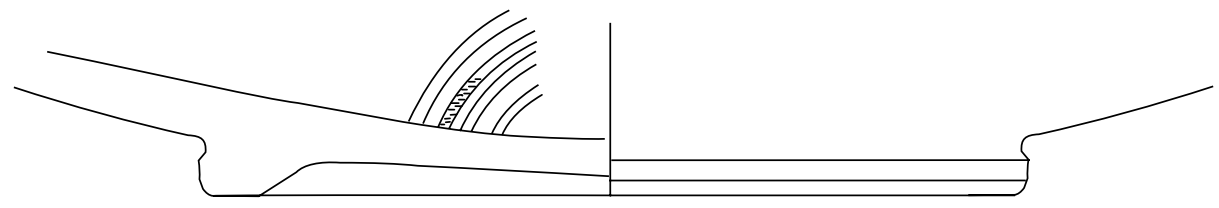

19
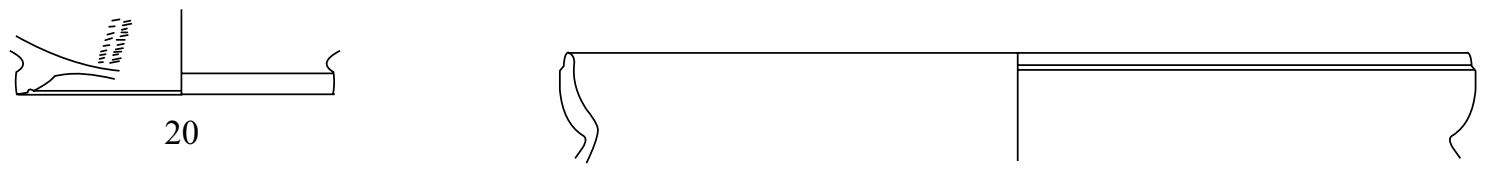
Tafel 2

\section{Glanztonware}
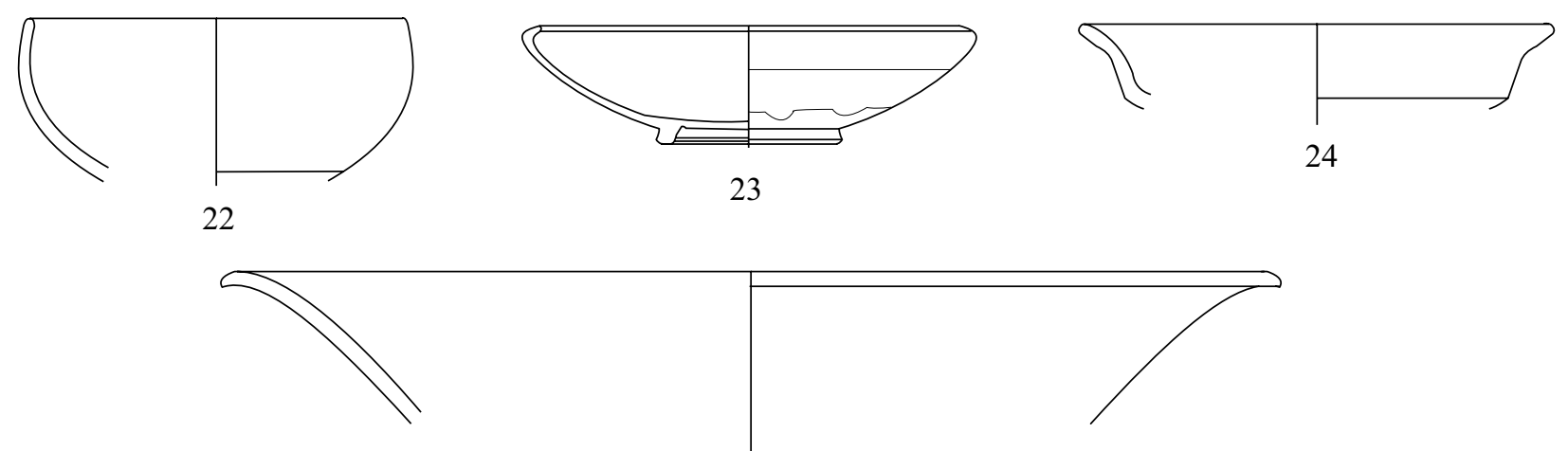

25

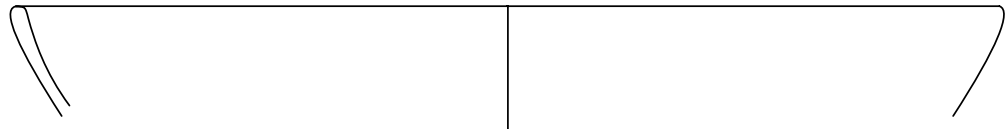

26

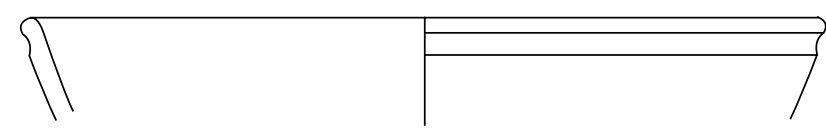

27

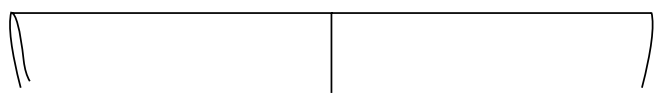

29
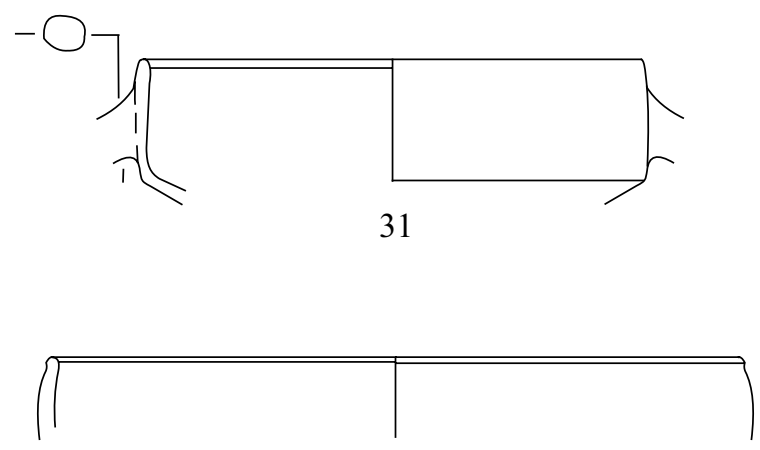

33
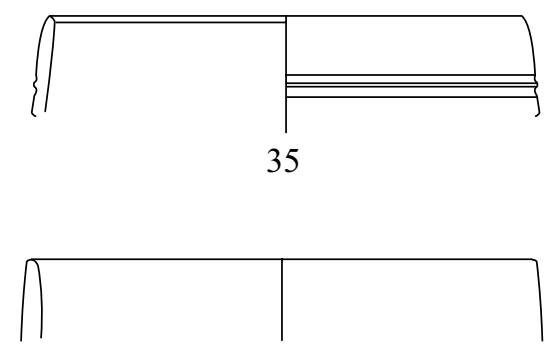

37

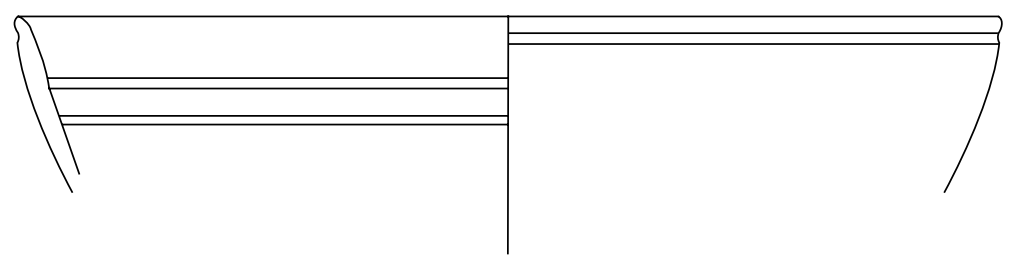

28

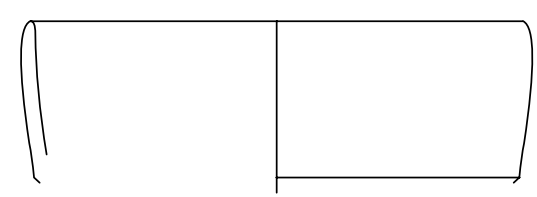

30

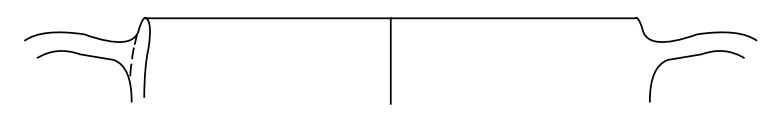

32

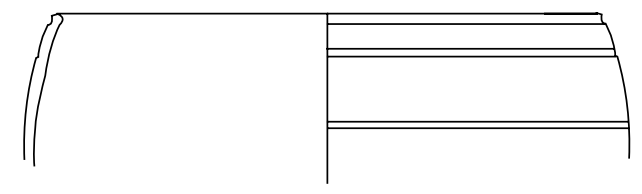

34
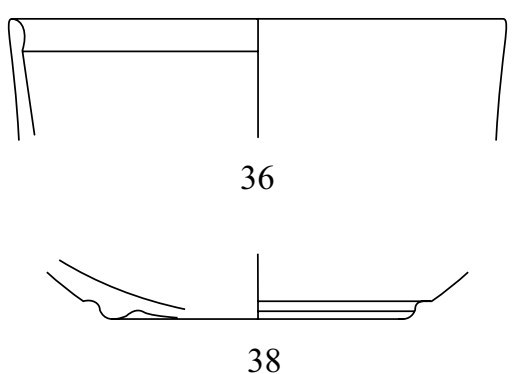
Tafel 3
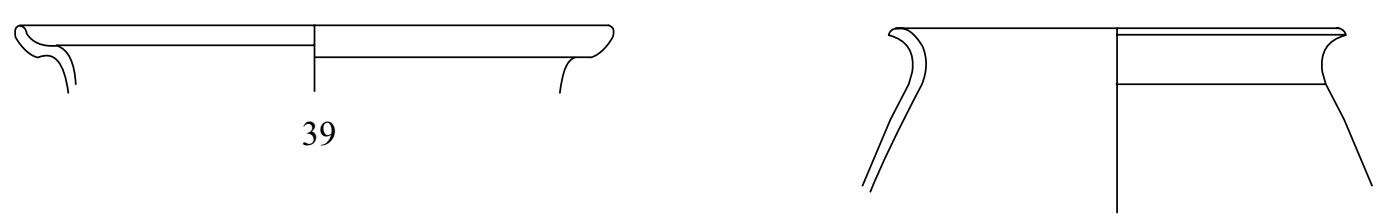

40

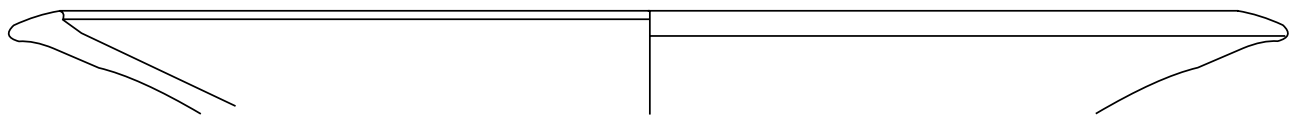

41
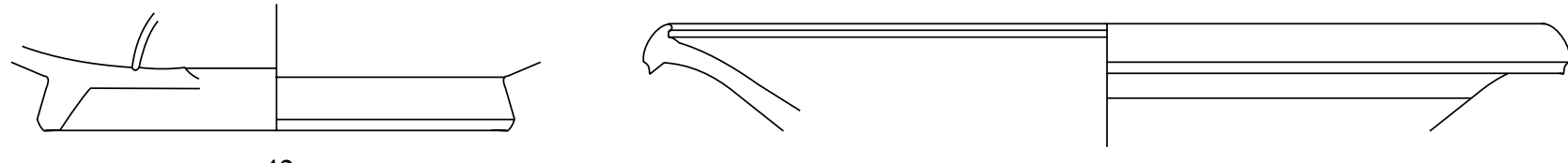

43

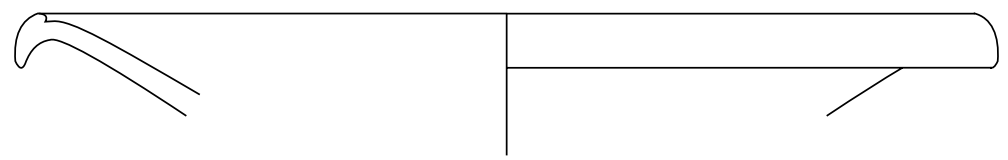

44
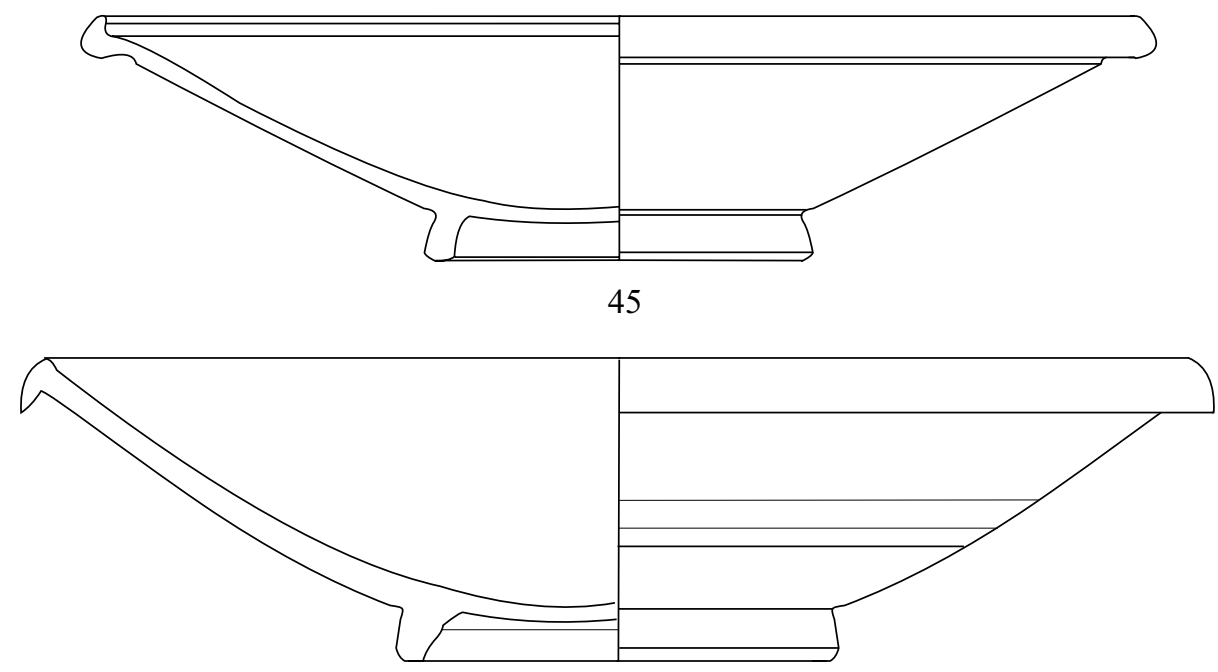

46
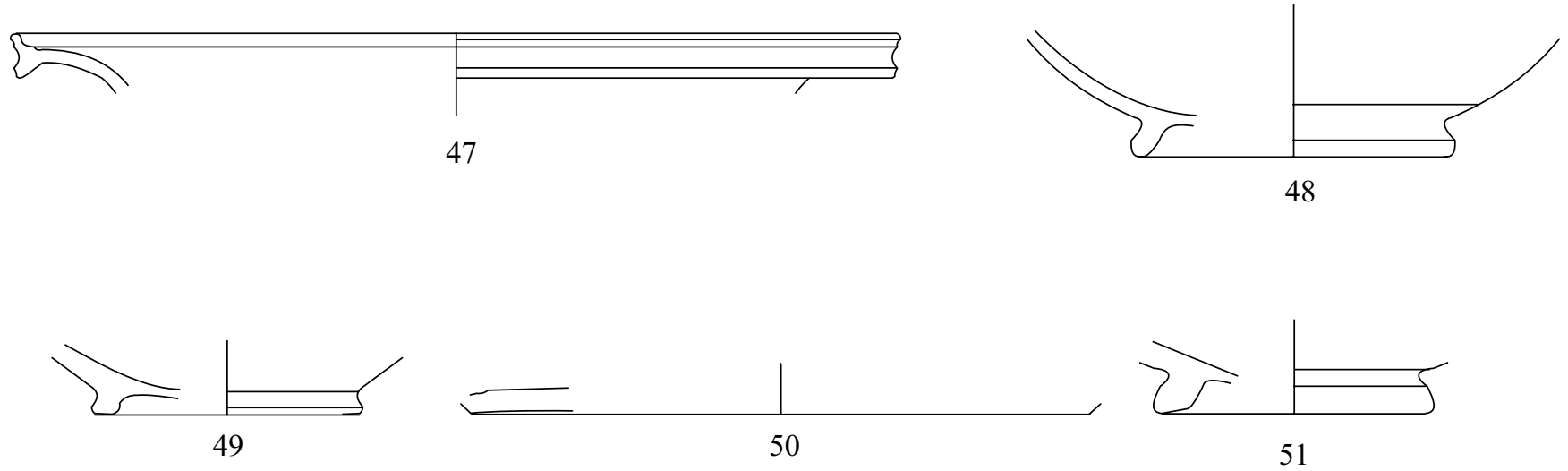
Tafel 4
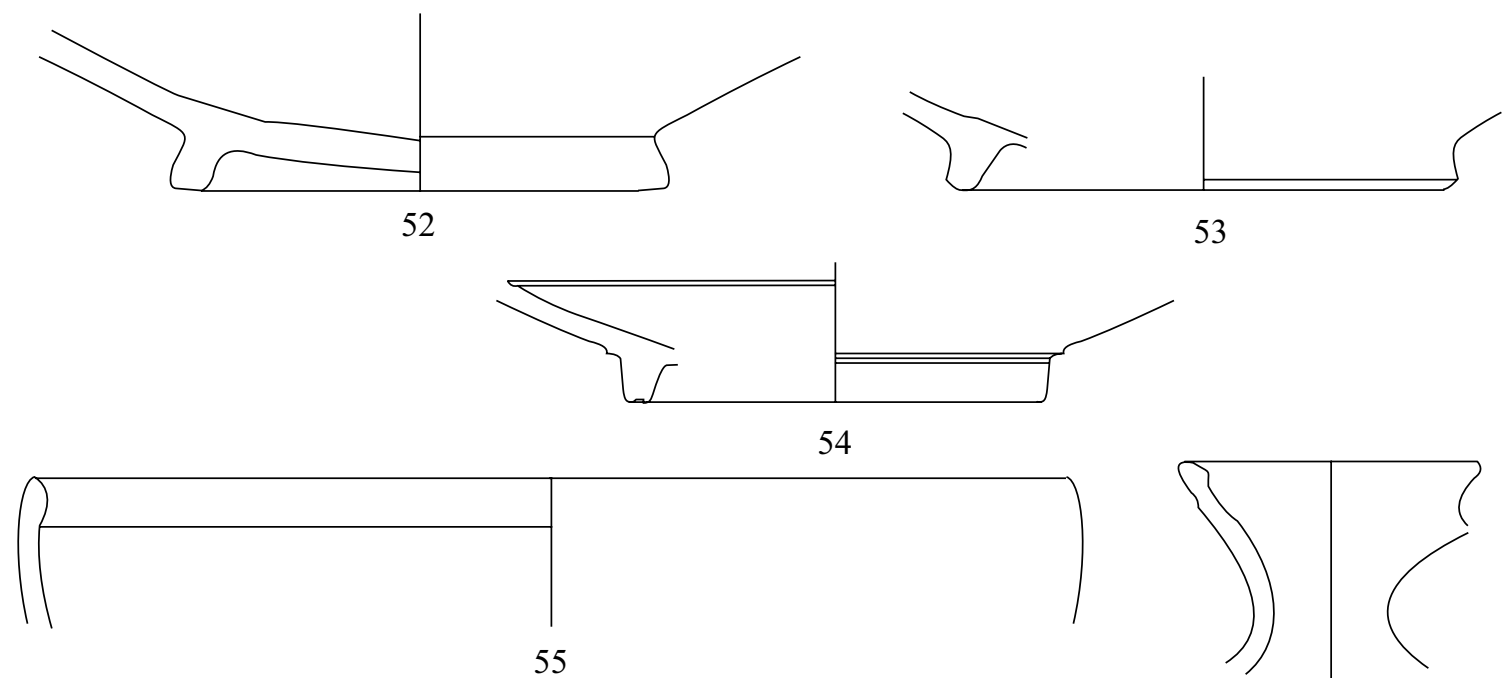

55

57

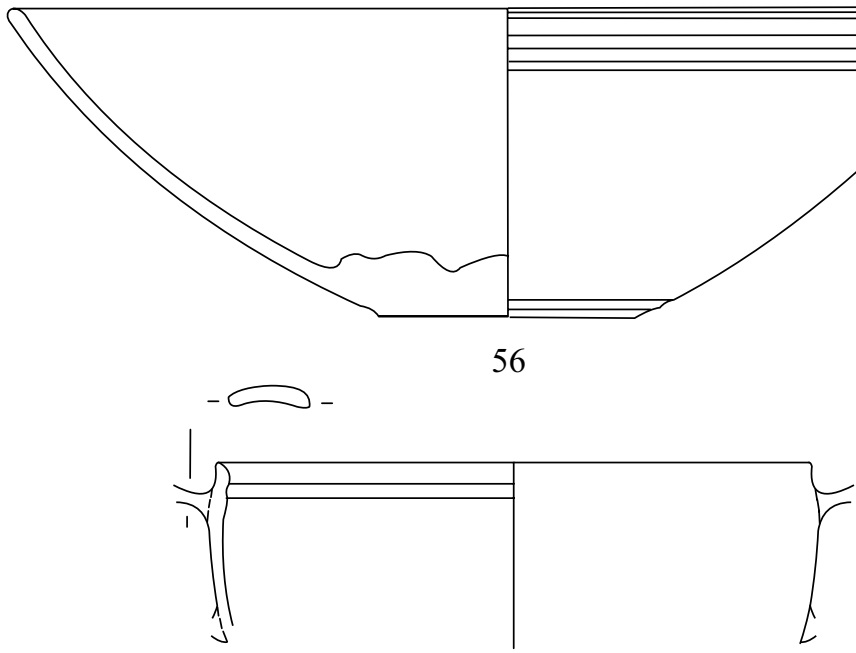

59
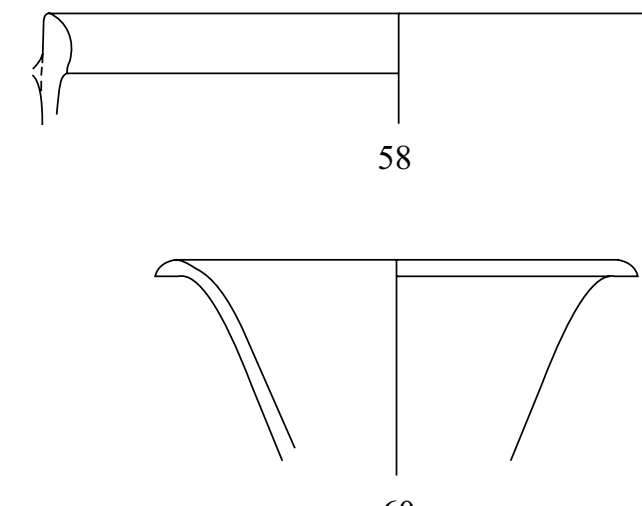

60

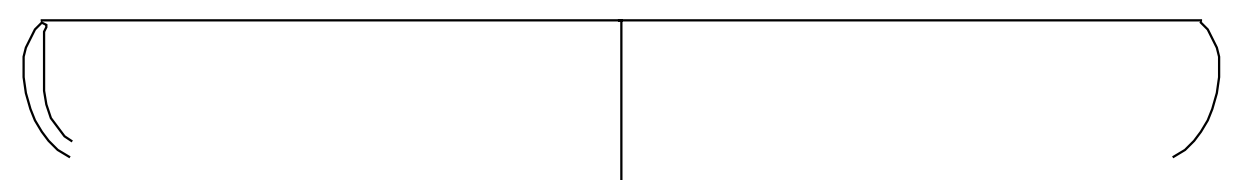

61

Westabhang-Nachfolgestil

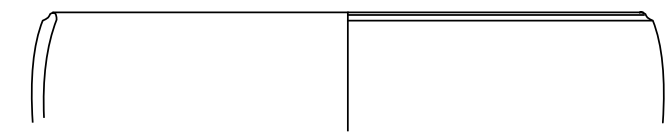

62

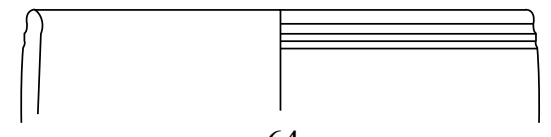

64

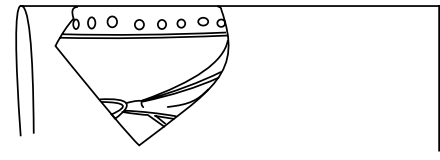

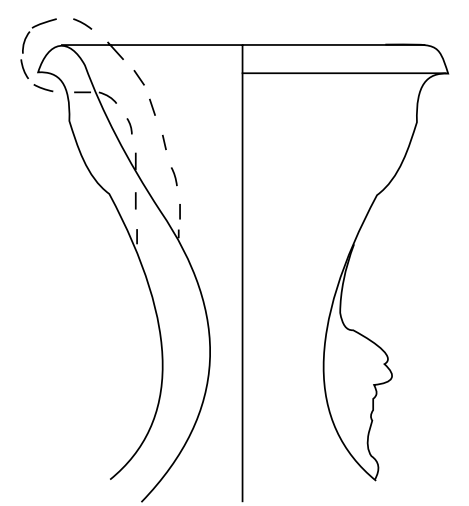

63

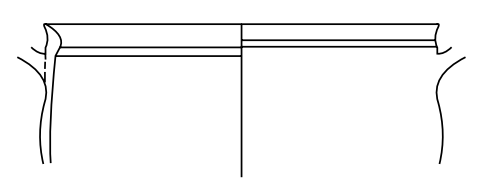

67 
Tafel 5

Graue Ware mit schwarzem Überzug
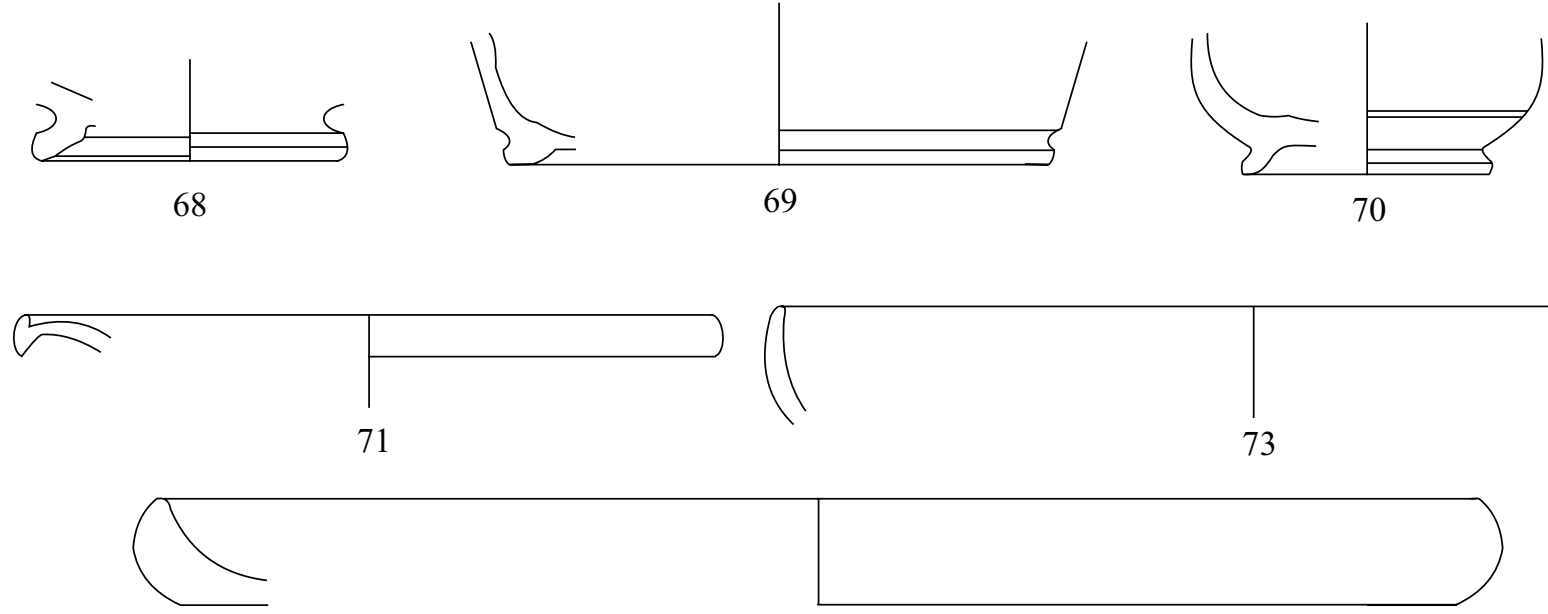

72

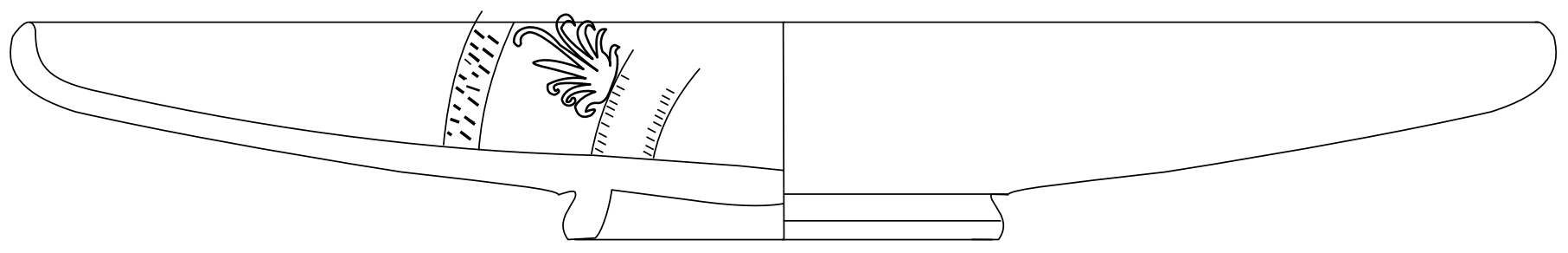

74

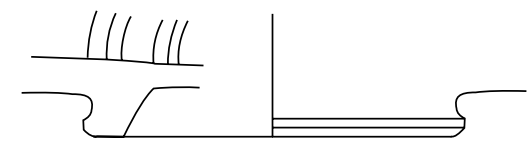

75
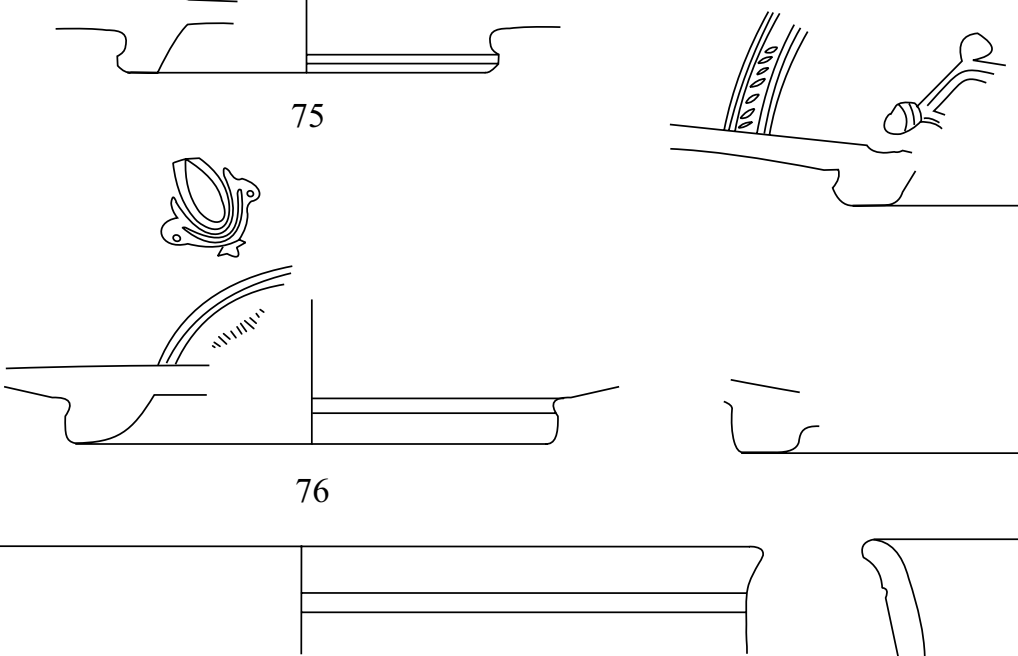

79

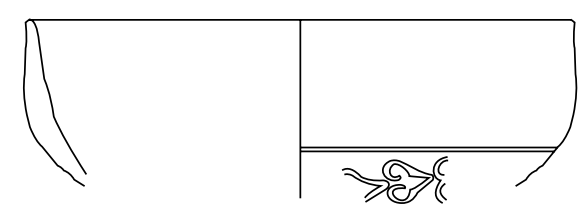

82

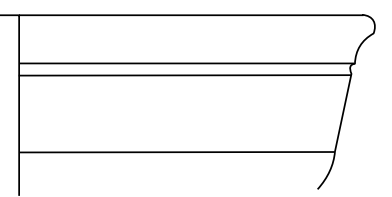

80

\section{Reliefbecher}

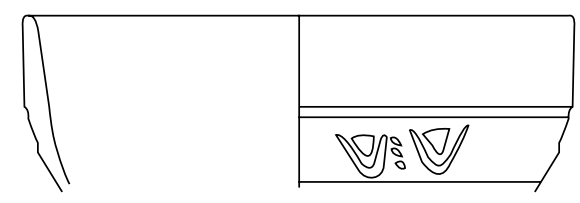

81

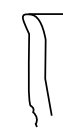

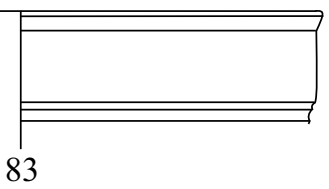

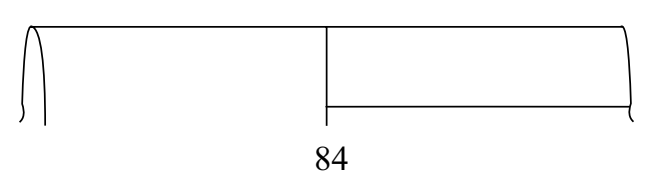


Tafel 6

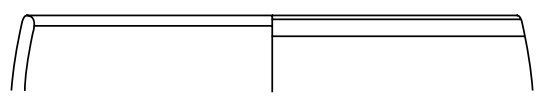

85

यद

tho

99
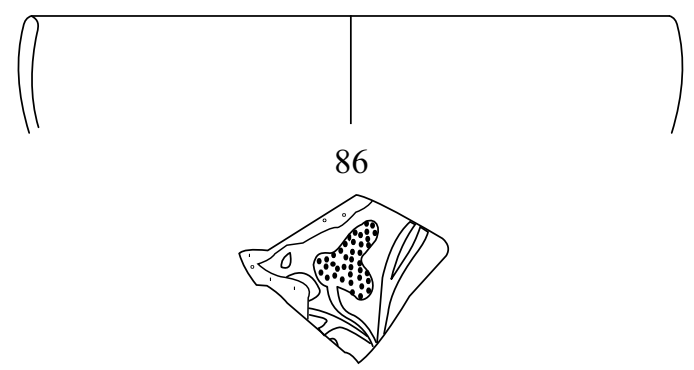

100

Tongrundige Ware
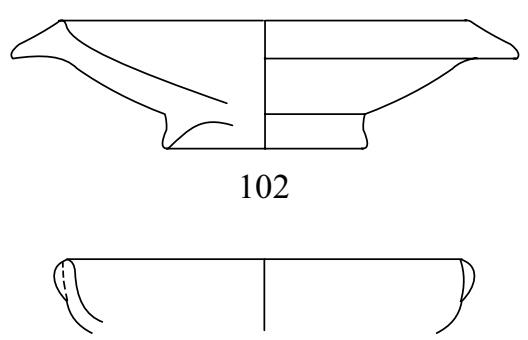

104

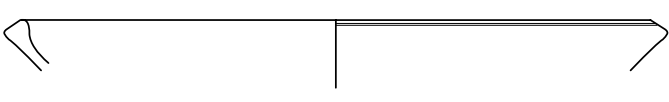

103

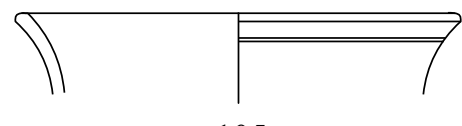

105

Dünnwandige Ware

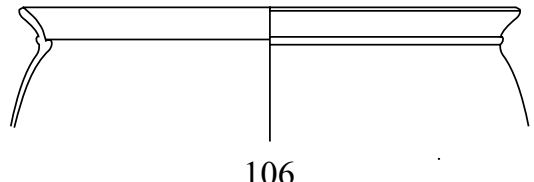

106
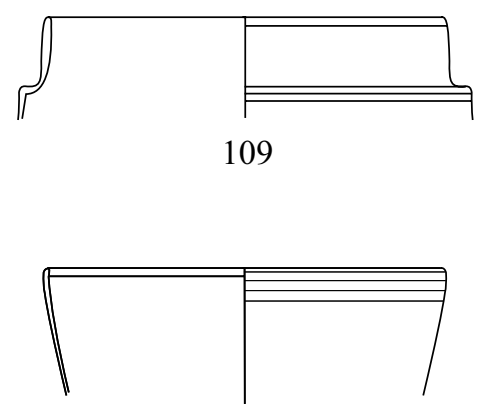

112

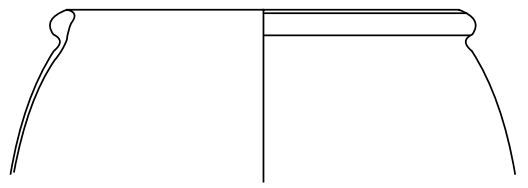

115

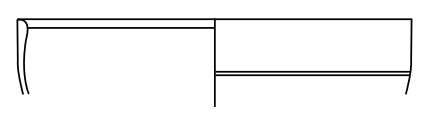

118

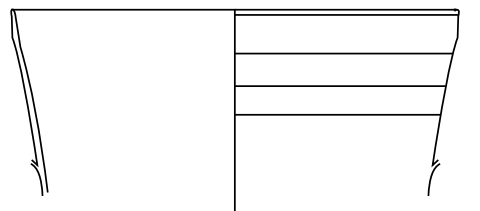

119

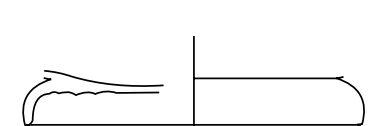

121

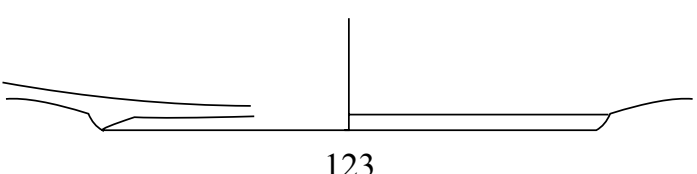

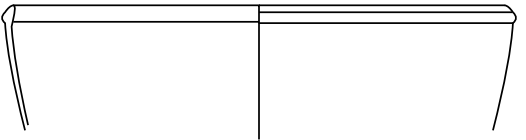

116

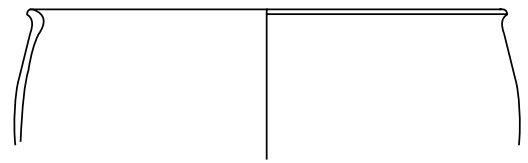

107

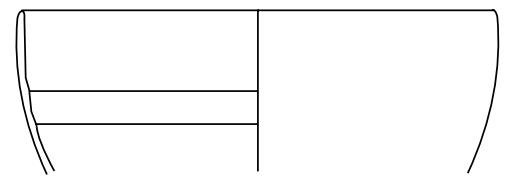

110

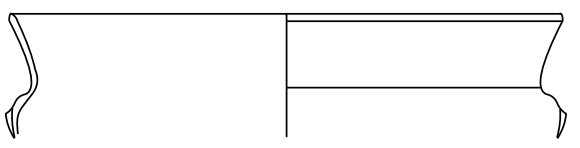

113

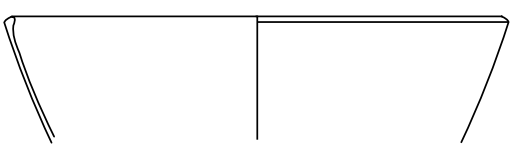

114

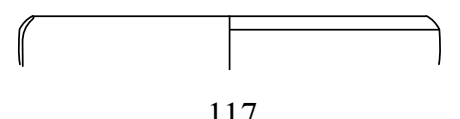

117

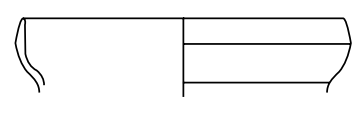

120

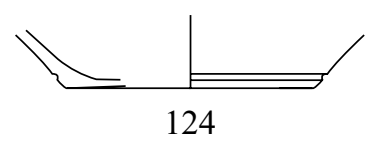


Tafel 7

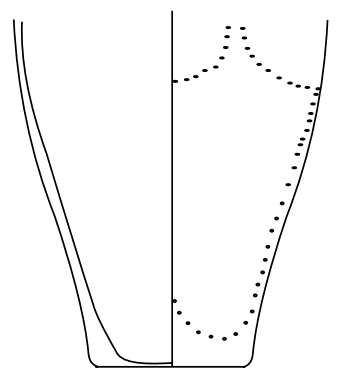

122

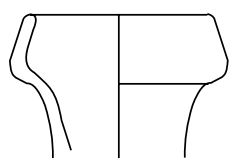

127

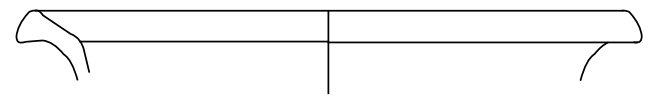

130

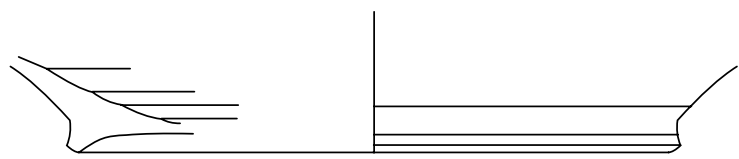

132

a

135

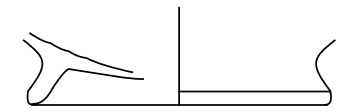

133

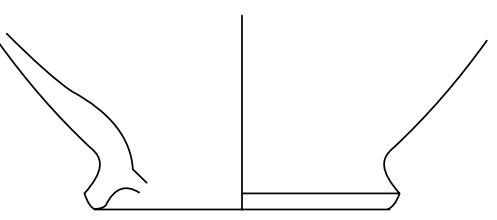

131

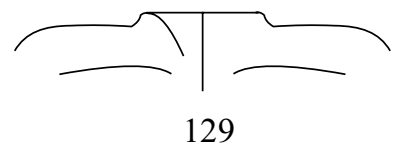

129

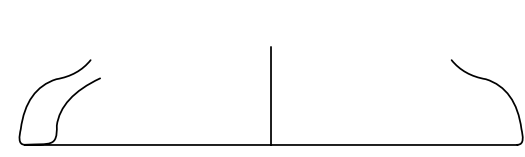

134

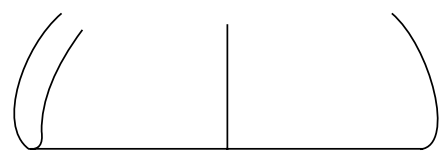

136

Import Ware
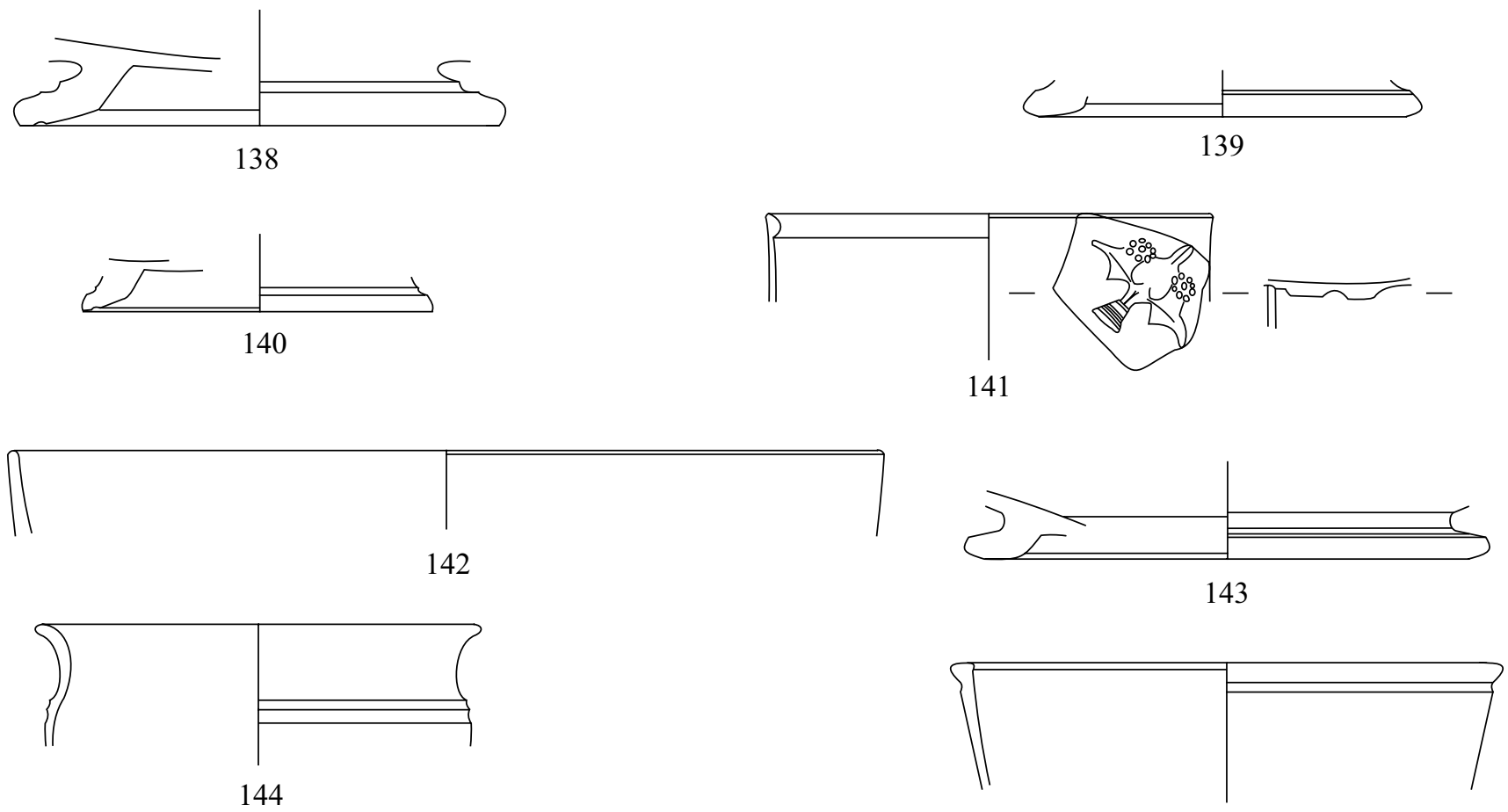

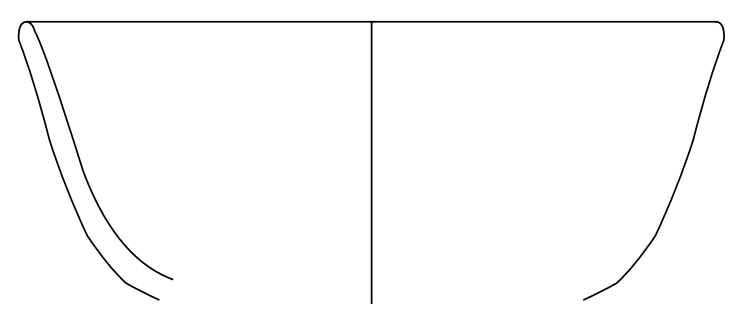

146

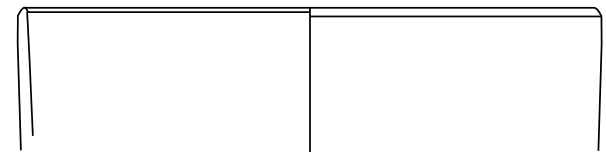

(9)

(1)

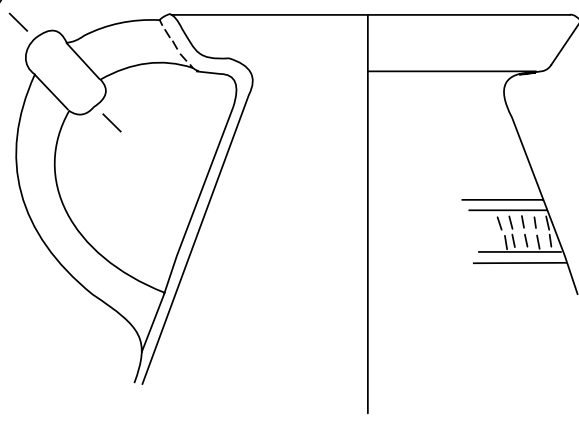

153
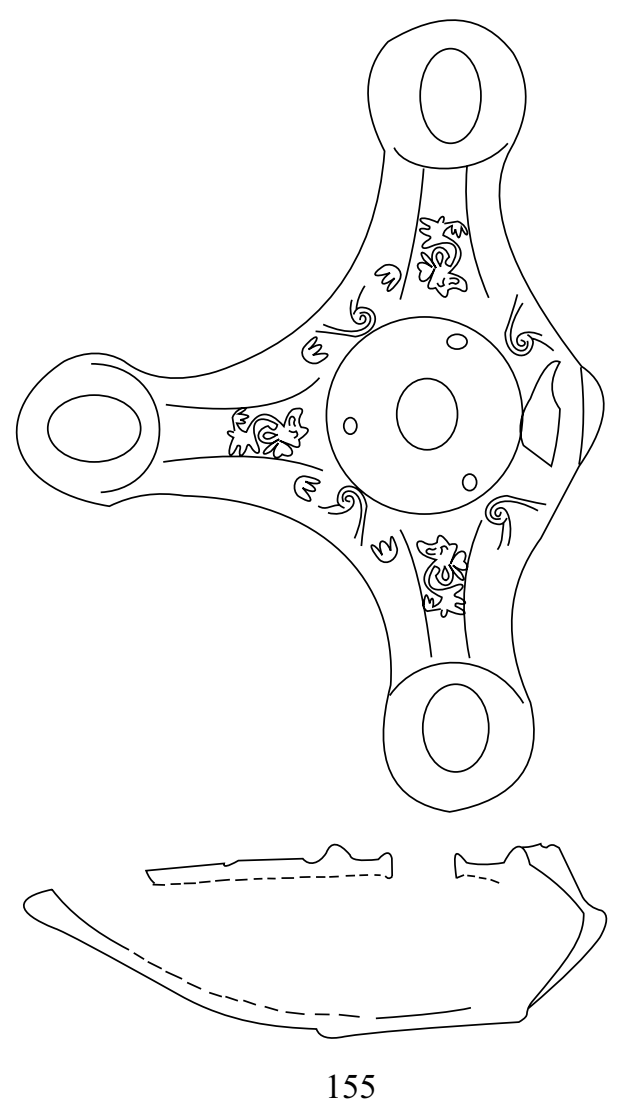
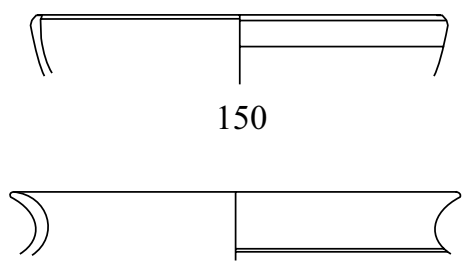

151

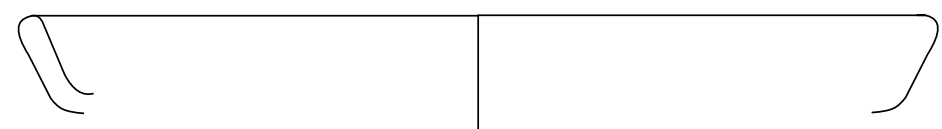

152

\section{Lampen}
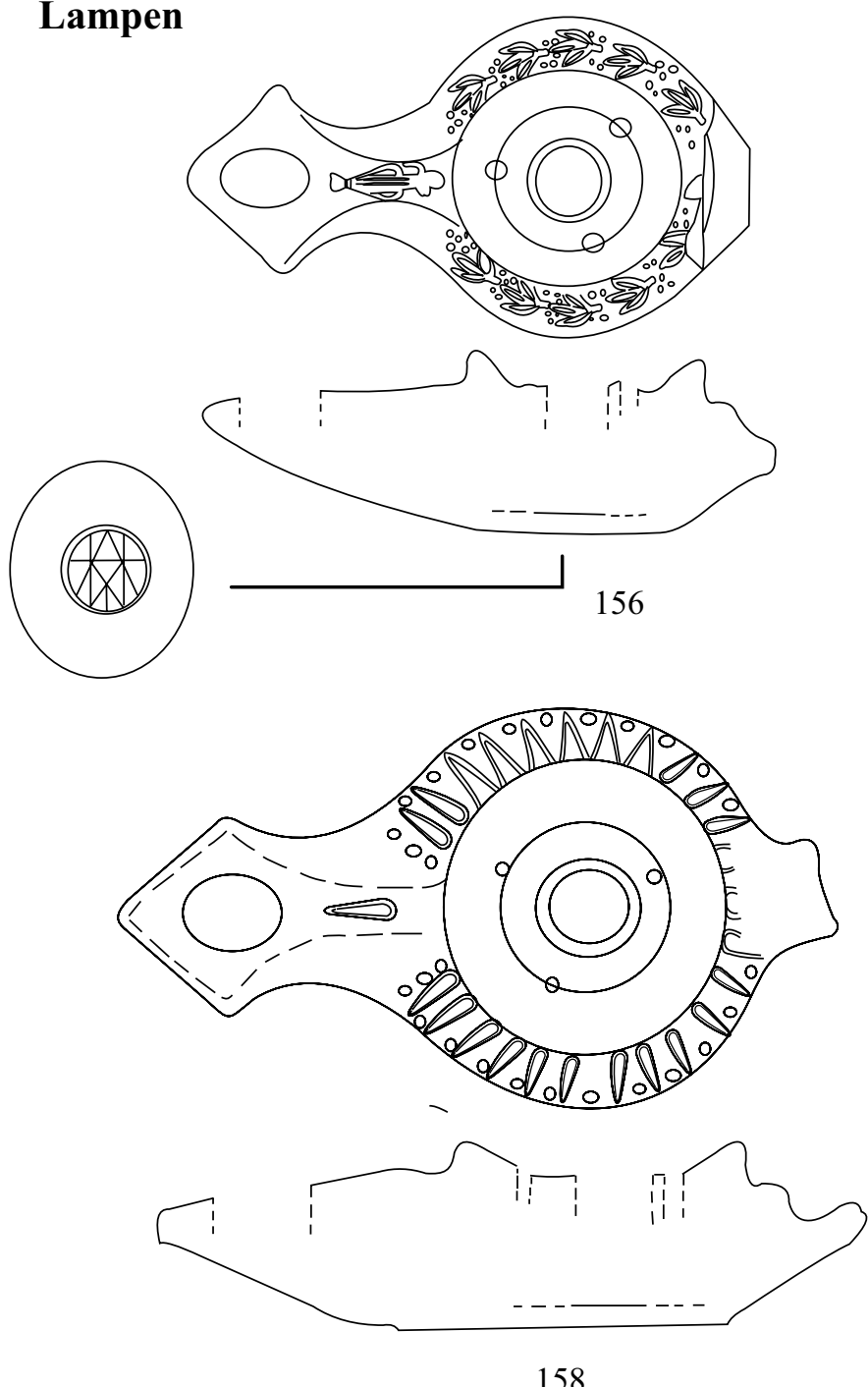
Tafel 9
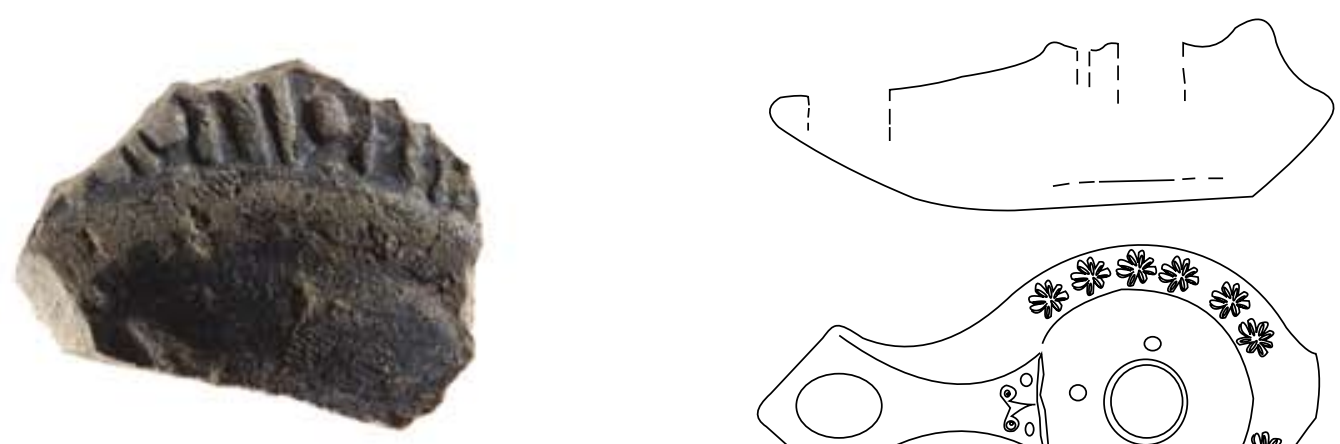

157

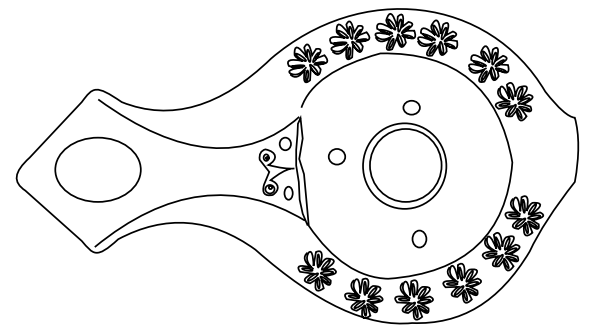

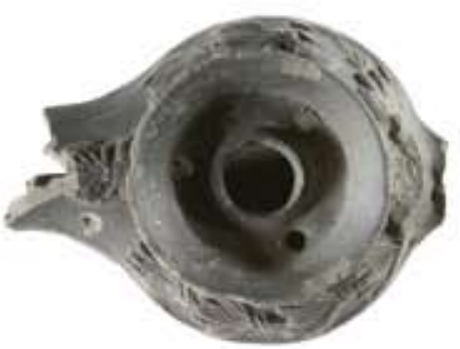

160

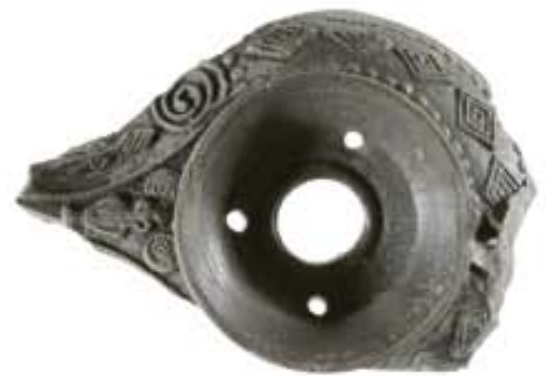

161

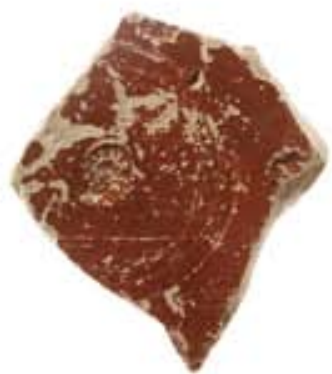

3

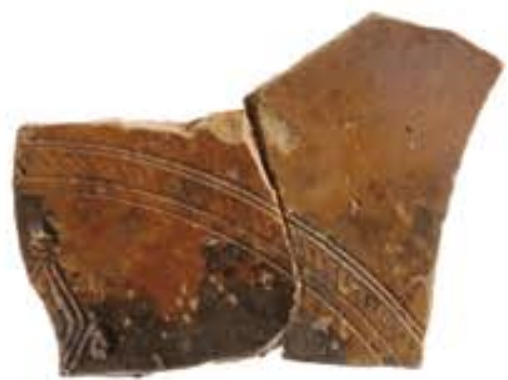

77

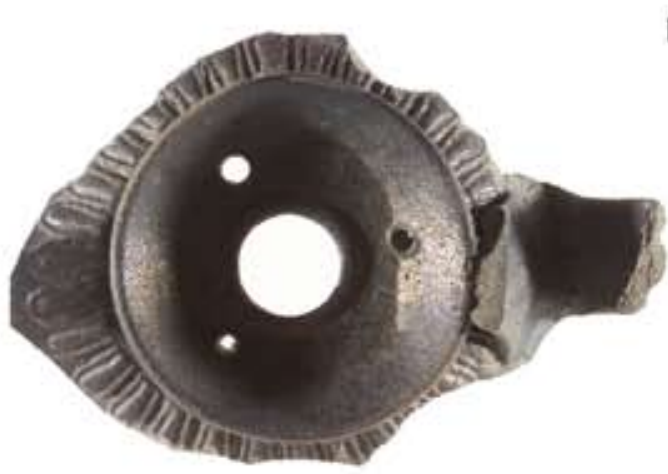

162

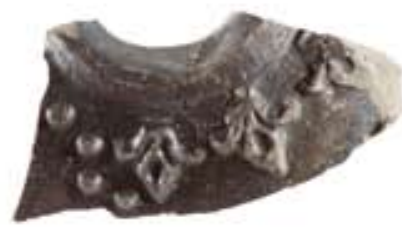

163

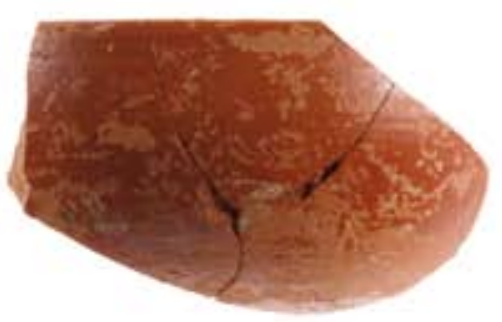

7

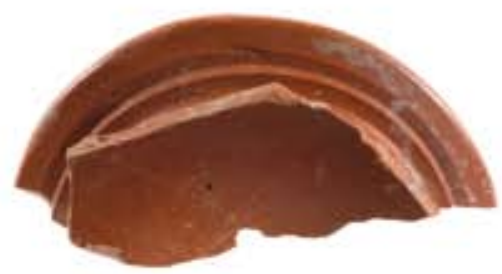

138
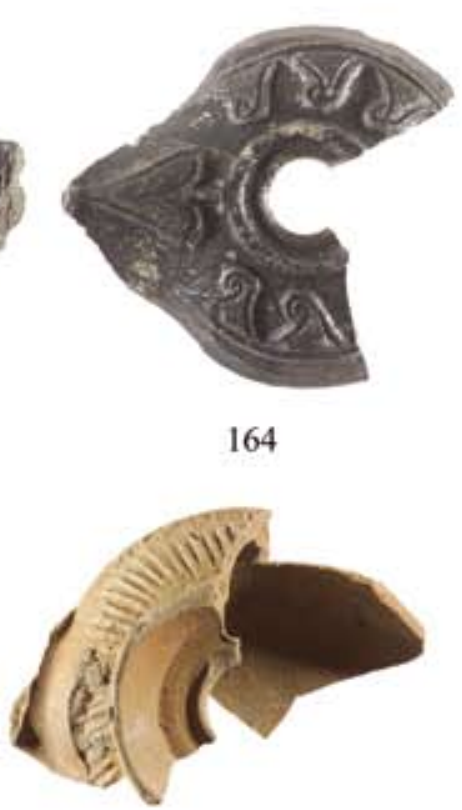

165

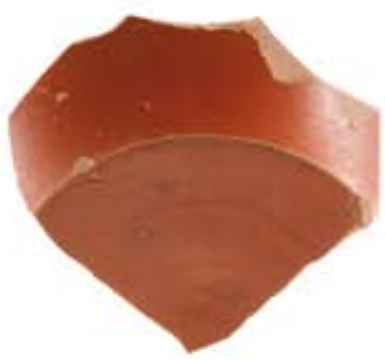

18

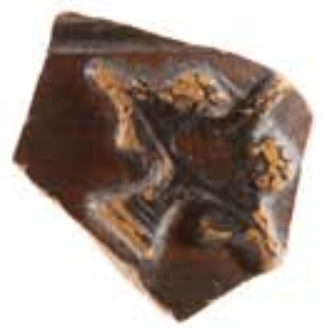

141 
Tafel 10

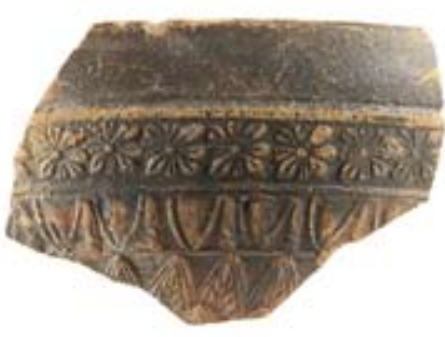

91

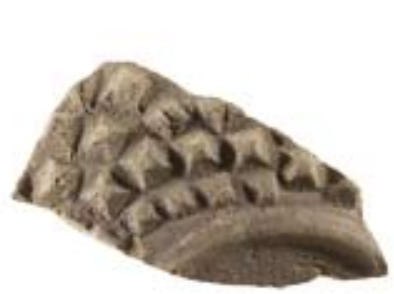

95

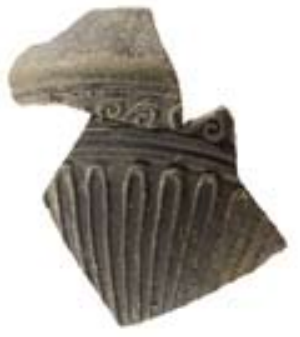

92

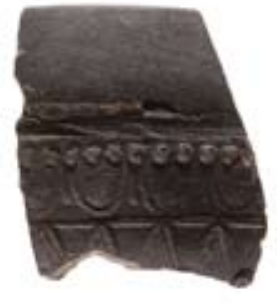

93

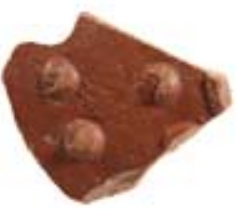

97

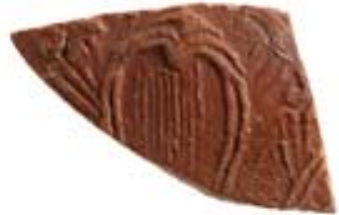

94

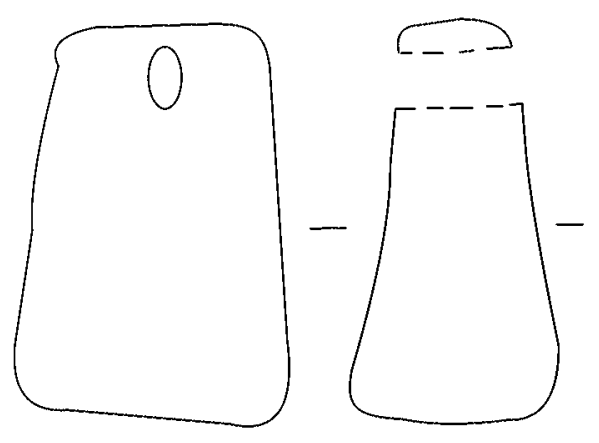

171

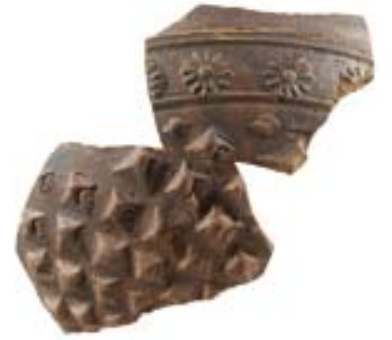

96

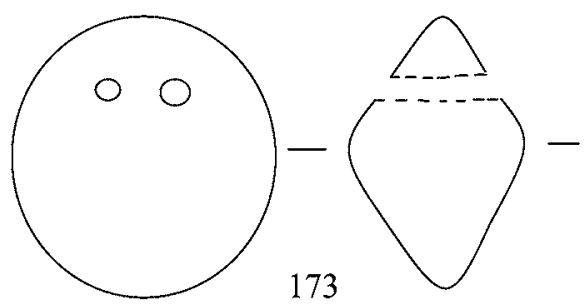

$\left(\begin{array}{ll}0 & 0 \\ (0)\end{array}\right)-\left[\begin{array}{l}-\cdot \\ \end{array}\right.$

178
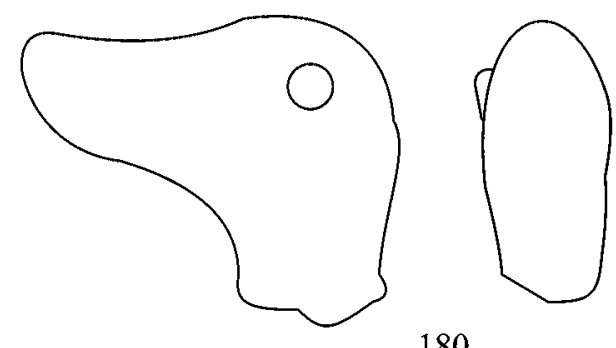

180

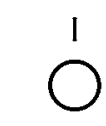

$\square^{1}$

186
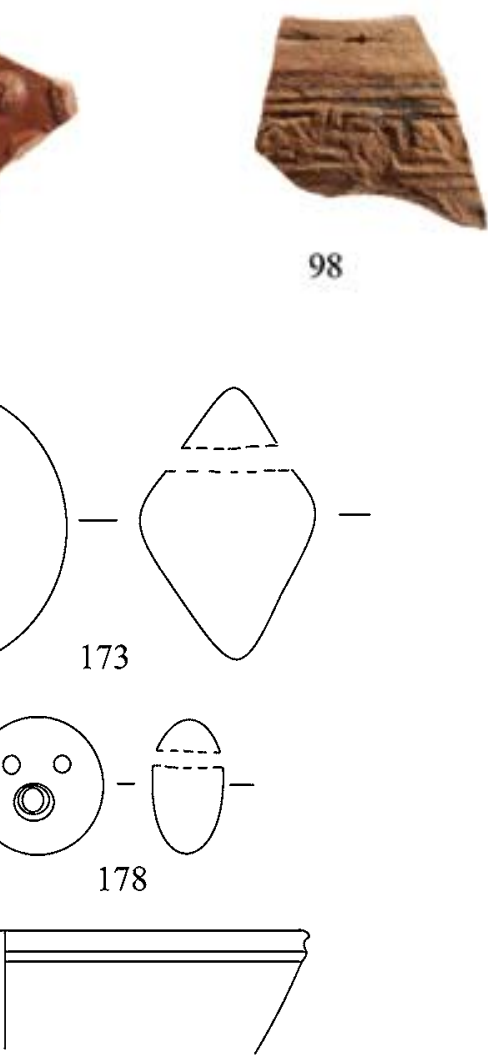

98

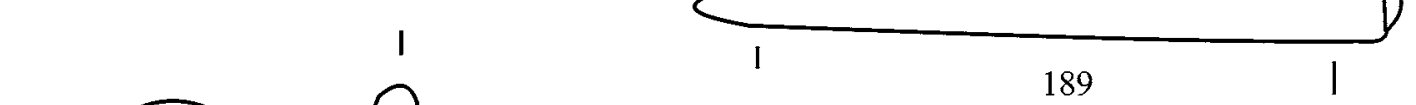

$-0-0$

187
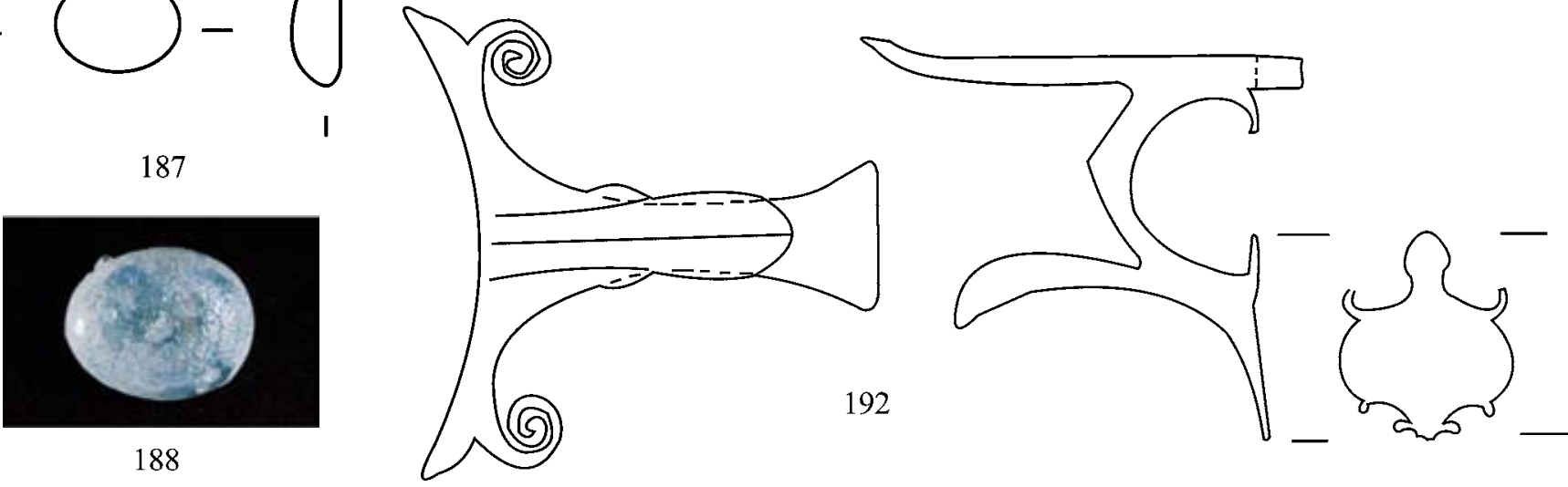
Anderson 1977

Arslan 1992

Behr 1988

Beyll 1993

Bounegru 1996

Bouzek 1974

Bouzek 2005

Bruneau 1970

Bruneau 1980

Burnett 1992

Callaghan 1992

Conspectus 1990

Cornell 1997

Crowfoot 1957

Czurda-Ruth 2007

Dereboylu 2001

Dikbaş 2002

Eiring 2000

Enklaar 1986

Fenn 2008

Gassner 1997

Gessl 2007

Giuliani 2001

Giuliani 2003

Giuliani 2004

Giuliani 2005

Giuliani 2007

Goldman 1959

Günay Tuluk 2001

Günay Tuluk 2003

Gürler 2003

Guldager Bilde 1993

\section{Abgekürzt zitierte Literatur}

V. R. Anderson, Pottery of the Late Hellenistic and Early Roman Periods at Stobi (Diss. Austin 1977). M. Arslan, Museum of Anatolian Civilizations. Roman coins (Ankara 1992).

D. Behr, Neue Ergebnisse zur pergamenischen Westabhangkeramik, IstMitt 38, 1988, 97-178.

D. Beyll, Terra Sigillata aus der Marienkirche in Ephesos, 1. Zwischenbericht, in: BerMatÖAI 5 (Wien 1993) 5-45.

O. Bounegru, Notes sur les ateliers de Çandarl, ReiCretActa 33, 1996, 105-106.

J. Bouzek (Hrsg.), Anatolian Collection of Charles University (Prag 1974).

J. Bouzek, Ephesier außerhalb von Ephesos. Ephesische Keramik in Mittel- und Schwarzmeergebiet, in: B. Brandt - V. Gassner - S. Ladstätter (Hrsg.), Synergia. Festschrift Friedrich Krinzinger I (Wien 2005) 55-66.

P. Bruneau (Hrsg.), L'îlot de la Maison des Comédiens, Délos 27 (Paris 1970).

P. Bruneau, Aperçu sommaire sur la céramique hellénistique, in: Céramiques Hellénistiques et Romaines (Paris 1980) 9-18.

A. Burnett - M. Amandry - P. P. Ripollès (Hrsg.), Roman Provincial Coinage (London 1992).

P. J. Callaghan, Archaic to Hellenic Pottery, in: L. H. Sackett (Hrsg.), Knossos from Greek City to Roman Colony. Excavations at the Unexplored Mansion, British School of Archaeology at Athens, Suppl. 21 (Athen 1992) 89-136.

E. Ettlinger - B. Hedinger - B. Hoffmann (Hrsg.), Conspectus Formarum Terrae Sigillatae Italico Modo Confectae, Materialien zur römisch-germanischen Keramik (Bonn 1990).

L. Cornell, A note on the Molded Bowls, in: S. C. Herbert (Hrsg.), The Hellenistic and Roman Pottery, Tel Anafa 2 I (Ann Arbor, MI 1997) 407-416.

J. W. Crowfoot u. a., Pottery: Hellenistic and Later, in: J. W. Crowfoot u. a. (Hrsg.), The Objects from Samaria (London 1957) 217-306.

B. Czurda-Ruth, Hanghaus 1 in Ephesos. Die Gläser, FiE 8, 7 (Wien 2007).

E. Dereboylu, Weißgrundige Keramik und hellenistische Reliefbecher aus dem Hanghaus 2 in Ephesos, in: F. Krinzinger (Hrsg.), Studien zur hellenistischen Keramik in Ephesos, ErghÖJh 2 (Wien 2001) 21-44.

G. Dikbaş, Die Graue Keramik aus der Tempel-Sondage in Aizanoi (ungedr. Mag. Universität Köln 2002).

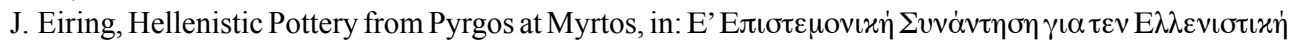

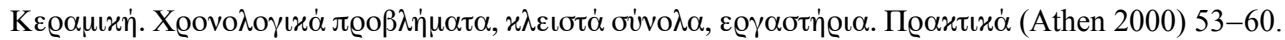

A. Enklaar, Les hydres de Hadra II: Formes et ateliers, BABesch 61, 1986, 46-48.

N. Fenn, Thin-walled Pottery from Priene/Ionia, ReiCretActa 40, 2008, 249-254.

V. Gassner, Das Südtor der Tetragonos-Agora. Keramik und Kleinfunde, FiE 13, 1 , 1 (Wien 1997).

M.-M. Gessl, Produktionslandschaften von Terra Sigillata im östlichen Mittelmeergebiet (ungedr. Mag. Universität Wien 2007).

A. Giuliani, Untersuchungen zu Ephesos-Lampen an Beispielen aus der Werkstatt des Asklepiades, in: F. Krinzinger (Hrsg.), Studien zur hellenistischen Keramik in Ephesos, ErghÖJh 2 (Wien 2001) 45-50.

A. Giuliani, Hellenistische Tonlampen von der Tetragonos Agora in Ephesos, in: Forum Archaeologiae. Zeitschrift für klassische Archäologie 26/III/ $2003<$ http://farch.net> (20. 07. 2007).

A. Giuliani, Namenssignaturen hellenistischer Lampenwerkstätten, ÖJh 73, 2004, 137-157.

A. Giuliani, Lampenmatrizen hellenistischer Zeit aus ephesischer Produktion im Rijksmuseum van Oudheden, Leiden, ÖJh 74, 2005, 73-84.

A. Giuliani, Innovationen im Beleuchtungswesen in Kleinasien, in: M. Meyer (Hrsg.), Neue Zeiten Neue Sitten. Zu Rezeption und Integration römischen und italischen Kulturguts in Kleinasien, WForsch 12 (Wien 2007) 171-180.

H. Goldman, Excavations at Gözlü Kule, Tarsus 1 (Princeton, NJ 1959).

G. Günay Tuluk, Hellenistische Reliefbecher im Museum von Ephesos, in: F. Krinzinger (Hrsg.), Studien zur hellenistischen Keramik in Ephesos, ErghÖJh 2 (Wien 2001) 51-69.

G. Günay Tuluk, Ionia bölgesi'ndeki hellenistik döneme ait kandiller, in: C. Abadie-Reynal (Hrsg.), Les Ceramiques en Antatolie aux Epoques Hellenistique et Romaine, Actes de la Table Ronde d'Istanbul 23-24 Mai 1996, Varia Anatolica 15 (Paris 2003) 17-26.

B. Gürler, Hellenistic Ceramic of Metropolis in Ionia, in: C. Abadie-Reynal (Hrsg.), Les Ceramiques en Antatolie aux Epoques Hellenistique et Romaine, Actes de la Table Ronde d'Istanbul 23-24 Mai 1996, Varia Anatolica 15 (Paris 2003) 9-16.

P. Guldager Bilde, Mouldmade Bowls, Centres and Peripheries in the Hellenistic World, in: P. Bilde (Hrsg.), Centre and Periphery in the Hellenistic World, Studies in Hellenistic Civilization 4 (Aarhus 1993) 192-209. 
Hausmann 1996

Hayes 1985

Hayes 1991a

Hayes 1991b

Hayes 1997

Head 1964

Hempel 2000

Howland 1958

Hübner 1993

Hübner 2000

Japp 1999

Japp 2003

Jilek 2003

Kenrick 2000

Kirbihler 2007

Krinzinger 2000

Künzl 2002

Kunisch 1989

Kunow u. a. 1986

Ladstätter 2000

Ladstätter 2002

Ladstätter 2003a

Ladstätter 2003b

Ladstätter 2003c

Ladstätter 2005a

Ladstätter 2005b

Ladstätter 2006

Ladstätter 2007
Kögler 1996

Ladstätter 2005c

U. Hausmann, Hellenistische Keramik: eine Brunnenfüllung nördlich von Bau C und Reliefkeramik verschiedener Fundplätze in Olympia, OF 27 (Berlin 1996).

J. W. Hayes, Sigillate Orientali, in: EAA. Atlante delle forme ceramiche II (Rom 1985) 1-96.

J. W. Hayes, The Hellenistic and Roman Pottery, Paphos 3, 1-3 (Nicosia 1991).

J. W. Hayes, Fine wares in the Hellenistic world, in: T. Rasmussen - N. Spivey (Hrsg.), Looking at Greek Vases (Cambridge 1991) 183-202.

J. W. Hayes, Handbook of Mediterranean Roman Pottery (London 1997).

B. V. Head, British Museum Catalogue. Catalogue of the Greek Coins of Ionia (Bologna 1964).

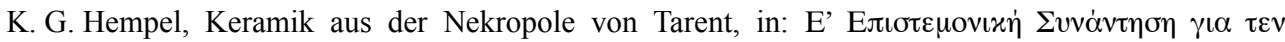

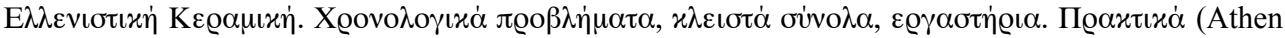
2000) 427-443.

R. W. Howland, Greek Lamps and Their Survivals, Agora 4 (Princeton 1958).

G. Hübner, Die pergamenische Applikenkeramik von Pergamon. Eine Bildersprache im Dienst des Herrscherkultes, PF 7 (Berlin 1993).

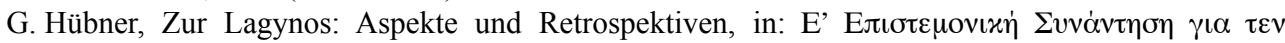

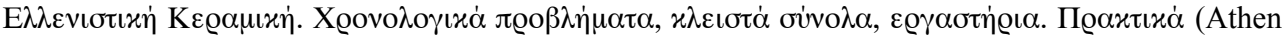
2000) 161-178.

S. Japp, Frührömische dünnwandige Hartware aus Pergamon, IstMitt 49, 1999, 301-332.

S. Japp, Sigillata und dünnwandige Hartware aus Pergamon. Bemerkungen zu westlichen Importen und stilistischer Einflussnahme, ReiCretActa 38, 2003, 243-246.

S. Jilek, Die Metall- und Beinfunde, in: C. Lang-Auinger (Hrsg.), Hanghaus 1 in Ephesos. Funde und Ausstattung, FiE 8, 4 (Wien 2003) 253-312.

P. Kenrick, Fine wares from the city wall section at Bait Nawashi (Area XLII), AA 2000, 235-265.

F. Kirbihler, Die Italiker in Kleinasien, mit besonderer Berücksichtigung von Ephesos (133 v. Chr. - 1. Jh. n. Chr.), in: M. Meyer (Hrsg.), Neue Zeiten - neue Sitten. Zu Rezeption und Integration römischen und italischen Kulturguts in Kleinasien, WForsch 12 (Wien 2007) 19-36.

P. Kögler, Trinkschalen mit П-förmigen Henkeln, in: M. Herfort-Koch - U. Mandel - U. Schädler (Hrsg.), Hellenistische und kaiserzeitliche Keramik des östlichen Mittelmeergebietes, Kolloquium Frankfurt 24.-25. April 1995 (Frankfurt 1996) 64.

F. Krinzinger (Hrsg.), Ein Dach für Ephesos, SoSchrÖAI 34 (Wien 2000).

S. Künzl, Ein Komplex von Formschüsseln für Megarische Becher. Die `Mainzer Werkstatt`, in: Kataloge vor- und frühgeschichtlicher Altertümer 32 (Mainz 2002).

N. Kunisch, Griechische Fischteller. Natur und Bild (Berlin 1989).

J. Kunow - J. Giesler - M. Gechter - W. Gaitzsch - A. B. Follmann-Schulz - D. v. Brandt (Hrsg.), Vorschläge zur systematischen Beschreibung von Keramik, Kunst und Altertum am Rhein 124 (Köln 1986).

S. Ladstätter, Ein flavischer Fundkomplex aus dem Hanghaus 2 in Ephesos, ReiCretActa 36, 2000, 97-103.

S. Ladstätter, Die hellenistischen Brennöfen und die darin gefundenen Miniaturgefäße unter dem Hanghaus 2 in Ephesos, in: E. Akurgal - M. Kerschner - H. Mommsen - W.-D. Niemeier, Töpferzentren der Ostägäis, ErghÖJh 3 (Wien 2002) 117-120.

S. Ladstätter, Ein hellenistischer Brunnen in SR 9C, in: C. Lang-Auinger (Hrsg.), Hanghaus 1 in Ephesos. Funde und Ausstattung, FiE 8, 4 (Wien 2003) 22-69.

S. Ladstätter, Ein hellenistischer Brunnen in SR 12, in: C. Lang-Auinger (Hrsg.), Hanghaus 1 in Ephesos. Funde und Ausstattung, FiE 8, 4 (Wien 2003) 70-80.

S. Ladstätter, Die Zerstörung des späthellenistischen Peristylhauses und die Errichtung der Domus, in: C. Lang-Auinger (Hrsg.), Hanghaus 1 in Ephesos. Funde und Ausstattung, FiE 8, 4 (Wien 2003) 81-84.

S. Ladstätter, Keramik, in: H. Thür (Hrsg.), Das Hanghaus 2 in Ephesos. Die Wohneinheit 4, Baubefund, Ausstattung, Funde, FiE 8, 6 (Wien 2005) 230-358.

S. Ladstätter, Griechisch oder römisch? Ein Teller als Beispiel für die Komplexität gegenseitiger Beeinflussungen in der frühkaiserzeitlichen Keramik von Ephesos, in: G. Grabherr u. a. (Hrsg.), IVS IMAGINVM. Festschrift Elisabeth Walde (Innsbruck 2005) 200-207.

S. Ladstätter, Die Grabungen des Jahres 2004 im Hanghaus 2 in Ephesos, ÖJh 74, 2005, 247-276.

S. Ladstätter, Meryemana bei Ephesos. Zur archäologischen Untersuchung des Jahres 2003, AnzWien 141, 2006, 71-104.

S. Ladstätter, Mode oder politisches Manifest? Überlegungen zur Übernahme römischen Formenguts in der frühkaiserzeitlichen Keramik von Ephesos, in: M. Meyer (Hrsg.), Neue Zeiten - Neue Sitten. Zu Rezeption und Integration römischen und italischen Kulturguts in Kleinasien, WForsch 12 (Wien 2007) $203-219$.

Ladstätter - Lang-Auinger 200 
Lang-Auinger 2003

Laumonier 1977

Leroux 1913

Liko 2001

Loeschcke 1912

de Luca - Radt 1999

Mandel u. a. 1996

Mandel 2000

Marabini Moevs 1973

Mayet 1980

Meriç 2002

Meyer-Schlichtmann 1988

Mitsopoulos-Leon 1972

Mitsopoulos-Leon 1978

Mitsopoulos-Leon 1991

Mitsopoulos-Leon 2007

Montana u. a. 2003

Neuru 1991

Newell 1977

Outschar 1996a

Outschar 1996b

Peignard-Giros 2000

Pülz - Ladstätter 2006

Rogl 2001a

Rogl 2001b

Rogl 2001c

Rogl 2003a

Rogl 2003b lon Kitharodos-Statuette, in: F. Krinzinger (Hrsg.), Studien zur hellenistischen Keramik in Ephesos, ErghÖJh 2(Wien 2001) 71-82.

C. Lang-Auinger (Hrsg.), Hanghaus 1 in Ephesos. Funde und Ausstattung, FiE 8, 4 (Wien 2003).

A. Laumonier, La Céramique Hellénistique à Reliefs. 1. Ateliers \Ioniens`, Délos 31 (Paris 1977).

G. Leroux, Lagynos. Recherches sur la céramique et l'art ornamental hellénistiques (Paris 1913).

H. Liko, Hellenistische Keramik aus der Grabung beim sogenannten Lukasgrab, in: F. Krinzinger (Hrsg.), Studien zur hellenistischen Keramik in Ephesos, ErghÖJh 2 (Wien 2001) 83-98.

S. Loeschcke, Sigillata-Töpfereien in Tschandarli, AM 37, 1912, 344-392.

G. de Luca - W. Radt, Sondagen im Fundament des großen Altars, PF 12 (Berlin 1999).

U. Mandel - P. Kögler - U. Dotterweich - G. Happel, Keramik aus Kndios - ein Vorbericht, in: M. Herfort-Koch - U. Mandel - U. Schädler (Hrsg.), Hellenistische und kaiserzeitliche Keramik des östlichen Mittelmeergebietes. Kolloquium Frankfurt 24.-25. April 1995 (Frankfurt 1996) 61-70.

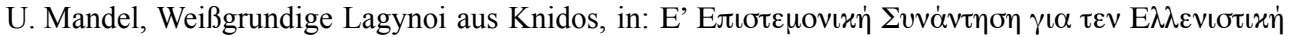

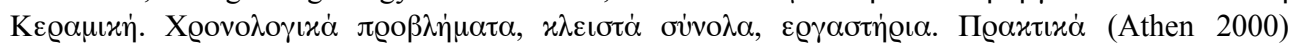
$179-188$.

M. T. Marabini Moevs, The Roman Thin Walled Pottery from Cosa (1948-1954), MemAmAc 32, 1973.

F. Mayet, Les céramiques a parois fines: état de la question, in: P. Lévêque - J.-P. Morel (Hrsg.), Céramiques Hellénistiques et Romaines (Paris 1980) 201-229.

R. Meriç, Späthellenistisch-römische Keramik und Kleinfunde aus einem Schachtbrunnen am Staatsmarkt in Ephesos, FiE 9, 3 (Wien 2002).

C. Meyer-Schlichtmann, Die pergamenische Sigillata aus der Stadtgrabung von Pergamon, PF 6 (Berlin 1988).

V. Mitsopoulos-Leon, Keramik aus Basilika und Prytaneion - Ein Überblick, ÖJh 50, 1975, Beibl. 497-523.

V. Mitsopoulos-Leon, Hellenistische Keramik mit Schlickerdekor aus Ephesos und ihr Verhältnis zur attischen Westabhangkeramik, in: G. Schwarz - E. Pochmarski (Hrsg.), Classica et Provincialia. Festschrift Erna Diez (Graz 1978) 113-124.

V. Mitsopoulos-Leon, Die Basilika am Staatsmarkt in Ephesos. Kleinfunde. 1. Teil: Keramik hellenistischer und römischer Zeit, FiE 9, 2, 2 (Wien 1991).

V. Mitsopoulos-Leon, Die Lampen. Webgewichte, in: V. Mitsopoulos-Leon - C. Lang-Auinger (Hrsg.), Die Basilika am Staatsmarkt in Ephesos. 2. Teil: Funde klassischer bis römischer Zeit, FiE 9, 2, 3 (Wien 2007) 64-113. 114-123.

G. Montana - H. Mommsen - I. Iliopoulos - A. Schwedt - M. Denaro, The Petrography and Chemistry of Thin-Walled Ware from an Hellenistic-Roman Site at Segesta (Sicily), Archaeometry 45, 2003, $375-389$.

L. L. Neuru, Megarian Relief Ware, in: J. W. Hayes, The Hellenistic and Roman Pottery, Paphos 3, 1-3 (Nicosia 1991) 13-17.

E. T. Newell, The Coinage of the Western Seleucid Mints. From Seleucus I to Antiochus III, Numismatic Studies IV (New York 1977).

U. Outschar, Analyse und Dokumentation exemplarisch ausgewählter keramischer Komplexe, in: C. Lang-Auinger, Hanghaus 1 in Ephesos. Der Baubefund, FiE 8, 3 (Wien 1996) 27-85.

U. Outschar, Beobachtungen und Aspekte zur ephesischen Keramik, in: M. Herfort-Koch - U. Mandel - U. Schädler (Hrsg.), Hellenistische und kaiserzeitliche Keramik des östlichen Mittelmeergebietes, Kolloquium Frankfurt 24.-25. April 1995 (Frankfurt 1996) 35-40.

A. Peignard-Giros, La céramique trouvée dans les fosses du péribole Est du sanctuaire d'Apollon à

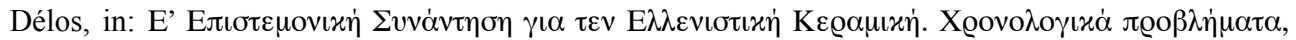

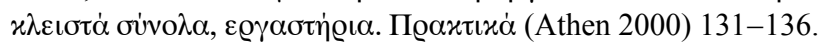

A. Pülz - S. Ladstätter, Meryemana bei Ephesos. Zur archäologischen Untersuchung des Jahres 2003, AnzWien 141, 2006, 71-104.

C. Rogl, Hellenistische Keramik aus Ephesos: Funde der Tetragonos-Agora, Forum Archaeologiae 18/ III/2001 <http://farch.net> (20. 07. 2007).

C. Rogl, Eine Vorschau zu den reliefverzierten Trinkbechern der ephesischen Monogramm-Werkstätte, in: F. Krinzinger (Hrsg.), Studien zur hellenistischen Keramik in Ephesos, ErgÖJh 2 (Wien 2001) 99-111.

C. Rogl, Töpfersignaturen auf hellenistischen Reliefbechern: Eine Liste, ÖJh 70, 2001, 135-155.

C. Rogl, Hellenistische Keramik aus den Grabungen auf der Tetragonos-Agora in Ephesos: Ein mittelhellenistischer Fundkomplex, in: B. Asamer - W. Wohlmayr (Hrsg.), Akten des 9. Österreichischen Archäologentags, Paris Lodron-Universität Salzburg, 6.-8. Dezember 2001 (Wien 2003) 175-182.

C. Rogl, Späthellenistische Applikenkeramik und Verwandtes aus Ephesos. Lokale Produktion - Einflüsse - Importe, ÖJh 72, 2003, 187-206. 
$\operatorname{Rog} 12004$

Rogl 2007

Rotroff 1982

Rotroff 1997

Rotroff - Oliver 2003

Rotroff 2006

Sauer 1995

Schäfer 1968

Scheibler 1976

Schindler 1967

Schmid 1996

Schmid 2000

Schwarzer 1999

Smetana-Scherrer 1984

Sparkes - Talcott 1970

Tekkök 2001

Tekkök 2003

Thompson 1934

Thompson 1973

Trink1 2003

Trümpler-Ries 1982

Vegas 1973

Voegtli 1993

Warner Slane 1997

Watzinger 1901

Wintermeyer 2004

Zabehlicky-Scheffenegger 1995a Forge, PA 1995) 217-228.

Zabehlicky-Scheffenegger 1995b

Zabehlicky-Scheffenegger u. a. 1996

S. Zabehlicky-Scheffenegger, Der Italiener in Ephesos, ReiCretActa 34, 1995, 253-271. Magdalensberg, in: M. Herfort-Koch - U. Mandel - U. Schädler (Hrsg.), Hellenistische und kaiserzeitliche Keramik des östlichen Mittelmeergebietes, Kolloquium Frankfurt 24.-25. April 1995 (Frankfurt 1996) 41-60.

Zabehlicky-Scheffenegger - Schneider $2000 \quad$ S. Zabehlicky-Scheffenegger - G. Schneider, Applikenverzierte Gefäße aus Ephesos, in: ReiCretActa 36, 2000, 105-112.

Zahn 1904

Zelle 1997

Zelle 2007

Ziegenhaus - de Luca 1968

C. Rogl, Zu dem Produktionsbeginn schwarzer Sigillata in Ephesos. Die Evidenz der Tetragonos AgoOJh 73, 2004, 207-220.

Vergleich, in: M. Meyer (Hrsg), Neue Zeiten - Neue Sitten. Zu Rezeption und Integration römischen und italischen Kulturguts in Kleinasien, WForsch 12 (Wien 2007) 181-193.

S. I. Rotroff, Hellenistic Pottery. Athenian and Imported Moldmade Bowls, Agora 22 (Princeton, NJ 1982).

Agora 29 (Princeton, NJ 1997).

S. I. Rotroff - A. Oliver Jr., The Hellenistic Pottery from Sardis, Sardis Monograph 12 (Cambridge (2003). Hesperia 75, 2006, 357-378.

Sauer, Produktionszentren späthellenistischer und römischer Keramik an der W-Küste Kleinasiens.

J. Schäfer, Hellenistische Keramik aus Pergamon, PF 2 (Berlin 1968).

M. Schindler, Die `schwarze Sigillata des Magdalensberges`, Kärntner Museumsschriften 43 (Klagenfurt 1967). Mittelmeergebietes, Kolloquium Frankfurt 24.-25. April 1995 (Frankfurt 1996) 127-146.

gründe, in: Petra. Ez Zantur 2, 1 (Mainz 2000) 1-199.

H. Schwarzer, Untersuchungen zum hellenistischen Herrscherkult in Pergamon, IstMitt 49, 1999, 249-300.

B. A. Sparkes - L. Talcott, Black and Plain Pottery of the $6^{\text {th }}, 5^{\text {th }}$ and $4^{\text {th }}$ centuries B.C., Agora 12 (Princeton, NJ 1970).

B. Tekkök, Two Roman Wells in the Lower City of Ilion, StTroica 11, 2001, 343-382.

B. Tekkök, Troy from the Julio-Claudian to the Flavian Period: Its Connections with the Mediterranean . ReiCretActa 38, 2003, 237-242.

D. B. Thompson, Ptolemaic Oinochoai and Portraits in Faience (Oxford 1973).

Trinkl, Artefakte für die Textilbearbeitung, in: C. Lang-Auinger (Hrsg.), Hanghaus 1 in Ephesos.

C. Trümpler-Ries, Patrize für ein pergamenisches Reliefgefäß, HASB 8, 1982, 39-42.

Vegas, Cerámica común romana del mediterránneo occidental (1973).

K. Warner Slane, The Fine Wares, in: S. C. Herbert (Hrsg.), The Hellenistic and Roman Pottery, Tel Anafa 2, 1 (Portsmouth 1997).

C. Watzinger, Vasenfunde aus Athen, AM 26, 1901, 50-102.

W. Wintermeyer, Die hellenistische und frühkaiserzeitliche Gebrauchskeramik. Auf Grundlage der stratifizierten Fundkeramik aus dem Bereich der heiligen Straße (Mainz 2004).

S. Zabehlicky-Scheffenegger, Subsidiary Factories of Italian Sigillata Potters. Ephesian Evience, in: H. Koester (Hrsg.), Ephesos, Metropolis of Asia, Harvard Theological Studies 41 (Valley

R. Zahn, Thongeschirr, in: Th. Wiegand - H. Schrader (Hrsg.), Priene. Ergebnisse der Ausgrabungen und Untersuchungen in den Jahren 1895-1898 (Berlin 1904).

M. Zelle, Die Terra Sigillata aus der Westtor-Nekropole in Assos, AMS 27 (Bonn 1997).

M. Zelle, Späthellenistische und frühkaiserzeitliche Keramik in Pednelissos, in: M. Meyer (Hrsg.), Neue Zeiten - Neue Sitten. Zu Rezeption und Integration römischen und italischen Kulturguts in Kleinasien, WForsch 12 (Wien 2007) 195-200.

O. Ziegenhaus - G. de Luca, Das Asklepieion. Der südliche Temenosbezirk in hellenistischer und frührömischer Zeit, AvP 11, 1 (Berlin 1968). 
Zimmermann u. a. (in Druck) N. Zimmermann - J. Weber - W. Prochaska - B. Tober - S. Falzone, La parte invisibile delle pittura. Qualità, cronologia e provenienza nell'analisi petrografia: L'esempio di Efeso ed Ostia, in: Internazionale dell'AIPMA, Napoli 16.-25. 09. 2007 (in Druck).

Mag. Asuman Lätzer

Archäologisches Institut der Universität zu Köln, Albertus-Magnus-Platz, D-50923 Köln

E-Mail: latzera@smail.uni-koeln.de

Abbildungsnachweis: Abb. 1-6. 23-26 Taf. 1-10: Verf.; Abb. 7-22 b. Taf. 9.10 (farbliche Abbildungen): ÖAI, Photo N. Gail; Abb. 27: Institut für Silikatchemie und Archäometrie der Hochschule für angewandte Kunst in Wien, R. Sauer. 